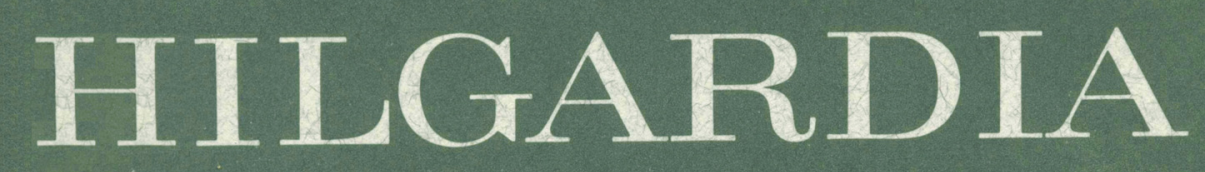

A JOURNAL OF AGRICULTURAL SCIENCE PUBLISHED BY THE CALIFORNIA AGRICULTURAL EXPERIMENT STATION

Volume 38, Number 1 - March, 1967

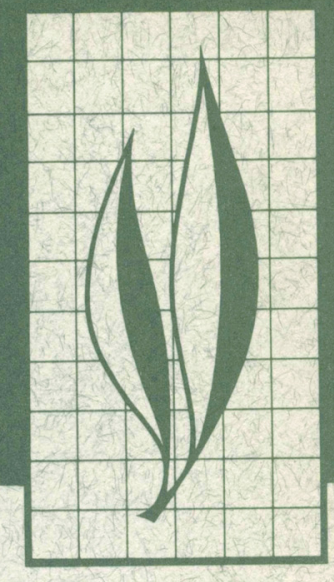

\title{
Supply and Demand for Forest Products-An Econometric Study
}

W. L. M. McKillop 


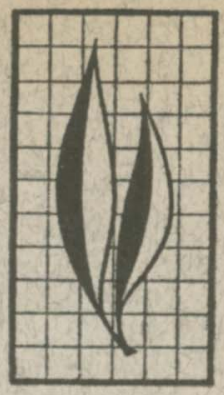

Forest products dealt with were "all" lumber, softwood lumber, paper, paperboard, building paper and board and softwood plywood (referred to collectively as wood products), and softwood sawlogs, pulpwood, peeler logs and softwood sawlog stumpage (referred to collectively as primary products). The foundation of the study was a system of interrelated linear demand and supply relationships. Although only milllevel relationships were specified, attention was given to higher levels of demand and supply in their formulation. The study was limited to producers and consumers in the United States except for a brief consideration of Canadian suppliers of lumber and newsprint.

Coefficients of wood product supply and demand relationships were estimated by 2-stage least squares, using annual data for the years 1929 to 1960. Point estimates of elasticities for wood products were prepared for the year 1960 to show the influence of "own" price, prices of competing materials, prices of inputs in production, and other supply and demand shifters. Lack of data on quantities marketed made it impossible to carry out estimation for primary products.

Forecasts of wood product prices and consumption levels, and primary product prices, were made for a prediction period ending in 1975. Three types of forecasting equations were used: "solved structural," "complete reduced form" and "exogenous reduced form." Forecasting methods were compared, using 1961 and 1962 data which had been excluded from the sample period. Basic predictions were adjusted using actual and predicted values for 1961 and 1962. On empirical and theoretical grounds the adjusted solved structural method was judged to be generally the most satisfactory one. Forecasts of consumption levels of certain wood products prepared in this way were compared with predictions made in studies carried out by the U. S. Forest Service, U. S. Department of Commerce, the Stanford Research Institute, and Resources for the Future, Inc.

(Table of Contents on inside back cover.)

\section{THE AUTHOR:}

W. L. M. McKillop is Assistant Professor and Assistant Forest Economist, School of Forestry, University of California, Berkeley. 


\section{Supply and Demand for Forest Products-An Econometric Study ${ }^{1}$}

\section{INTRODUCTION}

THIS STUDY deals with lumber, paper, paperboard, plywood, roundwood and stumpage. The study was an econometric investigation of supply and demand relationships using time-series data for the sample period 1929 to 1960 , and was restricted to the United States except for brief consideration of imports of wood products from Canada.

In this report "stumpage" refers to standing timber sold for cutting, "roundwood" refers to logs and pulpwood, "wood products" refers to lumber, paper, paperboard and plywood, and "forest products" refers to all these categories.

A preliminary aim was to specify an aggregate demand and supply relationship for the United States for each product considered. A major aim was to estimate the structural parameters of these relationships, and thus provide a quantitative assessment of demand and supply elasticities and of the relative importance of influences determining consumption and price levels during the sample period.

An additional aim was to forecast consumption and price levels in the United States for a period ending in 1975.

\section{Framework of Analysis}

The study had as its foundation an economic model consisting of a system of supply and demand relationships set up to explain the formation of prices and consumption levels for the products considered. These relationships may be represented in vector notation in the manner of Hood and Koopmans (1953) ${ }^{2}$ as

$$
\begin{aligned}
& h_{1}\left(Y_{t}, Y_{*}, Z_{t}, Z_{*}, U_{1 t}, \alpha_{1}\right)=0 \\
& t=1 \ldots T \\
& h_{2}\left(Y_{t}, Y_{*}, Z_{t}, Z_{*}, U_{2 t}, \alpha_{2}\right)=0 \\
& \vdots \\
& h_{G}\left(Y_{t}, Y_{*}, Z_{t}, Z_{*}, U_{G t}, \alpha_{G}\right)=0 \\
& \text { where }
\end{aligned}
$$

$Y_{t}$ represents the magnitudes in period $t$ of $G$ "endogenous" variables - the price and consumption levels of the products under study

$Y$ * represents values of endogenous variables in periods prior to period $t$

$Z_{t}$ representsthe magnitudesin period $t$ of a set of "exogenous" variables which are not affected by the magnitudes of endogenous variables, and in terms of which the formation of $Y_{t}$ is to be explained

$Z$ * represents magnitudes of exogenous variables in periods prior to period $t$

1 Submitted for publication June 17, 1965.

2 See "Literature Cited" for publications referred to in the text by author and date. 
$U_{g t}$ represents, for the $g$ th relationship, the magnitudes in period $t$ of unobserved disturbances denoting the aggregate effect of influences not depicted in the sets $Y_{*}, Z_{t}, Z_{*}$ above

$\alpha_{g}$ represents the "structural parameters" of the $g$ th relationship.

Investigation of the form of demand and supply relationships was not feasible, and a premise of the study was that the relationships could be adequately represented by simple linear functions. A second premise was that errors of measurement in time-series data would not seriously impair the quality of estimates, and thus could be ignored. The establishment of these premises permits the system of relationships to be written as

$$
B Y_{t}=C X_{t}+U_{t} \quad t=1 \ldots T
$$

where

$Y_{t}$ is a $(G \times 1)$ matrix representing the observed magnitudes of endogenous variables in period $t$

$B$ is a $(G \times G)$ matrix of unknown structural coefficients associated with $Y_{t}$

$X_{t}$ is a $(K \times 1)$ matrix representing the observed magnitudes of "predetermined" variables (lagged endogenous and exogenous variables) in period $t$

$C$ is a $(G \times K)$ matrix of unknown structural coefficients associated with $X_{t}$

$U_{t}$ is a $(G \times 1)$ matrix representing the magnitudes of disturbances in period $t$.

The $g$ th equation in the system may be written as

$$
\sum_{i} b_{g i} Y_{i t}=\sum_{k} c_{g k} x_{k t}+u_{g t}
$$

with certain of the coefficients deemed a priori to be zero.

\section{Properties of Estimates}

An aim of this study was estimation of the matrices $B$ and $C$. An additional aim was to estimate future price and consumption levels. As Mood (1950) indicates unbiased estimates are not unequivocally better than biased ones, nor are consistent ones necessarily better than inconsistent ones. However, in the absence of information on the magnitudes of biases and variances the problem is one of choosing estimates with known, rather than unknown, properties. Accordingly, unbiasedness (or consistency if unbiasedness was not attainable) was set up as a goal in estimating parameters and future magnitudes. Additional goals of minimum variance with respect to unbiased estimates, and efficiency with respect to consistent ones, were also specified.

Estimation procedures and properties of estimates are discussed at length in later chapters. However, two points are necessary to provide perspective for the discussion to follow. The first point is that, as Hood and Koopmans (1953) show, direct least squares estimation of a relationship such as equation (3) above will, in general, yield biased and inconsistent estimates of structural coefficients and that sound technique requires that the system be dealt with as a whole for estimation purposes. The second point is the problem of omission of variables. As Goldberger (1964) demonstrates for a classical linear regression model, least squares estimates of coefficients are, in general, biased if variables are omitted from the model unless the coefficients associated with these variables are zero. The same is true for predicted values of the dependent variable. This emphasized the need for careful construction of the economic model so that chances of excluding important 
variables from a relationship would be minimized. Economic consideration, also dictated that important variables not be omitted from relationships to be estimated; here the main consideration was that the structural coefficient associated with a variable should represent the genuine ceteris paribus effect of that variable on the quantity demanded (or supplied). In a linear relationship of the type $y_{h}=\alpha_{O}+\sum_{h} \alpha_{h} x_{h}+u_{h}$ the coefficient $\alpha_{h}$ will represent the ceteris paribus effect of $x_{h}$ only if the relationship contains the complete set of variables affecting the dependent one. Hence, only if this latter condition holds will estimates of demand and supply elasticities be correct in a definitional sense, and only then will an assessment of the relative importances of different variables be complete. While it is possible to regard the quantity of a good demanded (or supplied) as being dependent on a very large number of variables, practicality requires that this number be severely reduced. A prime task in the investigation was the selection of variables whose influence could not be neglected. This was done largely on a deductive basis utilizing economic theory, although theoretical functions thus derived were subject to verification and modification in the light of data availability and knowledge of the actual behavior of suppliers and demanders of forest products.

Finally, a point closely related to the problem of omission of variables should be mentioned. As Klein (1956) points out, the aim should be to seek out autonomous relationships for estimation purposes - that is, relationships that do not change freely in structure over the sample period. Certain models may be appealing in their simplicity, say for prediction purposes, but if they are susceptible to structural change estimates obtained from them may be unreliable. For instance, forecasts of wood-product consumption levels may be readily obtained by least squares regression analysis using a model depicting consumption as a linear function of some variable such as population or gross national product. But because of the omission of influential variables these predictions may be subject to bias; in fact, the technique of least squares regression analysis itself has limited meaning if the parameters of the regression model change during the sample period.

\section{Time Spans}

\section{Observation Period}

A critical step in the study was choosing the length of the observation period, a topic with which Klein (1956) deals briefly. Essentially, the choice was between annual or quarterly data since sufficient observations were not available for other lengths of time. The greater yield of information and the greater degrees of freedom associated with an analysis using quarterly data held strong appeal, but the difficulties of such a study appeared too great and so annual data were used. Lengthy lags were necessary to depict correctly influences in the demand for certain of the wood products studied and this required the use of a long sample period. Quarterly data could be obtained for the postwar years, but for the prewar period only annual data were readily available for many variables. An even more critical restriction was the need of a quarterly study for detailed information about the behavior of suppliers and demanders of forest products. The investigator had sufficient information at his disposal to specify reaction to prices and other in- 
fluences over a 12-month span, but had insufficient information to do this for shorter spans. Ideally, the investigation would have had an intensive field-work phase in which market behavior was examined but the breadth of the study (in terms of both products and geography) made this impossible. The only alternative would have been an empirical determination of variables and lags, but with only one set of observations available this approach was discarded as being statistically weak. Other difficulties associated with the choice of a shorter observation period are discussed later.

\section{Sample Period}

With the choosing of a year-long observation period the need for a 20 or 30 year sample period became evident and 1929 was taken as the starting year as it was the earliest one for which observations were generally available. The longer the period the more difficult it is to deal with structural change, but the presence of potential structural change was welcomed because the revealing of its presence was seen to be a useful part of the study. One type of structural change that could not be dealt with, however, was the influence of wartime price controls, and therefore the years 1942 to 1946 were omitted from the sample period. At the inception of the study the latest year for which data were available was 1960 , so that the years 1929 to 1941 and 1947 to 1960 were taken as the sample period.

\section{Prediction Period}

Predictions were made to the year 1975. Klein (1956) says "Extrapolations should not be carried too far into the future, perhaps not more than two years." Clearly, the prediction period in this study was of ambitious length, but it should be recognized that its choice was suggested by need rather than by statistical considerations. The need for price forecasts relatively far into the future is discussed later in this chapter.

\section{Products Studied}

Three types of forest products were recognized: primary, secondary and intermediate.

Roundwood and stumpage were classed as primary products. Lumber, paper, paperboard, plywood, and veneer not designed for manufacture into plywood were classed as major secondary products and referred to collectively as wood products. Shingles, shakes, cooperage, posts, poles, piling and distillation wood were classed as minor secondary products.

Market pulp, and veneer destined for manufacture into plywood were classed as intermediate forest products.

\section{Roundwood}

Only certain types of roundwoodsawlogs, veneer logs and pulpwoodwere considered in this study. Fuelwood, for instance, was not considered, partly because of lack of market data but mainly because of its minor importance as a marketed commodity. In addition, its over-all importance is declining rapidly-for instance, in 1929 some 27 per cent of all roundwood consumed in the U. S. was in the form of fuelwood; in 1960 its "share" of roundwood consumption was only 11 per cent (U. S. Forest Service, 1963). Minor secondary products were also ignored because their consumption (calculated on a roundwood 
basis using 1960 data) constituted less than 5 per cent of the total consumption of secondary forest products.

\section{Intermediate Products}

Intermediate products were not studied, for reasons similar to those stated above. Market pulp, for instance, has been declining steadily in importancefrom about 27 per cent (1937) to 17 per cent (1952) of all pulp consumed (Stanford Research Institute, 1954)-and production of green veneer never represented more than 25 per cent of the total consumption of all veneer in the softwood plywood industry during the sample period (Guthrie and Armstrong, 1961). Lack of market data also inhibited study of intermediate products.

At the outset, therefore, the study was restricted to lumber, paper, paperboard, plywood and veneer; to sawlogs, veneer logs and pulpwood; and to stumpage. The category "paper" covered newsprint, other printing papers, construction paper, "fine" papers, "coarse" papers, tissue, and other miscellaneous papers. "Paperboard" included wet machine board, insulating board and hardboard, with the latter categories being referred to collectively as "building board." "Lumber" covered both hardwood and softwood lumber and "plywood and veneer" included both types also.

\section{Limitations of Data}

The original aim of the study was to estimate demand and supply relationships and predict price and consumption levels for each of the major product categories, and also for hardwood and softwood subcategories. Data availability severely restricted this aim, however. For instance, complete price series were not available for hardwood lumber, for hardwood plywood, for both hardwood and softwood veneer, or for stumpage other than sawlog stumpage. Nor were data available on "marketings" of logs, pulpwood and stumpage. In the case of the wood products studied, consumption and marketings could be considered the same for all practical purposes, but because of much vertical integration in the harvesting and processing of timber this was not so for these other categories. As a consequence, demand and supply estimation was carried out for only "all" lumber, softwood lumber, paper, paperboard and softwood plywood. In addition, since there was some doubt as to whether construction paper and building board should be treated separately, estimation was carried out for building paper and board.

Nevertheless, statistical requirements demanded that consideration also be given to the nature of demand and supply for primary products. This made it feasible to engage in prediction of prices for these products, though not with the same exhaustiveness possible for wood products.

At this point it should be mentioned that in certain cases the price data used were somewhat restrictive in their coverage. For instance, the only complete series available for sawlogs and for veneer logs were for Douglas fir in western Oregon and western Washington. With regard to sawtimber prices the data used were average prices weighted by lumber shipments for Douglas fir, southern pine, and ponderosa pine, with basic stumpage prices used being mainly those recorded in sales on National Forests. With regard to softwood plywood, the measure used was a price index for Douglas fir interior grade and not one that covered both interior and exterior grades.

The term "softwood lumber" as used in the study refers only to principal species, namely Douglas fir, ponderosa 
pine and southern pine, because complete price data were available for only these types. During the sample period approximately 80 per cent of all softwood lumber consumed in the United States was of these species.

\section{Markets Considered}

More than one market level may exist for the products considered, with the exception of stumpage. For instance, it has been estimated (Brown, 1947) that about 50 per cent of all lumber goes through wholesalers and some 70 per cent to 80 per cent through retail yards. Much the same is true for plywood, but usually not for paper and paperboard. Guthrie (1947) estimated that between 75 per cent and 80 per cent of all newsprint consumed in the United States was sold under contract to publishers, and that about 55 per cent of all book paper and 50 per cent of all paperboard went directly from manufacturers to users. But it was estimated that in the case of writing paper and of bag and sack paper over 70 per cent was handled by paper merchants.
Time was not available for a multilevel study, and from the outset it was apparent that for estimation purposes the model would have to be restricted to one level for each product. In fact, it quickly became evident that because of the nature of the price data available only certain market levels could be studied. In the case of softwood plywood, for example, no continuous series was available except for f.o.b. Chicago prices.

For other products continuous series were available only for f.o.b. mill prices. However, in constructing the economic model account was taken of higher levels of demand in the formulation of mill level relationships. Details are given in the next chapter.

\section{Related Studies}

\section{Major Studies}

Major studies related to the present one in regard to objectives have been carried out by the Stanford Research Institute (1954), the U. S. Forest Service (1958, 1965), the U. S. Department of Commerce (see U. S. Congress 1957, 1958, 1959, 1963), and by Landsberg et al. (1963) on behalf of Resources for the Future, Inc. Essentially, all were attempts at forecasting consumption levels for a range of forest products. In addition to dealing with the aggregate commodities investigated here these studies in general predicted future consumption levels for various subcategories of products, especially in the pulp and paper field. The Stanford Research Insti- tute study was the most comprehensive, and it provided much useful information for later studies, including this one. The Forest Service's 1958 study, published as a chapter in Timber Resources for America's Future, was the culminating point of a number of prior studies. The 1965 study was an updating of the 1958 one and attention is focussed on it rather than on the earlier one. The Department of Commerce studies dealt only with wood pulp products; the 1963 study was essentially an extension of earlier ones.

The forecasting procedures used in these studies were relatively simple. With regard to lumber consumption the general method was to consider various end-uses for lumber-for instance, use in residential construction, 
nonresidential construction, maintenance and repair, manufacturing and shipping. For construction, historical data were used to estimate use factors representing the average number of board feet consumed per unit of end-use. In the case of residential construction the basic unit of end-use was an individual dwelling. For other construction the use factor was expressed in board feet per dollar of construction expenditures. Trends in use factors were examined and projections of them were made on the basis of the investigator's judgement and experience. Forecasts of levels of end-use (for example, the number of new dwelling units, and the levels of construction expenditures) were applied to these use factors to obtain estimates of future consumption in particular end-uses. Lumber use in manufacturing was projected in the same way. Use in shipping was predicted by examining past levels of consumption in that sector and projecting them on a judgement basis. Individual end-use estimates were aggregated to give forecasts of total consumption.

In the case of plywood, procedures used by the Forest Service and Resources for the Future were the same as were used for lumber. The Stanford Research Institute, on the other hand, regressed past consumption on population, disposable income and a trend variable, and utilized forecasts of independent variables to obtain estimates of future consumption.

For most wood pulp products the Forest Service forecasted levels of per capita consumption and applied to them forecasts of population. One exception was building board; forecasts for this utilized both an end-use approach and an approach which related per capita consumption to per capita gross national product. In the Resources for the Future study the method employed for wood pulp products was to examine past consumption per million of population, per dollar of disposable income, per dollar of goods output, or per dollar of consumer expenditures on various groups of commodities. Consumption factors obtained in this way were projected on a judgement basis and applied to forecasts of population, income, or expenditures as appropriate. Both the Department of Commerce and the Stanford Research Institute studies used regression analysis in projecting consumption levels of wood pulp products. In all cases the Stanford Research Institute study used population, disposable income and a trend variable as independent variables. The Department of Commerce used a single independent variable in each regression, either disposable personal income or an index of industrial production. One exception was special food boards whose future consumption levels were estimated by extrapolation of recent trends.

\section{Other Studies}

Other studies have been carried out by I. I. Holland (1955), G. R. Gregory (1960), J. A. Guthrie and G. R. Armstrong (1961), S. Makino (1960), and L. M. Shames (1946).

Holland's purpose was to estimate the elasticity of demand for sof twood lumber, to determine what factors were major demand shifters, and to assess their relative importance. He attempted to do this using "limited information" estimates for a two-equation model. His demand equation specified that the undeflated price of softwood construction lumber was a function of per capita shipments, of undeflated per capita expenditures for new construction, and of per capita production of Portland cement. His supply equation specified that per 
capita shipments of softwood construction lumber were a linear function of undeflated price, and of an index representing the average cost of manufacturing softwood lumber. Holland also carried out direct least squares estimation of demand equations for Douglas fir lumber, for ponderosa pine and for softwood construction lumber, recognizing that this represented ". . . an inappropriate estimating procedure ...."

Gregory dealt with a more narrow market-that for hardwood flooring. In one model he used a demand equation specifying that monthly shipments of red oak flooring were a function of deflated price, the number of nonfarm dwelling units started during the month, and the average construction cost for private, one-family dwelling units. In his supply equation he specified that monthly production was a function of the previous month's price, of the previous month's price for No. 1 red oak lumber, and of the number of nonfarm dwelling units started during the month. $\mathrm{He}$ also included a price equation which stated that price is a function of the previous month's price, the difference between last month's production and shipments, the level of mill stocks in the previous month and the change in the price of red oak lumber.

In the course of examining the outlook for western forest industry, Guthrie and Armstrong (1961) came to the conclusion that the Stanford Research Institute and Forest Service estimates of consumption in 1975 were too low, mainly because of the use of projections of GNP and population levels that were too low. They estimated future domestic lumber production by using regression analysis with gross national product and time as independent variables.

Makino (1960) was concerned with forecasting levels of hardwood plywood imports to the U. S. He prepared an estimate for 1970 by regressing past import levels on past consumption and then using estimates of future consumption based on forecasts of GNP.

Shames, in a study carried out in 1945 , made a prediction of U. S. lumber consumption. He did this by guessing at the relative importances of influences such as population, building costs, and prices, and gauging what their net effect would be in the 18-year period following World War II. He also made estimates of demand elasticity, using price and consumption changes over short periods.

In addition to his major study mentioned above, Holland has carried out two other related studies (Holland, $1960 a, 1960 b)$. In the first, he investigated changes in lumber price and consumption, using mainly graphical analysis as Zivnuska (1955) had done in an earlier, similar study. In the second, he predicted the price of eastern white pine stumpage, first forecasting the wholesale price index for all lumber and then estimating the future ratio of eastern white pine lumber price and this index and the ratio of stumpage price and eastern white pine lumber price. In projecting the price index for all lumber to the year 2010 he used an equation expressing the price index as function of per capita lumber consumption, per capita expenditures for construction, and an index of lumber processing costs. Future values of construction expenditures were based on gross national product projections. Estimates of future levels of the cost index were based on expected rates of increase; lumber consumption projections were based on Forest Service figures (U. S. Forest Service, 1958).

A recent study by Simpson and Halter (Simpson, 1963; Simpson and Halter 1963) on Douglas fir plywood should also be mentioned. Using quarterly data for 
the period 1950 to 1960 , they estimated market relationships for both sanded and unsanded types. The equation estimated for sanded plywood demand was mill price as a function of new orders, the value of wholesale inventories, lumber price lagged one quarter, and the change in wholesale price lagged one quarter. For unsanded demand the function was the same except that the value of new residential construction lagged one quarter appeared in place of lumber price.

In the case of sanded supply the equation estimated was mill price as a function of production, lagged sawmill workers' wages, and lagged mill price. For unsanded supply, change in unfilled orders appeared as an extra variable.

In addition to supply and demand, inventory, unfilled orders and accounting relationships were also estimated. For sanded inventories, value of inventories was expressed as a function of wholesale price lagged four quarters, value of total new construction lagged one quarter, lagged value of inventories, and mill price lagged four quarters. The unsanded relationship was similar, with current mill price and production included and lagged value of inventories omitted. In the case of unfilled orders the sanded equation had unfilled orders as a function of lagged mill price, lagged unfilled orders, and lagged wholesale price. For unsanded plywood the equation was unfilled orders as a function of value of public miscellaneous construction, lagged unfilled orders, lagged wholesale prices, and lagged new mill orders. The accounting relationship was estimated with production a function of new orders and change in unfilled orders in the case of sanded plywood and a function of new orders, change in unfilled orders, and lagged change in unfilled orders in the case of unsanded plywood.

From the standpoint of selection of variables for inclusion in a structural relationship the Simpson-Halter study was interesting. Basically, their procedure was to take a relationship consisting of numerous independent variables (including different types of lags for the same variable) and run preliminary regressions for ". . . all combinations ..." (apparently, all possible subsets) of these variables. The regression with the highest multiple correlation coefficient that ". . . made sense from an economic point of view ..." was considered best, and the variables in the best regression were used in the specification of the relationship in the final analysis. In addition to estimating structural relationships, predictions of price, production levels and new orders were made for the four quarters of 1961 using reduced form equations.

\section{Justification}

\section{General}

Although this study was not intended to solve specific problems it appeared that solutions to a number of major ones facing forest industries and government would be much facilitated by results of the study. An important problem is the one facing the forest industries in their decisions as to investment in land, tim- ber, silvicultural and managerial operations, and plant and equipment. Information about forest products prices 5, 10 or even 15 years in the future is almost always vital to the making of sound decisions. For government there is the problem of how much stumpage to release now and how much timber to produce in the future. Only with knowledge of future prices and potential con- 
sumption levels and some understanding of the impact of the prices of primary forest products on wood products supply can this problem be adequately dealt with. Government policy formation also requires some idea of the effect on the forest industries of major forces in the economy, such as population and income levels and levels of production in manufacturing and construction. This is attainable in part from knowledge of certain coefficients in the structural relationships estimated in this study. Lastly, it should be noted that estimates of supply and demand elasticities are critical to many economic analyses. Analyses of problems of the forest economy of the United States are no exception. Of particular interest to the U. S. lumber industry at the present moment is the increasing level of imports of softwood lumber from Canada (see U. S. Department of Commerce, 1962a, 1962b). Many suggestions have been made as to how the impact on the lumber industry of such imports can be lessened and they range from an increase in tariff to a partial embargo on imports. An accurate assessment of the effects of such moves on the economy and forest industries of the United States cannot be made unless estimates of elasticities of supply and demand for lumber are available. In contrast to this, there is a current demand for an assessment of the economic effects of exporting roundwood from the Pacific Northwest to Japan. Here also, estimates of elasticities of supply and demand for wood products are necessary for meaningful analysis. A number of other areas in which there is a need for such estimates could be cited, but in all cases the economic analysis is a lengthy investigation and the present study was necessarily restricted to obtaining estimates of structural coefficients and future magnitudes of price and consumption levels.

\section{Relationship to Other Studies}

With regard to estimation of structural coefficients, only the Holland (1955) and the Simpson-Halter (1963) studies come near to providing some of the results of the present investigation. Holland's work was a valuable pioneering effort and he deserves much credit although his specification of functions was perhaps inadequate. For instance, the only supply shifter was an index of average sawmilling cost, and such an index may change as output changes without any movement in the cost curves of individual firms. A proper supply shifter should depict movement of cost curves rather than simply movement along them. On the demand side, using Portland cement production as a shifter is difficult to justify on the basis of economic theory, though possibly when used in conjunction with construction expenditures it may have reflected changing proportions of residential and nonresidential construction. The analysis used only prewar data and dealt only with softwood lumber; furthermore, the influence of competitive materials was totally ignored, and it is unlikely that so incomplete a model could have yielded good estimates of elasticities of supply and demand.

The Simpson-Halter work was an excellent example of an intensive study of a single product, but its method of specifying relationships could be criticized. Ideally, only a priori knowledge should be used to specify relationships and only unimportant variables should be omitted. It seems obvious that if there is only one set of data available this set should not be used both to formulate and estimate a model. Some evidence of the dangers of such practice is given by Larson and Bancroft (1963) who use a simple prediction model to 
show that biased estimates are obtained. The main difficulty of the SimpsonHalter method may be seen in the relationships themselves. The sanded relationship was somewhat different in several instances from the unsanded one, and it seems that both specifications could not be correct. For instance, it is not clear why lumber price should be included in the sanded demand function and not in the unsanded one; nor is it clear why change in unfilled orders should appear in the unsanded supply function but not in the sanded one. Also, the reason for including certain variables and omitting others was not clear. For instance, the value of public miscellaneous construction was included in the equation explaining the level of unfilled orders for unsanded plywood rather than, say, the value of total construction despite the fact that all nonresidential construction accounted for only 14.5 per cent of consumption in 1962 (Simpson and Halter, 1963). In general, theoretical relationships used as a basis for specifying the complete set of variables appeared to be sound from a logical and observational standpoint, but the arbitrary elimination of seemingly useful variables resulted in relationships whose economic meaning was not clear. The correct specification of lags in an analysis using quarterly data is difficult, and Simpson and Halter were to some extent forced to take this empirical approach. If they had decided on certain basic variables, and had used preliminary computations only to choose between "competing" lags, little criticism could have been made on pragmatic grounds. Finally, it should be remarked that virtually no account was taken of the role of substitutes in the demand for plywood. In one equation (the demand for sanded plywood), lumber price lagged one quarter was in- cluded, but it is unlikely that any substitution effect would be felt in such a short time.

\section{Comparison of Techniques}

Though the price prediction and estimation of structural coefficients carried out in this study were to a large extent assaults on new problems, as has been mentioned, forecasts of consumption levels had been carried out by the Forest Service, the Stanford Research Institute, Resources for the Future and the Department of Commerce. Essentially, two methods of forecasting were used by these agencies; they were direct least squares regression analysis and what might be called the ratio method. The regression method was used by the Stanford Research Institute in its final projections of consumption levels of softwood plywood and wood pulp products, and in a supplementary projection of lumber consumption. Projections for wood pulp products made by the Department of Commerce also used this method. The ratio method was the basis for other projections carried out by all four agencies. The "model" underlying it is simply $Q_{t}=a_{t} X_{t}$, where $Q_{t}$ represents the consumption of the particular product in year $t$, and $X_{t}$ represents the level in year $t$ of a "key" variable known to be closely related to the consumption of the product, and where $a_{t}$ is the ratio $Q_{t} / X_{t}$, often called the use factor for year $t$. In this method forecasts of consumption are made by estimating future values of the use factor and of the key variable. In the end-use modification of the ratio method, total consumption of a product is broken down by consumption in various end-uses, the ratio method applied separately in each case, and forecasts of total consumption obtained by aggregating individual forecasts. 
The approach to forecasting adopted in this study involved the specifying of a set of behavioral functions for the purpose of explaining the formation of phenomena under study. Predicting equations were then formed on the basis of information about this set of functions and were used to obtain forecasts with desirable qualities, taking into consideration statistical properties and computational costs. The ultimate test of a method of prediction is whether or not it consistently gives accurate predictions, and in the absence of information about true future magnitudes no method, however sophisticated, can claim complete superiority. Furthermore, no method can take into account all possible influences-and the most comprehensive method may fail while (due perhaps to a cancellation of errors) a simple one may succeed. Given a fixed budget, the aim should be to choose a forecasting procedure that eliminates as many potential sources of error as possible. It is the author's belief that the approach adopted in this study does indeed do this. In addition, it should be pointed out that estimates of future levels of consumption were obtained with little additional effort once structural estimation and price prediction had been carried out.

With regard to elimination of potential sources of error, certain defects of the regression method are evident. In the first place, omission of apparently important variables can lead to biased estimates. The Stanford Research Institute final predictions for softwood plywood and wood pulp products and their supplementary forecasts for lumber may be susceptible to this type of defect, as perhaps are the Department of Commerce predictions for woodpulp products. Furthermore, the Stanford Research Institute supplementary forecasting model for lumber consumption utilized as a regressor variable the lumber price index, which is clearly determined simultaneously with consumption. This may make the estimates susceptible to both bias and inconsistency.

The ratio method, being basically different from the method used in this investigation, shows few relative defects and in fact may have certain advantages. For instance its data requirements are less demanding than the present approach and is not restricted to only commodities for which time series data are available. It can be used with information for only one year, though this may be dangerous especially when only crude estimates of end-use data are available. At the same time it provides scope for the investigator to use his personal judgement, though this may be a defect rather than a strength since his preconceptions as to what future magnitudes will be may have too much influence on the outcome of his investigation.

In addition, as Theil (1960) points out there is "... some kind of social pressure..." that leads forecasters to produce estimates acceptable to their audience. In particular, government agencies and large organizations may be susceptible to this pressure, and to a certain extent the forecasting of consumption levels in this study may be regarded as an attempt at verifying previous results. 


\section{STRUCTURE}

\section{Relationships Considered}

The BuILding of the economic model phasized the behavioral basis of supply was oriented towards participants in the and demand functions. The participant demand and supply process rather than hierarchy evident in the growing, transtowards products. This was partly be- formation, and consumption of wood cause of the multiple role of certain is shown below in simplified schematic participants and partly because it em- form by broad product categories.

Stumpage

Roundwood
Timber growers

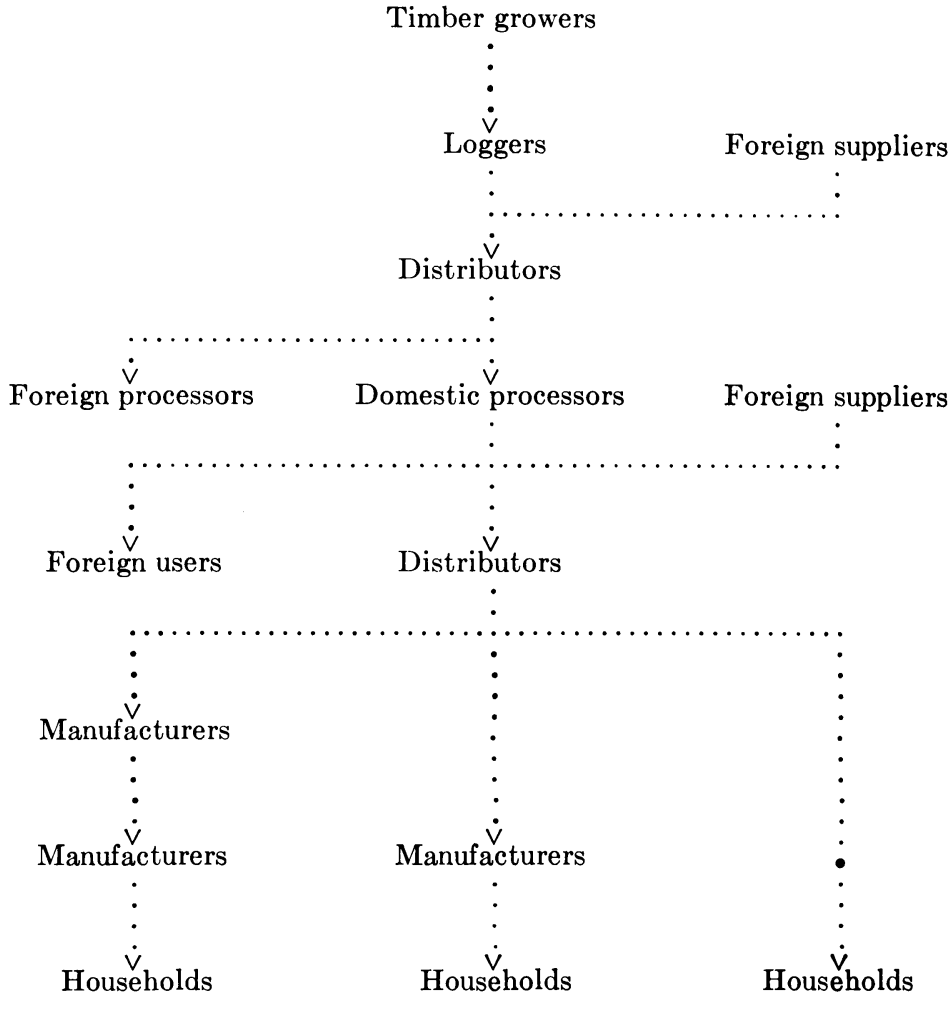

No attempt was made to show in the above diagram that the same company or individual may engage in several of the activities depicted, but this possibility was allowed for when the model was constructed.

As indicated earlier, estimation was restricted to supply and demand functions for wood products. No other structural relationships were estimated, but roundwood and stumpage demand and supply functions were explicitly considered in the economic model. Wood products demand and supply relationships at levels higher than the mill level were not directly included in the economic model, but their influence was accounted for by the introduction of appropriate variables into the demand relationships. 


\section{Important Participants}

In constructing the model only important types of participants were considered, with importance being judged by the proportion of a product consumed or produced by them in certain years. A breakdown of consumption by enduses and quantity supplied by sources is given in Appendix A. With regard to primary products it can be seen that, where all timber is concerned, farmers and other small private owners of forest land have supplied roughly half the country's output in recent years. Where softwood timber is concerned, however, it can be seen that the National Forests and the holdings of wood-processing firms are just as important as the forest lands of small private owners. The influence of distributors of roundwood, such as brokers and operators of concentration yards, was not considered because of their minor role. For the same reason no attention was given to roundwood demand and supply by foreign processors and operators. In addition, foreign demand for wood products was not considered because exports have generally been of negligible magnitude relative to $\mathrm{U}$. $\mathrm{S}$. consumption. The only product exported in quantity during the sample period was lumber, but even in this case exports declined in relative importance in the sample period, being equivalent to 9 per cent of consumption in 1929 but only to 2 per cent in 1960 . Imports of certain other wood products, especially paper (mainly newsprint), made up roughly 30 per cent of paper consumption throughout the sample period. Lumber imports were less important in relation to consumption but showed a more or less steady relative increase, being only 4 per cent of consumption in 1929 but some 11 per cent in 1960 . Domestic wood processors were the only important suppliers of paperboard, softwood plywood, and building paper and board.

The economic model might have included behavioral functions associated with wholesalers and retailers, covering, for example, demand for inventories. While such things as the level of distributor inventories could be important in a study using quarterly data, it is doubtful that speculative actions of wholesalers and retailers have any appreciable effect on marketings or price over the period of a year. For this reason, and because of the inadequacy of quantitative information on factors affecting their behavior, the influence of distributors on wood products supply and demand was not considered.

Users of wood products considered were: construction firms; manufacturers of containers; manufacturers of furniture and fixtures; manufacturers of other goods; firms using wood products for shipping; and households.

It may be seen from Appendix A that in recent years over 70 per cent of all lumber consumed was used in construction, and that the remainder was almost equally divided between shipping and manufacturing. The proportion of softwood plywood used in construction was approximately the same as for lumber, but only 11 per cent of all paperboard was used in construction, with containerboard being the most important category of the product and accounting for almost 50 per cent of consumption. Newsprint accounts for the largest segment of paper consumption, followed by book and other printing papers and coarse paper; tissue and building papers are relatively unimportant. As was mentioned the influence of users of wood products was taken into account in the formulation of demand relationships facing processors by specifying individ- 
ual demand functions for each type of user and then aggregating these sector functions.

\section{Specifying Functions}

In specifying the individual functions a problem arose because of the multiplicity of relationships that could be formed. The demand for a particular wood product by the construction industry could be formulated, for instance, as a function of the level of construction activity. Alternatively, the level of construction could be dispensed with and replaced by a host of variables that determine it-such as income, rate of family formation, mortgage terms, costs of inputs in construction, and so on. Similarly, the demand for a wood product by furniture manufacturers could be expressed as a function of the level of furniture output, or as a function of higher level shifters that determine this output, such as consumer income and prices of other goods. Two criterions were employed to overcome this difficulty. The first one was that the relationship should be as simple as possible, in the sense that it dealt with the lowest level of product manufacture and required a minimum of information about sectors of the economy other than the forest industries. It was, for example, desirable to avoid considering factors influencing the demand and supply for housing because of the cumbersome mill demand relationships necessary to account for them. The second criterion was that any variable appearing in the system of relationships should be explained by the system or should be exogenous to it. Expansion of the system to include additional explanatory relationships was considered infeasible and, therefore (as is emphasized in part III) the statistical requirements of the estimating procedure made it necessary to seek relationships containing no endogenous variables other than prices and consumption levels of the products studied.

The simplest type of producer-demand relationship is one containing the output of the demanding industry. This was used as a basis for the demand for wood products by construction firms, but in no other cases did it appear that the level of output of the demanding industry was exogenous and unaffected by the prices of the wood products utilized. Where the demanding industry was consumer goods, as in the case of furniture and fixtures and in some parts of the paper and printing goods industry, higher level shifters were introduced into the relationship in place of output (as indicated below). Where the demanding industry was producer goods, as in the case of container manufacturing, paper goods and printing, the output of higher level industries together with the price of substitutes for the product of the demanding industry were used in place of output.

\section{Theoretical Framework}

A preliminary step in selecting variables for inclusion in relationships involved the use of economic theory as a guide to important types of variables. In an initial attempt at establishing theoretical relationships much reliance was placed on mathematical economic theory, and supply and demand func- tions were derived using the classical tools of monoperiodic utility and production functions, pure competition, perfect knowledge, and profit and utility maximization. Subsequently, theoretical derivations were modified in an attempt to deal with reaction to past prices, elements of monopoly, and imperfect 
maximization. This approach proved to be too cumbersome, and in a second attempt economic theory was used only to outline the type of variable that could be expected to enter into relationships. Key relationships utilized were classical consumer demand, producer demand, and supply. The theoretical basis for these is briefly indicated in Appendix B. In the same appendix the derivation of various types of producer demand relationships is presented. In all, six types of theoretical relationships were utilized in the construction of the economic model. They are presented below with the numerals in parentheses referring to functions in Appendix B.

(1) Consumer demand (2)

Quantity of the good demanded: a function of its price, the prices of substitutes, the prices of other goods, population and per capita income.

(2) Supply (4)

Quantity of the good supplied: a function of its price and the prices of inputs in the production process.
(3) Demand for a producer good (5)

Quantity of the good demanded: a function of its price, the price of the product and the prices of other inputs in the production process.

(4) Demand for a producer good as a function of the output of the demanding industry $(11,12)$

Quantity of the good demanded: a function of its price, the price of substitutes and the output of the demanding industry.

(5) Demand for a producer good by a consumer goods industry as a function of shifters in the demand for the consumer good (17)

Quantity of the good demanded: a function of the price of the good, the prices of "other" consumer goods, the prices of inputs in the consumer goods industry, population and per capita income.

(6) Demand for a primary producer good by a secondary producer goods industry as a function of the output of the industry demanding the secondary good (18)

Quantity of the good demanded: a function of its price, the prices of inputs in the secondary industry, the output of the industry demanding the secondary good, and the prices of substitutes for the secondary producer good.

\section{Specification of Relationships}

In the sections following, demand and supply relationships are specified for each participant type considered, namely: construction firms, manufacturers of consumer and producer goods, firms using wood products in shipping, households, stumpage producers, roundwood suppliers and domestic and foreign wood processers. In a final section of the chapter, "sector" functions associated with each participant type are aggregated for each product to obtain the complete economic model.

\section{Construction Firms}

"All" lumber, softwood lumber, softwood plywood and building paper and board are discussed in this section with regard to their use in auxiliary roles, such as scaffolding, shoring, and shuttering, and to their use in completed structures. It was decided that a demand function containing level of output in construction and prices of substitutes was the most appropriate type of function for this sector, and function (4) above was used as the theoretical basis. In the case of "all" lumber, the quantity demanded was regarded as a function of: current prices of lumber, softwood plywood, and building paper and board; past prices of these commodities; past prices of clay products and structural steel; past wages of construction workers; and the value of total construction. A similar function was specified in the case of softwood plywood, except for the inclusion of the price of wallboard in 
previous years in place of past prices of structural steel and clay products. Softwood lumber demand function was the same as that for "all" lumber, except for the use of softwood lumber prices. The building paper and board function was similar to that for softwood plywood.

Originally, the intention was to break up total construction into residential and nonresidential construction, public and private construction, and maintenance and repair. This was partly to provide information on the relative influences of the outputs of these sectors, and partly to ensure that any effect of their changing relative magnitudes could be brought out. However, preliminary computations indicated a high degree of collinearity in the time-series data for the various types, so the idea was abandoned in favor of using only total construction.

Besides being highly competitive among themselves in the construction field, lumber, building board and softwood plywood suffer from competition from numerous non-wood-based materials. Notable among competitors is wallboard (used here to denote gypsum board and plaster board) which competes with both plywood and building board. Lumber however-and especially softwood lumber-suffers competition from structural materials such as brick and other structural clay products, concrete and structural steel.

Major changes in construction technique took place during the sample period. Residential units showed a marked decline in size; the average size of single family nonfarm homes was 1500 square feet in 1920 and 1000 square feet in 1950. Use of slab-type foundations increased rapidly - they were used in only 4 per cent of all new homes in 1940 but in 1953 they were found in 34 per cent of such structures. The proportion of single-storied dwelling units increased from 60 per cent in 1920 to 80 per cent in 1950, and in the same period the proportion of single storied multi-family structures increased from 10 per cent to 50 per cent. Lastly, marked changes in architectural requirements took place and were characterized by a lowering of roof pitches, a reduction in "gingerbread," fewer interior walls, wider spans and larger windows. Information on trends prior to 1954 is to be found in the study by the Stanford Research Institute (1954). Details on trends in the period after 1953 are available in the recent Forest Service report (U. S. Forest Service, 1965).

Hardest hit by these changes was lumber use in residential construction which declined from 18,900 board feet per house on the average in 1920 to 10,520 board feet in 1953 and to 8,700 board feet in 1962. This was partly due to displacement by sheet materials in flooring, roofing, and exterior sheathing. Lumber had 50 per cent of the market for exterior sheathing in 1940 and only 4 per cent in 1950 (Stanford Research Institute, 1954).

A major factor motivating the shift to sheet materials was the rapid increase of construction wage rates. Approximately half of construction costs are in the form of wages, and it is the installed price of a construction material versus the installed price of a substitute that is important in the demand for that material. Wage rates of construction workers were therefore selected for inclusion in demand functions. An unsuccessful attempt was made to compile a series for wage rates of carpenters in preference to other skilled construction workers. An attempt to establish complete series for the prices of all major competitors of wood products in construction was also unsuccessful, but it was possible to ob- 
tain data for the major non-wood competitors-wallboard, structural steel and structural clay products.

The use of only "current" wages and prices of substitutes was not deemed appropriate. A great deal of what might be termed "technical rigidity" exists in the construction industry, and response in technique to short-run changes in prices of materials is slight. Nor was the use of simple 1-year lags thought adequate, for the great heterogeneity of the industry and the complexity of changegenerating forces were recognized. It was felt that it was logically and statistically impossible to identify each of these forces, and therefore it was decided to seek a single type of variable that would capture their essential nature. Numerous possibilities were considered, and it was concluded that some sort of moving average price would best represent the influence of a particular competing material on the demand for a given wood product. What the exact nature of this moving average should be was not easy to determine. It appeared, however, that where structural materials (structural clay products, softwood lumber, and structural steel) were concerned the length of the averaging period should be longer than in the case of non-structural materials. It was finally decided that a 5 -year average should be used in the case of sheet materials and a 10-year average in the case of structural materials. The moving average prices were lagged 1 year, and current prices were inserted separately in the demand functions; to do otherwise would have created a problem with regard to the estimation technique employed (as will be apparent in part III). Also, it was expected that current prices would have a greater influence than prices in any other single year. Current prices of non-wood materials were not included because of their apparently minor importance. Construction wages were dealt with in essentially the same way, although installation costs appeared to be less important in the case of structural materials and only a 5-year moving average was considered.

In an attempt to confirm the usefulness of the 5- and 10-year averaging periods vis-à-vis other time periods, some preliminary "construction demand" equations were run with total consumption of a particular wood product regressed on the value of "total" construction, the average price of the wood product over the past $n$ years, and the average prices of important substitutes over the same period. Regressions of this sort were run for softwood lumber for $n=1,2, \ldots 10$, and for softwood plywood and building board for $n=1,2$, ...5. Results of these regressions are presented in Appendix C. It is evident that they neither confirm nor deny the realism of the chosen pericds, but it should be noted that data on total consumption of the particular wood product had to be used rather than data on consumption in construction, because of the unavailability of the latter. An exhaustive investigation using complete demand functions rather than ones restricted to construction alone could have been carried out, but the computational effort would have been much greater.

\section{Producers of Consumer Goods}

Wood products particularly considered here are printing, fine and tissue paper; and lumber, softwood plywood and paperboard (especially hardboard) used in furniture and fixtures and in a miscellany of other manufactured products. The U. S. Forest Service (1965) estimated that in 1960, 53 per cent of all lumber used in manufacturing, 32 per cent of all hardboard, and 49 per cent of all plywood and veneer used in manu- 
facturing, went into furniture and fixtures. It was estimated that 55 per cent of the paper was consumed in the form of newsprint and other printing paper, 8 per cent was "fine" and 10 per cent was "sanitary and tissue."

The type of function appropriate for this sector was one which described the "demand" for a wood product as a function of its price, the prices of substitutes for it, and of supply and demand shifters for the consumer good being produced. Function (5) on page 16 is of this type. In the case of lumber, softwood plywood, and paperboard, the quantity of the wood product demanded was specified to be a function of the current prices of lumber, softwood plywood and paperboard; population and per capita disposable income. In the case of the demand for paper in manufacturing consumer goods, the quantity demanded was considered to be a function of the price of paper, population, per capita disposable income, and the consumer price index.

In the manufacture of furniture, fixtures and other consumer goods, the major competitive materials are lumber, plywood, hardboard, metals and plastics. Because suitable time-series data were available only for wood products, metals and plastics had to be ignored.

With regard to demand shifters for consumer goods being produced, it was necessary to limit these to a few major ones, partly because of statistical necessity and partly because of the heterogeneity and greater number of the goods in question. As a result population, per capita disposable income, and the consumer price index alone were utilized. The consumer price index was somewhat inappropriate as a measure of the prices of "other" goods because of its generality and because it depends on the prices of the consumer goods in question, but these defects were thought to be outweighed by its convenience.

In a search for appropriate supply shifters for consumer goods, series were compiled for electric power, and for wages in printing and publishing, in "furnitures and fixtures," and in all manufacturing. These variables were not included in the final model mainly because they were not thought important. No prices other than current ones appeared to be important.

\section{Manufacturers of Producer Goods}

The basic relationship used here was quantity demanded as a function of the prices of inputs (especially substitutes) in the producer goods industry, the output of the industry supplied, and the prices of substitutes for the key producer good. Function (6) on page 16 is of this type. Wood products dealt with in this section are mainly lumber, paperboard and softwood plywood used in container manufacturing; lumber for pallets; and paper for sacks and for business stationery and printed matter. With regard to container manufacturing the U. S. Forest Service (1965) reported that in 1960, 9 per cent of all lumber went into boxes, crates and pallets; 74 per cent of all paperboard was containerboard and bending board; and that about 11 per cent of all plywood and veneer was used for containers and pallets.

It was obvious that separate measures of output for all relevant producer goods industries could not be included in the model, and consequently the Federal Reserve Board index of industrial production for all manufacturing was used as a catch-all variable. The only other variables used in this sector were current prices of the wood products in question, with lumber, paperboard, and plywood considered to be competitive in the 
manufacture of boxes and crates. Paper and paperboard were viewed as competitive with each other because paper packaging materials and sacks tend to be substitutes for paperboard containers. This competition might have been expressed by price measures for the products (sacks and containers) themselves, but such prices in part depend on the prices of paper and paperboard and their use would have required the inclusion of additional explanatory relationships in the model.

For lumber and softwood plywood, the quantity demanded was specified as a function of the current prices of lumber, plywood, and paperboard, the index of manufacturing production, population, and per capita disposable income. In the case of paper, the quantity demanded was specified as a function of the current prices of paper and paperboard, the index of manufacturing production, population, per capita disposable income, and the consumer price index. The demand for paperboard was identical except for the addition of the current prices of lumber and softwood plywood.

\section{Firms Shipping}

The only products of importance in this sector are lumber used for dunnage (4 per cent of all lumber consumed in 1952) and "coarse" paper used in its raw form rather than in the form of bags and sacks. Sufficient recognition was given to this sector by a demand relationship expressing the quantity of the wood product demanded as a function of its price and of the index of manufacturing production.

\section{Households}

Direct use of wood products by households is of only minor importance and stems mainly from hobbies and do-ityourself projects. To a certain extent plywood, lumber, and building board are competitors in this use. The type of demand relationship represented by function (1) on page 16 was considered to be an appropriate basic function here. The variables population, per capita income, and the consumer price index were selected as relevant additions to a demand relationship depicting the quantity of a wood product demanded as a function of its own price and the price of competing materials.

\section{Stumpage Producers}

Supply of stumpage by both private and public producers is dealt with in this section. The activities of timber growers who are wood processors or who do their own logging are not considered here and are dealt with in later sections. In the case of both private and public stumpage the quantity supplied was specified to be a function of only the current price of stumpage and a trend variable. Multi-period production theory was of some help in clarifying the type of variable that might enter into a supply of stumpage relationship, but it yielded no function that was directly useful. Characteristically, this type of theory assumes a known production function invariant over time, profit maximization, and perfect knowledge of future prices of products and inputs. In view of the long period and high degree of uncertainty involved in the production of stumpage, and the predominance among stumpage producers of aims other than profit maximization, the deductive approach was abandoned in favor of a more empirical one.

In the case of private producers, experience indicated that a type of stocksupply function would be the most appropriate, with the understanding that 
individual producers could have one or more parcels of timber each with a reservation price. It was recognized that in the aggregate, current price would have a powerful effect in bringing additional parcels or individuals into the market. It was also noted that expectations of future price levels might have some influence in forming reservation prices for individual producers, and consideration was given to the inclusion of some type of lagged price or price change variable that would represent expectations. The step was not taken, however, because of the over-all unimportance of the variable in the system. In any case, knowledge of the motivations of the type of individual under consideration (the non-logging, non-processing grower) indicated that, on the whole, reservation prices were not formed by any comprehensible process.

Prices of inputs in timber growing were discarded without hesitation as possible variables, but a serious (though unsuccessful) attempt was made to obtain data on property tax rates on mature timber as it was felt that changes in holding costs were an important influence on the supply of stumpage.

If the length of the production period for stumpage was shorter, no other variables need have been consideredbut it was evident that in a time-series analysis recognition had to be given to the changing physical availability of timber in the hands of these private producers. No suitable data were available, but it was evident that a continuous trend variable would represent to some extent the steady decrease that took place in the stock of mature, high quality timber throughout the sample period.

With regard to the supply of public stumpage, attention was focused on the U.S. Forest Service because of the much greater importance of national forests in this respect. Initially some difficulty was experienced in conceptualizing a supply function for Forest Service timber because of the features of allowable cut and appraised minimum prices associated with it. Eventually it was concluded that a supply schedule inelastic at prices above the appraised price, with zero supply at lower prices, characterized the individual timber sale. It was observed that aggregation of such schedules would lead to a discontinuous steplike schedule of total supply, with discontinuities becoming less marked as the size of individual sales became smaller and appraised prices became more continuous. It was noted that this total schedule would be subject to shifts as the level of allowable cut was changed, and that the level of Forest Service budgets for timber sale preparation would also act as a supply shifter. Complete series of observations on these variables were not available but data at hand showed that they had undergone a steady increase in magnitude, especially in the latter part of the sample period. It was therefore concluded that a continuous trend variable would be of some assistance in depicting their infl1ence.

The complexities arising from the heterogeneous nature of stumpage are great. For instance, there is much variation in log quality and there are wide locational differences among timber sales with regard to length of haul and difficulties of terrain. There also are additional problems resulting from the method of appraising minimum prices and from Forest Service policy regarding size, timing and conditions of sales. The study of the supply of public timber is a complete topic in itself, and the present superficial treatment is justified only by the fact that it played a somewhat minor role in the final model because estima- 
tion of stumpage supply was not carried out and because information on it was used only indirectly in estimating other relationships.

\section{Roundwood Suppliers}

This section deals with the role of logging concerns as suppliers of roundwood and demanders of stumpage but does not cover concerns engaged also in wood processing although loggers who are also timber growers are covered.

In the case of the "non-integrated" logger who demands stumpage and supplies roundwood, simple "classical" supply and producer demand functions were thought to be appropriate basic relationships. This meant that attention had to be given to the prices of inputs in logging and $\log$ transportation, as well as to prices of roundwood and stumpage. Among the inputs considered were labor, automotive fuel, equipment, vehicles, tires and accessories. Adequate data on wages in logging were not available, so wages in sawmills were used instead. Automotive fuel prices were also included in the final model, but the other inputs were discarded. The reason for this was partly lack of data and partly lack of knowledge as to their influence; this was particularly true in the case of more durable types of equipment such as tractors and trucks. Increases in stock of such fixed assets must have led to increases in supply over the sample period and, while past prices of a particular input relative to the prices of roundwood and other logging inputs could have been introduced to depict part of the motivation for increases in equipment stocks, difficulties in obtaining data and specifying the exact nature of variables suggested that the step should not be taken. Ideally, variables representing levels of stocks of fixed inputs should have been included-but again lack of information led to their exclusion. Complete price data were available for sawlog stumpage, but not for pulpwood stumpage or peeler-grade timber.

In the case of the integrated logger who both grows timber and supplies roundwood it was apparent that his supply-of-roundwood function should include roundwood prices, prices of logging inputs, and shifters similar to those in the supply of private stumpage. As with stumpage, the only feasible shifter was a continuous trend variable to represent decreasing physical availability of timber. It was recognized, however, that the timber grower doing his own logging may be a shrewder businessman than the non-logging timber grower and that he may frequently hold roundwood off the market in anticipation of higher future prices. If more information on his formation of price expectations had been available some sort of "expectation" shifter could have been devised and might have been a useful addition to the relationship.

\section{Domestic Wood Processors}

The supply of wood products, the demand for roundwood and the demand for stumpage by domestic processors are considered here. No attempt was made to specify special types of functions for horizontally integrated firms; their supply functions with regard to a particular wood product were assumed to be unaffected by the price of their other products. This approach was taken partly for the sake of simplicity but mainly because multi-product wood processing companies may frequently treat the manufacture of different products as separate operations, except for such things as the recovery of chips for pulping. Nevertheless it was recognized that decreasing supplies of raw materials in the future might make the theoretical supply 
function under joint production a reality, because a company faced with shortages of logs would have to make decisions as to which product to favor in their allocation. Attention was paid, however, to the effects of vertical integration on processor behavior, and distinction was made between the nonintegrated firm (purchasing only logs), the partially integrated firm (purchasing stumpage and perhaps logs), and the completely integrated firm (growing timber and perhaps also purchasing stumpage and $\operatorname{logs}$ ).

In the case of lumber the quantity supplied was characterized as a function of its current price, current prices of sawlogs, sawlog stumpage, electric power, petroleum products, current wages in sawmills, a variable depicting productivity in sawmilling, and two proxy variables. The quantity of paper and paperboard supplied was specified to be a function of current price, the prices of pulpwood, electric power, petroleum products, current wages in pulp and paper, and a productivity variable and proxy variables. The quantity of softwood plywood supplied was designated to be a function of its price, the price of veneer logs, electric power, wages and productivity in plywood plants, and a single proxy variable.

In the case of the demand for roundwood, functions were basically similar. For sawlogs the quantity demanded was specified to be a function of the prices of sawlogs, lumber, electric power, petroleum products, and wages in sawmills. For pulpwood it was specified to be a function of the prices of pulpwood, paper, paperboard, electric power, and wages in pulp and paper mills. In the case of veneer logs it was characterized as a function of the prices of veneer logs, plywood, electric power, and wages in sawmills.
With regard to the demand for stumpage by domestic processors, the quantity demanded was specified to be a function of its price, the prices of wood products, roundwood, electric power, petroleum products, and wages in processing plants.

In the simplest case, the non-integrated firm, the "classical" supply function indicated that the quantity of a wood product supplied should be a function of its price and the price of inputs used in its manufacture. The demand for an input was indicated to be a function of its price, the price of the product, and the prices of other inputs. Inputs for which data were available were sawlogs and petroleum products in the case of lumber manufacture, veneer logs in the case of plywood production, and pulpwood in the case of paper and paperboard manufacture. Data on the price of electric power and wages in sawmills and in pulp and paper mills were also available. In the case of lumber manufacturing, it has been estimated recently (Western Lumber Manufacturers, 1958) that 77 per cent of variable sawing costs (excluding $\log$ costs) of certain mills were due to labor requirements and 23 per cent due to supplies and power requirements. Of the latter component, power was 35 per cent and petroleum products 7 per cent. For yard and shipping operations the percentage attributed to labor requirements was much the same, although purchases of petroleum products amounted to 36 per cent of the remaining costs. These figures exclude log costs, but it should be noted that such costs rose sharply during the sample period and in the late 1950's accounted for more than half of total lumber costs in many regions. For wood pulp production, Guthrie (1950) estimated that in 1946 wood costs varied from 55 per cent to 71 per cent of total manufacturing costs, depending on local- 
ity and the type of pulp produced. It was estimated from his data that during the same period on the average 65 per cent of the cost of manufacturing newsprint went for pulp, 11 per cent for labor, and 7 per cent for fuel and power. It was also estimated (using 1942 data) that 55 per cent of costs were for pulp and other raw materials in the case of Kraft wrapping paper manufacture and 59 per cent in the case of writing paper. Data on wages in plywood plants were not available, and wages in sawmills were used in their place in the plywood supply and veneer log demand functions; it is likely that the two wage series are closely correlated. Available cost data on wood processing are scanty, but detailed knowledge of cost structure is not critical to the estimation of supply functions. What is necessary is that sufficient information be available to indicate which variables are important and which are not.

At the start of this study pilot estimations of wood products supply equations were made, using the simple models indicated by classical supply theory. These regressions consistently showed negatively sloped supply schedules which induced some skepticism as to the validity of the models. Though static economic theory permits such schedules to exist where external economies prevail this was not sufficient justification for accepting the estimates obtained. In the first place, the concept of external economies is incomplete in the sense that it deals with a situation in which influences such as technology and the prices of inputs are allowed to vary. In an econometric study the objective should be to account for the effects of such influences and not to use them to justify results. Secondly, it appeared that to admit the presence of external economies was to accept the existence of structural change due to the omission of variables. From the outset it was evident that the simple models suggested by classical theory were inadequate to depict the real behavior of wood processors with regard to their demand for inputs and their supply of wood products. Such models were thought to be particularly deficient in handling such influences as changes in the capital intensiveness of wood processing, changes in the size and distribution of industry capacity, and technological advance.

The role of changing capital intensiveness of production as a supply shifting influence was not immediately obvious, but some reflection led to the conclusion that it might well have been an important supply increaser over the sample period. In all phases of wood processing marked substitution of machinery and equipment for labor took place during the latter part of the sample period, and it was felt that this move served to bring down variable costs of production and thereby increase the supply of firms that made the change. No really satisfactory direct measure of changing capital intensiveness was available, and so an effort was made to find a proxy variable that would be a good indicator of it. As a result, output per man year in U. S. sawmills was included in the lumber relationships, and output per man year in pulp, paper, and paperboard mills was included in paper and paperboard relationships. No such proxy variable was available in the case of plywood and (as will be explained in the next chapter) it seemed advisable to use the sawmilling productivity variable in the supply equation for that product. It was not overlooked that these proxy variables might be endogenous because they were dependent on levels of output of the particular wood products. Nevertheless, they were included on the premise that 
(in this case) any slight least-squares bias was preferable to bias due to omission of an important variable.

Finally, it was hoped that productivity variables would to a certain extent represent some of the technological change that had been taking place during the sample period. Since these variables represent changes in output for a fixed level of a particular input (labor), it was anticipated that they would capture the effects of movement along the surface of production functions due to increasing levels of other inputs, and the elevation of that surface due to technological advance.

The effect of changes in capacity was much less easy to deal with. Part of the trouble was that not all changes in capacity represent changes in supply. For instance, increase in the output of an industry due to entry of high-cost firms in times of high prices is not an increase in supply but a movement along a previously existing supply schedule. On the other hand, entry of low-cost firms, say in times of rapid technological advance, does result in an increase in supply. Some data on capacity changes during the sample period were available, but because of this lack of clarity as to its role the variable was not used in the final model. The theoretically ideal solution would be to attack the problem at its roots, and to bypass capacity by specifying comprehensive relationships that would account for increased capacity by considering such basic influences as expectations of future prices and costs. This was not thought to be practicable, however.

With regard to technological advance, it was obviously impossible to get some direct measure of this influence to include in the model, yet it was apparent that such advance had taken place over the sample period, especially in pulp and paper. It was especially evident that although little change had taken place in the prewar period, the postwar years had seen a great upsurge in technological development. Thus, a 0-1 dummy variable referring to the prewar-postwar periods was introduced into the model, even though it might act as a catch-all variable and bring in the effect of variables other than technological advance. This is what appeared to happen in the case of plywood and lumber supply functions where the estimated coefficient of the dummy variable showed a significantly negative sign. In the case of wood pulp products, the coefficient was positive. One reason for the negative sign in the case of the other products could be a "picking up" of a quality decrease in raw materials which was not reflected in the price data used for them. Theoretically, decreasing quality of an input with a constant price should result in a decrease in supply, and it could be argued that deterioration in log-grading standards may have taken place during the sample period, especially in postwar years. The view that this was the real reason for the nature of the estimates cannot be substantiated however. (Other possible reasons are discussed on page 43).

With regard to behavioral relationships for partially integrated and fully integrated wood processors it should be noted that their essential attributes have been discussed in this and the previous sections. For the partially integrated wood processors who purchase logs and do their own logging, the supply function was considered to be the same as for non-integrated processors with the addition of the price of roundwood, the price of stumpage, and the prices of logging inputs (see pages 22-23). For those partially integrated processors who do not purchase roundwood, the relationship 
used was as just described except for the omission of the price of roundwood which is irrelevant in this case.

For completely integrated processors who purchase logs and stumpage and also grow timber, the relationships employed were those which included all the variables described in this section plus a trend variable to depict decreasing physical availability of mature timber.

In the case of plywood processing no attention was given to logging and timber growing influences, as it was felt that their effect would be sufficiently reflected in the price of peeler logs.

No explicit consideration was given to miscellaneous types of participants such as pulp companies selling sawlogs or lumber companies selling veneer logs, because such sources of roundwood supply are minor.

\section{Foreign Wood Processors}

Of the products discussed, only lumber and newsprint are imported into the United States in any quantity. Almost all of these imports come from Canada, so the activities of processors other than Canadian ones were not considered in the analysis. Demand for United States roundwood by Canadian processors was ignored. The quantity of lumber supplied by Canadian mills was specified to be a function of price, the tariff on lumber, and the rate of exchange on the Canadian dollar. In the case of newsprint, only price and the rate of exchange were considered. A complete model would have specified the supply of Canadian newsprint or lumber as a function of (among other things) its price in Canadian and European markets as well as in U. S. markets. Such prices would not be exogenous because of the effect of U. S. prices on Canadian exports to Europe and the supply to domestic markets. This, coupled with difficulties of obtaining data, led to the inclusion of only U. S. prices. Input prices in the Canadian wood-processing industries might also have been considered but were not, partly because of their over-all insignificance in the model, and partly because the series on them were not readily available. For the latter reason, freight rates from Canada to U. S. markets vis-à-vis internal rates had to be dropped from the model, though they are an important factor in the increased imports of Canadian lumber in recent years (U. S. Department of Commerce, 1963). The rate of exchange is generally thought to be an important shifter now in the supply of Canadian lumber to U.S. markets (U. S. Department of Commerce, 1963); this is not true of the tariff on lumber, which is only a minute handicap to Canadian exporters. For Douglas fir construction lumber in 1960 it was only about 1 per cent of the average price. In the early 1930's, however, it was as much as 38 per cent of the price and must then have been a significant influence.

\section{Market Equilibrium}

In short-run studies using, say, quarterly or monthly data, discrepancies between quantity demanded and quantity supplied may occur. Such studies may require the specification of additional relationships to account for these discrepancies by a consideration of movements in inventory levels. One advantage of using annual data was that this was unnecessary because of the minor nature of changes in inventory levels for the products considered. For instance, changes in lumber stocks in relation to consumption were only 2 per 
cent in 1939, 3 per cent in 1947 and 0.5 per cent in 1959 ; for pulpwood, percentages were 5 per cent in 1947 and 2 per cent in 1959 ; for paper other than build- ing paper and newsprint, changes in stocks as a percentage of U. S. production were 0.7 per cent in $1939,0.5$ per cent in 1948, and 0.3 per cent in 1959 .

\section{The Complete Structure}

The economic model consisted of two major parts: a subsystem of demand and supply relationships for wood products, and a similar sybsystem for the primary products-roundwood and stumpage. Within the wood products subsystem relationships are interrelated in the sense that the price of one wood product may affect the demand for another product, and in turn may have its demand affected by the price of the other product. Both subsystems are subject to exogenous forces and at the same time they influence each other because roundwood and stumpage prices affect wood products supply-and these primary products in turn have their demands affected by the prices of wood products.

It is not feasible to show diagramatically the interrelationship between products, but some idea of its complexity may be obtained from the much simplified case presented in figure 1. In this figure the interaction between lumber and plywood only is shown, and no attempt is made to indicate the effect of prices other than current ones.

The wood products subsystem was the one specified in detail and subjected to structural estimation. The primary products subsystem played only an auxiliary role and was specified mainly because of the requirements of the simultaneous estimation technique employed. It was thought profitable to estimate structural relationships for softwood lumber and building paper and board as well as for lumber, paper, paperboard and plywood-the main commodities in the wood products subsystem. Twelve rela- tionships in the wood products subsystem were specified. Only eight in the primary products subsystem were specified, because sawtimber was the only category of stumpage for which data were available. The twenty relationships, which are described immediately below, conform to the discussion in the previous sections except for the introduction of freight rates into demand equations to cover shipment costs for wood products where price data available were f.o.b. mill rather than f.o.b. destination.

The term "quantity demanded (or supplied) a function of" is implicit in the presentation, and the variables shown are the "right-hand" variables in the relationship. After each variable the sector or sectors of demand or supply in which it originated is indicated by a code letter in parentheses. Sector code letters are as follows:
A. Construction
B. Container manufacturing
C. Furniture and fixtures manufacturing
D. Other manufacturing
E. Firms shipping
F. Use by households
G. Shipment of wood products
H. Stumpage production
I. Round wood production
J. Domestic wood processing
K. Foreign wood processing

For wood products relationships the basic character of the variable is shown by the word "positive" or "negative" appearing after it with positive referring to a variable that increases the quantity demanded or supplied as it itself increases, and negative referring to 


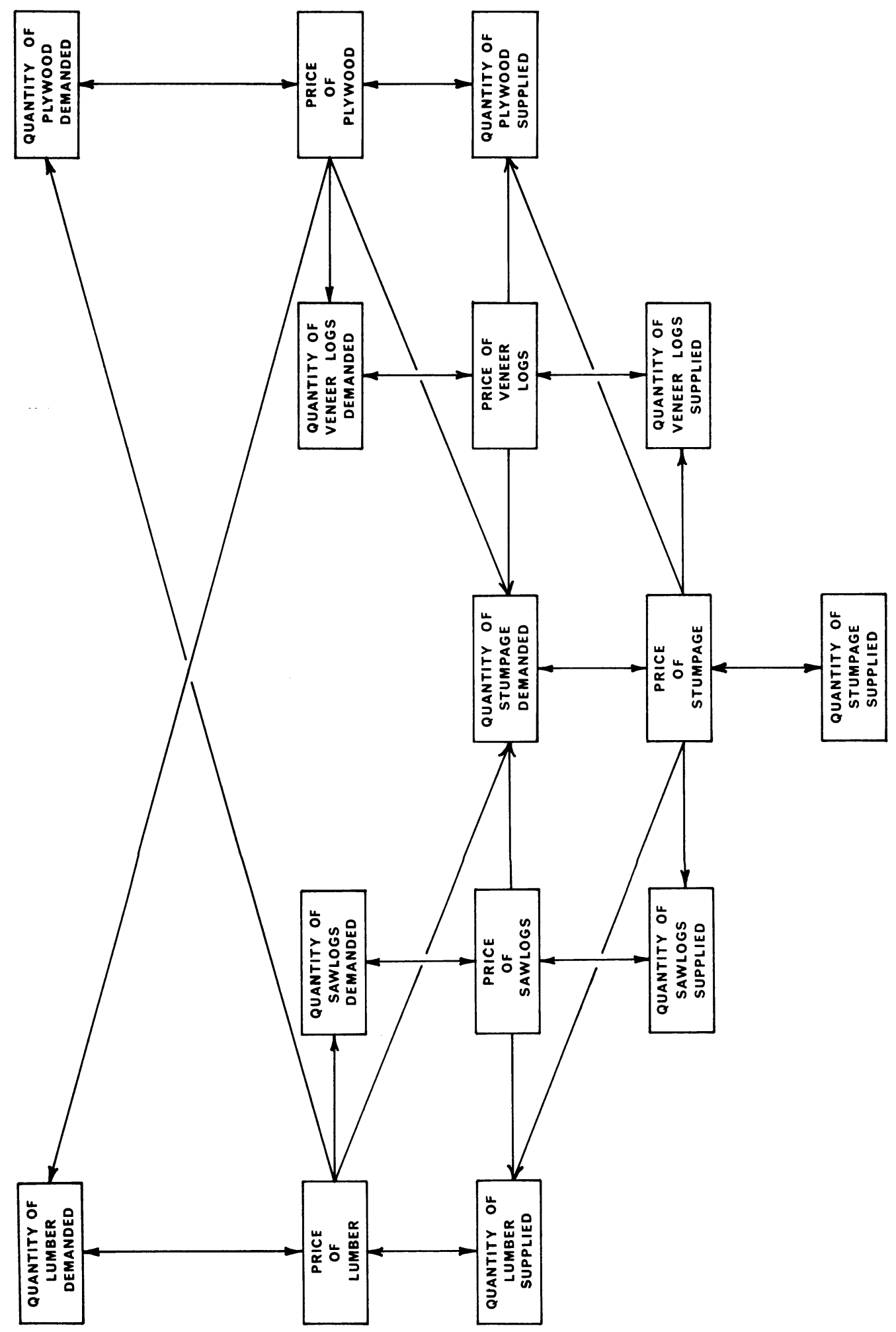


demand or supply decreasers. These notations are also the a priori expectations of signs of associated coefficients obtained through statistical estimation (as discussed in the next chapter). Judg- ment as to whether a variable was a positive or negative shifter was formed partly through knowledge of the behavior of participants and partly on the basis of economic theory.

\section{Lumber demand:}

Current price of lumber (sectors $A$ to $G) \ldots \ldots \ldots \ldots \ldots \ldots \ldots \ldots \ldots \ldots \ldots$ Negative

Current price of softwood plywood (sectors A to G) .................. Positive

Current price of paperboard $(\mathrm{A}, \mathrm{B}, \mathrm{C}, \mathrm{E}, \mathrm{F}) \ldots \ldots \ldots \ldots \ldots$ Positive

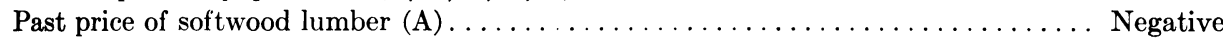

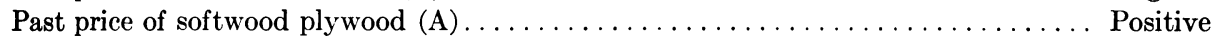

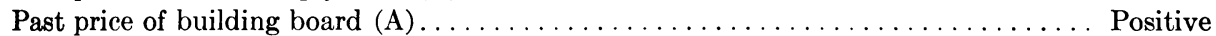

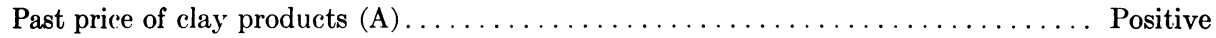

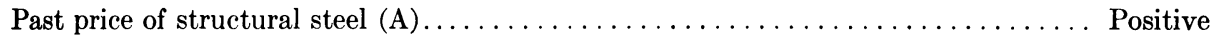

Past wages of construction workers $(A) \ldots \ldots \ldots \ldots \ldots \ldots \ldots \ldots \ldots$ Negative

Index of manufacturing production $(\mathrm{B}, \mathrm{D}, \mathrm{E}) \ldots \ldots \ldots \ldots \ldots \ldots$ Positive

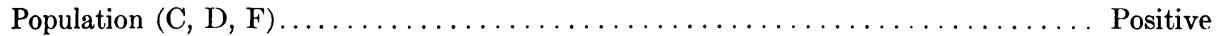

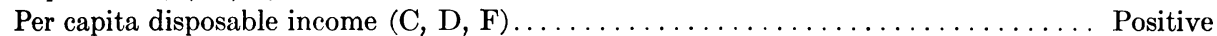

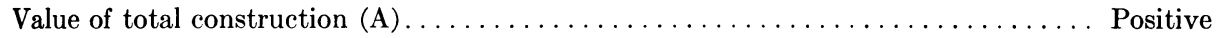

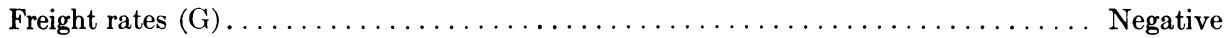

Lumber supply:

Current price of lumber $(\mathrm{J}, \mathrm{K}) \ldots \ldots \ldots \ldots \ldots \ldots \ldots \ldots$ Positive

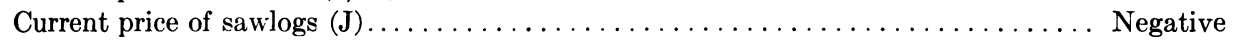

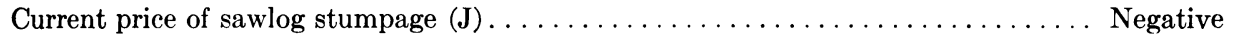

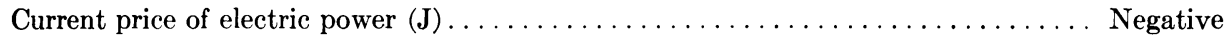

Current price of petroleum products $(\mathrm{J}) \ldots \ldots \ldots \ldots \ldots \ldots \ldots \ldots \ldots \ldots \ldots$ Negative

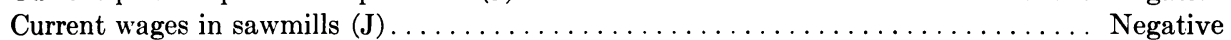

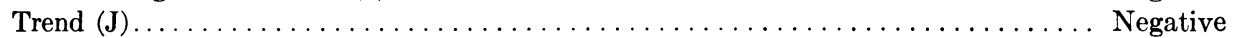

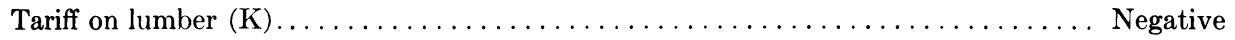

Rate of exchange on the Canadian dollar $(\mathrm{K}) \ldots \ldots \ldots \ldots \ldots \ldots \ldots \ldots$ Negative

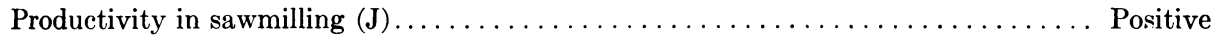

Dummy variable $(\mathbf{J}) \ldots \ldots \ldots \ldots \ldots \ldots \ldots$ Positive

Paper demand:

Current price of paper $(A, B, C, D, E, F, G) \ldots \ldots \ldots \ldots \ldots \ldots$ Negative

Current price of paperboard $(\mathrm{B}, \mathrm{E}) \ldots \ldots \ldots \ldots \ldots \ldots \ldots \ldots \ldots \ldots \ldots \ldots \ldots \ldots \ldots \ldots \ldots$ Positive

Index of manufacturing production $(\mathrm{B}, \mathrm{D}) \ldots \ldots \ldots \ldots \ldots \ldots \ldots \ldots \ldots \ldots \ldots$ Positive

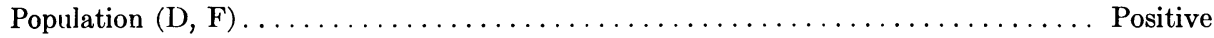

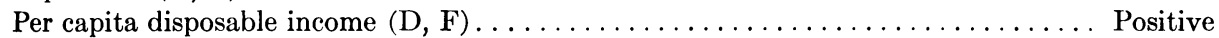

Value of total construction $(\mathrm{A}) \ldots \ldots \ldots \ldots \ldots \ldots \ldots \ldots \ldots \ldots \ldots \ldots$ Positive

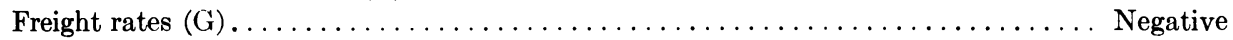

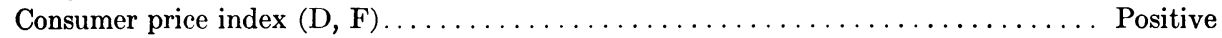

Paper supply:

Current price of paper $(\mathrm{J}, \mathrm{K}) \ldots \ldots \ldots \ldots \ldots \ldots \ldots \ldots \ldots \ldots \ldots \ldots \ldots \ldots \ldots$ Positive

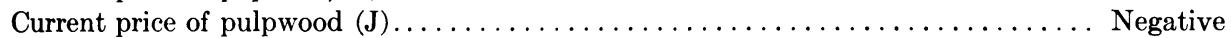

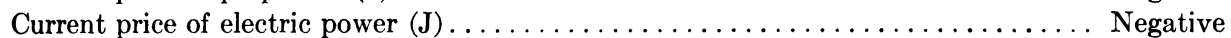

Current price of petroleum products $(\mathbf{J}) \ldots \ldots \ldots \ldots \ldots \ldots \ldots \ldots \ldots \ldots \ldots \ldots$ Negative

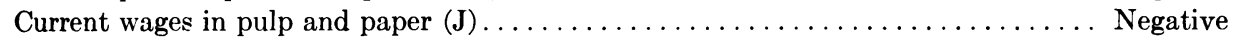

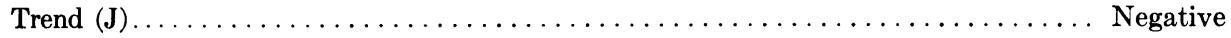

Rate of exchange on Canadian dollar $(\mathrm{K}) \ldots \ldots \ldots \ldots \ldots \ldots \ldots \ldots \ldots \ldots \ldots$ Negative

Productivity in pulp and paper $(\mathrm{J}) \ldots \ldots \ldots \ldots \ldots \ldots \ldots \ldots \ldots \ldots \ldots \ldots \ldots \ldots \ldots$ Positive

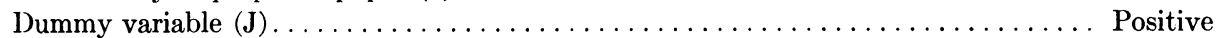

Paperboard demand:

Current price of paperboard (sectors $A$ to $G) \ldots \ldots \ldots \ldots \ldots \ldots \ldots \ldots \ldots \ldots$ Negative

Current price of lumber $(\mathrm{A}, \mathrm{B}, \mathrm{C}, \mathrm{D}, \mathrm{F}) \ldots \ldots \ldots \ldots \ldots \ldots \ldots \ldots \ldots \ldots \ldots \ldots$ Positive 
Current price of paper (B)

Current price of softwood plywood $(\mathrm{A}, \mathrm{B}, \mathrm{C}, \mathrm{D}, \mathrm{F}) \ldots \ldots \ldots \ldots \ldots$ Positive

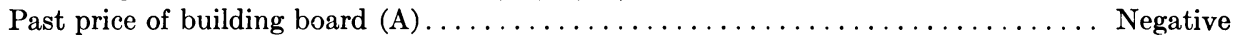

Past price of softwood lumber $(\mathrm{A}) \ldots \ldots \ldots \ldots \ldots \ldots \ldots \ldots \ldots \ldots \ldots$ Positive

Past price of softwood plywood $(\mathrm{A}) \ldots \ldots \ldots \ldots \ldots \ldots \ldots \ldots \ldots \ldots \ldots \ldots \ldots$ Positive

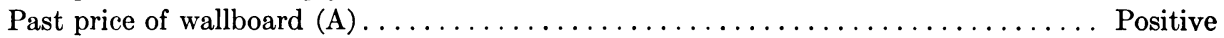

Past wages of construction workers $(\mathrm{A}) \ldots \ldots \ldots \ldots \ldots \ldots \ldots \ldots \ldots$ Positive

Index of manufacturing production $(B, D) \ldots \ldots \ldots \ldots \ldots \ldots \ldots \ldots \ldots$ Positive

Value of total construction $(\mathrm{A}) \ldots \ldots \ldots \ldots \ldots \ldots \ldots \ldots \ldots \ldots \ldots \ldots \ldots \ldots$ Positive

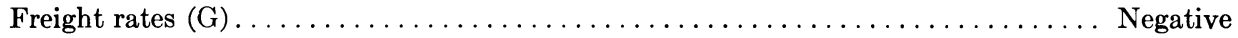

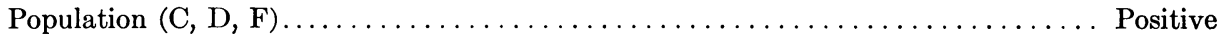

Per capita disposable income $(\mathrm{C}, \mathrm{D}, \mathrm{F}) \ldots \ldots \ldots \ldots \ldots \ldots \ldots \ldots \ldots \ldots \ldots$ Positive

Paperboard supply:

Current price of paperboard $(\mathrm{J}) \ldots \ldots \ldots \ldots \ldots \ldots \ldots \ldots \ldots \ldots \ldots$ Positive

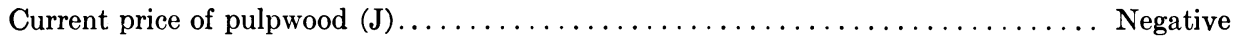

Current price of electric power $(\mathrm{J}) \ldots \ldots \ldots \ldots \ldots \ldots \ldots \ldots \ldots \ldots \ldots \ldots \ldots \ldots \ldots$ Negative

Current price of petroleum products $(\mathrm{J}) \ldots \ldots \ldots \ldots \ldots \ldots \ldots \ldots \ldots \ldots \ldots \ldots$ Negative

Current wages in pulp and paper $(J) \ldots \ldots \ldots \ldots \ldots \ldots \ldots \ldots \ldots \ldots \ldots \ldots \ldots$ Negative

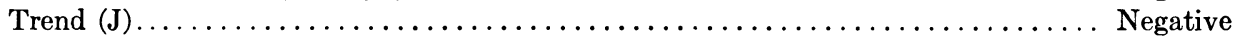

Productivity in pulp and paper $(\mathrm{J}) \ldots \ldots \ldots \ldots \ldots \ldots \ldots \ldots \ldots \ldots \ldots$ Positive

Dummy variable $(\mathbf{J}) \ldots \ldots \ldots \ldots \ldots \ldots \ldots \ldots \ldots \ldots \ldots \ldots \ldots$ Positive

Softwood plywood demand:

Current price of softwood plywood $(\mathrm{A}, \mathrm{B}, \mathrm{C}, \mathrm{D}, \mathrm{F}) \ldots \ldots \ldots \ldots \ldots \ldots \ldots \ldots \ldots$ Negative

Current price of lumber $(\mathrm{A}, \mathrm{B}, \mathrm{C}, \mathrm{D}, \mathrm{F}) \ldots \ldots \ldots \ldots \ldots \ldots \ldots \ldots \ldots \ldots \ldots$ Positive

Current price of paperboard $(\mathrm{A}, \mathrm{B}, \mathrm{C}, \mathrm{D}, \mathrm{F}) \ldots \ldots \ldots \ldots \ldots \ldots \ldots$ Positive

Past price of softwood plywood $(\mathrm{A}) \ldots \ldots \ldots \ldots \ldots \ldots \ldots \ldots \ldots \ldots \ldots \ldots \ldots \ldots \ldots$ Negative

Past price of softwood lumber $(\mathrm{A}) \ldots \ldots \ldots \ldots \ldots \ldots \ldots \ldots \ldots \ldots \ldots \ldots$ Positive

Past price of building board $(\mathrm{A}) \ldots \ldots \ldots \ldots \ldots \ldots \ldots \ldots \ldots \ldots \ldots \ldots \ldots \ldots \ldots$ Positive

Past price of wallboard $(\mathrm{A}) \ldots \ldots \ldots \ldots \ldots \ldots \ldots \ldots \ldots \ldots \ldots \ldots \ldots \ldots \ldots$ Positive

Past wages of construction workers $(\mathrm{A}) \ldots \ldots \ldots \ldots \ldots \ldots \ldots \ldots \ldots \ldots$ Positive

Index of manufacturing production $(\mathrm{B}, \mathrm{D}) \ldots \ldots \ldots \ldots \ldots \ldots \ldots \ldots$ Positive

Value of total construction $(\mathrm{A}) \ldots \ldots \ldots \ldots \ldots \ldots \ldots \ldots \ldots \ldots$ Positive

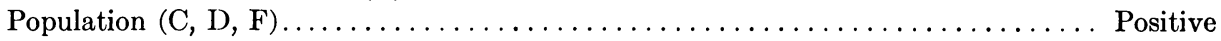

Per capita disposable income $(\mathrm{C}, \mathrm{D}, \mathrm{F}) \ldots \ldots \ldots \ldots \ldots \ldots \ldots \ldots \ldots \ldots \ldots$ Positive

Softwood plywood supply:

Current price of softwood plywood $(\mathrm{J}) \ldots \ldots \ldots \ldots \ldots \ldots \ldots \ldots$ Positive

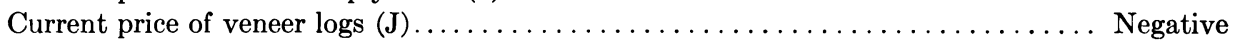

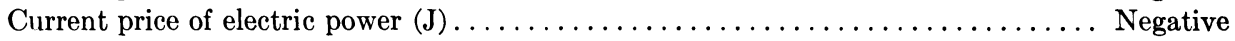

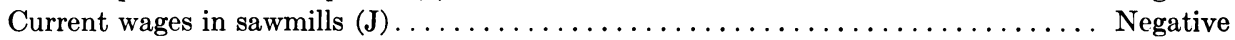

Productivity in sawmills $(\mathrm{J}) \ldots \ldots \ldots \ldots \ldots \ldots \ldots \ldots \ldots \ldots \ldots \ldots \ldots \ldots \ldots \ldots \ldots \ldots \ldots$ Positive

Dummy variable $(\mathrm{J}) \ldots \ldots \ldots \ldots \ldots \ldots \ldots \ldots \ldots \ldots \ldots \ldots$ Positive

Softwood lumber demand:

Current price of softwood lumber (sectors $A$ to $G) \ldots \ldots \ldots \ldots \ldots \ldots$ Negative

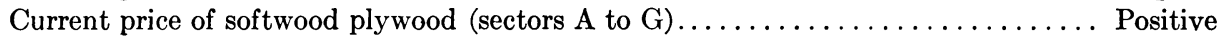

Current price of paperboard $(A, B, C, E, F) \ldots \ldots \ldots \ldots \ldots \ldots \ldots \ldots$ Positive

Past price of softwood lumber $(\mathrm{A}) \ldots \ldots \ldots \ldots \ldots \ldots \ldots \ldots \ldots \ldots \ldots \ldots \ldots \ldots \ldots$ Negative

Past price of softwood plywood $(\mathrm{A}) \ldots \ldots \ldots \ldots \ldots \ldots \ldots \ldots \ldots \ldots \ldots \ldots$ Positive

Past price of building board $(\mathrm{A}) \ldots \ldots \ldots \ldots \ldots \ldots \ldots \ldots \ldots \ldots \ldots \ldots \ldots \ldots$ Positive

Past price of clay products $(\mathrm{A}) \ldots \ldots \ldots \ldots \ldots \ldots \ldots \ldots \ldots \ldots \ldots \ldots$ Positive

Past price of structural steel (A) $\ldots \ldots \ldots \ldots \ldots \ldots \ldots \ldots \ldots \ldots \ldots \ldots \ldots$ Positive

Past wages of construction workers $(\mathrm{A}) \ldots \ldots \ldots \ldots \ldots \ldots \ldots \ldots \ldots \ldots \ldots \ldots$ Negative

Index of manufacturing production $(B, D, E) \ldots \ldots \ldots \ldots \ldots \ldots \ldots$ Positive

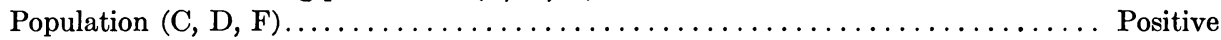

Per capita disposable income $(\mathrm{C}, \mathrm{D}, \mathrm{F}) \ldots \ldots \ldots \ldots \ldots \ldots \ldots \ldots \ldots \ldots$ Positive

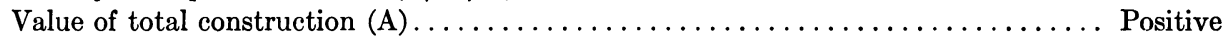

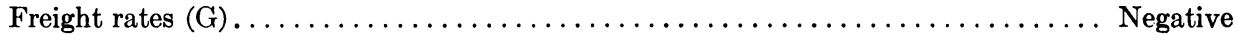


Softwood lumber supply:

Current price of softwood lumber $(\mathrm{J}, \mathrm{K}) \ldots \ldots \ldots \ldots \ldots \ldots \ldots$ Positive

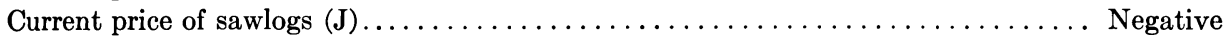

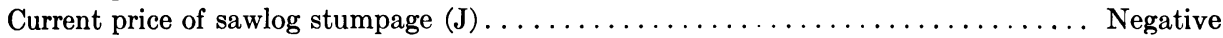

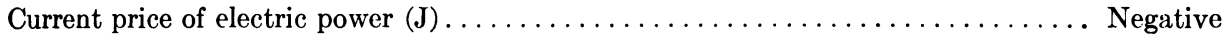

Current price of petroleum products $(\mathrm{J}) \ldots \ldots \ldots \ldots \ldots \ldots \ldots \ldots \ldots \ldots \ldots \ldots \ldots$ Negative

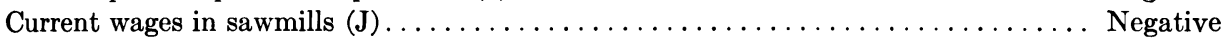

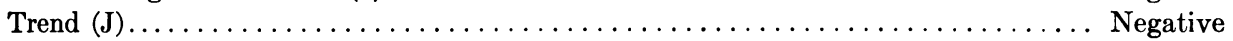

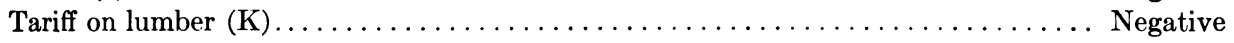

Rate of exchange on the Canadian dollar $(\mathrm{K}) \ldots \ldots \ldots \ldots \ldots \ldots \ldots \ldots$ Negative

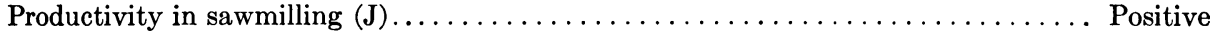

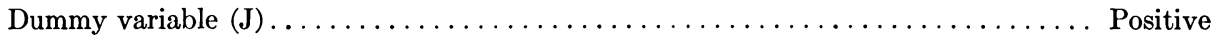

Building paper and board demand:

Current price of building paper and board $(\mathrm{A}) \ldots \ldots \ldots \ldots \ldots \ldots \ldots \ldots \ldots$ Negative

Current price of softwood plywood (A) $\ldots \ldots \ldots \ldots \ldots \ldots \ldots \ldots \ldots \ldots \ldots$ Positive

Current price of softwood lumber (A) $\ldots \ldots \ldots \ldots \ldots \ldots \ldots \ldots \ldots \ldots \ldots$ Positive

Past price of building board (A) $\ldots \ldots \ldots \ldots \ldots \ldots \ldots \ldots \ldots \ldots \ldots \ldots \ldots \ldots \ldots$ Negative

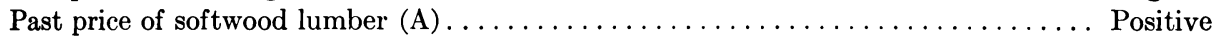

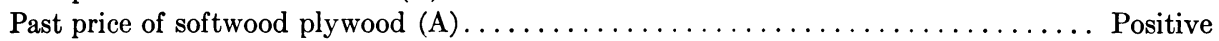

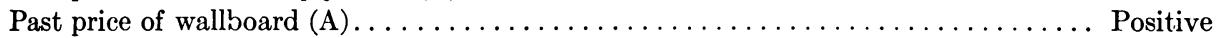

Past wages of construction workers $(\mathrm{A}) \ldots \ldots \ldots \ldots \ldots \ldots \ldots \ldots \ldots \ldots \ldots \ldots \ldots \ldots$ Positive

Value of total construction (A) ............................... Positive

Building paper and board supply:

Current price of building paper and board $(\mathrm{J}) \ldots \ldots \ldots \ldots \ldots \ldots$ Positive

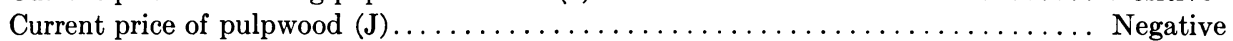

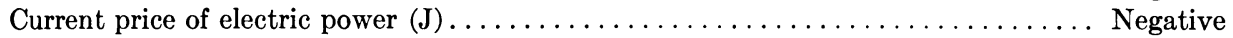

Current price of petroleum products $(\mathrm{J}) \ldots \ldots \ldots \ldots \ldots \ldots \ldots \ldots \ldots \ldots \ldots$ Negative

Current wages in pulp and paper $(\mathbf{J}) \ldots \ldots \ldots \ldots \ldots \ldots \ldots \ldots \ldots \ldots \ldots \ldots \ldots$ Negative

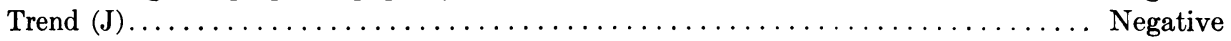

Productivity in pulp and paper $(\mathrm{J}) \ldots \ldots \ldots \ldots \ldots \ldots \ldots \ldots \ldots \ldots \ldots \ldots \ldots \ldots$ Positive

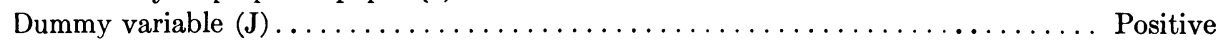

Sawlog demand:

Current price of sawlogs $(J)$

Current price of lumber $(\mathbf{J})$

Current price of electric power $(\mathrm{J})$

Current price of petroleum products $(\mathrm{J})$

Current wages in sawmills $(J)$

Sawlog supply:

Current price of sawlogs (I)

Current price of sawlog stumpage (I)

Current price of petroleum products (I)

Current wages in sawmills (I)

Trend (I)

Pulpwood demand:

Current price of pulpwood $(\mathrm{J})$

Current price of paper $(\mathrm{J})$

Current price of paperboard $(\mathrm{J})$

Current price of electric power $(\mathrm{J})$

Current wages in pulp and paper $(\mathrm{J})$

Pulpwood supply:

Current price of pulpwood (I)

Current price of petroleum products (I)

Current wages in sawmills (I)

Trend (I)

Veneer log demand:

Current price of veneer logs $(\mathbf{J})$

Current price of plywood $(\mathrm{J})$

Current price of electric power (J)

Current wages in sawmills $(J)$

Veneer log supply:

Current price of veneer logs (I)

Current price of petroleum products (I)

Current wages in sawmills (I)

Trend (I)

Stumpage demand:

Current price of stumpage (I, J)

Current price of lumber $(\mathrm{J})$

Current price of paper $(J)$

Current price of paperboard $(J)$

Current price of plywood (J)

Current price of sawlogs (I, J)

Current price of pulpwood (I, J)

Current price of veneer logs (I, J)

Current price of electric power $(\mathrm{J})$

Current price of petroleum products (I, J)

Current wages in sawmilling (I, J)

Current wages in pulp and paper $(J)$

Stumpage supply:

Current price of stumpage $(\mathrm{H})$

Trend $(\mathrm{H})$ 


\section{STRUCTURAL ESTIMATION}

\section{The Statistical Model}

The set of twenty relationships considered in the economic model may be represented as

$$
B Y_{t}=C X_{t}+U_{t}
$$

where

$Y_{t}$ is a $(20 \times 1)$ matrix of endogenous variables representing the prices and consumption levels in year $t$ of the forest products considered,

$B$ is a $(20 \times 20)$ matrix of coefficients associated with $Y_{t}$,

$X_{\iota}$ is a $(24 \times 1)$ matrix representing

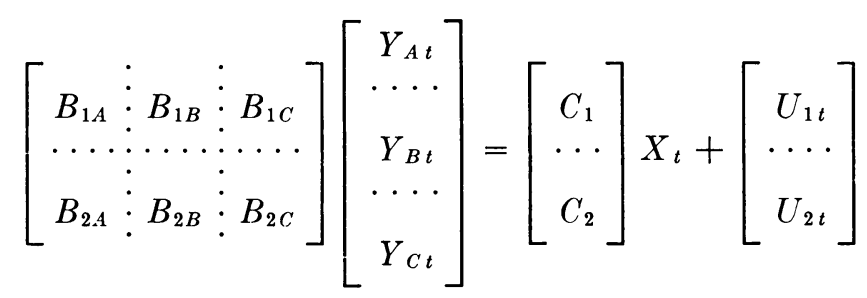

where

$Y_{A t}$ is a $(12 \times 1)$ matrix representing prices and levels of consumption of wood products in year $t$,

$Y_{B t}$ is a $(4 \times 1)$ matrix representing prices of primary products in year $t$,

$$
\left(B_{1 A} \vdots B_{1 B} \vdots B_{1 C}\right)\left(Y_{A t} \vdots Y_{B t} \vdots Y_{C t}\right)^{\prime}=C_{1} X_{t}+U_{1 t}
$$

and

$$
\left(B_{2 A} \vdots B_{2 B} \vdots B_{2 C}\right)\left(Y_{A t} \vdots Y_{B t} \vdots Y_{C t}\right)^{\prime}=C_{2} X_{t}+U_{2 t}
$$

Since, a priori, levels of marketings of primary products do not appear in demand and supply functions for wood products, $B_{1 C}$ is null and the woodproducts subsystem may be written $B_{1 A} Y_{A t}=C_{1} X_{t}-B_{1 B} Y_{B t}+U_{1 t}$

In the case of the primary products subsystem the matrix $B_{2 A}$ is null, a priori, and (4) may be written $B_{2 C} Y_{C t}=C_{2} X_{t}-B_{2 B} Y_{B t}+U_{2 t}$
The magnitude of $Y_{C t}$ was unknown for all $t$. This made it impossible to estimate (6) and estimation was carried out only for the wood products subsystem.

Each equation in the wood products subsystem represented by (5) above had, a priori, two or more of the components of the matrix $\left(B_{1 A}: B_{1 B}\right)$ non-zero. Direct least squares estimation was therefore ruled out as a possible technique, as it 
would have resulted in biased and inconsistent estimates (Hood and Koopmans, 1953). As Chernoff and Rubin note (Hood and Koopmans, 1953), consistent, efficient estimates of the coefficient matrices $\left(B_{1 A} \vdots B_{1 B}\right)$ and $C_{1}$ may be obtained by full information maximum likelihood estimation. This method was rejected because of the large computational burden associated with it. Consistent estimates could have been obtained by the "limited information" maximum likelihood method, but that method was rejected in favor of the computationally easier method of twostage least squares described by Theil (1958) and Basmann (1957) which has the same asymptotic properties as the limited information method (Goldberger, 1964). With regard to the small sample properties of estimating techniques, little theoretical evidence is available, but the Monte Carlo studies of Basmann (1958), Nagar (1960) and Summers (Johnson, 1963) throw some light on the matter. In summarizing results of these studies, Johnson (1963) suggests discarding full information maximum likelihood estimation as a practical tool, and indicates that two-stage estimation was found to be generally superior to the limited information approach.

Algebraic manipulation of (1) above yields the set of reduced-form equations

$$
Y_{t}=D X_{t}+V_{t}
$$

where $D=B^{-1} C$ and $V_{t}=B^{-1} U_{t}$ This system, also, may be partitioned and written as

$$
\left[\begin{array}{c}
Y_{A t} \\
\cdots \\
Y_{B t} \\
\cdots \\
Y_{C t}
\end{array}\right]=\left[\begin{array}{c}
D_{A} \\
\cdots \\
D_{B} \\
\cdots \\
D_{C}
\end{array}\right] X_{t}+\left[\begin{array}{c}
V_{A t} \\
\cdots \\
V_{B t} \\
\cdots \\
V_{C t}
\end{array}\right]
$$

In the first stage of the two-stage estimation procedure $D_{A}$ and $D_{B}$ were estimated by direct least squares to yield the estimated reduced-form equations

$$
\left[\begin{array}{c}
\hat{Y}_{A t} \\
\cdots \\
\hat{Y}_{B t}
\end{array}\right]=\left[\begin{array}{c}
\hat{D}_{A} \\
\cdots \\
\hat{D}_{B}
\end{array}\right] X_{t}
$$

where $\hat{Y}_{A t}=\left(\hat{y}_{1 t}, \hat{y}_{2 t}, \ldots, \hat{y}_{12 t}\right)^{\prime}$ represents computed values in year $t$ of prices and levels of consumption of the wood products considered, and where $\hat{Y}_{B t}=$ $\left(\hat{y}_{13 t}, \hat{y}_{14 t}, \hat{y}_{15 t}, \hat{y}_{16 t}\right)^{\prime}$ represents computed values in year $t$ of prices of the primary products considered.

In the second stage of the two-stage procedure each equation in system (5) above is normalized with respect to a particular element of $Y_{A t}$, and direct least squares estimation are carried out for a model of the type

$$
\begin{aligned}
\hat{y}_{i t}= & a_{O}+\sum_{\substack{j \\
j \neq i}} a_{j} \hat{y}_{j t} \\
& +\sum_{k} c_{k} x_{k t}+e_{i t}
\end{aligned}
$$

with certain coefficients as indicated in part II deemed, a priori, to be zero. The estimated wood products subsystem may be written

$\widehat{B}_{1 A} Y_{A t}=\hat{C}_{1} X_{t}-\hat{B}_{1 B} Y_{B t}+\hat{O}_{1 t}$

Estimates of coefficients are presented in a later section. As Theil (1958) points out, these estimates are consistent provided consistent estimates of $\hat{Y}_{A t}$ and $\widehat{Y}_{B t}$ are obtainable from (9) above. This requires, with reference to system (1) above, that
(i) $E\left(U_{t}\right)=O$
(ii) $E\left(U_{t} U_{t^{\prime}}^{\prime}\right)=\sum_{U}$ for $t=t^{\prime}$ $=O$ for $t \neq t^{\prime}$
(iii) $E\left(X_{t} U^{\prime}{ }_{t}\right)=0$. 


\section{Computational Procedure}

Computations were carried out on an IBM 1620 computer using the 80 series regression system, which employs the inversion of a matrix of simple correlation coefficients between the independent variables in the regression model (Boles, 1964). The stepwise regression option was utilized as a means of inverting near singular matrices. This option, described by Boles (1961), entails the selection of "pivot" elements from the diagonal of the matrix being inverted for the formation of pre-multiplier matrices. The initial pivot element chosen corresponds to the selection of the independent variable with the highest simple correlation with the dependent variable. Thereafter, a pivot element is selected after each transformation so as to "bring in" the independent variable that will cause the greatest reduction in the unexplained variance of the dependent one. This may be shown to be equivalent to bringing in the variable having the largest absolute partial correlation with the dependent variable (i.e., net of variables already included). No pivot element smaller than 0.001 is selected, and this is equivalent to excluding an independent variable if it has a squared multiple correlation coefficient of 0.999 or greater with the included set of regressor variables. In using the stepwise routine a critical value of the $F$ statistic can be selected, so that no regressor variable is added to the included set unless the actual $F$ value associated with it exceeds the critical one. Any included variable must maintain an actual $F$ value greater than the critical one or be automatically deleted. This option was not used in this study; the stepwise routine was utilized simply as a means of selecting a set of linearly independent regressor variables.

\section{Effect of Stepwise Procedure}

The stepwise routine was used in estimating reduced form equations in the first stage of estimation, and also in the final estimation of structural equations. In the first stage in particular it led to the elimination of a number of independent variables, and its effect is seen to be analogous to the deliberate omission of variables for computational convenience or necessity in maximum likelihood estimation. Mention of this problem is made by Chernoff and Rubin (Hood and Koopmans, 1953). Consistency is not lost through omission of variables in maximum likelihood estimation, but reduction in efficiency takes place and the problem is one of selecting a subset of the predetermined variables so as to minimize this reduction. Chernoff and Rubin suggest that it is desirable to use those independent variables that ". . . help explain most of the variance . .." of the endogenous variables in the system of reduced form equations. Because variables excluded by the stepwise process are virtually linearly dependent on the included set, further reduction in the unexplained variance in the reduced form equations was not possible. Arrow and Hoffenberg (1959) encountered a similar problem in a study of interindustry demands. A high degree of multicollinearity existed in the set of nineteen predetermined variables included in their model, and of these only twelve were for practical purposes linearly independent. They comment incisively on the obstacles raised by the lack of independent variation in time-series data.

\section{Reformulating Relationships}

With regard to structural estimation, initial computations resulted in the ex- 
clusion of some variables and did not always yield estimates of coefficients that made sense from an economic point of view. To minimize subjective judgment and ensure consistency in treatment of different equations, a systematic procedure was established for avoiding implausible results and reducing multicollinearity.

First, sample correlation coefficients between all pairs of variables in the system were obtained. Where two variables in an equation had a correlation of more than 0.98 the less important one (from an economic point of view) was deleted, provided it was not of considerable absolute importance. For example, because a high correlation existed between value of total construction and population one or the other was excluded from demand equations estimated. A similar procedure was employed in the case of value of construction and per capita income.

After this step, the equation was estimated and the coefficients examined. If a coefficient was "wrong" in sign but not significantly different from zero at the 90 per cent level nothing was done; if it was wrong and "significant" the specification of the relationship was carefully examined to see whether any important variable had been omitted or whether a variable had been wrongly included in the equation. Because a major aim of the study was the estimation of demand and supply elasticities, the current price of the product whose demand or supply was being estimated was not permitted to drop from the regression because of collinearity. If the stepwise process did result in its exclusion correlation coefficients were examined, and if a variable was highly correlated with the price of the product that variable was dropped from the function in question. Sound statistical practice requires the discarding of data used to assist in model building and the drawing of a fresh sample for final estimation. Because this was not possible dependence was placed on the economic significance of coefficients, wherever feasible, rather than on their statistical significance in modifying relationships.

\section{Dependent Variables}

Estimation was always carried out with quantity supplied (or demanded) as the dependent variable. From a statistical viewpoint product price would have been acceptable as a dependent variable, but quantity was preferred because it emphasized consumers' and suppliers' reactions to price and because it was the formulation directly obtained from the aggregation of various sector relationships in the economic model.

\section{Estimates of Structural Coefficients}

The twelve estimated equations are given in tables 1 to 12 . The standard error is shown for each coefficient, along with the ratio of the coefficient to its standard error-a statistic with a "Student's $t$ " distribution under the hypothesis that the true value of the coefficient is zero. If the absolute value of a coefficient's $t$ ratio is greater than the critical value the hypothesis that the true value of the coefficient is zero is rejected at the 90 per cent level. In addition, values of the squared multiple correlation coefficient are shown for each equation. An explanation of notation depicting variables is given in Appendix D. A circumflex attached to a variable denotes that reduced form estimates of it were used in place of actual values, as required by the estimation procedure. In all cases the dependent variable was quantity demanded or quantity supplied. 
TABLE 1

ESTIMATED LUMBER DEMAND EQUATION*

\begin{tabular}{|c|c|c|c|}
\hline Variable & Coefficient & Standard error & $t$ ratiof \\
\hline Wages in construction $(X 17)$. & -18.34936 & 7.56134 & -2.42673 \\
\hline Index of manufacturing production $(X 22)$ & 0.34359 & 0.12079 & 2.84447 \\
\hline Value of construction $(X 25) \ldots \ldots \ldots \ldots$ & 0.00080 & 0.00031 & 2.54001 \\
\hline Freight rates $(X 26) \ldots \ldots \ldots \ldots \ldots \ldots$ & -8.58895 & 16.22840 & -0.52925 \\
\hline Ratio past prices plywood/lumber $(X 75) \ldots \ldots \ldots \ldots$ & 13.20979 & 13.77278 & 0.95912 \\
\hline Ratio past prices building board/lumber $(X 76) \ldots$ & -7.73156 & 4.19704 & -1.84214 \\
\hline Ratio past prices steel/lumber $(X 79) \ldots \ldots \ldots \ldots$ & 8.48513 & 9.73917 & 0.87123 \\
\hline Current price of lumber $(\hat{P} 1) \dagger \ldots \ldots \ldots$ & -1.02204 & 0.43284 & -2.36123 \\
\hline Current price of paperboard $(\hat{P} 3) \dagger \ldots \ldots \ldots \ldots \ldots \ldots \ldots$ & 0.36413 & 0.19565 & 1.86113 \\
\hline Current price of plywood $\left(\hat{P}^{4}\right) \dagger \ldots \ldots \ldots \ldots \ldots \ldots \ldots \ldots$ & 0.56038 & 0.26110 & 2.14618 \\
\hline
\end{tabular}

$*$ Constant term $=8.02333$, squared multiple correlation coefficient $=0.95219$, critical $t$ value $=1.74600$. Critical $t$ values are such that if the absolute value of a coefficient's $t$ ratio is greater than the critical value, the hypothesis that the true value of the coefficient is zero is rejected at the 90 per cent level.

$\dagger$ Reduced form estimates of this variable were used rather than actual values, as required by estimation procedures.

$\ddagger$ Ratio of coefficient to its standard error.

TABLE 2

ESTIMATED LUMBER SUPPLY EQUATION*

\begin{tabular}{|c|c|c|c|}
\hline Variable & Coefficient & Standard error & $t$ ratio $\ddagger$ \\
\hline Trend (X27) & -1.52356 & 0.51028 & -2.98570 \\
\hline 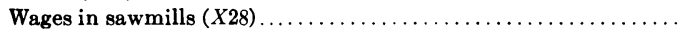 & 14.17517 & 11.42625 & 1.24057 \\
\hline Price of electric power (X29). & -0.47729 & 0.10274 & -4.64560 \\
\hline Tariff on lumber $(X 30) \ldots \ldots \ldots \ldots \ldots \ldots \ldots \ldots$ & -1.03112 & 0.51871 & -1.98785 \\
\hline Rate of exchange $(X 31) \ldots \ldots \ldots \ldots \ldots \ldots \ldots$ & -28.20633 & 11.15856 & -2.52777 \\
\hline 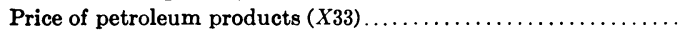 & 0.04378 & 0.08344 & 0.52473 \\
\hline Productivity in sawmilling ( $X 73)$. & 0.45127 & 0.17269 & 2.61310 \\
\hline 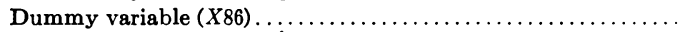 & 19.84070 & 5.60693 & -3.53860 \\
\hline Current price of lumber $\left(\hat{P}_{1}\right) \dagger \ldots \ldots \ldots \ldots \ldots \ldots \ldots \ldots \ldots \ldots$ & 0.22428 & 0.11369 & 1.97264 \\
\hline
\end{tabular}

- Constant term $=93.99845$, squared multiple correlation coefficient $=0.96241$, critical $t$ value $=1.740$. Critical $t$ values are such that if the absolute value of a coefficient's $t$ ratio is greater than the critical value, the hypothesis that the true value of the coefficient is zero is rejected at the 90 per cent level.

$t$ Reduced form estimates of this variable were used rather than actual values, as required by estimation procedures.

$\ddagger$ Ratio of coefficient to its standard error.

TABLE 3

ESTIMATED PAPER DEMAND EQUATION*

\begin{tabular}{|c|c|c|c|}
\hline Variable & Coefficient & Standard error & $t$ ratio $\ddagger$ \\
\hline Index of manufacturing production (X22). & 31.08707 & 25.35720 & 1.22596 \\
\hline Population $(X 23) \ldots \ldots \ldots \ldots \ldots \ldots \ldots$ & 16.96079 & 51.15744 & 0.33154 \\
\hline Per capita income $(X 24) \ldots \ldots \ldots \ldots \ldots$ & 13580.00000 & 6180.42200 & 2.19734 \\
\hline Freight rates $(X 26) \ldots \ldots \ldots \ldots \ldots$ & -1107.67730 & 2147.15160 & -0.51588 \\
\hline Consumer price index $(X 34) \ldots \ldots \ldots \ldots$ & -119.23085 & 85.49485 & -1.39459 \\
\hline Current price of paper $\left(\hat{P}^{2}\right) \dagger \ldots \ldots \ldots \ldots \ldots \ldots \ldots \ldots \ldots \ldots \ldots$ & -65.39546 & 50.44164 & -1.29645 \\
\hline 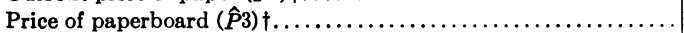 & 34.69029 & 18.00515 & 1.92668 \\
\hline
\end{tabular}

* Constant term $=8760.19400$, squared multiple correlation coefficient $=0.99566$, critical $t$ value $=1.729$. Critical $t$ values are such that if the absolute value of a coefficient's $t$ ratio is greater than the critical value, the hypothesis that the true value of the coefficient is zero is rejected at the 90 per cent level.

$\dagger$ Reduced form estimates of this variable were used rather than actual values, as required by estimation procedures.

$\ddagger$ Ratio of coefficient to its standard error. 
TABLE 4

ESTIMATEI PAPER SUPPLY EQUATION*

\begin{tabular}{|c|c|c|c|}
\hline Variable & Coefficient & Standard error & $t$ error $\ddagger$ \\
\hline Trend (X27).. & -58.79321 & 175.57759 & -0.33485 \\
\hline Price of electric power $(X 29) \ldots$ & -57.60196 & 21.68389 & -2.65644 \\
\hline Rate of exchange $(X 31) \ldots \ldots \ldots \ldots$ & 377.48437 & 2447.15710 & 0.15425 \\
\hline Wages in pulp and paper $(X 32) \ldots \ldots \ldots \ldots \ldots \ldots \ldots \ldots \ldots$ & 1838.04710 & 2794.14780 & 0.65782 \\
\hline Price of petroleum products $(X 33)$. & 29.69517 & 17.76720 & 1.67134 \\
\hline Productivity in pulp and paper $(X 74) \ldots \ldots \ldots \ldots$ & 90.25070 & 26.18683 & 3.44641 \\
\hline Dummy variable $(X 86)$ & 829.74664 & 1316.11250 & 0.63045 \\
\hline Current price of paper $(\hat{P} 2) \dagger \ldots \ldots$ & -16.19356 & 55.37509 & -0.29243 \\
\hline 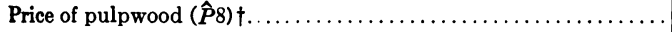 & 130.36189 & 224.62867 & 0.58034 \\
\hline
\end{tabular}

* Constant term $=5731.85680$, squared multiple correlation coefficient $=0.99615$, critical $t$ value $=1.740$. Critical $t$ values are such that if the absolute value of a coefficient's $t$ ratio is greater than the critical value, the hypothesis that the true value of the coefficient is zero is rejected at the 90 per cent level.

$t$ Reduced form estimates of this variable were used rather than actual values, as required by estimation procedures.

$\ddagger$ Ratio of coefficient to its standard error.

TABLE 5

ESTIMATED PAPERBOARD DEMAND EQUATION*

\begin{tabular}{|c|c|c|c|}
\hline Variable & Coefficient & Standard error & $t$ ratiof \\
\hline Wages in construction $(X 17)$. & 2549.49520 & 1509.67340 & 1.68877 \\
\hline Index of manufacturing production (X22). & 63.00975 & 16.96271 & 3.71460 \\
\hline Value of construction $(X 25) \ldots \ldots \ldots \ldots \ldots$ & -0.00275 & 0.04729 & -0.05820 \\
\hline Freight rates $(X 26) \ldots \ldots \ldots$ & -3240.69970 & $2466.980 \subseteq 0$ & -1.31362 \\
\hline Ratio past prices plywood/building board (X81). & -2700.05110 & 1629.60050 & -1.65687 \\
\hline Ratio past prices wallboard/building board ( $X 82)$. & 5974.64560 & $2994.752 \varepsilon 0$ & 1.99503 \\
\hline Current price of lumber $\left(\hat{P}_{1}\right) \dagger \ldots \ldots \ldots \ldots \ldots \ldots$ & 52.12030 & 62.52134 & 0.83364 \\
\hline Current price of paperboard $\left(\hat{P}^{3}\right) \dagger \ldots$. & -39.20137 & 22.16709 & -1.76844 \\
\hline Current price of plywood $\left(\hat{P}^{4}\right) \dagger \ldots \ldots \ldots$ & 10.41534 & 54.85602 & 0.18986 \\
\hline
\end{tabular}

- Constant term $=-2209.96520$, squared multiple correlation coefficient $=99715$, critical $t$ value $=1.740$. Critical $t$ values are such that if the absolute value of a cefficient's $t$ ratio is greater than the critical value, the hypothesis that the true value of the coefficient is zero is rejected at the 90 per cent level.

$t$ Reduced form estimates of this variable were used rather than actual values, as required by estimation procedures.

t Ratio of coefficient to its standard error.

TABLE 6

ESTIMATED PAPER SUPPLY EQUATION*

\begin{tabular}{|c|c|c|c|}
\hline Variable & Coefficient & Standard error & $t$ ratio $\ddagger$ \\
\hline Trend $(X 27)$. & -42.99231 & 119.71883 & -.35911 \\
\hline Price of electric power $(X 29) .$. & -11.77524 & 18.62882 & -.63209 \\
\hline Wages in pulp and paper $(X 32)$. & 1092.41280 & 2053.04820 & 0.53209 \\
\hline Price of petroleum products $(X 33)$. & 10.60318 & 14.79718 & 0.71656 \\
\hline Productivity in pulp and paper $(X 74) \ldots$ & 102.95717 & 18.30349 & 5.62500 \\
\hline Dummy variable $(X 86) \ldots \ldots \ldots \ldots \ldots \ldots \ldots$ & 1536.32030 & 877.05658 & 1.75167 \\
\hline Current price of paperboard $(\hat{P} 3) \dagger \ldots \ldots \ldots \ldots \ldots \ldots$ & 46.78610 & 18.56659 & 2.51990 \\
\hline 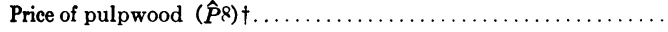 & -138.17112 & 125.95382 & -1.09699 \\
\hline
\end{tabular}

* Constant term $=-4525.97170$, squared multiple correlation coefficient $=0.99684$, critical $t$ value $=1.734$. Critical $t$ values are such that if the absolute value of a coefficient's $t$ ratio is greater than the critical value, the hypothesis that the true value of the coefficient is zero is rejected at the 90 per cent level.

t Reduced form estimates of this variable were used rather than actual values, as required by estimation procedures.

\pm Ratio of coefficient to its standard error. 
TABLE 7

ESTIMATED SOFTWOOD PLYWOOD DEMAND EQUATION*

\begin{tabular}{|c|c|c|c|}
\hline Variable & Coefficient & Standard error & $t$ ratioł \\
\hline Wages in construction $(X 17)$. & 1744.67520 & 507.42033 & 3.43832 \\
\hline Value of construction $(X 25) \ldots \ldots \ldots \ldots$ & 0.04833 & 0.02373 & 2.03650 \\
\hline Ratio past prices plywood/lumber (X75) & 4.90036 & 424.91022 & 0.01153 \\
\hline Ratio past prices plywood/building board (X81) & -1426.00510 & 630.86189 & -2.26040 \\
\hline Current price of plywood $\left(\hat{\boldsymbol{P}}^{4}\right) \dagger \ldots \ldots \ldots \ldots \ldots \ldots \ldots \ldots$ & -6.20699 & 6.62057 & -0.93753 \\
\hline
\end{tabular}

* Constant term $=-3506.64940$, squared multiple correlation coefficient $=0.99523$, critical $t$ value $=1.729$. Critical $t$ values are such that if the absolute value of a coefficient's $t$ ratio is greater than the critical value, the hypothesis that the true value of the coefficient is zero is rejected at the 90 per cent level.

t Reduced form estimates of this variable were used rather than actual values, as required by estimation procedures.

$\ddagger$ Ratio of coefficient to its standard error.

TABle 8

ESTIMATED SOFTWOOD PLYWOOD SUPPLY EQUATION*

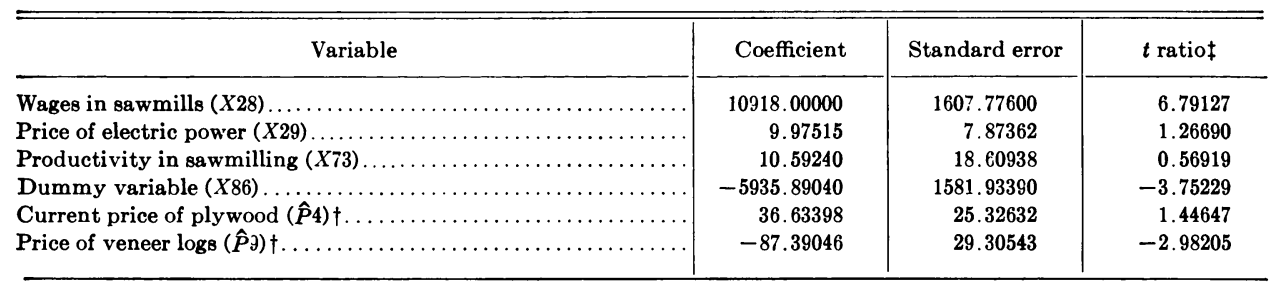

* Constant term $=-4518.16360$, squared multiple correlation coefficient $=0.98943$, critical $t$ value $=1.725$. Critical $t$ values are such that if the absolute value of a coefficient's $t$ ratio is greater than the critical value, the hypothesis that the true value of the coefficient is zero is rejected at the 90 per cent level.

$\dagger$ Reduced form estimates of this variable were used rather than actual values, as required by estimation procedures.

$\ddagger$ Ratio of coefficient to its standard error.

TABLE 9

ESTIMATED SOFTWOOD LUMBER DEMAND EQUATION*

\begin{tabular}{|c|c|c|c|}
\hline Variable & Coefficient & Standard error & $t$ ratio $\neq$ \\
\hline Wages in construction $(X 17) \ldots \ldots \ldots \ldots \ldots$ & -16.82301 & 5.03123 & -3.34371 \\
\hline Index of manufacturing production (X22). & 0.23413 & 0.08315 & 2.81558 \\
\hline Value of construction $(X 25) \ldots \ldots \ldots \ldots$ & 0.00045 & 0.00017 & 2.58247 \\
\hline Freight rates $(X 26) \ldots \ldots \ldots \ldots \ldots \ldots$ & -4.93940 & 9.62471 & -0.51319 \\
\hline Ratio of past prices plywood/lumber ( $X 75)$. & 13.45302 & 6.87298 & 1.95737 \\
\hline Ratio of past prices building board/lumber $(X 76)$. & -7.02302 & 2.50947 & -2.79860 \\
\hline Ratio of past prices clay products/lumber (X78). & -10.97084 & 11.66182 & -0.94074 \\
\hline Ratio of past prices steel/lumber $(X 79) \ldots \ldots \ldots$ & 16.19885 & 7.86520 & 2.05955 \\
\hline Current price of paperboard $(\hat{\boldsymbol{P}} 3) \dagger \ldots \ldots \ldots \ldots$ & 0.38581 & 0.17154 & 2.24900 \\
\hline Current price of plywood $\left(\hat{P}^{\mathbf{t}}\right) \dagger \ldots \ldots \ldots \ldots$ & 0.24371 & 0.21166 & 1.15143 \\
\hline Current price of sof twood lumber $\left(\hat{P}_{\tilde{j}}\right) \dagger \ldots$ & -0.91550 & 0.49767 & -1.83957 \\
\hline
\end{tabular}

* Constant term $=7.05158$, squared multiple correlation coefficient $=0.97322$, critical $t$ value $=1.753$. Critical $t$ values are such that if the absolute value of a coefficient's $t$ ratio is greater than the critical value, the hypothesis that the true value of the coefficient is zero is rejected at the 90 per cent level.

$t$ Reduced form estimates of this variable were used rather than actual values, as required by estimation procedures.

$\mp$ Ratio of coefficient to its standard error. 
TABLE 10

ESTIMATED SOFTWOOD LUMBER SUPPLY EQUATION*

\begin{tabular}{|c|c|c|c|}
\hline Variable & Coefficient & Standard error & $t$ ratiof \\
\hline Trend (X27). & -0.12076 & 0.43935 & -0.27487 \\
\hline Wages in sawmills $(X 28)$. & -2.13711 & 8.13811 & -0.26260 \\
\hline Price of electric power (X29). & -0.13316 & 0.11581 & -1.14981 \\
\hline Tariff on lumber $(X 30) \ldots \ldots$ & -1.00888 & 0.32433 & -3.11060 \\
\hline Rate of exchange $(X 31) \ldots \ldots$ & -15.80228 & 6.96644 & -2.26834 \\
\hline Price of petroleum products $(X 33) \ldots$ & -0.03126 & 0.05271 & -0.59316 \\
\hline Productivity in sawmilling $(X 73) \ldots$ & 0.27276 & 0.10442 & 2.61217 \\
\hline Dummy variable $(X 86) \ldots \ldots \ldots \ldots$ & -18.57495 & 7.69304 & -2.41451 \\
\hline Current price of sof twood lumber $(\hat{P} 5) \dagger \ldots$ & 0.47293 & 0.28455 & 1.66203 \\
\hline Price of sawlog stumpage $(\hat{P} 10) \dagger \ldots \ldots \ldots \ldots \ldots$ & -0.10151 & 0.26327 & -0.38558 \\
\hline
\end{tabular}

* Constant term $=31.21464$, squared multiple correlation coefficient $=0.97625$, critical $t$ value $=1.734$. Critical $t$ val ues are such that if the absolute value of a coefficient's $t$ ratio is greater than the critical value, the hypothesis that the true value of the coefficient is zero is rejected at the 90 per cent level.

t Reduced form estimates of this variable were used rather than actual values, as required by estimation procedures.

$\$$ Ratio of coefficient to its standard error.

TABLE 11

ESTIMATED BUILDING PAPER AND BOARD DEMAND EQUATION*

\begin{tabular}{|c|c|c|c|}
\hline Variable & Coefficient & Standard error & $t$ ratiof \\
\hline Wages in constructions ( $X 17)$. & -95.70901 & 438.21667 & -0.21840 \\
\hline Value of total construction (X25). & 0.03746 & 0.01831 & 2.04524 \\
\hline Ratio past prices building board/lumber ( $X 76)$. & -153.84541 & 167.01581 & -0.92114 \\
\hline Ratio past prices plywood/building board ( $X 81)$. & -440.07376 & 507.10720 & -0.86781 \\
\hline Ratio past prices wallboard/building board ( $X 82)$. & -676.86656 & 777.95992 & -0.87005 \\
\hline Current price of plywood $\left(\hat{P}_{4}\right) \dagger \ldots \ldots \ldots \ldots$ & -12.49354 & 10.44044 & -1.19664 \\
\hline Current price of sof twood lumber $(\hat{P} \bar{j}) \dagger \ldots$ & 39.14179 & 15.40801 & 2.54035 \\
\hline Current price of building paper and board $\left(\hat{P}^{6}\right) \dagger$. & -22.59753 & 16.41908 & -1.37629 \\
\hline
\end{tabular}

* Constant term $=317150300$, squared multiple correlation coefficient $=0.98795$, critical $t$ value $=1.734$.Critical $t$ values are such that if the absolute value of a coefficient's $t$ ratio is greater than the critical value, the hypothesis that the true value of the coefficient is zero is rejected at the 90 per cent level.

$\dagger$ Reduced form estimates of this variable were used rather than actual values, as required by estimation procedures.

$\ddagger$ Ratio of coefficient to its standard error.

TABLE 12

ESTIMATED BUILDING PAPER AND BOARD SUPPLY EQUATION*

\begin{tabular}{|c|c|c|c|}
\hline Variable & Coefficient & Standard error & $t$ ratio $\ddagger$ \\
\hline Trend $(X 27)$. & 39.52423 & 51.54778 & 0.76674 \\
\hline Price of electric power $(X 29) \ldots \ldots$ & -6.65425 & 7.74517 & -0.85914 \\
\hline Wages in pulp and paper $(X 32) \ldots$ & -1828.41590 & 1264.11200 & -1.44640 \\
\hline Price of petroleum products $(X 33) \ldots \ldots \ldots \ldots \ldots \ldots \ldots \ldots \ldots \ldots \ldots \ldots \ldots \ldots \ldots$ & 3.53594 & 6.71107 & 0.52688 \\
\hline Productivity in pulp and paper $(X 74) \ldots \ldots \ldots \ldots \ldots \ldots \ldots \ldots \ldots$ & 23.92619 & 7.37100 & 3.24598 \\
\hline 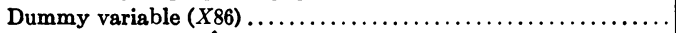 & 1057.62530 & 442.40385 & 2.39063 \\
\hline 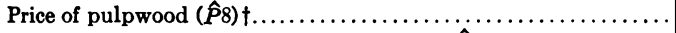 & 64.29999 & 48.80023 & 1.31761 \\
\hline Current price of building paper and board $(\hat{P} 6) \dagger \ldots \ldots \ldots \ldots \ldots$ & 16.54850 & 18.60464 & 0.88948 \\
\hline
\end{tabular}

* Constant term $=-1919.69540$, squared multiple correlation coefficient $=0.98975$, critical $t$ value $=1.734$. Critical $t$ values are such that if the absolute value of a coefficient's $t$ ratio is greater than the critical value, the hypothesis that the true value of the coefficient is zero is rejected at the 90 per cent level.

$t$ Reduced form estimates of this variable were used rather than actual values, as required by estimation procedures.

$\ddagger$ Ratio of coefficient to its standard error. 


\section{Estimates of Demand and Supply Elasticities}

Table 13 shows interval and point estimates of demand and supply elasticities. Elasticity of demand, as used here, refers to the change in the quantity of a good demanded in response to a one unit increase ceteris paribus in its price. Elasticity of supply refers to the change in the quantity supplied in response to a similar increase in price. Point estimates that are significantly different from zero at the 0.90 probability level are marked by an asterisk.

It will be noted that both the supply and demand for paper is indicated to be "inelastic"- that is, absolute value of the elasticity is estimated to be less than 1. The same is true for paperboard and softwood plywood. For all lumber, soft- wood lumber and building paper and board, no indication of whether supply and demand are inelastic or elastic is given. With regard to the demand for lumber, the view appears to be prevalent that it is inelastic, although this is not documented nor supported by evidence.

Because the construction industry uses over 70 per cent of all lumber consumed in the U. S. (Appendix A), and because lumber costs are a minor portion of total expenditures for construction, the idea that the quantity of lumber demanded is little affected by price is appealing. Although the point estimates of elasticity of demand are high, the hypothesis of an inelastic schedule is not rejected.

TABLE 13

INTERVAL AND POINT ESTIMATES OF SUPPLY AND DEMAND ELASTICITIES

\begin{tabular}{|c|c|c|c|}
\hline Products & $\begin{array}{l}\text { Lower } \\
\text { bound* }\end{array}$ & $\begin{array}{c}\text { Upper } \\
\text { bound* }\end{array}$ & $\begin{array}{c}\text { Point } \\
\text { estimate }\end{array}$ \\
\hline \multicolumn{4}{|l|}{ All lumber: } \\
\hline Demand.. & -6.0 & -0.9 & $-3.5 \dagger$ \\
\hline Supply................ & 0.1 & 1.4 & $0.8 \dagger$ \\
\hline \multicolumn{4}{|l|}{ Softwood lumber: } \\
\hline Demand......... & -6.3 & -0.2 & $-3.2 \dagger$ \\
\hline Supply......... & 0.0 & 3.4 & 1.7 \\
\hline \multicolumn{4}{|l|}{ Paper: } \\
\hline Demand.......... & -1.0 & 0.0 & -0.4 \\
\hline Supply.......... & 0.0 & 0.5 & -0.1 \\
\hline \multicolumn{4}{|l|}{ Paperboard: } \\
\hline Demand......... & -0.6 & 0.0 & $-0.3 \dagger$ \\
\hline Supply.................. & 0.1 & 0.6 & $0.4 \dagger$ \\
\hline \multicolumn{4}{|l|}{ Building paper and board: } \\
\hline Demand...$\ldots \ldots \ldots \ldots \ldots$ & -2.3 & 0.0 & -1.0 \\
\hline Supply.................. & 0.0 & 2.2 & 0.7 \\
\hline \multicolumn{4}{|l|}{ Sof twood plywood: } \\
\hline Demand......... & -0.2 & 0.0 & -0.1 \\
\hline 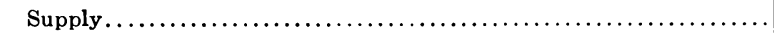 & 0.0 & 0.8 & 0.4 \\
\hline
\end{tabular}

* Where the computed upper bound for a demand elasticity was positive the interval has been truncated at zero on a priori grounds. Where the lower bound for a supply elasticity was found to be negative, the interval has been similarly truncated.

$\dagger$ Significantly different from zero at the 0.90 probability level. 


\section{Characteristics of Data}

A complete listing of all variables used in the analysis is given in Appendix D, and descriptions and sources of basic data are given in Appendix E.

\section{Price Deflation}

Price data were not deflated. In a simple relationship, such as a demand relationship with income as the only shifter, deflation is necessary to obtain an estimate of demand elasticity that reflects the holding constant of the prices of other goods. However, the relationships dealt with in this study included prices of competitive goods, and thus materials and deflation appeared to be unnecessary. It was decided that actual prices should be forecast rather than deflated ones, and that computational costs should be restrained by using the same type of price data in both the structural estimation and the prediction part of the study.

\section{Per Capita Data}

No attempt was made to use per capita consumption data because of the difficulty of finding a basis in economic theory for this formulation, especially in the case of supply relationships. Although any linear relationship with population as an explanatory variable could be transformed into a per capita one by division by population, the resulting model may be criticized on the grounds that structural change may occur. For instance, if the correct model is:

$$
q^{d}{ }_{t}=\alpha_{O}+\alpha_{1} p_{t}+\alpha_{2} n_{t}+e_{t}
$$

where $q^{d}{ }_{t}, p_{t}, n_{t}$ and $e_{t}$ are respectively the quantity of a good demanded, its price, population, and a disturbance term in period $t$, then the transformed model

$$
(q / n)_{t}=\beta_{O}+\beta_{1} p_{t}+u_{t}
$$

will be susceptible to structural change in $\beta_{O}$ and $\beta_{1}$ as the level of population changes, because $\beta_{O}=\alpha_{2}+\alpha_{O} / n_{t}$ and $\beta_{1}=\alpha_{1} / n_{t}$.

\section{Past Prices}

The influence of past prices was depicted in demand relationships by ratios of past prices of the materials demanded to past prices of competing materials. Preliminary studies, not using ratios, revealed a high degree of collinearity among past prices, with many being excluded from the regression or appearing nonsignificant.

\section{Restrictions of Data}

Lastly, it should be repeated that data used to represent prices of certain products in some instances did not cover prices of all product categories. Products that had to be treated in this way were softwood sawlogs, softwood plywocd and peeler logs. In the case of sawlogs and peeler logs, prices for only Douglas fir in western Washington and western Oregon were available. In the case of softwood plywood, prices for Douglas fir interior grades were the only ones obtainable for the major part of the sample period. Nearly all softwood plywood manufactured in the U. S. is Douglas fir, and nearly all of it is produced in the Pacific Northwest (Guthrie and Armstrong, 1961) so that the use of Douglas fir data to represent all species and the use of Pacific Northwest data to represent all regions is not a serious defect. With regard to use of the price index for interior grade Douglas fir plywood in place of an "all" softwood plywood index it should be noted that for the years for which both indexes are available they show a 
very close correlation $\left(r^{2}=0.99\right)$. Data on plywood prices were not available prior to 1936, and so were estimated using a reduced-form equation employed in an earlier study by the investigator using a 1936-1960 sample period. These data were not used directly in structural estimation, because prices were treated as regressor variables in all relationships and were represented by computed values as required by the two-stage estimation procedure.

\section{Discussion of Estimated Relationships}

To help compare influences of different variables, estimates of elasticities for the year 1960 are presented. The term elasticity as used here refers to the effect of a one-unit ceteris paribus increase in any regressor variable in a demand or supply equation on the quantity demanded or supplied, whether that variable be the price of the product under consideration or some other variable in the function. For instance in an estimated demand function of the type $Q_{t}=a_{O}+a_{1} P_{t}+$ $a_{2} X_{t}$, an estimate of elasticity at time $t$ with respect to $P$ would be $a_{1} P_{t} / Q_{t}$ and with respect to $X, a_{2} X_{t} / Q_{t}$. Although elasticities of demand are frequently given in terms of their absolute magnitudes, this has not been done in the present report. The estimated elasticities could have been calculated using values of variables for any year, or using average values over the sample period, but 1960 data were used to give particular emphasis to variables of current importance. Other estimates of relative importance could have been used, for instance the so called Beta coefficients which (in the case of the above demand function) would be $\beta_{1}=a_{1} S_{\mathrm{P}} / S_{\mathbf{Q}}$, and $\beta_{2}=a_{2} S_{\mathbf{X}} / S_{\mathbf{Q}}$ where $S_{\mathrm{P}}, S_{\mathrm{Q}}$ and $S_{\mathrm{X}}$ are, respectively, the sample standard deviations of $P, Q$ and $X$. Like elasticities they are useful because they remove the effect on regression coefficients of scale of measurement of the variables. Goldberger (1964) suggests that they represent the "typical effect" on the dependent variable during the sample period of typical changes in the independent variables. Elasticities on the other hand may be more simply interpreted as, for example, the percentage change induced in a dependent variable by a 1 per cent change in an independent one. This simplicity of interpretation, together with their ability to measure the current importance of associated variables, led to their being preferred over Beta coefficients. However, these elasticities refer to a single equation and ignore the fact that any change in the magnitude of a variable will generate change in other parts of the system which will induce secondary effects in the relationship under consideration. The estimated total effects of changes in exogenous variables on certain of the endogenous variables in the system are indicated by the estimated coefficients of the reduced form equations presented in the next chapter. Lastly it should be mentioned that only point estimates of elasticities are shown, and that they are not necessarily significantly different from zero or from each other.

\section{Lumber Demand}

The function estimated was as presented in part II, with the following exceptions. Population (X23) and per capita income (X24) were omitted because of collinearity with value of construction (X25) which was felt to be a highly important variable in this particular function. The variable $X 78$ denoting the influence of past price of structural 
clay products was excluded in the stepwise regression process.

All coefficients were of the "correct" sign, except for that of $X 76$ (relative past price of building board), which was not only wrong but significantly different from zero at the same time. The only evident explanation (or perhaps rationalization) of this was that perhaps building board may play a complementary role rather than a competitive role in the demand for lumber. Some $a$ prior $i$ support for this view is seen in the fact that the low structural strength of building board creates an auxiliary role for lumber as framing. Omission of $X 76$ from the regression resulted only in a wrong sign for one of the other coefficients.

Estimates of elasticities of demand for lumber with respect to each variable in the estimated equation, in order of absolute magnitude, were:

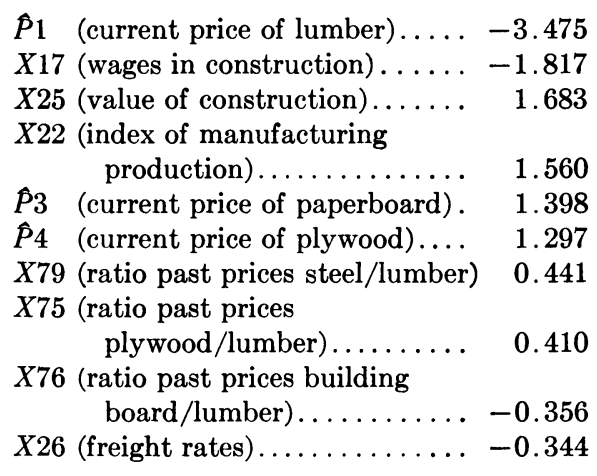

It will be observed that both value of construction and wages of construction workers are indicated to be major shifters in the demand for lumber. Building board price on the other hand is indicated to play a minor role.

\section{Lumber Supply}

The computed price of sawlogs $(\hat{P} 7)$ and the computed price of sawlog stumpage $(\hat{P} 10)$ were highly correlated with the computed price of lumber $(\hat{P} 1)$, with the result that the inclusion of either of them in a regression led to the exclusion of $\hat{P} 1$ through the stepwise process because of near linear dependence. As it seemed more important to have information on the effect of lumber price, $\hat{P} 7$ and $\hat{P} 10$ were omitted from the final regression. Both these variables may be strongly influenced by the state of the lumber market. The supply of both sawlogs and stumpage may be considerably more stable than the demand for them, with the result that shifts in demand associated with fluctuations in the level of lumber production during the sample period may have had an overriding influence on their price and consumption levels. It should be pointed out that when a variable is omitted because of high correlation with an included variable, the coefficient associated with the included variable depicts the joint effect of simultaneous movement in the two variables.

Estimates of elasticities, again in order of absolute magnitude, were:

\begin{tabular}{|c|c|}
\hline$X 27$ & -1 \\
\hline$X 29$ (price of electric power) & -1.362 \\
\hline$X 31$ (rate of exchange). & 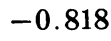 \\
\hline$X 28$ (wages in sawmills) & 0.8 \\
\hline$X 73$ (productivity in sawmilling) & 0.76 \\
\hline$\widehat{P} 1$ (current price of lumber) & 0.7 \\
\hline X86 (dummy variable). & -0.556 \\
\hline$X 33$ (price of petroleum produc & 0 . \\
\hline & \\
\hline
\end{tabular}

Estimates of coefficients associated with $X 28$ and $X 33$ were of wrong sign though not significantly different from zero.

The coefficient associated with $X 86$ suggests that a decrease in the supply of lumber has occurred in postwar years. One reason for the negative sign may have been omission of $\hat{P} 7$ and $\hat{P} 10$, but preliminary regressions in which they were included were no different in this respect. Further, in the prewar period the small lumberman had a low opportunity cost for his own services and was willing to 
sell at prices scarcely above variable costs just to stay employed, whereas in the postwar period the many opportunities for alternative employment allowed him to move out of the lumber business if he so desired. Yet another explanation for the negative sign is the one relating to decreased log quality in the postwar period (see page 22).

\section{Paper Demand}

Before estimation, value of construction was omitted from the function outlined in part II because of collinearity with population and income. Building paper consumption was never more than 9 per cent of total paper consumption during the sample period, so the omission was not considered a serious defect.

Estimated elasticities were:

$X 24$ (per capita income)......... 1.209

$X 34$ (consumer price index)...... -0.687

$\hat{P} 2 \quad$ (current price of paper)..... -0.433

$X 22$ (index of manufacturing production)............ 0.230

$\hat{P} 3$ (price of paperboard)....... 0.217

$X 23$ (population)............ 0.140

$X 26$ (freight rates)........... -0.072

The coefficient associated with $X 34$ was of the wrong sign though non-significant. It will be noted that the demand for paper is indicated to be inelastic, and that per capita income appears to have a somewhat greater influence than does population.

\section{Paper Supply}

The estimated relationship was as presented in part II. Estimates of elasticities are presented below. Coefficients were of wrong sign (though nonsignificant) for $X 31, X 32, X 33, \hat{P} 2$ and Pि8.

$X 74$ (productivity in pulp and paper).............. 0.633

$X 29$ (price of electric power).... -0.268
$\begin{array}{lll}X 32 \text { (wages in pulp and paper)... } & 0.204\end{array}$ $X 33$ (price of petroleum products). $\quad 0.159$

Pि8 (price of pulpwood)........ 0.140

$\hat{P} 2$ (current price of paper)..... -0.107

$X 27$ (trend)................ -0.086

$X 86$ (dummy variable)......... 0.038

$X 31$ (rate of exchange)........ 0.018

In contrast to supply of lumber, the sign of the coefficient associated with $X 86$ suggests that an increase in the supply of paper took place in postwar years, but as the coefficient is not significantly different from zero, little importance should be attached to this.

Only the coefficients for $X 74$ and $X 29$ were significantly different from zero. This is in part due to a small size of sample, but it is noteworthy that supply functions of the paper and paperboard industries tended to have more nonsignificant variables than those of the lumber and plywood industries. This is not surprising, however, as the latter industries are considerably less competitive and lower in concentration relative to the pulp and paper industry (Zaremba, 1963). For instance in 1954, 18 per cent of the total output of the lumber industry was produced by the twenty largest firms; for the plywood industry, the figure was 42 per cent, and for the pulp and paper industry 61 per cent (U. S. Congress, 1957b). Furthermore price setting and maintenance have been evident in the pulp and paper industry (Guthrie, 1950); when producers exercise direct control over prices it is likely that costs of inputs have less influence over supply than they would in more competitive industries, and it is also likely that coefficients associated with these costs would be near zero.

\section{Paperboard Demand}

Value of construction was retained in the equation for estimation purposes in preference to population and income. 
The only other differences between the function originally specified and the one estimated were that $\hat{P} 2$, was excluded by the stepwise process and $X 76$ was omitted before final estimation because a high correlation between it and $\hat{P} 1$ was leading to the exclusion of $\hat{P} 1$ in preliminary regressions.

Estimates of elasticities were:

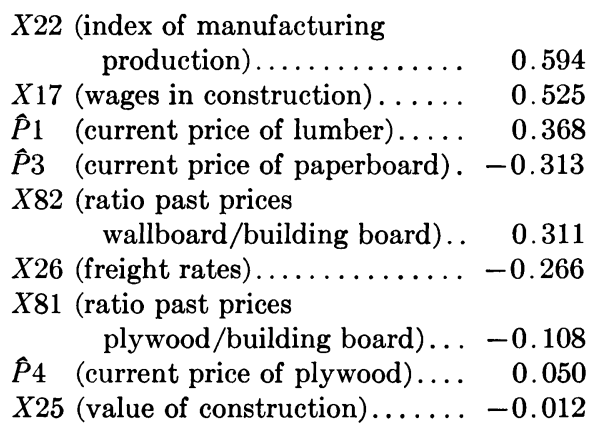

Coefficients for $X 81$ and $X 25$ were of wrong sign, though not significantly different from zero.

\section{Paperboard Supply}

The function estimated was as originally specified. Estimates of elasticities were:

$X 74$ (productivity in pulp and paper)............. 0.921

$\hat{P} 3$ (current price of paperboard). $\quad 0.373$

$\hat{P} 8$ (price of pulpwood)........ -0.190

$X 32$ (wages in pulp and paper)... 0.154

$X 86$ (dummy variable)........ 0.089

$X 27$ (trend) ............ -0.080

$X 33$ (price of petroleum products) $\quad 0.072$

$X 29$ (price of electric power).... -0.070

Coefficients for $X 32$ and $X 33$ were of wrong sign though non-significant. As in paper supply, use of the dummy variable $X 86$ indicated an increase in supply in the postwar years - though in this case the associated coefficient was significantly different from zero.

\section{Softwood Plywood Demand}

Estimation of the function was carried out initially without change except for omission of population and income. Results of the intial estimation were disappointing, however, with the omission of $\hat{P} 1$ and the obtaining of wrong significant coefficients for $\hat{P} 3$ and $\hat{P} 4$. Several modifications of the function were tried, and one which involved the omission of $\hat{P} 1$ and $\hat{P} 3$ from the original function was chosen as most satisfactory.

Estimates of elasticities were:

\begin{tabular}{|c|c|}
\hline$X 17$ (wages in construction) & 0.771 \\
\hline$X 25$ (value of construction). & 0.454 \\
\hline $\begin{array}{r}X 22 \text { (index of manufacturing } \\
\text { production) } \ldots \ldots \ldots \ldots\end{array}$ & 0.234 \\
\hline$X 85$ (ratio past prices & \\
\hline $\begin{array}{l}\text { wallboard/plywood). } \\
X 81 \text { (ratio past prices }\end{array}$ & 0.148 \\
\hline plywood/building board)... & -0.121 \\
\hline $\begin{array}{l}P 4 \\
X 75 \text { (ratio past prices } \\
\text { plywood /lumber)...... }\end{array}$ & -0.064 \\
\hline
\end{tabular}

The coefficient for $X 75$ was wrong in sigh though non-significant.

\section{Softwood Plywood Supply}

Difficulty was also encountered in the estimation of the plywood supply function. The problem was a positive sign for the coefficient for $X 28$ (the variable depicting wages in the plywood industry) which persisted through numerous modifications of the original function. Omission of X28 led only to wrong signs for several other coefficients and so it was decided to accept the results of the initial estimation as the best available.

Estimates of elasticities were:

$X 28$ (wages in sawmills)........ 2.773

$\hat{P} 9 \quad$ (price of veneer logs)....... -1.076

$X 86$ (dummy variable).......... -0.742

$\hat{P} 4 \quad$ (current price of plywood)... 0.378

$X 29$ (price of electric power)..... 0.127

$X 73$ (productivity in sawmilling). $\quad 0.081$

Simpson and Halter (1963) also used sawmill wages to depict wages in the plywood industry and it is interesting that they also obtained an estimated 
coefficient that was positive and significantly different from zero. They suggested that sawmill wages were playing the role of a productivity variable-a suggestion that is closely tied to the idea that substitution of equipment for labor in response to rising wages tends to increase supply. It is possible that if this movement could have been depicted by some variable more suitable than proproductivity in sawmilling, the implausible estimate of the wage coefficient would not have been observed.

The sign of the coefficient of the dummy variable $X 86$ suggested that a ceteris paribus decrease in supply took place in the postwar period. It was intended that this variable should represent the increase in technology that occurred after the war in the plywood industry. What it may have done is to have expressed the decreasing quality of peeler logs that the industry has had to contend with in the postwar period. Empirical evidence is not available to support this view, but economic theory suggests that the effect of a decrease in in quality of an input for a constant price of that input will result in a decrease in supply.

\section{Softwood Lumber Demand}

Only population and income were omitted from the original function.

Estimates of elasticities were:

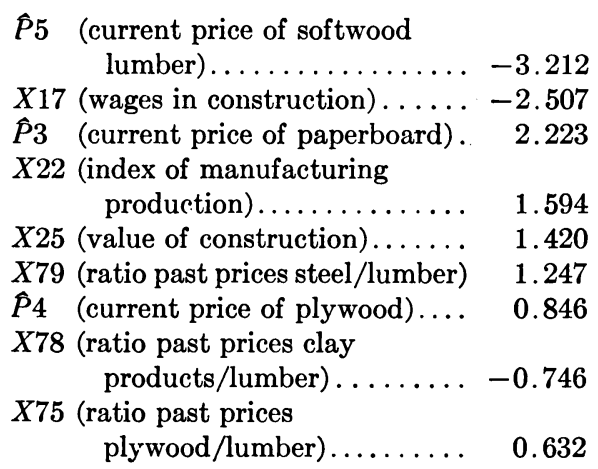

$X 76$ (ratio past prices building board/lumber) .......... -0.478

$X 26$ (freight rates)........... -0.296

The coefficients associated with $X 76$ and $X 78$ were wrong in sign. That for $X 78$ was not significantly different from zero but, as in the case of all lumber demand, the $X 76$ coefficient was significantly different-again suggesting that some sort of complementarity may exist between lumber and building board. Wages in construction again appeared to be an important variable, and this tends to support the view that high costs of installation have been a major factor in decreasing the demand for lumber in construction.

\section{Softwood Lumber Supply}

No deliberate changes were made in the function originally specified, but $\hat{P} 7$ (price of sawlogs) was excluded through the stepwise process.

Estimates of elasticities were:

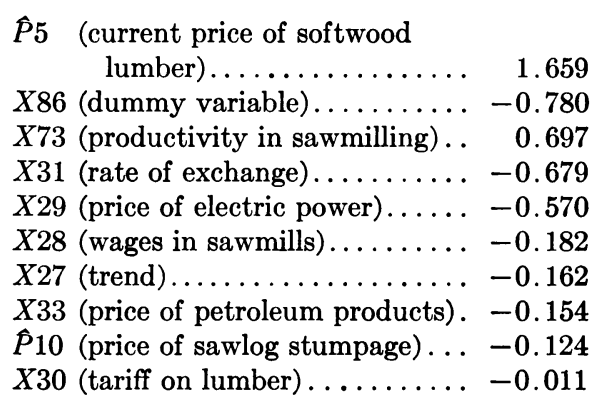

Not unexpectedly, the tariff on lumber (X30) was indicated to be of minor importance at the present time, but it is doubtful that the price of sawlog stumpage $(\hat{P} 10)$ is of such slight influence as the results suggest. The tariff on Douglas fir, the major species of imported lumber, was only about 1 per cent of the price in 1960 , but for the same species in the same year the average stumpage price in National Forest sales was more than 40 per cent of the lumber price (U. S. Forest Service, 1963). 


\section{Building Paper and Board Demand}

No variables were omitted prior to estimation and none was excluded via the stepwise process.

Estimates of elasticities were:

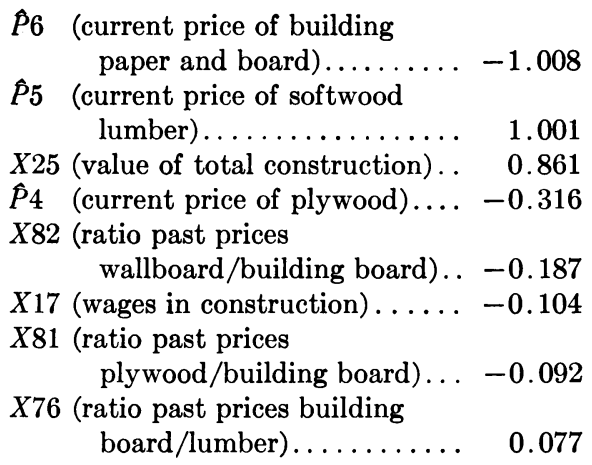

Coefficients of wrong sign, though nonsignificant, were obtained for $X 81, X 82$ and $\hat{P} 4$. It is not unexpected that value of construction should appear to be an important variable, but it is surprising that past prices of substitutes appear to be less important than current ones. Though current price is likely to be more influential than price in any other year, these results suggest that substitution in response to past prices has been of minor importance in the demand for this product.

\section{Building Paper and Board Supply}

The estimated equation was as originally formulated. Estimates of elasticities were:

$X 32$ (wages in pulp and paper) $\ldots-1.360$

$X 74$ (productivity in pulp and paper) .............. 1.127

P̂6 (current price of building paper and board)......... 0.738

$\hat{P} 8$ (price of pulpwood) ........ 0.464

$X 27$ (trend)................. 0.387

$X 86$ (dummy variable)......... 0.324

$X 29$ (price of electric power)..... -0.208

$X 33$ (price of petroleum products). 0.127

The coefficients for $X 33$ and $\hat{P} 8$ were wrong in sign, though not significantly different from zero. The sign of $X 86$ conformed to a priori expectations in this case, but that of $X 27$ (the continuous trend variable) did not.

\section{Remarks}

There are some similarities between relationships. As expected, the demand functions for all lumber and for softwood lumber were somewhat similar in structure, with price the most important variable (as judged by the point estimates of elasticities) followed by wages in construction, with the variables depicting past prices of competing materials being generally low in importance. In fact, for all demand functions in which they appeared, "own" price and wages in construction appeared to be important. In three functions out of six the price of the product was the most important variable. Prices of other materials generally appeared to be less important demand shifters than were such general shifters as value of con- struction and index of manufacturing production. "Freight rates" was nearly always the least important variable and might have been omitted from the model without any serious effect.

In contrast to its role in demand functions, product price was not a leader of importance in supply functions, being in the first three positions in only three cases out of six. The productivity variables $X 73$ and $X 74$ ranked first in importance in two functions and second in another. In both lumber supply functions the Canadian dollar rate of exchange appeared fairly important, but not in the case of paper supply where it appeared last in absolute magnitude. In addition, the supply functions of the less competitive industries (paper and paper- 
board) showed noticeably fewer coefficients that were significantly different from zero than did those for plywood and lumber.

With regard to the role of the same variable in different relationships, past wages of construction workers appeared to be more influential in lumber demand functions than in other functions. This was not unexpected, because of the high degree of handling required for this type of product relative to rapidly installed panel products such as plywood and building board. Index of manufacturing production, value of construction, and freight rates also showed this characteristic; in the case of index of manufactur- ing production and value of construction the reason for this is not clear.

A high proportion of total lumber consumption is accounted for by the construction industry but (as can be seen from Appendix A) the proportion accounted for by this industry in the case of softwood plywood consumption is equally high. With freight rates, however, the high weight/value ratio of lumber (as compared to the other products) could be cited as a reason for the result, as a change in freight rates may be expected to have a greater impact on high ratio products than on products having a low weight relative to their value.

\section{PREDICTION}

\section{Preliminary}

Predictions were made of prices and consumption levels for the period ending in 1975. All products were not treated equally with respect to prediction, a more comprehensive approach being taken in the case of wood products. For these, three methods of prediction were considered and both prices and levels of consumption were forecast. For pulpwood, peeler logs, sawlogs, and sawlog stumpage two methods of prediction were employed and future values of prices alone were estimated. Emphasis was placed on long-range forecasts rather than on predictions made for 1 or 2 years following the sample period. Ideally, predictions should be in the form of unbiased interval estimates which are small in relation to the magnitude being predicted. Where long-range forecasts are concerned, it is not generally possible to obtain meaningful interval estimates. In the first place, where regressor variables are such things as population, income, wage rates, levels of construction activity, and index of manufacturing production, their values in a growing economy will be considerably greater during the forecast period than during the sample period-with consequent inflation of standard errors of forecast. Secondly, future values of these regressor variables are seldom known exactly, and therefore must be predicted. It is possible to prepare conditional interval estimates, but if probability statements are to be meaningful they must allow for possibility of errors in predicting the independent variables. Attempts may be made to gauge possible ranges in future values of these variables and incorporate them in computations of estimates, but this may be expected to lead to further inflation of confidence intervals. For these reasons an attempt was made to obtain only point estimates of future values. 


\section{Prediction Techniques}

The estimated reduced-form equation systems

$$
\begin{aligned}
& \hat{Y}_{A t}=\hat{D}_{A} X_{t} \\
& \hat{Y}_{B t}=\hat{D}_{B} X_{t}
\end{aligned}
$$

were obtained in the first stage of the two-stage least squares estimation where

$\hat{Y}_{A t}$ is a $(12 \times 1)$ matrix representing predicted values in year $t$ of wood product prices and consumption levels,

$\hat{Y}_{B t}$ is a $(4 \times 1)$ matrix representing predicted values in year $t$ of primary product prices,

$X_{t}$ is a matrix representing values of predetermined variables in year $t$, and $\hat{D}_{A}$ and $\hat{D}_{B}$ are matrices of estimated coefficients.

Predicted values of endogenous variables in year $(t+n)$ may be represented as

$$
\begin{aligned}
& \hat{Y}_{A t+n}=\hat{D}_{A} \hat{X}_{t+n} \\
& \hat{Y}_{B t+n}=\hat{D}_{B} \hat{X}_{t+n}
\end{aligned}
$$

where $\hat{X}_{t+n}$ is a matrix representing predicted values of predetermined variables in year $(t+n)$.

The prediction technique utilizing these equations may be called the complete reduced form method. Its properties are discussed later.

Another technique employed was the solved structural method which utilized the estimated system of wood products demand and supply relationships presented in part III. This system may be depicted as

$$
\hat{B}_{1 A} Y_{A t}=\hat{C}_{1} X_{t}-\hat{B}_{1 B} \hat{Y}_{B t}+\hat{O}_{1 t}
$$

where $\hat{B}_{1 A}, \hat{B}_{1 B}$ and $\hat{C}_{1}$ are matrices of estimated structural coefficients and $\hat{V}_{1 t}$ is a matrix of residuals.

Algebraic manipulation of this system yielded the set of solved structural equations

$$
\begin{aligned}
\hat{Y}_{A t}=\hat{B}_{1 A}^{-1} \hat{C}_{1} X_{t}-\hat{B}_{1 A}^{-1} \hat{B}_{1 B} Y_{B t} \\
+\hat{B}_{1 A}^{-1} \hat{U}_{1 t} \\
=G X_{t}+F \mathrm{Y}_{B t}+E_{t}
\end{aligned}
$$

so that predicted values for year $(t+n)$ of variables endogenous to the wood products subsystem may be represented as

$$
\hat{Y}_{A t+n}=G \hat{X}_{t+n}+F \hat{Y}_{B t+n}
$$

where $\hat{Y}_{B t+n}$ represents forecasts of primary product prices in year $(t+n)$. Properties of solved structural estimates are discussed later.

Predictions were also made using "exogenous reduced form" equations derived by eliminating lagged endogenous variables from the complete system. The set of reduced-form equations for the wood products considered may be written as

$$
\begin{aligned}
Y_{A t} & =\left(D_{A E}: D_{A D}\right)\left(X_{E t}: X_{D t}\right)^{\prime}+V_{A t} \\
& =D_{A E} X_{E t}+D_{A D} X_{D t}+V_{A t} \\
& =D_{A E} X_{e t}+W_{A t} \quad \text { where } \quad W_{A t}=D_{A D} X_{D t}+V_{A t}
\end{aligned}
$$

with

$X_{E t}$ a column matrix representing the values in year $t$ of variables exogenous to the complete system,

$X_{D t}$ a column matrix representing the values in year $t$ of lagged endogenous variables, and $D_{A E}$ and $D_{A D}$ matrices of associated coefficients.

Treating $W_{A t}$ as a vector of disturbances and carrying out least squares estimation yielded the set of estimated equations

$$
\hat{Y}_{A t}=\hat{D}_{A E} X_{E t}
$$


Predicting equations for primary product prices may be similarly represented as $\hat{Y}_{B t}=\hat{D}_{B E} X_{E t}$, so that the exogenous reduced form predictions of endogenous variables for year $(t+n)$ may be represented as

$$
\begin{gathered}
\hat{Y}_{A t+n}=\hat{D}_{A E} \hat{X}_{E t+n} \quad \text { and } \\
\hat{Y}_{B t+n}=\hat{D}_{B E} \hat{X}_{E t+n}
\end{gathered}
$$

where $\hat{X}_{E t+n}$ represents forecasts of exogenous variables for the year $(t+n)$. The validity of this predicting technique is commented upon in a later section.

\section{Forecasting Equations}

Forecasting equations had good explanatory power with the squared multiple correlation coefficient never less than 0.95 . The estimated relationships are presented in Appendix F.

Solved structural equations had as predictors all regressor variables (with the exception of own price) that were used in estimating structural relationships.

Reduced form equations contained all exogenous or lagged endogenous variables except for those omitted because of multicollinearity.

\section{Forecasts of Shifters}

\section{Exogenous Variables}

Before predictions of prices and consumption levels could be carried out, forecasts of future values of exogenous variables had to be obtained. Reports by a number of agencies were consulted, namely the U. S. Forest Service (1965), the U. S. Bureau of the Census (1964), the National Planning Association (1962) and Resources for the Future (Landsberg et al., 1963). At the same time, independent forecasts were made by the investigator. The principal procedure used in this independent effort was to examine past trends of exogenous variables plotted against time, and to extrapolate any stable trends observed. Strong linear trends were usually evident for the postwar period and lines were fitted by least squares, using data for the years 1947 to 1960 . Table 14 gives the results of these regressions. A poor fit was obtained in the case of the price of electric power (X29), which underwent erratic movement in the latter part of the sample period after showing a marked downward trend in the earlier years. The

TABLE 14

\begin{tabular}{|c|c|c|c|}
\hline Variable & Constant & Coefficient & $R^{2}$ \\
\hline Wages in construction $(X 17)$. & -1.23455 & 0.14985 & 0.99835 \\
\hline Population $(X 23) \ldots \ldots$ & 90.33649 & 2.79296 & 0.99834 \\
\hline Per capita disposable income $(X 24)$. & 0.09835 & 0.05813 & 0.98906 \\
\hline 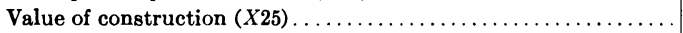 & -37343.00000 & 3563.02840 & 0.98891 \\
\hline Price of electric power $(X 29) \ldots$ & 99.57692 & -0.01758 & 0.00090 \\
\hline Wages in pulp and paper (X32). & -0.52125 & 0.09206 & 0.99761 \\
\hline Price of petroleum products $(X 33) \ldots \ldots$ & 66.18396 & 1.76505 & 0.62876 \\
\hline Consumer price index $(X 34) \ldots \ldots \ldots \ldots$ & 57.56286 & 2.17428 & 0.94292 \\
\hline Productivity in sawmills $(X 73) \ldots \ldots \ldots \ldots \ldots \ldots \ldots$ & 22.68154 & 1.22593 & 0.91603 \\
\hline
\end{tabular}

REGRESSIONS ON TIME 
least square fit did, however, yield a plausible projection for the prediction period in the form of a slow downward trend. Forecasted values are presented in Appendix E.

A distinct curvilinear trend was observed for wallboard price $(X 9)$ and forecasts were prepared graphically. For certain other variables, knowledge of change-promoting forces was considered a better basis for forecasting. In the case of the tariff on lumber (X30), for instance, it was felt that no change would occur during the prediction period. U. S. trade policy is becoming more and more liberal, as evidenced by the Trade Expansion Act of 1962 (see U. S. Tariff Commission, 1963), so that no increase in the tariff is likely-but strong demands by Pacific Northwest lumber manufacturers that something be done about rising levels of imports of Canadian lumber suggest that the tariff will not be removed. Marked changes in the rate of exchange on the Canadian dollar (X31) took place between 1961 and 1963, with the Canadian dollar dropping in value from $\$ 1.03$ (U. S.) to $\$ 0.93$ (U. S.). However, in May, 1962 the Canadian dollar was pegged at $\$ 0.925$ (U. S.) under agreements of the International Monetary Fund (Board of Governors of the Federal Reserve System, 1962) and it was anticipated that this rate would persist throughout the prediction period as evidence of the Canadian government's determination to stabilize the Canadian dollar at a level that would promote a less unfavorable balance of trade with the United States than that which existed in the late 1950's.

Forecasts made by the investigator were the only ones available for a majority of variables. For variables $X 23, X 24$ and $X 25$ the possibility of adapting forecasts made in other studies was considered but not accepted, partly because continuous series for all years were generally not given and partly because of the difficulty of obtaining forecasts of the particular variable used in this study. For instance, forecasts of monetary values were presented in these othe studies in terms of 1954, 1959, 1960 or 1961 dollars rather than in future undeflated dollars. Table 15 compares forecasts made in this study with those made in other studies. Where necessary, values expressed in terms of dollars for some base year were converted to "actual" magnitudes in years for which forecasts are shown. This conversion was made using multipliers obtained through projections of the consumer price index or the deflator for value of construction used by Landsberg et al. (1963).

Although population forecasts used in this study agree fairly well with those made in other studies, forecasts of value data are slightly lower. Exact comparison of forecasts of value is difficult however, because forecasts from other studies had to be converted from values in terms of base year dollars to values that were expected to actually prevail.

\section{Endogenous Variables}

In addition to forecasts of values of exogenous variables, predictions of certain variables endogenous to the complete system had to be made. In the reduced form equations primary forest product prices did not appear, but because they were included in the supply equations in the wood products subsystem they entered into the solved structural equations, as may be seen from function (6) on page 16 . One of the advantages that these equations were thought to have was their ability to allow for future availability of raw materials. Because estimates of future values of primary product prices could not be generated within the wood prod- 


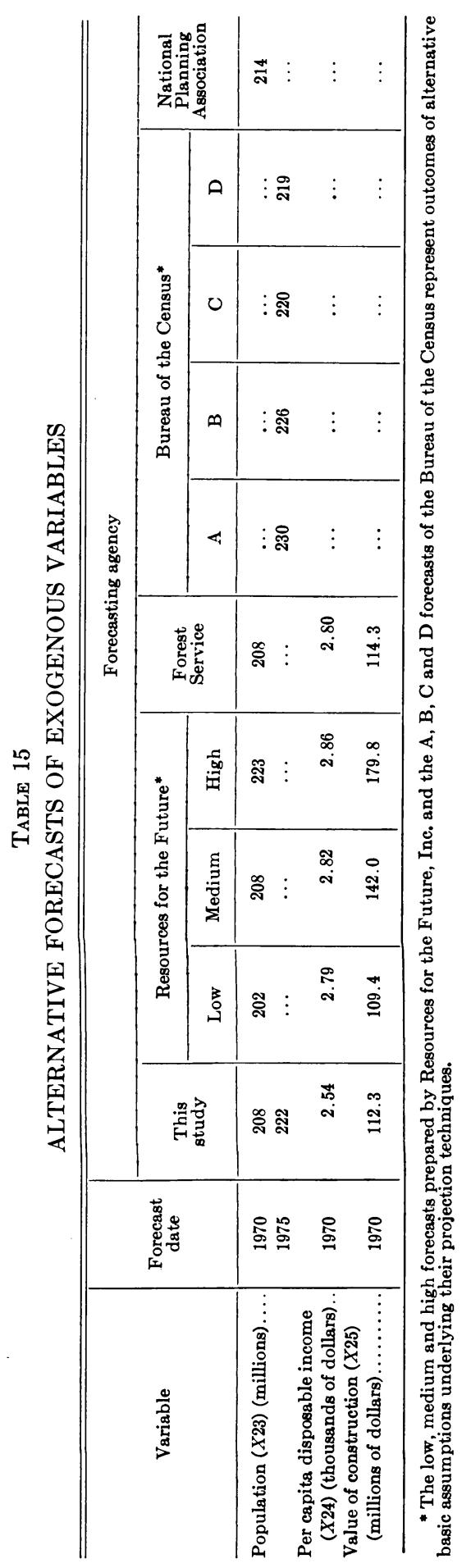


ucts subsystem, forecasts of them were obtained from the complete reduced form equations. In addition, forecasts of lagged endogenous variables in the wood products subsystem had to be obtained for use with both the solved structural and complete reduced form equations. These variables were the ratios of past prices of competing materials in construction and, since they depended on endogenous wood product prices, they had to be generated year by year using wood product prices predicted for the preceding period. Values generated with the complete reduced form equations were used for both methods, partly to reduce the computational burden and partly because preliminary calculations indicated that somewhat implausible forecasts of the price of softwood plywood, a key component in the set of lagged variables, would be obtained using the solved structural equations. (See pages $61-62$ for discussion of this characteristic of the solved structural equations.)

\section{Predictions}

Table 16 gives predictions for the years 1963-1975 for each variable considered and for each method employed (predictions for 1961 and 1962 are given in the next section). Past trends and predicted values for the years 1965, 1970 and 1975 are shown graphically in Appendix G.

From the graphical presentation it will be seen that good correspondence between all methods of prediction was obtained for $Q 2, Q 3, Q 4, P 1, P 2, P 7, P 8$ and $P$ 9. Relatively good correspondence was obtained between the solved struc- tural predictions and the exogenous reduced form predictions in the case of Q6, P3, P4, P5 and P6, with the complete reduced form predictions being noticeably lower for $Q 6$ and $P 6$ but considerably higher otherwise, especially in the case of the price of softwood plywood (P4). For $Q 1, Q 5$ and $P 10$ the correspondence between all methods was only fair, with some tendency for solved structural and exogenous reduced form estimates to move in a stable manner while the complete reduced form predictions showed a rather erratic movement.

\section{Comparison of Methods}

If the different methods had yielded predictions consistently close to each other in magnitude the need to investigate their relative merits would not have been great-but in several instances the methods gave future value estimates that were considerably different. The most striking difference appeared in $\mathbf{1 9 7 5}$ CRF (complete reduced form) and the SS (solved structural) predictions for $P 4$ and $P 5$, with the CRF prediction more than twice that of the SS in the case of $P 4$ and about one and a half times in the case of $P 5$.
In an attempt to choose between alternative predictions, consideration was given to the theoretical advantages of the different methods used and to the plausibility of the results obtained. Empirical analyses were also carried out, using data for the test years 1961 and 1962.

\section{Theoretical Advantages}

Because the CRF method is based on the application of direct least squares to models containing only predetermined variables as regressors, it can produce 


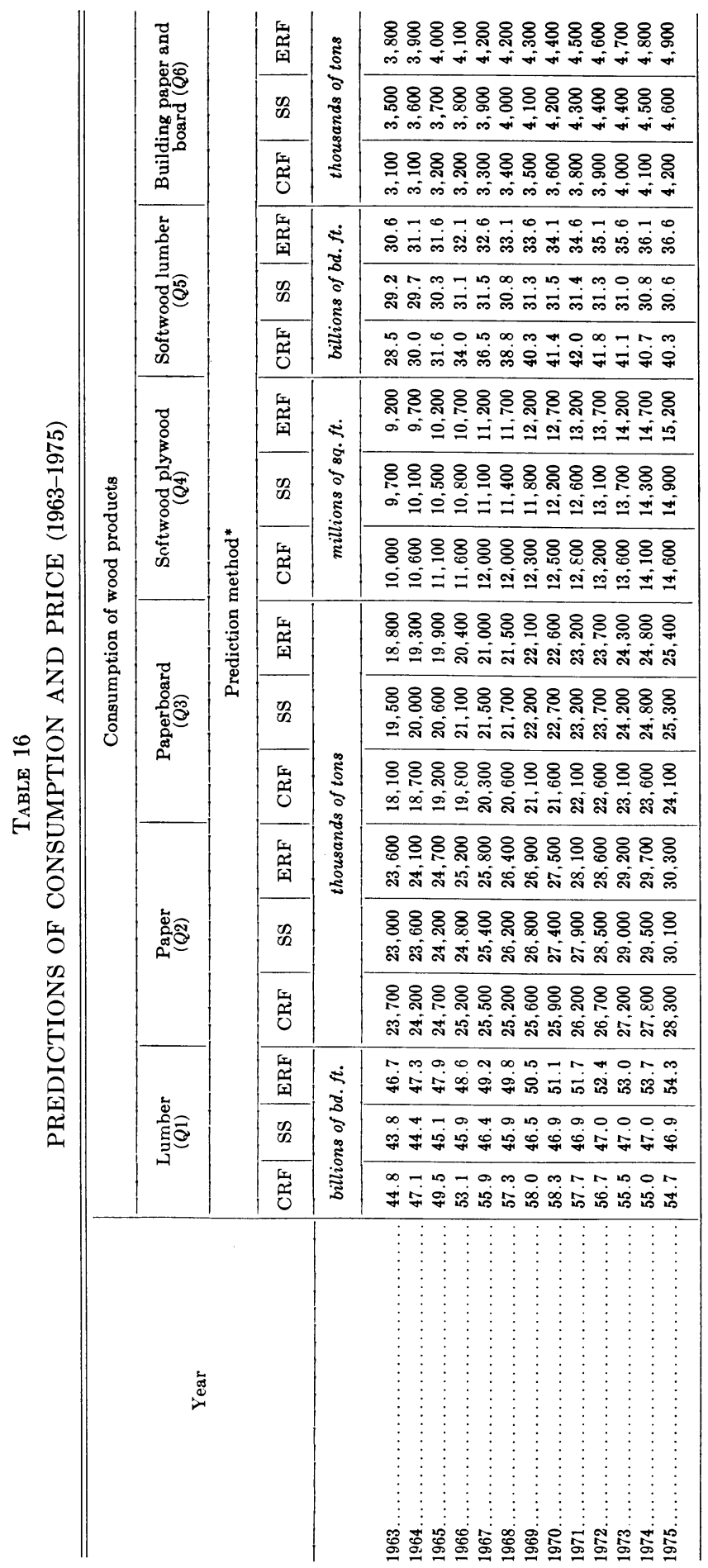




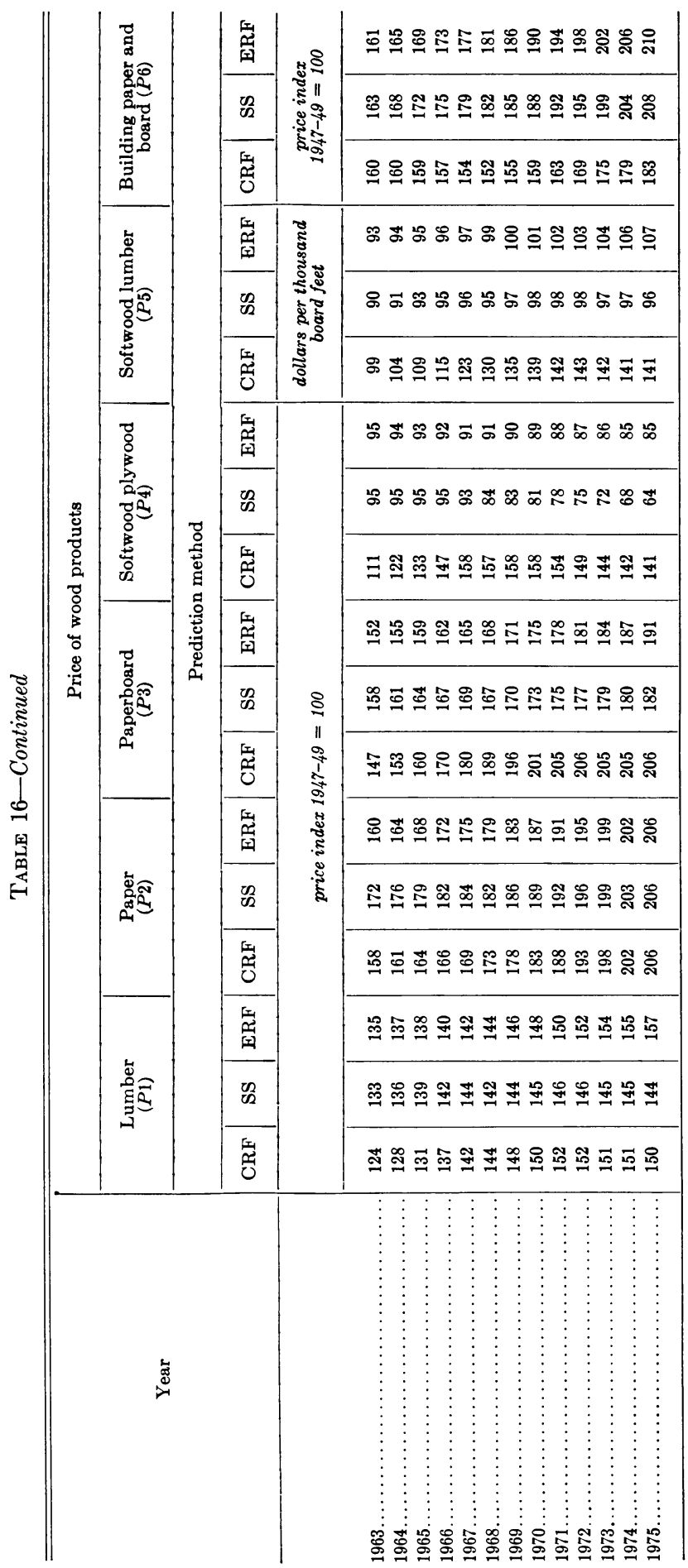




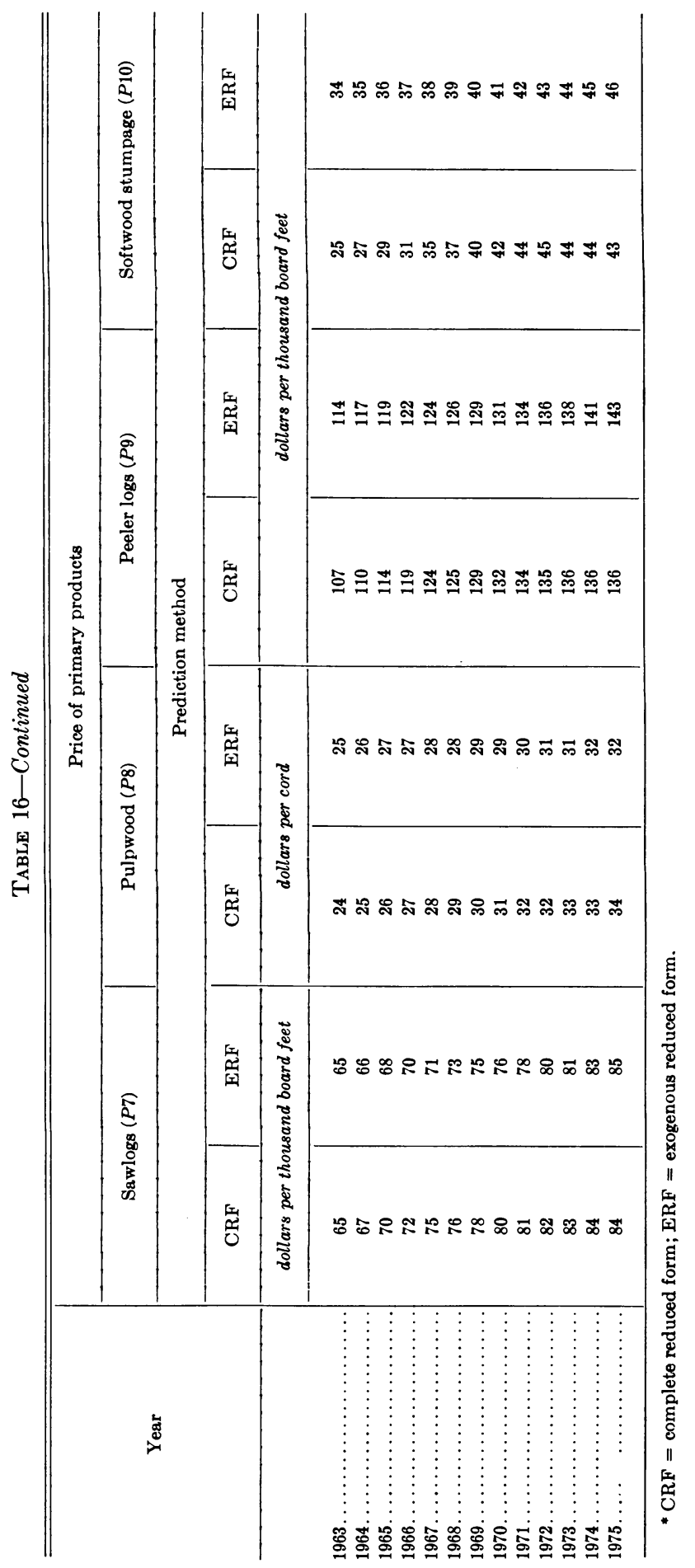


predictions having the statistical properties of consistency and efficiency. It should be understood that they are efficient relative to other estimators utilizing the same quantity of information (Hood and Koopmans, 1953). The SS method is consistent (Goldberger, 1964), and it utilizes additional information in the form of a priori restrictions on the structural coefficients. In particular, it utilizes information as to which coefficients are zero in individual structural relationships. Klein (see Pfouts, 1960) presents evidence to show that this type of restriction will lead to forecasts with lower asymptotic variances, although his results are not directly applicable here because he deals with maximum likelihood structural estimation. Furthermore, the prices of primary forest products are important influences in the supply of wood products. In the CRF predictions of wood product prices they are indirectly accounted for through the inclusion of predetermined variables from the primary products subsystem. In the SS predictions they are directly considered, because they are represented in predicting equations.

The CRF and the SS equations contained lagged variables in the form of ratios of past prices of wood products and other competing materials used in construction. This appeared to add substantially to the realism of the predicting equations because of the importance of substitutes in the demand for wood products. However, the mechanics of the predicting process required that the prices of wood products be predicted for 1 year and used to generate values of regressor variables to be used in predicting for the following year. This was computationally expensive and, as an experimental effort, the exogenous re- duced form predicting equations, having only exogenous variables as regressors, were developed. It was recognized, however, that the omission of apparently important variables might lead to biased estimates.

Table 17 gives actual and predicted values for the years 1961 and 1962. Predicted values were obtained for each test year using both actual values of shifters, and forecasts of them prepared by the investigator in the manner mentioned earlier. Predictions obtained using actual values of shifters are referred to as "unconditional" predictions; those obtained using forecasted values are referred to as "conditional" predictions.

\section{Turning Points}

One type of empirical analysis involved examination of turning points. As Theil (1960) indicates, it is relatively easy to predict continuous movement in a single direction but somewhat more difficult to forecast change of direction. In table 18 the occurrence of actual and predicted turning points is indicated by the letter $t$. In table 19 the measures $E 1$ and $E 2$ are given as quantitative indicators of turning point errors of the various methods for both conditional and unconditional predictions. They are respectively measures of what Theil refers to as turning point errors of the first and second kind. $E 1$ is the fraction of predicted turning points that were wrong and $E 2$ is the fraction of actual turning points that were not predicted. From table 19 it can be seen that the ERF unconditional predictions appeared to be superior to the other unconditional types, with 50 per cent of predicted turning points wrong in the case of prices and consumption levels for wood products and 36 per cent wrong in the case 
TABLE 17

PREDICTIONS FOR 1961 AND 1962

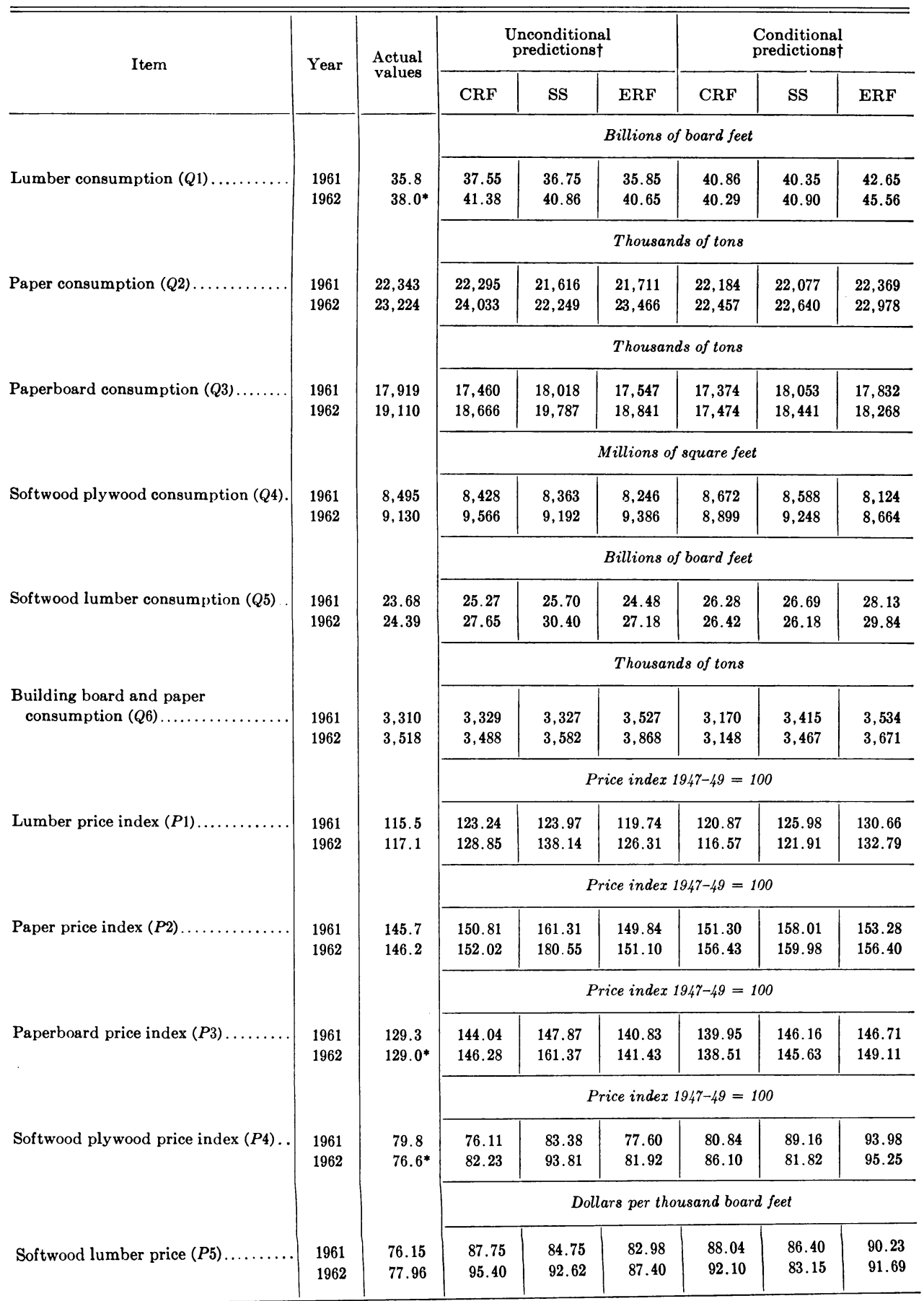


TABLE 17-Continued

\begin{tabular}{|c|c|c|c|c|c|c|c|c|}
\hline \multirow{2}{*}{ Item } & \multirow{2}{*}{ Year } & \multirow{2}{*}{$\begin{array}{l}\text { Actual } \\
\text { values }\end{array}$} & \multicolumn{3}{|c|}{$\begin{array}{c}\text { Unconditional } \\
\text { predictions } \dagger\end{array}$} & \multicolumn{3}{|c|}{$\begin{array}{l}\text { Conditional } \\
\text { predictions } \dagger\end{array}$} \\
\hline & & & CRF & ss & ERF & CRF & ss & ERF \\
\hline \multirow{4}{*}{$\begin{array}{l}\text { Building paper and board } \\
\text { price index }(P 6) \ldots \ldots \ldots \ldots\end{array}$} & \multirow{4}{*}{$\begin{array}{l}1961 \\
1962\end{array}$} & \multirow{4}{*}{$\begin{array}{l}144.9 \\
139.7^{*}\end{array}$} & \multicolumn{6}{|c|}{ Price index $1947-49=100$} \\
\hline & & & 150.31 & 153.73 & 149.90 & 157.39 & 156.23 & 154.01 \\
\hline & & & 153.40 & 161.25 & 152.68 & 159.24 & 158.45 & 157.31 \\
\hline & & & \multicolumn{6}{|c|}{ Dollars per thousand board feet } \\
\hline \multirow[t]{3}{*}{ Sawlog price $(P 7)}$. & \multirow{3}{*}{$\begin{array}{l}1961 \\
1962\end{array}$} & \multirow{3}{*}{$\begin{array}{l}57.50 \\
57.41\end{array}$} & 59.76 & $\ldots$ & 57.04 & 59.72 & $\ldots$ & 61.11 \\
\hline & & & 64.11 & $\ldots$. & 61.18 & 59.70 & $\ldots$ & 62.87 \\
\hline & & & & & rs per th & and boa & & \\
\hline \multirow[t]{3}{*}{ Pulpwood price $(P 8)$. } & \multirow{3}{*}{$\begin{array}{l}1961 \\
1962\end{array}$} & \multirow{3}{*}{$\begin{array}{l}23.20 \\
23.05\end{array}$} & 24.36 & $\ldots$ & 24.23 & 23.36 & $\ldots$ & 24.19 \\
\hline & & & 24.96 & $\ldots$ & 24.92 & 23.98 & $\ldots$ & 24.74 \\
\hline & & & & & rs per th & and boa & & \\
\hline \multirow[t]{3}{*}{ Peeler log price $(P 9) .}$. & \multirow{3}{*}{$\begin{array}{l}1961 \\
1962\end{array}$} & \multirow{3}{*}{$\begin{array}{l}94.90 \\
95.01\end{array}$} & 98.55 & $\cdots$ & 96.11 & 100.53 & $\ldots$ & 108.82 \\
\hline & & & 102.21 & $\cdots$ & 98.78 & 98.30 & $\ldots$ & 111.89 \\
\hline & & & \multicolumn{6}{|c|}{ Dollars per thousand board feet } \\
\hline \multirow[t]{2}{*}{ Softwood stumpage price $(P 10)$} & 1961 & 21.40 & 27.90 & $\ldots$ & 25.76 & 25.13 & $\ldots$ & 32.45 \\
\hline & 1962 & 21.67 & 30.11 & .. & 29.30 & 22.98 & .. & 33.04 \\
\hline
\end{tabular}

* Preliminary figure.

$\dagger \mathrm{CRF}=$ complete reduced form; $\mathrm{SS}=$ solved structural; $\mathrm{ERF}=$ exogenous reduced form.

of all variables predicted. Futhermore, the ERF unconditional predictions showed correct turning points in all instances where wood product prices and consumption levels were considered, and in 90 per cent of the instances for all variables predicted. Only when conditional predictions were subjected to turning point analysis did the more comprehensive methods of prediction show improvement, with the CRF method making the fewest errors of the second kind where all variables were concerned, and the SS method making the fewest errors of the first kind in the case of wood product predictions. Over-all, however, the ERF method appeared somewhat better, although it should be recognized that an analysis based on so few turning points can give little more than a rough comparison. Furthermore, a turning point analysis disregards how precisely movements are predicted and gives no credit to the method that almost predicts turning points without actually doing so.

\section{Inequality Coefficients}

To find a more powerful means of assessing the relative success of the different types of predictions the inequality coefficient devised by Theil (1960) was computed for each set of predictions Theil defines it as

$$
U=\frac{\left[\frac{1}{n} \sum_{i}\left(F_{i}-A_{i}\right)^{2}\right]^{\frac{1}{2}}}{\left[\frac{1}{n} \sum_{i} F_{i}^{2}\right]^{\frac{1}{2}}+\left[\frac{1}{n} \sum_{i} A_{i}{ }^{2}\right]^{\frac{1}{2}}}
$$


TABLE 18

TURNING POINTS

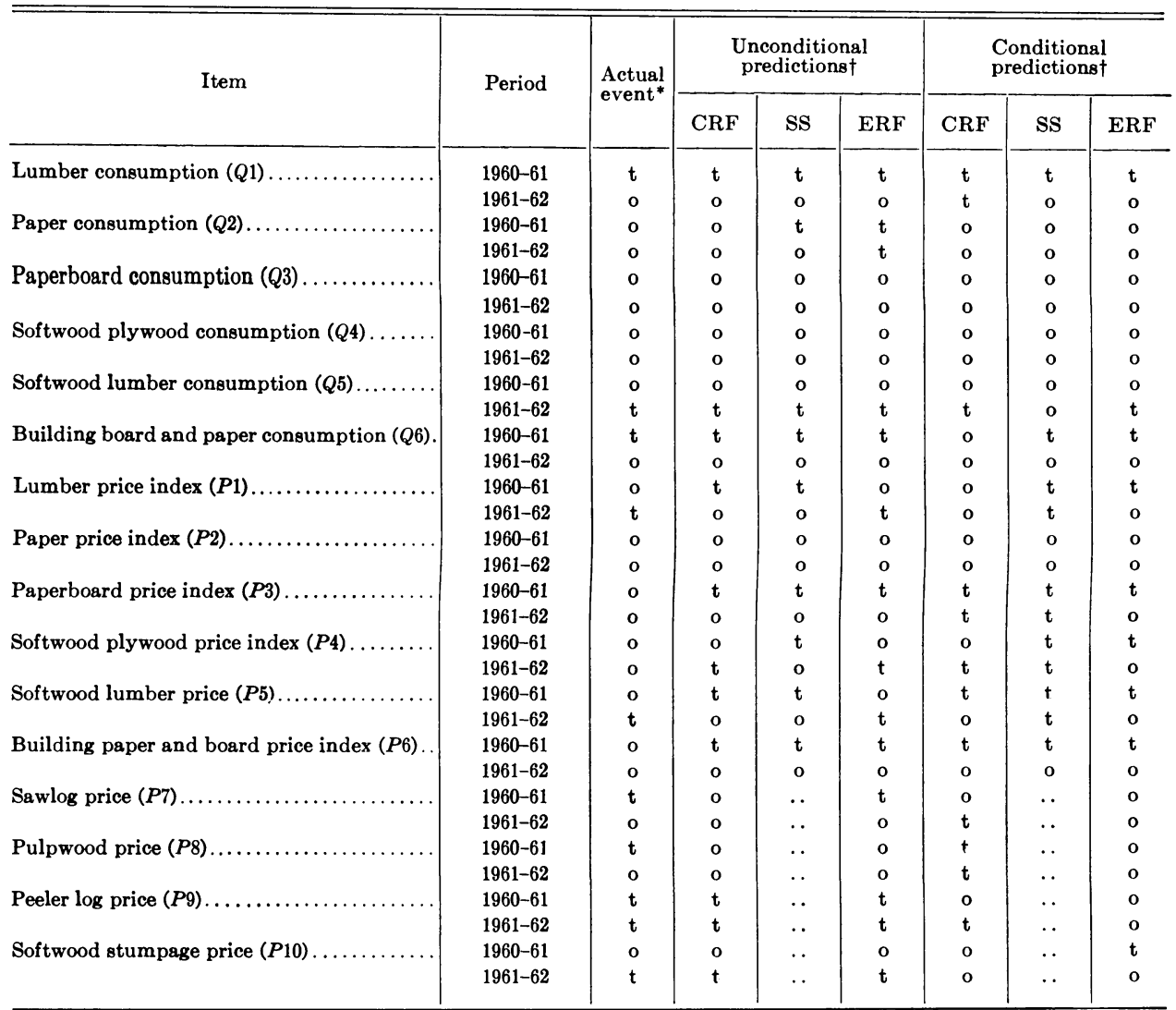

* $t$ denotes the existence of a turning point; o indicates no change.

† $\mathrm{CRF}=$ complete reduced form; $\mathrm{SS}=$ solved structural; $\mathrm{ERF}=$ exogenous reduced form.

TABLE 19

TURNING POINT ERRORS

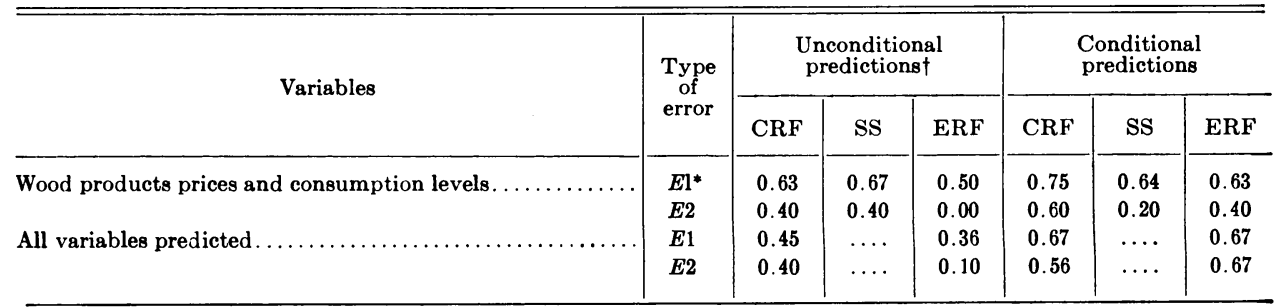

* $E 1=$ fraction of predicted turning points that were wrong;

$E 2=$ fraction of actual turning points not predicted.

$+\mathrm{CRF}=$ complete reduced form; $\mathrm{SS}=$ solved structural: $\mathrm{ERF}=$ exogenous reduced form. 
where

$$
\begin{aligned}
F_{i}= & \text { forecasted value in period } i \text { of } \\
& \text { the variable being predicted, } \\
& i=1 \ldots n \\
A_{i}= & \text { actual value in period } i \text { of the } \\
& \text { variable being predicted. }
\end{aligned}
$$

Theil shows that the inequality coefficient varies from zero to 1 , with zero indicating perfect forecasting and 1 indicating poor forecasting. He points out that it is considerably superior to the product moment correlation coeffic $\mathrm{nt}$ which merely indicates linearity of relationship. Also, it appears superior to measures employing absolute values of deviations, as it favors the more consistent methods.

Table 20 gives values of inequality coefficients. The ERF method was better in the case of unconditional predictions, with the lowest values in nine out of twelve cases for wood products and thirteen out of sixteen cases where all products were concerned. The CRF and the SS methods appeared to be little different from each other. Where con- ditional predictions were concerned little difference was apparent between the two latter methods, but the ERF method appeared to be considerably poorer than either one, with eight out of twelve values highest in the case of wood products and twelve out of sixteen highest for all products.

\section{Plausibility Criteria}

As Theil points out, an assessment of the quality of forecasts cannot be made on the basis of statistical criteria alone, and the plausibility of predictions was given particular attention as a means of comparing prediction methods. Indiscriminate use of such a highly subjective criterion as plausibility could be dangerous, for as Keynes (1936) said ". . . the facts of the existing situation enter, in a sense disproportionately, into the formation of our long term expectations." As Theil also says, changes are generally underestimated because social pressure on forecasters prevents them predicting very large changes. However, certain predictions in this study appeared to be

TABLE 20

INEQUALITY COEFFICIENTS

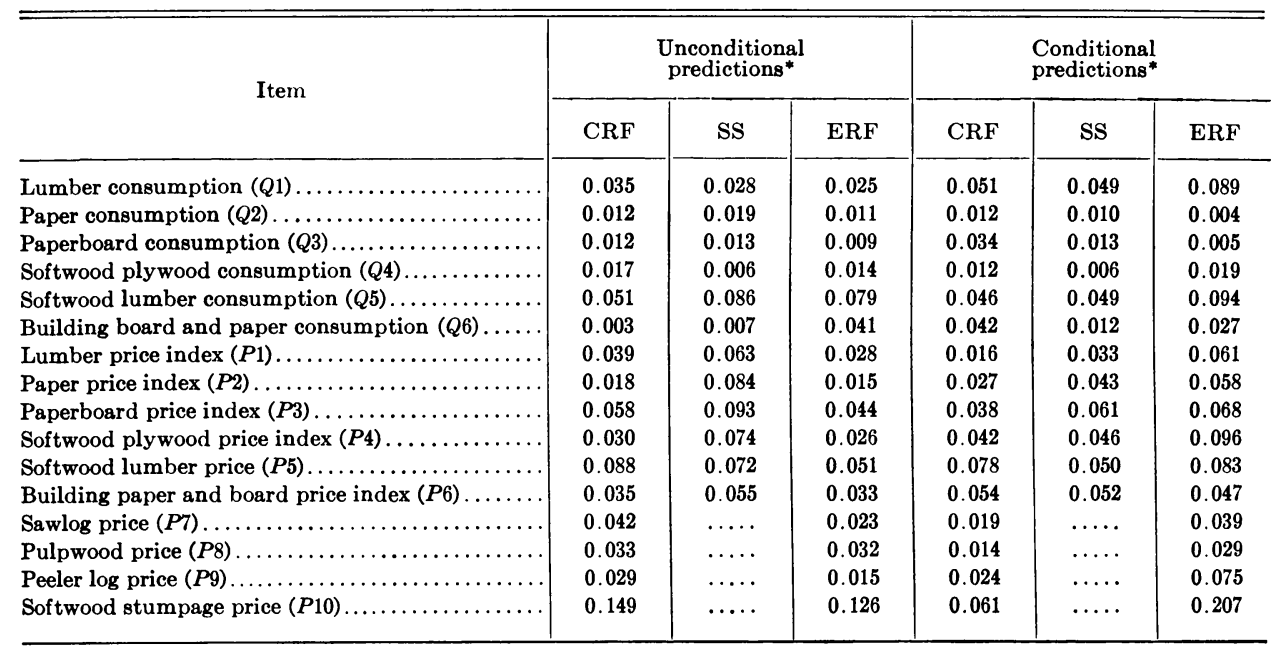

${ }^{*} \mathrm{CRF}=$ complete reduced form; $\mathrm{SS}=$ solved structural; $\mathrm{ERF}=$ exogenous reduced form. 
TABLE 21

ADJUSTED FORECASTS FOR 1965, 1970, AND 1975*

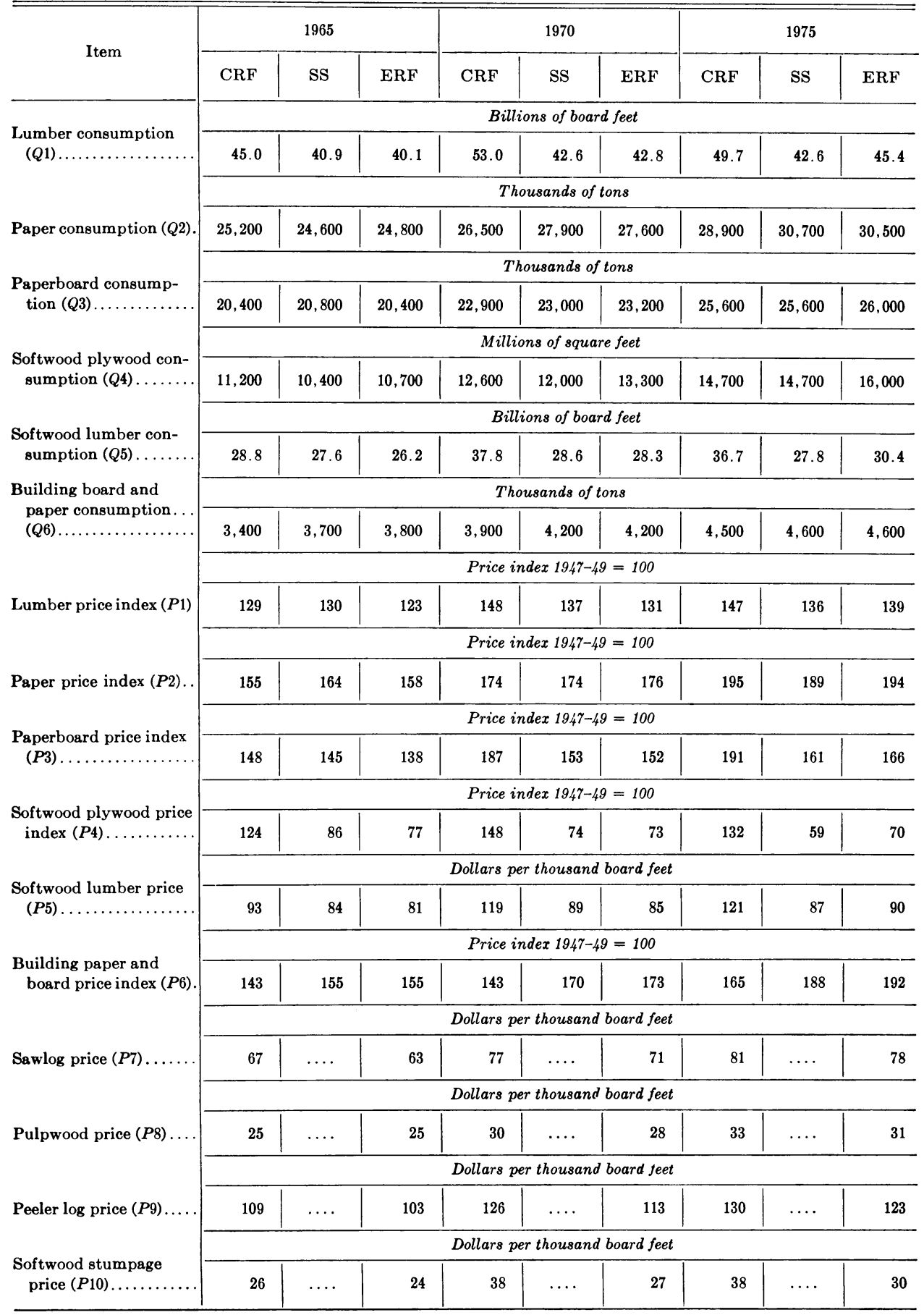

* $\mathrm{CRF}=$ complete reduced form; $\mathrm{SS}=$ solved structural; $\mathrm{ERF}=$ exogenous reduced form. 
somewhat less plausible than others. In particular the solved structural forecasts for the price of softwood plywood (P4) appeared to be unrealistic, with the index of price in 1975 estimated to be only 64 as compared to the actual 1962 value of 79 . The ERF forecasts also indicated a decline, and only the CRF method predicted that a price increase would take place. Since 1950 the softwood plywood price index has been declining steadily (Appendix E), but it should be noted that predictions are made in terms of undeflated values and that the costs of labor and peeler logstwo of the most important inputs in plywood manufacture - have been rising markedly in recent years and should continue to rise throughout the forecast period. Preliminary reports (U. S. Forest Service, 1964b) indicate that in 1963 the softwood plywood price showed a slight increase over the 1962 level. It was thought that the SS method yielded better predictions in the case of lumber consumption. The reduced form methods yielded predictions in excess of 54 billion board feet for 1975, but the SS method forecasted a figure of less than 47 billion. In 1962 the actual level of consumption was 38 billion, a decline of several billion from the postwar high of 41 billion board feet.

It was clear that certain influences (notably inflation) could lead to marked increase in prices, but in the case of lumber consumption no such influences were apparent.

\section{Adjustment of Forecasts}

In several of the sets of predictions there was a tendency to overestimate actual values for the test years. Variables particularly affected in this respect were the prices of all the products dealt with, and the consumption levels of all lumber and softwood lumber. The effects of this were evident in the sharp and unrealistic differences between actual values for 1962 and predicted values for 1963, and it appeared that the overestimation might seriously reduce the realism of the forecasts presented in previous sections. To avoid this defect a procedure utilizing predicted and actual values for the test years was adopted to give adjusted forecasts for selected years. A preliminary step was the computation of ratios of predicted magnitudes of variables in the selected years to the average of their conditional predictions for 1961 and 1962. Table 21 gives these relative magnitudes. These ratios were subsequently multiplied by the averages of actual values of variables in 1961 and 1962 to yield the adjusted forecasts. Table 21 shows the set of adjusted forecasts. The adjustment procedure may be represented as

$$
Z_{t}=\hat{Y}_{t}\left(\frac{1}{2} Y_{1}+\frac{1}{2} Y_{2}\right) /\left(\frac{1}{2} \hat{Y}_{1}+\frac{1}{2} \hat{Y}_{2}\right)
$$
where

$Z_{t}=$ adjusted forecast for year $t$

$\hat{Y}_{t}=$ unadjusted forecast for year $t$

$\hat{Y}_{1}=$ unadjusted forecast for 1961

$\hat{Y}_{2}=$ unadjusted forecast for 1962

$Y_{1}=$ actual value for 1961

$Y_{2}=$ actual value for 1962

Table 22 gives an indication of forecasted changes in relation to the 1961-62 base period, and also offers means by which crude forecasts can be made for products whose prices and consumption levels are closely related to the variables dealt with in this study. With regard to the adjusted forecasts it will be observed that the different methods of prediction agree well in most cases. Notably dissident predictions are the CRF predic- 
tions of $Q 1$ and $P 4$ for 1965, of $Q 1, Q 5$, $P 3, P 4, P 5$ and $P 6$ for 1970 and P3, P4 and $P 5$ for 1975 . The fact that little dis- agreement is evident between SS and ERF predictions speaks favorably for these methods.

\section{Remarks}

A number of rival predictions have been presented, with unadjusted predictions vying with adjusted ones and different methods of prediction competing among themselves. Each set of predictions has some advantage not possessed by others, and no incontrovertible statement can be made as to which is preferable. However, it is suggested that, in general, the adjusted predictions may be regarded as superior to the ones obtained directly from the predicting equations as they may not have the tendency to overestimate that unadjusted ones appear to have. With regard to the different methods of forecasting, it is suggested that the solved structural predictions be preferred for all wood product prices and consumption levels except for the price of softwood plywood (P4). The ability of the solved structural method to utilize more information than the other methods is a major advantage. With regard to softwood plywood price it is suggested that the CRF predictions be preferred, for the reasons given earlier. In the case of primary product prices, for which solved structural estimates are not available, the basis for choosing between the exogenous reduced-form predictions and the complete reduced-form ones is less firm. In favor of the ERF method are the facts that its unconditional predictions were more accurate for the test years, and that in general the estimates it produces are closer to SS ones than are the complete reducedform predictions. In favor of the CRF

TABLE 22

RELATIVE MAGNITUDES OF FORECASTS*

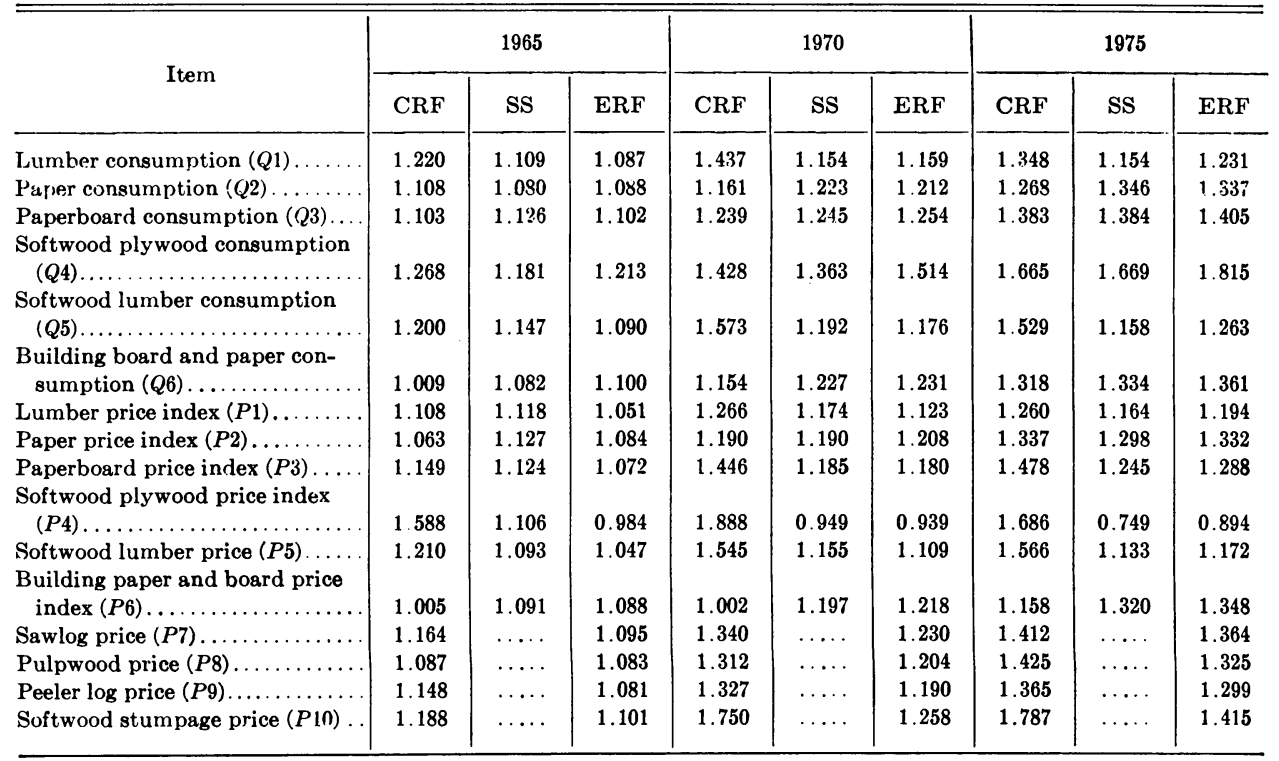

${ }^{*} \mathrm{CRF}=$ complete reduced form; $\mathrm{SS}=$ solved structural; $\mathrm{ERF}=$ exogenous reduced form. 
method are the facts that it showed up better with regard to conditional forecasts for the test years and that it was based on a more complete economic model.

Table 23 gives the adjusted solved structural estimates of consumption for the years 1970 and 1975, together with actual values for 1950 and 1960 and alternative forecasts produced by other investigations. The magnitudes of these alternative forecasts expressed as a percentage of corresponding estimates made in this study are shown in parentheses.
It will be observed that of the thirty-six alternative forecasts shown just over half are within 10 per cent of the estimates produced by this study. It should be noted that all but one of the Forest Service estimates (C. S. Forest Service, 1965) are within 10 per cent of those of this study. Forest Service estimates are higher for all products except lumber, for which the estimate is 7 per cent lower. However, a preliminary estimate (U. S. Forest Service, 1964b) indicates that lumber consumption in 1964 was 41.3 billion board feet or 1.6 billion feet

T.ABLE 23

COMPARISON ()F FORECASTS ()F CONSUMPTION

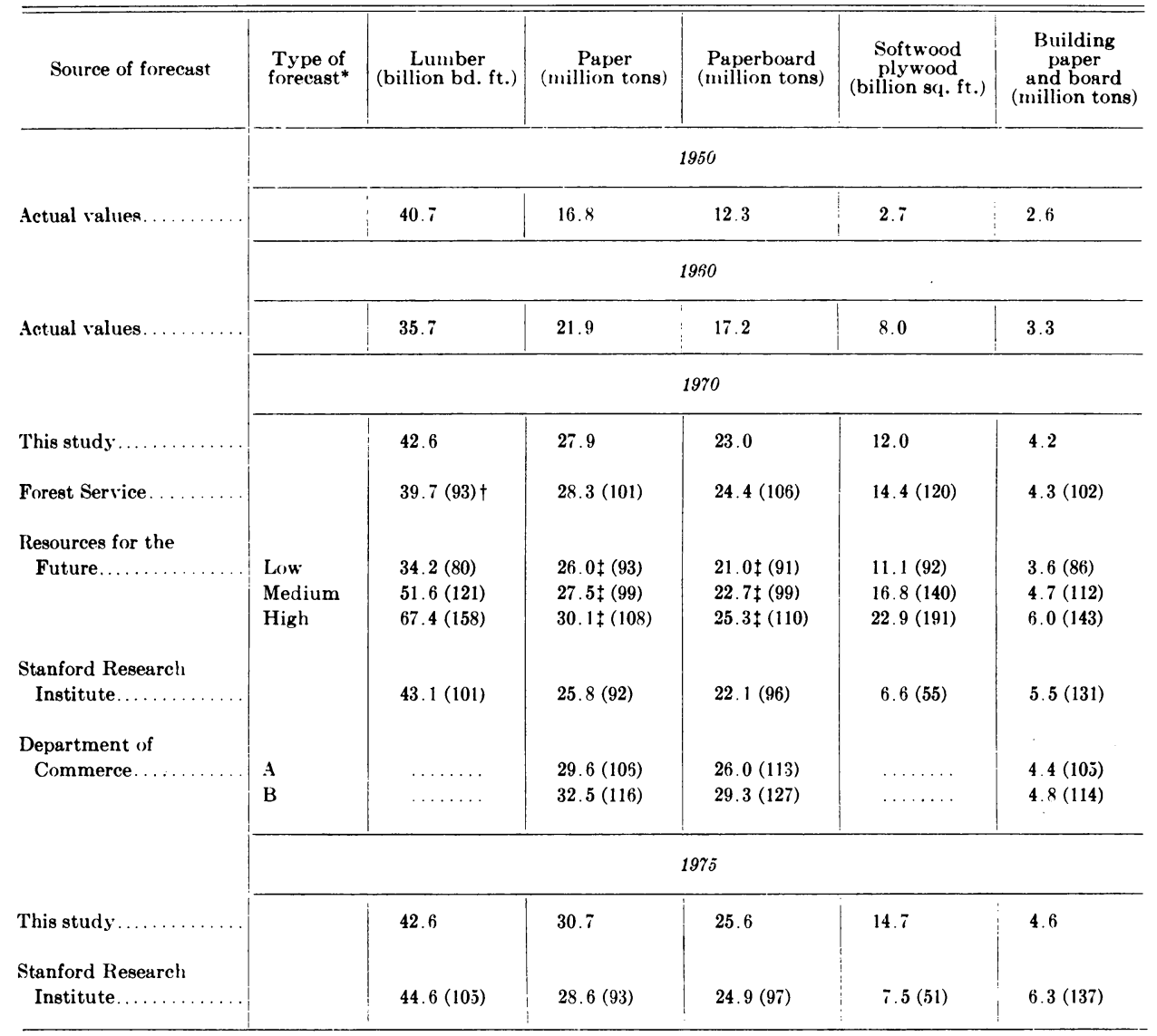

* The low, medium and high forecasts prepared by Resources for the Future, Inc. and the $\mathbf{A}$ and $\mathrm{B}$ forecasts of the Department of Commerce represent outcomes of alternative basic assumptions underlying their projection techniques. $\dagger$ Figures in parentheses indicate the magnitudes of alternative forecasts as a percentage of estimates made in this study. $\ddagger$ Excluding building paper and board. 
greater than the Forest Service estimate for 1970. Only in the case of softwood plywood was a Forest Service estimate markedly different. In a review draft of its publication (U. S. Forest Service, $1964 b$ ) the forecast of softwood plywood consumption in 1970 was 12.9 billion square feet, only 7 per cent greater than the forecast made in this study.

Only six out of fifteen of the Resources for the Future predictions (Landsberg et al., 1963) are within 10 per cent of those in this study, and while their medium projections for paper and paperboard are in close agreement their other forecasts, especially their high projections, are generally quite different. Stanford Research Institute (1954) projections for lumber, paper and paperboard agree reasonably well with the results of this study, but their estimates for softwood plywood and building paper and board do not. Their softwood plywood estimate is clearly erroneous, being less than the actual 1960 value. Finally, it should be mentioned with regard to the projections of the Department of Commerce (1963) that all but the "A" paper and building paper and board estimates were somewhat different than those produced by the present investigation.

While forecasts of price are not available for comparison, it is interesting to note some of the assumptions and anticipations with regard to price that are referred to in these other studies. The Forest Service assumed that ". . . future price trends for timber products between 1962 and 2000 will not differ significantly from price trends for competing materials." The Stanford Research Institute anticipated that the prices of lumber and plywood would rise relative to the prices of competing materials, but that prices of wood pulp products would not. In the Resources for the Future study it was expected that lumber prices would experience a relative upward movement. The Department of Commerce made no explicit assumptions with regard to price but stated that it was anticipated that the pulp and paper industry would continue ". . . to meet competition for present and future markets."

Table 21 gives an indication of relative price movements for wood products predicted by this study. With regard to solved structural forecasts for 1975 it may be seen that the largest movements are predicted for pulp and paper products, especially building paper and board. But for lumber relatively modest increases of 16 per cent in the case of all lumber and 13 per cent in the case of sof twood lumber relative to the 1961-62 average are predicted. For competitive non-wood materials projections of prices for wallboard, structural clay products and structural steel had to be made in the course of preparing forecasts for wood products. These projections suggested that fairly substantial price increases would take place in the case of clay products and structural steel, with 1975 price levels some 50 per cent greater than the 1961-62 averages; for wallboard prices, an increase of only 41 per cent was indicated. The procedure used to obtain these latter projections was of necessity elementary and thus it is advisable that they be regarded with caution. 


\section{CONCLUSION}

\section{Validity of Premises}

The premises serving as a basis for the present study were that an aggregate supply or demand relationship could be adequately represented by a linear function (plus a stochastic term), and that errors of measurement in variables would not appreciably impair the quality of the results. The subject for debate about the linearity premise should probably not be whether such relationships can be represented by mathematical functions, because on the one hand such functions can be made exceedingly complex and comprehensive and on the other, provision can be made for non-measurable or unknown influences by the introduction of an unobserved random term. The question is rather whether stochasticized linear functions were adequate representations of true (perhaps complex) functions. In the case of the errors of measurement premise the argument should not be whether such errors were present but whether their presence was a serious defect. As to whether or not the premises were valid, no direct answer can be given, but certain results of the study furnish strong evidence substantiating their validity. First, past phenomena (prices and consumption levels) were well explained by the estimated structural and reduced form equations. In no instance was a value less than 0.95 obtained for the square of a multiple correlation coefficient, and usually it was greater than 0.99. In some studies, as Theil (1960) suggests, high values of $R^{2}$ are perhaps no more than a tribute to the tenacity of the investigator. In this study no regard was paid to values of this statistic in modifying preliminary models. In any event, preliminary regressions showed similarly high values for $R^{2}$.

Secondly, and as Klein (1956) puts it, ". . . the real test of the validity and usefulness of any theory is its ability to predict." Estimated structural equations may be regarded as theories as to how people behave and how prices and consumption levels are generated. The results of the study with regard to forecasting indicate that these theories and their associated premises stood up well under test.

\section{Improving Estimates}

Errors of measurement in time-series data, and the fact that available statistical techniques can yield only consistent estimates, are major potential sources of inaccuracy in estimates of coefficients and future phenomena. The presence of structural change is another potential source of inaccuracy and can be a distinct handicap in long-range forecasting. The individual investigator can in general do little about the first two sources of error, but he has at his disposal a means of dealing with the third one.
Experience indicates that if structural change is taking place in the relationships estimated in this study, it is occurring slowly and in a systematic manner. This offers hope that it can be detected, if it does exist, by dropping early years from the sample period as data for later years become available. The detection of statistically significant change would of course require that data for a number of additional years be available. A procedure of re-estimating relationships also holds considerable prom- 
ise for improving forecasts as it may be repeated a number of times and an effort made to "map" movement in the magnitudes of coefficients and prepare estimates of these magnitudes for the latter years of the projection period or even beyond.

Another source of error in predicting was errors in forecasts of exogenous variables. This is also a defect that can be eliminated as data for additional years become available and permit recent trends to be taken into account.

It is anticipated that an updating procedure employing both revisions of coefficients and revisions of forecasts of exogenous variables will result in considerably better estimates of future prices and consumption levels.

\section{Extensions of the Study}

The scope of the study was broad, and restrictions on time and effort made it impossible to dig deep into any particular aspect. As a result, numerous lines of potential future investigation are clearly evident. Especially so are "in depth" studies of particular industries. An unfortunate restriction of available statistical techniques in the present study was the need to consider the lumber, plywood and pulp and paper industries simultaneously, and consequently time was not available for close scrutiny of the workings of any one industry. However, the least squares estimates of prices obtained in the first round of the two stage process in this study make it feasible to single out functions for a particular industry and apply least squares directly to them, since these first round estimates of values of endogenous variables may be used as observations on regressor variables rather than raw data. In particular, the role of investment on supply should be a subject for further investigation. In the present study a labor productivity variable and a dummy variable were used in an attempt to capture the influence of changing levels of plant and equipment on supply. It was suggested that an increase in the use of fixed inputs vis-àvis variable inputs would act as a positive supply shifter. Clarification of the role of such influences, and expansion of the system to take explicit account of them, would result in significant improvement in the specification of supply relationships. However, such study would require much effort to study producer motivation and to collect data not available in print.

The study dealt primarily with broad product categories, although an effort was made to deal with finer categories as in the case of softwood lumber and building paper and board. It is felt that estimation of supply and demand for various subcategories of products would be a valuable extension of the study. Commodities that might be investigated in this way are individual types of softwood lumber and the more important categories of paper, such as newsprint, other printing papers, and coarse papers. Each of the product categories dealt with in this investigation, particularly all lumber, paper and paperboard, is quite heterogeneous, and studies dealing with more homogeneous commodities would provide more meaningful and useful results.

In the introductory chapter, mention was made of the rapidly increasing imports of softwood lumber from Canada. It was noted that estimates of supply and demand elasticities obtained in this study would be valuable tools in analyz- 
ing the effects of the various means suggested for curbing such imports. Complete solution of the problem requires, however, an estimate of the elasticity of Canadian supply to United States markets. Estimation of this elasticity is a potentially rewarding though difficult line of investigation.

Another useful extension would be an intensive empirical examination of forecating techniques. The techniques used in this study were chosen largely on theoretical grounds and it is possible that modifications of them may yield more accurate forecasts. Suitable modifications can be selected by a trial and error process in which forecasts are made for a substantial number of years and compared with values that actually prevailed. Investigations in this area have already been initiated by the author. Numerous other lines of investigation could be suggested, but lack of data is a major obstacle in their pursuit. Statistical study of virtually all economic problems relating to U. S. forest industries is much handicapped by this lack of data, and it is perhaps a fitting conclusion to plead for more and better quantitative information concerning these industries. Data on prices, inventories, and rates and levels of investment are most sorely needed. The econometrician is not alone in his need for more and better data but special heed might be given to his case, for an econometric investigation is not an end in itself but rather a process by which data are transformed into useful tools for the attacking and solving of problems. 


\section{LITERATURE CITED}

Aluen, R. G. D.

1956. Mathematical economics. New York: The Macmillan Company.

ARrow, K. J. and M. HofFEnBerg

1959. A time series analysis of inter-industry demands. Amsterdam: North Holland Publishing Company.

BASMANN, R. L.

1957. A generalized classical method of linear estimation of coefficients in a structural equation. Econometrica, Vol. 25, No. 1.

1958. An experimental investigation of some small sample properties of GCL estimators of structural equations: some preliminary results. Richland, Washington: General Electric Company.

Board of Governors of Federal Reserve System

1962. Washington: Federal Reserve Bulletin, September, 1962.

Boles, J. N.

1961. Stepwise matrix inversion and stepwise regression analysis. Berkeley: Department of Agricultural Economics, University of California.

1964. 80-series linear multiple regression system. 1620 general program library, I. B. M.

Brown, N. C.

1947. Lumber. New York: John Wiley and Sons, Inc.

Cramer, H.

1946. Mathematical methods of statistics. Princeton: Princeton University Press.

Goldberger, A. S.

1964. Econometric theory. New York: John Wiley and Sons, Inc.

GrEGORY, G. R.

1960. A statistical investigation of factors affecting the market for hardwood flooring. Forest Science, Vol. 6, No. 2.

Guthrie, J. A.

1950. The economics of pulp and paper. Pullman: State College of Washington Press.

Guthrie, J. A. and G. R. Armstrong

1961. Western forest industry. Resources for the Future, Inc. Baltimore: Johns Hopkins Press.

Holland, I. I.

1955. Some factors affecting the consumption of lumber in the United States with emphasis on demand. Unpublished Ph.D. thesis, University of California.

1960a. An explanation of changing lumber consumption and price. Forest Science, Vol. 6, No. 2. 1960b. A suggested technique for estimating the future price of Eastern white pine stumpage. Forest Science, Vol. 6, No. 4.

Hood, W. C. and T. C. Koopmans (Editors)

1953. Studies in econometric method. Cowles Commission Monograph No. 14, New York: John Wiley and Sons, Inc.

Johnson, J.

1963. Econometric methods. New York: McGraw-Hill Book Company.

KeYNES, J. M.

1936. The general theory of employment, interest and money. New York: Harcourt, Brace and Company.

KLein, L. R.

1956. A textbook of econometrics. New York: Row, Peterson and Company.

Landsberg, H. H., L. L. Fischman, and J. L. Fisher

1963. Resources in America's future. Resources for the Future, Inc. Baltimore: Johns Hopkins Press. 
Larson, H. J. and T. A. BANCrofT

1963. Sequential model building for prediction in regression analysis I. Annals of Math. Stat., Vol. 34, No. 2.

Makino, S.

1960. A ten year forecast for imported hardwood plywood. Oregon Business Review, University of Oregon.

Mood, A. M.

1950. Introduction to the theory of statistics. New York: McGraw-Hill Book Company.

NAGAR, A. L.

1960. A Monte Carlo study of alternative simultaneous equation estimators. Econometrica, Vol. 28, No. 3.

National Planning Association

1962. "Projections to the years 1976 and 2000 . . "Washington, D.C.: Report to the O.R.R.R.C., No. 23.

Pfouts, R. W. (Editor)

1960. Essays in economics and econometrics. Chapel Hill: University of North Carolina Press.

Shames, L. M.

1946. A forecast of lumber demand. Journal of Forestry, Vol. 44, No. 7.

Simpson, R. S.

1963. An econometric analysis of demand and supply relationships in the Douglas-fi plywood industry. M.S. thesis, Oregon State University.

Simpson, R. S. and A. N. Halter

1963. Forecasting prices, production and new orders in the Douglas fir plywood industry. Special report 165, Agricultural Experiment Station. Corvallis: Oregon State University.

Stanford Research Institute

1954. America's demand for wood. Stanford: A report to the Weyerhaeuser Timber Company.

TheIL, H.

1960. Economic forecasts and policy. Amsterdam: North Holland Publishing Company.

U. S. Bureau of the Census

1964. "Projections of the population of the United States . . ." Current population reports, Series P25, No. 286. Washington, D.C.

U. S. Congress

1957a. Pulp, paper and board supply-demand. Report of Committee on Interstate and Foreign Commerce, 85th Congress, 1st Session, House Report 573, Washington, D.C.

1957b. Concentration in American industry. Senate Judiciary Committee. Senate Resolution 57. Washington, D.C.

1958. Pulp, paper, and board supply-demand-newsprint outlook. 85th Congress, 2nd Session, House Report 736, Washington, D.C.

1959. Pulp, paper and board supply-demand-newsprint outlook, 1959. 86th Congress, 1st Session, House Report 671, Washington, D.C.

1963. Pulp, paper and board supply and demand. 88th Congress, 1st Session. House Report 693, Washington, D.C.

U. S. Department of Commerce

1957. Business and Defense Services Administration. Technical guide to pulp, paper and board supply-demand. Washington, D.C.

1962a. Business and Defense Services Administration. "Impact of imported Canadian lumber on the United States lumber industry." Washington, D.C.

1962b. Business and Defense Services Administration. Statement on the lumber problem. Washington, D.C.

1961. Office of Business Economics. Business statistics-a supplement to the Survey of Current Business. Washington, D.C. 


\section{U. S. Forest Service}

1958. Timber resources for America's future. U. S. Department of Agriculture, Forest Resource Report No. 14, Washington,D.C.

1963. The demand and price situation for forest products, 1963. U. S. Department of Agriculture, Misc. Pub. 953. Washington, D.C.

1964a. Timber trends in the United States. Review draft, Washington, D.C.

1964b. The demand and price situation for forest products, 1964. U. S. Department of Agriculture, Misc. Pub. 983. Washington, D.C.

1965. Timber trends in the United States. U. S. Department of Agriculture. Forest Resource Report No. 17. Washington, D.C.

\section{U. S. TARIFF Commission}

1963. Softwood lumber. T. C. Publication 79, Washington, D.C.

Western Lumber Manufacturers, Inc.

1958. Development of WLM's index of operating cost. Mimeo 121, January 15, 1958.

ZAREMBA, J.

1963. Economics of the American lumber industry. New York: Robert Speller and Sons.

Zivnuska, J. A.

1955 Supply, demand and the lumber market. Journal of Forestry, Vol. 3, No. 8. 


\section{APPENDIX A}

\section{SECTORS OF DEMAND AND SUPPLY FOR WOOD PRODUCTS}

\section{End-uses of Wood Products in the U. S.*}

Stanford Research Institute estimates for 1952

\begin{tabular}{|c|c|c|c|}
\hline Product & End-use & $\begin{array}{l}\text { Per cent } \\
\text { of end- } \\
\text { uset }\end{array}$ & $\begin{array}{c}\text { Per cent } \\
\text { of product } \\
\text { usef }\end{array}$ \\
\hline \multirow[t]{14}{*}{ Lumber } & Construction & & \\
\hline & Residential. & 51 & . \\
\hline & Non-residential. & 26 & .. \\
\hline & Maintenance and repair... & 23 & . \\
\hline & All construction.................... & . & 72 \\
\hline & Shipping & & \\
\hline & Boxes and crates........ & 64 & . \\
\hline & Pallets. . & 13 & .. \\
\hline & Dunnage. . & 23 & . \\
\hline & All shipping...... & .. & 16 \\
\hline & Manufactures & & \\
\hline & 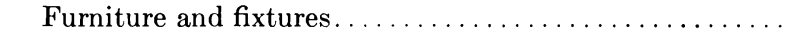 & 45 & .. \\
\hline & 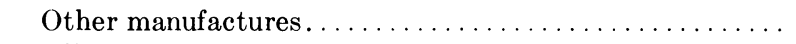 & 55 & .. \\
\hline & All manufactures.... & .. & 12 \\
\hline \multirow[t]{6}{*}{ Paper } & Newsprint............. & .. & 36 \\
\hline & Book and other printing. & . & 20 \\
\hline & Coarse $\ldots \ldots \ldots \ldots \ldots \ldots \ldots \ldots \ldots$ & .. & 18 \\
\hline & Tissue & .. & 11 \\
\hline & 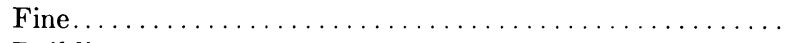 & . & 7 \\
\hline & $\ldots \ldots \ldots \ldots \ldots \ldots \ldots \ldots \ldots \ldots$, & .. & 8 \\
\hline \multirow{3}{*}{ Paperboard } & Container board. & .. & 46 \\
\hline & Boxboard...... & .. & 43 \\
\hline & Building board $\ldots \ldots \ldots \ldots \ldots \ldots \ldots \ldots$ & .. & 11 \\
\hline \multirow{11}{*}{$\begin{array}{l}\text { Plywood and } \\
\text { veneer }\end{array}$} & Construction & & \\
\hline & $\ldots \ldots \ldots \ldots \ldots \ldots \ldots \ldots \ldots \ldots$ & 68 & . \\
\hline & Non-residential $\ldots \ldots \ldots \ldots \ldots \ldots \ldots \ldots \ldots$ & 7 & .. \\
\hline & Maintenance and repair. & 25 & .. \\
\hline & All construction...................... & .. & 50 \\
\hline & Shipping & & \\
\hline & Plywood containers. & 25 & .. \\
\hline & 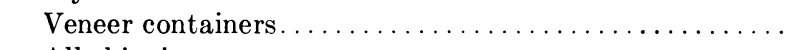 & 75 & . \\
\hline & All shipping..... & .. & 33 \\
\hline & Manufactures & & \\
\hline & All manufactures.. & .. & 17 \\
\hline
\end{tabular}

(Table continued next page) 
U. S. Forest Service estimates, 1952-1962

\begin{tabular}{|c|c|c|c|c|c|}
\hline Product & End-use & $\begin{array}{c}\text { Per cent } \\
\text { of end- } \\
\text { uset }\end{array}$ & $\begin{array}{c}952 \text { Per cent } \\
\text { of product } \\
\text { use }\end{array}$ & $\begin{array}{c}\text { Per cent } \\
\text { of end- } \\
\text { uset }\end{array}$ & $\begin{array}{c}962 \\
\text { Per cent } \\
\text { of product } \\
\text { usef }\end{array}$ \\
\hline \multirow[t]{8}{*}{ Lumber } & Construction & & & & \\
\hline & Residential. & 41 & .. & 50 & .. \\
\hline & Non-residential. & 17 & .. & 18 & .. \\
\hline & Maintenance and repair.......... & 18 & . & 19 & . \\
\hline & Other. $\ldots \ldots \ldots \ldots \ldots \ldots \ldots \ldots$ & 23 & .. & 12 & . \\
\hline & All construction... & . & 76 & . & 74 \\
\hline & Shipping. . & .. & 15 & .. & 12 \\
\hline & Manufactures and miscellaneous..... & .. & 10 & .. & 14 \\
\hline \multirow[t]{5}{*}{ Paper } & Newsprint and ground wood $\ldots \ldots \ldots$ & .. & 40 & .. & 36 \\
\hline & Book, fine and absorbent. . & .. & 24 & .. & 26 \\
\hline & Coarse and industrial $\ldots \ldots \ldots \ldots \ldots$ & . & 21 & .. & 22 \\
\hline & Tissue and sanitary .............. & .. & 8 & .. & 10 \\
\hline & Building.................... & .. & 8 & .. & 6 \\
\hline \multirow[t]{4}{*}{ Paperboard } & Container board. . & .. & 47 & .. & 50 \\
\hline & Bending board.... & .. & 26 & .. & 26 \\
\hline & Building board.. & .. & 11 & .. & 11 \\
\hline & Other.......... & .. & 17 & .. & 14 \\
\hline \multirow{2}{*}{$\begin{array}{l}\text { Softwood } \\
\text { plywood } \\
\text { and veneer }\end{array}$} & Construction ................... & . & $76 \S$ & .. & 73 \\
\hline & Other. . & . & $24 \S$ & .. & 27 \\
\hline
\end{tabular}

* Basic lumber consumption data in board feet; paper and paperboard data in tons; plywood data in square feet 3/8" equivalent).

t Percentage of end-use consumption accounted for by subcategories.

Percentage of total product consumption accounted for by end-uses.

Based on 1955 data.
Sources: Stanford Research Institute, "America's demand for wood." Stanford, California, 1954. U. S. Forest Service. 1952 data from Timber Resources for America's Future, Wash., D.C., 1958; 1962 data from Timber Trends in the United States, review draft, Wash., D. C., 1964. 


\section{U. S. Imports and Exports of Wood Products}

Percentages of consumption for selected years*

\begin{tabular}{|c|c|c|c|c|}
\hline & 1929 & 1940 & 1950 & 1960 \\
\hline \multicolumn{5}{|l|}{ Lumber: } \\
\hline Imports......... & 4.1 & 2.1 & 8.4 & 11.0 \\
\hline Exports $\ldots \ldots \ldots \ldots \ldots \ldots \ldots \ldots \ldots \ldots \ldots \ldots$ & 8.5 & 2.7 & 1.3 & 2.4 \\
\hline \multicolumn{5}{|l|}{ Paper: } \\
\hline 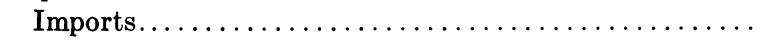 & 29.6 & 28.3 & 32.1 & 27.1 \\
\hline 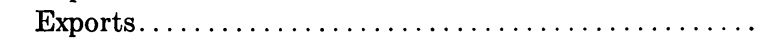 & 2.6 & 3.0 & 1.5 & 2.1 \\
\hline \multicolumn{5}{|l|}{ Paperboard: } \\
\hline 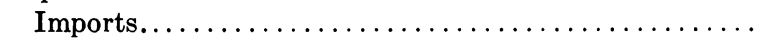 & 0.0 & 0.0 & 0.0 & 0.0 \\
\hline Exports $\ldots \ldots \ldots \ldots \ldots \ldots \ldots \ldots \ldots \ldots \ldots$ & 1.4 & 3.7 & 1.0 & 3.7 \\
\hline \multicolumn{5}{|l|}{ Softwood plywood: } \\
\hline 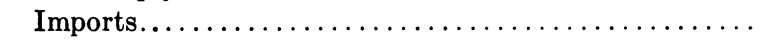 & - & - & 0.0 & 0.1 \\
\hline 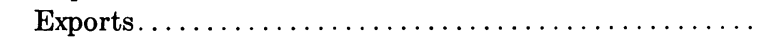 & - & - & 0.1 & 0.2 \\
\hline \multicolumn{5}{|l|}{ Softwood lumber: } \\
\hline 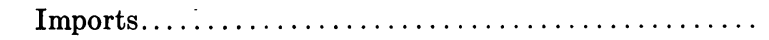 & 3.8 & 1.8 & 7.7 & 10.2 \\
\hline Exports. $\ldots \ldots \ldots \ldots \ldots \ldots \ldots \ldots \ldots \ldots \ldots$ & 7.2 & 2.2 & 1.0 & 1.9 \\
\hline \multicolumn{5}{|l|}{ Building paper and board: } \\
\hline Imports.............. & 3.8 & 1.3 & 1.2 & 3.3 \\
\hline 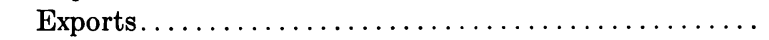 & 5.9 & 4.0 & 1.2 & 1.0 \\
\hline
\end{tabular}

* Basic lumber consumption data in board feet: paper and paperboard data in tons; plywood data in square feet 8/8" equivalent).

Source: Paper, paperboard and building paper and board data from American Paper and Pulp Association, Operating and financial statistics, Special statistical studies No. 1, April 30,1964. Lumber and plywood data from U.S. Forest Service, The demand and price situation for forest products-1963, Wash., D.C., 1963.

\section{U. S. Timber Cut in 1962}

Sawtimber production

Total timber cut

Percentages by species and ownership*

Softwoods Hardwoods All species

\begin{tabular}{|c|c|c|c|}
\hline National Forests..... & 23.4 & 3.9 & 17.8 \\
\hline 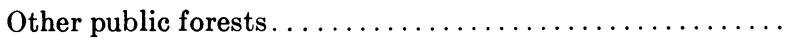 & 8.0 & 4.7 & 7.1 \\
\hline Forest industry $\ldots \ldots \ldots \ldots \ldots \ldots \ldots \ldots \ldots \ldots \ldots$ & 30.2 & 15.8 & 26.1 \\
\hline Farmer and miscellaneous private $\ldots \ldots \ldots \ldots \ldots \ldots$ & 38.4 & 75.6 & 49.0 \\
\hline \multicolumn{4}{|c|}{ Percentages by species and ownership $\dagger$} \\
\hline National Forests. . & 27.8 & 3.6 & 22.1 \\
\hline Other public forests... . & 9.0 & 3.8 & 7.8 \\
\hline 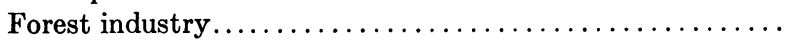 & 33.2 & 15.2 & 28.9 \\
\hline Farmer and miscellaneous private... & 30.0 & 77.4 & 41.2 \\
\hline
\end{tabular}

* Based on cubic foot measure.

$\dagger$ Based on board foot measure, international $1 / 4 "$ rule.
Source: U. S. Forest Service, Timber trends in the United States, Review draft, Washington, D. C., 1964. 


\section{APPENDIX B \\ THEORETICAL RELATIONSHIPS}

\section{Consumer Demand}

Consider a group of $n$ consumers in year $t$ with consumer $j(j=1 \ldots n)$ having a disposable income of $e_{j t}$. The classical function expressing the quantity of a good demanded by consumer $j$ in year $t$ may be written (Allen, 1956) $q_{i j t}^{(d)}=f_{j}\left(p_{1 t} \ldots p_{m t}, e_{j t}\right)$, where $q_{i j t^{(d)}}=$ quantity of good $i$ demanded by consumer $j$ in year $t$ and $p_{k t}=$ price of good $k$ in year $t(k=1 \ldots m)$. This formulation assumes a known utility function invariant over time, known and given prices, and utility maximization. Numerous derivations of aggregate demand functions are possible. One derivation is as follows.

Assume that the $j$ th individual's demand function is of the form

Hence

$$
q_{i j t}^{(d)}=a_{O j}+a_{1 j} p_{1 t} \cdots+a_{m j} p_{m j}+b_{j} e_{j t}
$$

$$
q_{i t}^{(d)}=\sum_{j=1}^{n} a_{O_{j}}+p_{1 t} \sum_{j=1}^{n} a_{1 j} \cdots+p_{m j} \sum_{j=1}^{n} a_{m j}+\sum_{j=1}^{n} b_{j} e_{j t}
$$

If it is assumed that $\sum_{j_{i \neq k}} \sum_{k} b_{j} e_{k t}=O$, the aggregate function may be written as

where

$$
q_{i t}^{(d)}=A_{o}+A_{1} p_{1 t} \cdots+A_{m} p_{m t}+B e_{t}
$$

$$
A_{k}=\sum_{j=1}^{n} a_{k j}, B=\sum_{j=1}^{n} b_{j}, e_{t}=\sum_{j=1}^{n} e_{j t}
$$

This function may be written in terms of average consumer income provided the coefficient $B$ is modified. For example:

where

$$
q_{i t}^{(d)}=A_{o}+A_{1} p_{1 t} \cdots+A_{m} p_{m t}+B^{\prime} e_{t^{\prime}}
$$

$$
\begin{aligned}
\mathrm{e}_{t}^{\prime} & =e_{t} / n=\text { average disposable income } \\
B^{\prime} & =n B
\end{aligned}
$$

Allowing for the influence of changing total numbers of consumers over time via some theoretical derivation was felt to be too complicated, yet it was apparent that changing numbers of consumers might both shift the demand schedule and change its slope. Accordingly, the function (1) above was modified by the inclusion of population and per capita income in place of total income. The modified function may be written as where $N_{t}=$ population in year $t$.

\section{Producer Response}

Consider a group of $n$ producers of a single good in year $t$ with each producer maximizing profit, having prices given to him, and having a known continuous production function. The classical supply function of the $j$ th producer is (Allen, 1956). $q_{j t}^{(s)}=g_{j}\left(p_{t}, w_{1 t} \cdots w_{k t}\right)$ 
where $q_{j t}^{(s)}=$ quantity of the good supplied by producer $j$ in year $t, p_{t}=$ price of the good in year $t$, and $w_{i t}=$ price of factor $i$ in year $t . i=1 \ldots k$. Assuming that technology and factor prices are unaffected by the level of industry output, the aggregate supply function for the good may be written as

$$
q_{t}^{(s)}=g\left(p_{t}, w_{1 t} \cdots w_{k t}\right)
$$

where

$$
q_{t}^{(s)}=\sum_{j=1}^{n} q_{j t}^{(s)}
$$

$=$ total quantity supplied in year $t$.

The aggregate demand by the group of producers for an input may be depicted in a similar manner as

$$
x_{i t}^{(d)}=h\left(p_{t}, w_{1 t} \cdots w_{k t}\right),
$$

where $x_{i t}{ }^{(d)}=$ quantity of input $i$ demanded in year $t$.

\section{Producer Demand}

Consider a consumer good industry supplied with a secondary producer good from a secondary industry which in turn is supplied with a primary producer good from a primary industry. A simple supply and demand system using the type of classical aggregate functions dealt with in the preceding sections may be depicted as

$$
\begin{aligned}
& q_{c}^{(d)}=f_{c}\left(p_{c}, p_{o}, e\right) \\
& q_{c}^{(s)}=g_{c}\left(p_{c}, p_{s}, w_{c}\right) \\
& q_{s}^{(d)}=f_{s}\left(p_{c}, p_{s}, w_{c}\right) \\
& q_{s}^{(s)}=g_{s}\left(p_{s}, p_{p}, w_{s}\right) \\
& q_{p}^{(d)}=f_{p}\left(p_{s}, p_{p}, w_{s}\right)
\end{aligned}
$$

where

function (6) represents the demand for the consumer good

function (7) represents the supply of the consumer good function (8) represents the demand for the secondary producer good

function (9) represents the supply of the secondary producer good

function (10) represents the demand for the primary producer good

and where

$$
\begin{aligned}
& q_{c}^{(d)}= \text { quantity of the consumer good } \\
& \text { demanded } \\
& q_{c}^{(s)}= \text { quantity of the consumer good } \\
& \text { supplied } \\
& p_{c}= \text { price of the consumer good } \\
& p_{o}= \text { set of prices of "other" con- } \\
& \text { sumer goods } \\
& e \text { income } \\
& p_{s}= \text { price of the secondary producer } \\
& \text { good } \\
& w_{c}= \text { set of prices of other inputs in } \\
& \text { the consumer good industry } \\
& q_{s}{ }^{(d)}= \text { quantity of the secondary pro- } \\
& \text { ducer good demanded } \\
& q_{s}{ }^{(s)}= \text { quantity of the secondary pro- } \\
& \text { ducer good supplied } \\
& p_{p}= \text { price of the primary producer } \\
& \text { good } \\
& w_{s}= \text { set of prices of other inputs in } \\
& \text { the secondary industry } \\
& q_{p}{ }^{(d)}= \text { quantity of the primary pro- } \\
& \text { ducer good demanded } \\
& q_{p}{ }^{(s)}= \text { quantity of the primary pro- } \\
& \text { ducer good supplied. }
\end{aligned}
$$

Demand for a producer good may also be expressed in terms of the output of the demanding industry, for example

$$
\begin{aligned}
& q_{s}^{(d)}=h_{s}\left(q_{c}, p_{s}, w_{c}^{*}\right) \\
& q_{p}^{(d)}=h_{p}\left(q_{s}, p_{p}, w_{s}^{*}\right)
\end{aligned}
$$

where $q_{c}$ and $q_{s}$ are the outputs of the demanding industries and $w_{c}{ }^{*}$ and $w_{s}{ }^{*}$, subsets of $w_{c}$ and $w_{s}$, are the prices of inputs competitive with the producer good.

The partially reduced form functions 
are derivable from pairs of functions; for instance from (6) and (7) we obtain

$$
\begin{aligned}
& q_{c}=k_{c}\left(p_{o}, e, p_{s}, w_{c}\right) \\
& p_{c}=l c\left(p_{o}, e, p_{s}, w_{c}\right)
\end{aligned}
$$

and from (9) and (11)

$$
\begin{aligned}
& q_{s}=k_{s}\left(p_{p}, w_{s}, q_{c}, w_{c}{ }^{*}\right) \\
& p_{s}=l_{s}\left(p_{p}, w_{s}, q_{c}, w_{c}{ }^{*}\right)
\end{aligned}
$$

By substituting these reduced form functions for prices and outputs in original demand equations a further set of producer demand equations may be obtained. For instance from (8) and (14) may be obtained

$$
q_{s}^{(d)}=f_{s}^{*}\left(p_{s}, w_{c}, p_{O}, e\right)
$$

which represents "demand" for a secondary producer good by a consumer good industry in terms of shifters in the demand for the consumer good.

Lastly, from (12) and (15) may be obtained

$$
q_{p}^{(d)}=h_{p}^{*}\left(p_{p}, w_{s}, q_{c}, w_{c}^{*}\right)
$$

which represents the demand for a primary producer good by a secondary industry in terms of the output of the consumer good industry using the secondary producer good. 


\section{APPENDIX C}

\section{TEST REGRESSIONS ON LENGTH OF MOVING AVERAGE PERIOD}

Softwood Lumber Demand

Dependent variable: $Q 5$

(1) One-year lag only Constant $=42.20454$

$\mathrm{R}^{2}=0.87495$

Variable Coefficient Standard error $t$ ratio

$\begin{array}{llll}X 25 & 0.00072 & 0.00023 & 3.16439\end{array}$

$\begin{array}{llll}X 43 & 0.12139 & 0.10213 & 1.18854\end{array}$

$\begin{array}{lrrr}X 46 & 0.06280 & 0.12555 & 0.50022\end{array}$

$\begin{array}{llll}X 49 & -0.48917 & 0.11273 & -4.33935\end{array}$

$\begin{array}{llll}X 60 & -8.26865 & 5.68203 & -1.45522\end{array}$

$\begin{array}{llll}X 63 & 0.04145 & 0.19056 & 0.21753\end{array}$

(2) Two-year period

Constant $=38.86065 \quad \mathrm{R}^{2}=0.87336$

\begin{tabular}{lrcr} 
Variable & Coefficient & Standard error & \multicolumn{1}{c}{$t$ ratio } \\
$X 25$ & 0.00065 & 0.00021 & 3.10938 \\
$X 44$ & 0.13842 & 0.12417 & 1.11475 \\
$X 47$ & 0.09163 & 0.13038 & 0.70282 \\
$X 50$ & -0.48121 & 0.12049 & -3.99368 \\
$X 61$ & -7.38151 & 5.71092 & -1.29252 \\
$X 64$ & 0.01319 & 0.24387 & 0.05411
\end{tabular}

(3) Three-year period

Constant $=36.58029 \quad \mathrm{R}^{2}=0.85892$

Variable Coefficient Standard error $t$ ratio

$\begin{array}{lrrr}X 3 & 0.17750 & 0.18993 & 0.93458 \\ X 4 & 0.06509 & 0.15095 & 0.43119 \\ X 5 & -0.39543 & 0.13127 & -3.01234 \\ X 16 & -8.38225 & 6.53941 & -1.28180 \\ X 25 & 0.00071 & 0.00024 & 2.89486 \\ X 65 & -0.10834 & 0.39390 & -0.27506\end{array}$

(4) Four-year period

Constant $=35.12094 \quad \mathrm{R}^{2}=0.85390$

Variable Coefficient Standard error $t$ ratio

$\begin{array}{llll}X 25 & 0.00087 & 0.00031 & 2.80213\end{array}$

$\begin{array}{rrrr}X 45 & 0.30130 & 0.32170 & 0.93656\end{array}$

$\begin{array}{llll}X 48 & -0.02054 & 0.18416 & -0.11155\end{array}$

$\begin{array}{lllll}X 51 & -0.27229 & 0.13528 & -2.01272\end{array}$

$\begin{array}{lllll}X 62 & -8.09880 & 8.91324 & -0.90862\end{array}$

$\begin{array}{llll}X 66 & -0.43875 & 0.66919 & -0.65564\end{array}$

(5) Five-year period

Constant $=32.56151 \quad \mathrm{R}^{2}=0.86212$

Variable Coefficient Standard error $t$ ratio

$\begin{array}{lrrr}X 7 & 0.36043 & 0.35527 & 1.01453 \\ X 8 & -0.09372 & 0.18174 & -0.51566 \\ X 9 & -0.13607 & 0.14169 & -0.96033 \\ X 17 & -8.04653 & 10.72437 & -0.75030 \\ X 25 & 0.00094 & 0.00027 & 3.47653 \\ X 67 & -0.63780 & 0.71739 & -0.88906\end{array}$

(6) Six-year period

Constant $=51.29502 \quad \mathrm{R}^{2}=0.89528$

Variable Coefficient Standard error $t$ ratio

$\begin{array}{lrrr}X 25 & 0.00073 & 0.00011 & 6.60879\end{array}$

$\begin{array}{llll}X 52 & -1.61185 & 0.32389 & -4.97647\end{array}$

$\begin{array}{llll}X 56 & 0.70703 & 0.18342 & 3.85453\end{array}$

$\begin{array}{llll}X 68 & 0.42369 & 0.13320 & 3.18089\end{array}$

(7) Seven-year period

Constant $=22.30384 \quad \mathrm{R}^{2}=0.80459$

Variable Coefficient Standard error $t$ ratio

$\begin{array}{llll}X 25 & 0.00063 & 0.00014 & 4.49498\end{array}$

$\begin{array}{rrrr}X 53 & 0.00648 & 0.06303 & 0.10283\end{array}$

$\begin{array}{llll}X 57 & -0.18676 & 0.07963 & -2.34525\end{array}$

$\begin{array}{llll}X 69 & -0.16317 & 0.12129 & -1.34531\end{array}$

(8) Eight-year period

Constant $=45.95285 \quad \mathrm{R}^{2}=0.87017$

Variable Coefficient Standard error $t$ ratio

$\begin{array}{lrrr}X 25 & 0.00060 & 0.00010 & 5.68833\end{array}$

$\begin{array}{llll}X 54 & -1.34486 & 0.53202 & -2.52783\end{array}$

$\begin{array}{llll}X 58 & 0.58979 & 0.30322 & 1.94508\end{array}$

$\begin{array}{llll}X 70 & 0.34037 & 0.24877 & 1.36818\end{array}$

(9) Nine-year period

Constant $=46.30634 \quad \mathrm{R}^{2}=0.87153$

Variable Coefficient Standard error $t$ ratio

$\begin{array}{lrrr}X 25 & 0.00055 & 0.00010 & 5.11736\end{array}$

$\begin{array}{llll}X 55 & -1.39022 & 0.64894 & -2.14229\end{array}$

$\begin{array}{llll}X 59 & 0.63310 & 0.36283 & 1.74487\end{array}$

$\begin{array}{llll}X 71 & 0.36239 & 0.32468 & 1.11614\end{array}$

(10) Ten-year period

Constant $=65.52824 \quad R^{2}=0.90420$

$\begin{array}{lrcr}\text { Variable } & \text { Coefficient } & \text { Standard error } & t \text { ratio } \\ X 13 & -2.52225 & 0.73063 & -3.45215 \\ X 14 & 1.25397 & 0.39750 & 3.15459 \\ X 25 & 0.00041 & 0.00010 & 4.16249 \\ X 72 & 0.93685 & 0.38244 & 2.44967\end{array}$

Softwood Plywood Demand

Dependent variable: $Q 4$

1) One-year lag only

Constant $=159.91967 \quad \mathrm{R}^{2}=0.98619$

Variable Coefficient Standard error $t$ ratio

$\begin{array}{rrrr}X 25 & 0.13722 & 0.02168 & 6.32719\end{array}$

$\begin{array}{llll}X 43 & -28.59261 & 12.88531 & -2.21900\end{array}$

$\begin{array}{llll}X 46 & 2.59528 & 12.08276 & 0.21479\end{array}$

$\begin{array}{llll}X 63 & -7.92876 & 23.54358 & -0.33676\end{array}$

(2) Two-year period

Constant $=-806.91145 \quad R^{2}=0.98491$ 
Softwood Plywood Demand-Continued

$\begin{array}{lrcr}\text { Variable } & \text { Coefficient } & \text { Standard error } & t \text { ratio } \\ X 25 & 0.11802 & 0.02400 & 4.91779 \\ X 44 & -35.72550 & 15.70021 & -2.27547 \\ X 47 & 16.80775 & 10.96115 & 1.53339 \\ X 64 & 4.68395 & 29.66537 & 0.15789\end{array}$

(3) Three-year period

Constant $=-1550.93280 \quad \mathrm{R}^{2}=0.98283$

Variable Coefficient Standard error $t$ ratio

$\begin{array}{llll}X 3 & -51.67440 & 21.54098 & -2.39888\end{array}$

$\begin{array}{llll}X 4 & 28.14608 & 10.84781 & 2.59463\end{array}$

$\begin{array}{llll}X 25 & 0.09219 & 0.03239 & 2.84595\end{array}$

$\begin{array}{llll}X 65 & 35.69696 & 43.30245 & 0.82436\end{array}$

(4) Four-year period

Constant $=-2195.89460 \quad \mathrm{R}^{2}=0.98121$

Variable Coefficient Standard error $t$ ratio

$\begin{array}{lrrr}X 25 & 0.05553 & 0.03949 & 1.40586\end{array}$

$\begin{array}{llll}X 45 & -78.71920 & 27.47136 & -2.86550\end{array}$

$\begin{array}{llll}X 48 & 38.49789 & 10.32326 & 3.72923\end{array}$

$\begin{array}{llll}X 66 & 90.20443 & 56.78244 & 1.58859\end{array}$

(5) Five-year period

Constant $=-2537.09630 \quad \mathrm{R}^{2}=0.97812$

Variable Coefficient Standard error $t$ ratio

$\begin{array}{llll}X 7 & -82.83658 & 27.75043 & -2.98505\end{array}$

$\begin{array}{llll}X 8 & 43.12233 & 9.53119 & 4.52433\end{array}$

$\begin{array}{llll}X 25 & 0.05324 & 0.03690 & 1.44292\end{array}$

$\begin{array}{llll}X 67 & 96.39470 & 56.56761 & 1.70406\end{array}$

Building Paper and Board

Dependent variable: $Q 6$

(1) One-year lag only

Constant $=3198.04030 \quad \mathrm{R}^{2}=0.98058$

\begin{tabular}{lrrr} 
Variable & Coefficient & Standard error & \multicolumn{1}{c}{$t$ ratio } \\
$X 25$ & 0.08735 & 0.01231 & 7.09483 \\
$X 43$ & 7.37756 & 7.31560 & 1.00846 \\
$X 46$ & -43.75211 & 6.85995 & -6.37789 \\
$X 63$ & -7.25459 & 13.36680 & -0.54273 \\
(2) Two-year period & &
\end{tabular}

Constant $=3061.99110 \quad \mathrm{R}^{2}=0.98246$

Variable Coefficient Standard error $t$ ratio

$\begin{array}{llll}X 25 & 0.09120 & 0.01239 & 7.36116\end{array}$

$\begin{array}{lrrr}X 44 & 13.02504 & 8.10537 & 1.60696\end{array}$

$\begin{array}{llll}X 47 & -41.44110 & 5.65879 & -7.32331\end{array}$

$\begin{array}{llll}X 64 & -20.06865 & 15.31501 & -1.31039\end{array}$

(3) Three-year period

Constant $=2755.96130 \quad \mathrm{R}^{2}=0.98011$

Variable Coefficient Standard error $t$ ratio

$\begin{array}{llll}X 3 & 15.79187 & 11.09934 & 1.42277\end{array}$

$\begin{array}{lllll}X 4 & -36.63968 & 5.58950 & -6.55508\end{array}$

$\begin{array}{llll}X 25 & 0.08872 & 0.01669 & 5.31505\end{array}$

$\begin{array}{llll}X 65 & -26.44855 & 22.31229 & -1.18537\end{array}$

(4) Four-year period

Constant $=2485.69860 \quad \mathrm{R}^{2}=0.97718$

Variable Coefficient Standard error $t$ ratio

$\begin{array}{llll}X 25 & 0.08485 & 0.02084 & 4.07132\end{array}$

$\begin{array}{lrrr}X 45 & 17.08046 & 14.49633 & 1.17826\end{array}$

$\begin{array}{lllll}X 48 & -32.24512 & 5.44747 & -5.91927\end{array}$

$\begin{array}{llll}X 66 & -29.72251 & 29.96346 & -0.99195\end{array}$

(5) Five-year period

Constant $=2334.71600 \quad \mathrm{R}^{2}=0.97637$

Variable Coefficient Standard error $t$ ratio

$\begin{array}{llll}X 7 & 17.28538 & 13.80763 & 1.25187\end{array}$

$\begin{array}{llll}X 8 & -29.57479 & 4.74239 & -6.23626\end{array}$

$\begin{array}{lrrr}X 25 & 0.08115 & 0.01836 & 4.41977\end{array}$

$\begin{array}{llll}X 67 & -30.56872 & 28.14608 & -1.08607\end{array}$ 


\section{APPENDIX D}

\section{KEY TO NOTATION}

Notations in the text of the report, such as $\hat{P} 1$, refer to a predicted value of a variable from a reduced form equation.

$P 1 \quad=$ index of lumber prices $(1947-49=100)$

$P 2=$ index of paper prices $(1947-49=100)$

$P 3=$ index of paperboard prices $(1947-49=100)$

$P 4=$ index of softwood plywood prices $(1947-49=100)$

$P 5=$ price of softwood lumber (dollars per thousand board feet)

$P 6=$ index of building paper and board prices $(1947-49=100)$

$P 7 \quad=$ price of Douglas fir sawlogs (dollars per thousand board feet)

$P 8=$ price of pulpwood, f.o.b. mill (dollars per cord)

$P 9$ = price of Douglas fir peeler logs (dollars per thousand board feet)

$P 10=$ price of softwood sawlog stumpage (dollars per thousand board feet)

$Q 1=$ consumption of lumber (billions of board feet)

Q2 = consumption of paper (thousands of tons)

Q3 = consumption of paperboard (thousands of tons)

$Q 4=$ consumption of softwood plywood (millions of square feet $3 / 8$ " basis)

Q5 = consumption of softwood lumber (billions of board feet)

Q6 = consumption of building paper and board (thousands of tons)

$X 1=$ index of wallboard prices $(1947-49=100)$

$X 2$ = average price of lumber over the previous 3 years

$X 3$ = average price of softwood plywood over the previous 3 years

$X 4=$ average price of building board over the previous 3 years

$X 5=$ average price of wallboard over the previous 3 years

$X 6=$ average price of lumber over the previous 5 years

$X 7=$ average price of softwood plywood over the previous 5 years

$X 8=$ average price of building board over the previous 5 years

$X 9=$ average price of wallboard over the previous 5 years

$X 10=$ average price of clay products over the previous 5 years

$X 11=$ average price of structural steel over the previous 5 years

$X 12=$ average price of lumber over the previous 10 years

$X 13=$ average price of clay products over the previous 10 years

$X 14=$ average price of structural steel over the previous 10 years

$X 15$ = wage of construction workers (dollars per hour)

$X 16=$ average wage of construction workers over the previous 3 years

$X 17$ = average wage of construction workers over the previous 5 years

$X 18=$ value of new private residential construction (millions of dollars)

$X 19$ = value of new private non-residential construction (millions of dollars)

$X 20=$ value of public construction (millions of dollars)

$X 21=$ value of maintenance and repair construction (millions of dollars)

$X 22=$ index of manufacturing production $(1947-49=100)$

$X 23=$ population (millions)

$X 24=$ per capita disposable income (thousands of dollars) 
$X 25=$ value of total construction (millions of dollars)

$X 26=$ freight rates (cents per ton mile)

$X 27=$ trend $(1929=1,1930=2 \ldots 1960=32)$

$X 28=$ wages in sawmills (dollars per hour)

$X 29=$ index of electric power prices $(1947-49=100)$

$X 30=$ lumber tariff (dollars per thousand board feet)

$X 31$ = rate of exchange (U. S. dollars per Canadian dollar)

$X 32$ = wages in pulp and paper (dollars per hour)

$X 33=$ index of prices of petroleum products $(1947-49=100)$

$X 34=$ consumer price index $(1947-49=100)$

$X 35$ = per capita personal consumption expenditure (thousands of dollars)

$X 36=$ lumber price for the previous year

$X 37=$ average lumber price over the previous 2 years

$X 38=$ average lumber price over the previous 4 years

$X 39=$ average lumber price over the previous 6 years

$X 40=$ average lumber price over the previous 7 years

$X 41$ = average lumber price over the previous 8 years

$X 42$ = average lumber price over the previous 9 years

$X 43$ = average plywood price over the previous year

$X 44$ = average plywood price over the previous 2 years

$X 45=$ average plywood price over the previous 4 years

$X 46=$ average building board price over the previous year

$X 47=$ average building board price over the previous 2 years

$X 48=$ average building board price over the previous 4 years

$X 49=$ average wallboard price over the previous year

$X 50=$ average wallboard price over the previous 2 years

$X 51$ = average wallboard price over the previous 4 years

$X 52$ = average clay products price over the previous 6 years

$X 53$ = average clay products price over the previous 7 years

$X 54=$ average clay products price over the previous 8 years

$X 55$ = average clay products price over the previous 9 years

$X 56=$ average structural steel price over the previous 6 years

$X 57=$ average structural steel price over the previous 7 years

$X 58=$ average structural steel price over the previous 8 years

$X 59=$ average structural steel price over the previous 9 years

$X 60=$ wage of construction workers in the previous year

$X 61=$ average wage of construction workers over the previous 2 years

$X 62=$ average wage of construction workers over the previous 4 years

$X 63=$ price of softwood lumber for the previous year

$X 64=$ average price of softwood lumber over the previous 2 years

$X 65=$ average price of softwood lumber over the previous 3 years

$X 66=$ average price of softwood lumber over the previous 4 years

$X 67=$ average price of softwood lumber over the previous 5 years

$X 68=$ average price of softwood lumber over the previous 6 years

$X 69=$ average price of softwood lumber over the previous 7 years

$X 70=$ average price of softwood lumber over the previous 8 years

$X 71=$ average price of softwood lumber over the previous 9 years 
$X 72=$ average price of softwood lumber over the previous 10 years

$X 73=$ productivity in sawmilling

$X 74=$ productivity in pulp and paper

$X 75=$ ratio past 5 year prices softwood plywood/softwood lumber $(X 7 / X 67)$

$X 76=$ ratio past 5 year prices building board/softwood lumber $(X 8 / X 67)$

$X 77=$ ratio past 5 year prices wallboard/softwood lumber $(X 9 / X 67)$

$X 78=$ ratio past 10 year prices clay products/softwood lumber $(X 13 / X 72)$

$X 79=$ ratio past 10 year prices structural steel/softwood lumber $(X 14 / X 72)$

$X 80=$ ratio past 5 year prices softwood lumber/building board $(X 67 / X 8)$

$X 81=$ ratio past 5 year prices softwood plywood/building board $(X 7 / X 8)$

$X 82=$ ratio past 5 year prices wallboard/building board $(X 9 / X 8)$

$X 83=$ ratio past 5 year prices softwood lumber/softwood plywood $(X 67 / X 7)$

$X 84=$ ratio past 5 year prices building board/softwood plywood $(X 8 / X 7)$

$X 85=$ ratio past 5 year prices wallboard/softwood plywood $(X 9 / X 7)$

$X 86$ = dummy variable, 0 for 1929 to 1941,1 for 1947 to 1960

$X 87=$ index of prices of structural clay products

$X 88=$ index of prices of structural steel shapes 


\section{APPENDIX E}

\section{DATA}

\section{Description and Source of Data}

Price of Lumber: $P 1$

Description: BLS wholesale price index for all lumber $(1947-49=100)$

Source: $\quad$ U. S. Department of Labor, Bureau of Labor Statistics, "Wholesale prices and price indexes," "Prices and price relatives for individual commodities," "Handbook of labor statistics." Various dates of publication.

Price of Paper: $P 2$

Description: BLS wholesale price index for all paper $(1947-49=100)$

Source: $\quad$ As in $P 1$.

Price of Paperboard: $P 3$

Description: A weighted average price index $(1947-49=100)$ prepared using consumption data and price indexes for building board and paperboard (excluding building board).

Source: $\quad$ Price data as in $P 1$. Consumption data as in $Q 2$ below.

Price of Softwood Plywood: $P 4$

Description: Price index $(1947-49=100)$ for Douglas fir interior grade (average A-D) f.o.b. Chicago. Data prior to 1936 estimated, using reduced form equations from preliminary studies.

Source: U. S. Forest Service, "Timber Resources for America's Future," Washington, 1958. U. S. Department of Labor, Bureau of Labor Statistics, "Wholesale prices and price indexes." Various dates of publication.

Price of Softwood Lumber: P5

Description: Average price for Douglas fir, southern pine and ponderosa pine lumber weighted by shipments. Dollars per thousand board feet.

Source: Data prior to 1951 from I. I. Holland, "Factors affecting the consumption of lumber in the United States," Ph.D. thesis, University of California, 1955. Douglas fir and ponderosa pine prices from Western Pine Association, "Statistical summary." Various years. Southern pine prices estimated from wholesale price index for No. 2 boards from U. S. Bureau of Labor Statistics, "Wholesale prices and price indexes." Various years. Shipments data see $X 15$ below.

Price of Building Paper and Board: $P 6$

Description: BLS wholesale price index $(1947-49=100)$ for building paper and board.

Source: $\quad$ As in $P 1$.

Price of Sawlogs: $P 7$

Description: Douglas fir sawlog prices in western Oregon and western Washington. Average grade. Dollars per thousand board feet. 
Source: U. S. Congress, House Document 195, 85th Congress, 1st Session, "Price trends and relationships for forest products." Data for years after 1955 from Pacific Northwest Forest and Range Experiment Station by correspondence.

Price of Pulpwood: $P 8$

Description: Price of pulpwood f.o.b. mill in dollars per cord. Certain years after 1947 estimated from prices at local delivery points.

Source: F.o.b. mill prices from U. S. Bureau of the Census, "Census of manufactures." Various years. Local delivery prices from U. S. Forest Service, "The demand and price situation for forest products," 1962.

Price of Peeler Logs: $P 9$

Description: Douglas fir peeler log prices in western Oregon and western Washington. Average grade. Dollars per thousand board feet.

Source: $\quad$ As in $P 7$.

Price of Softwood Sawtimber: P10

Description: Average price for Douglas fir, southern pine, ponderosa pine stumpage weighted by shipments of lumber of these species. Data primarily from National Forest sales. Dollars per thousand board feet.

Source: $\quad$ Price data from U. S. Forest Service, "The demand and price situation for forest products," 1962. Shipments data see $X 15$ below.

Quantity of Lumber Consumed: $Q 1$

Description: "Apparent consumption" of all lumber in billions of board feet. (Apparent consumption is domestic production plus imports less exports.)

Source: U. S. Forest Service, "The demand and price situation for forest products-1963."

Quantity of Paper Consumed: Q2

Description: "Apparent consumption" of all paper (including newsprint) and construction paper in thousands of tons.

Source: American Paper and Pulp Association, "Operating and financial statistics," Special statistical studies no. 1, April 30, 1964.

Quantity of Paperboard Consumed: Q3

Description: "Apparent consumption" of paperboard, wet machine board and insulating and hard-pressed board in thousands of tons.

Source: $\quad$ As in $Q 2$.

Quantity of Softwood Plywood Consumed: $Q 4$

Description: Data prior to 1950 estimated from Douglas fir production data. Later data adjusted for imports and exports. Millions of square feet $3 / 8^{\prime \prime}$ basis.

Source: $\quad$ Production data from The Timberman, "Annual plywood supplement." Various years. Data after 1951 from U. S. Forest Service as in $Q 1$ and from U. S. Department of Commerce, Business and Defense Services Administration, "Softwood Plywood IndustryOutlook," 1958.

Quantity of Softwood Lumber Consumed: Q5

Description: Total shipments from U. S. mills of Douglas fir, southern pine and 
ponderosa pine lumber plus imports of Douglas fir. Billions of board feet.

Source: Data prior to 1951 from Holland, see P9. Shipments data from U. S. Department of Commerce, "Business Statistics." Various editions. Imports data from U. S. Department of Commerce, "United States imports of merchandise for consumption." Various years.

Quantity of Building Paper and Board Consumed : $Q 6$

Description: Apparent consumption of construction paper and board in thousands of tons.

Source: $\quad$ As in $Q 2$.

Price of Wallboard: $X 1$

Description: BLS wholesale price index $(1947-49=100)$ for gypsum wallboard. Data prior to 1947 estimated from BLS wholesale price index for plaster board.

Source: $\quad$ As in $P 1$.

Price of Clay Products: $X 87$

Description: BLS wholesale price index $(1947-49=100)$ for structural clay products.

Source: $\quad$ As in $P 1$.

Price of Structural Steel: $X 88$

Description: BLS wholesale price index $(1947-49=100)$ for structural steel shapes.

Source: $\quad$ As in $P 1$.

Wages in Construction: $X 15$

Description: Wage rates for skilled labor in construction. Dollars per hours.

Source: U. S. Department of Commerce, "Business Statistics," various editions.

Index of Manufacturing Production: X22

Description: Federal Reserve Index of production for "total" manufacturing $(1947-49=100)$.

Source: $\quad$ As in $X 15$.

Population: $X 23$

Description: Total population of the United States including armed forces overseas. In millions.

Source: U. S. Bureau of the Census, "Statistical abstract of the United States," 1962.

Per Capita Disposable Income: $X 24$

Description: Total disposable personal income divided by population. In thousands of dollars.

Source: $\quad$ Population as in X23. Income as in $X 15$

Value of Total Construction: $X 25$

Description: Value of total new construction (public and private) and maintenance and repair. Data on maintenance and repair estimated for 1961 and 1962. In millions of dollars. 
Source: U.S. Departments of Labor and Commerce, "Construction Review" and supplement "Construction volume and cost, 1915-1956." Various years.

Freight Rates: $X 26$

Description: Revenue per ton-mile, freight service, all railroads, in cents.

Source: Interstate Commerce Commission, Bureau of Transport Economics

Wages in Sawmills: $X 28$ and Statistics. Annual report. Various years.

Description: Average hourly earnings in sawmills and planing mills, in dollars.

Source: $\quad A s$ in $X 15$.

Price of Electric Power: $X 29$

Description: BLS wholesale price index $(1947-49=100)$ for electricity.

Source: $\quad$ As in $X 15$

Tariff on Lumber: $X 30$

Description: Duty imposed under paragraph 401 of the Tariff Act of 1930 plus import tax imposed under the Revenue Act of 1932, for major types of imported softwood lumber. In dollars per thousand board feet.

Source: U. S. Tariff Commission, "Softwood Lumber," 1963.

Rate of Exchange: $X 31$

Description: U. S. dollars per Canadian dollar.

Source: U. S. Federal Reserve System, Board of Governors, "Federal reserve bulletin," and "Banking and monetary statistics." Various years.

Wages in Pulp and Paper: X32

Description: Average hourly earnings in pulp, paper and paperboard mills in dollars. Data prior to 1932 estimated from average hourly earnings in factories.

Source: $\quad$ As in $X 15$.

Price of Petroleum Products: X33

Description: BLS wholesale price index $(1947-49=100)$ for petroleum and petroleum products.

Source: $\quad$ As in $X 15$.

Consumer Price Index: $X 34$

Description: BLS consumer price index $(1947-49=100)$ for all items.

Source: $\quad$ As in $X 15$.

Productivity in Sawmilling: $X 73$

Description: U. S. lumber production divided by employment in the lumber and wood products industry. Thousands of board feet per man year.

Source: $\quad$ Production data as in Q1. Employment data as in $X 15$.

Productivity in Pulp and Paper: X74

Description: U. S. production of paper and paperboard divided by number of production workers employed in pulp, paper and paperboard mills. Thousands of tons per man year.

Source: $\quad$ Production data as in Q2. Employment data as in P8, and American Paper and Pulp Association, "Industry fact sheet." Various years. 
Basic Data Used in Investigation

\begin{tabular}{|c|c|c|c|c|c|}
\hline Year & $\begin{array}{c}\text { Lumber } \\
\text { consumption } \\
(Q 1), \\
\text { billions of } \\
\text { board feet }\end{array}$ & $\begin{array}{c}\text { Paper } \\
\text { consumption } \\
\text { (Q2), } \\
\text { thousands } \\
\text { of tons }\end{array}$ & $\begin{array}{c}\text { Paperboard } \\
\text { consumption } \\
\text { (Q3), } \\
\text { thousands } \\
\text { of tons }\end{array}$ & $\begin{array}{c}\text { Softwood } \\
\text { plywood } \\
\text { consumption } \\
(Q 4), \\
\text { millions of } \\
\text { square feet }\end{array}$ & $\begin{array}{c}\text { Softwood } \\
\text { lumber } \\
\text { consumption } \\
(Q 5), \\
\text { billions of } \\
\text { board feet }\end{array}$ \\
\hline 1929. & 37.6 & 9108 & 4303 & 358 & 21.1 \\
\hline $1930 \ldots \ldots \ldots \ldots$ & 28.2 & 8401 & 3917 & 305 & 14.5 \\
\hline $1931 \ldots \ldots \ldots$ & . 19.0 & 7625 & 3729 & 235 & 10.9 \\
\hline $1932 \ldots \ldots \ldots$ & 12.7 & 6517 & 3216 & 200 & 8.0 \\
\hline $1933 \ldots \ldots \ldots$ & 16.3 & 6944 & 3973 & 390 & 9.7 \\
\hline $1934 \ldots \ldots \ldots$ & 17.8 & 7312 & 3977 & 384 & 9.0 \\
\hline $1935 \ldots \ldots \ldots$ & 23.3 & 8174 & 4583 & 480 & 12.3 \\
\hline $1936 \ldots \ldots \ldots$ & 25.7 & 9308 & 5343 & 700 & 15.5 \\
\hline $1937 \ldots \ldots \ldots$ & 25.9 & 10351 & 5677 & 725 & 16.6 \\
\hline $1938 \ldots \ldots \ldots$ & 23.6 & 8575 & 4968 & 650 & 15.1 \\
\hline $1939 \ldots \ldots \ldots$ & 28.4 & 10005 & 5943 & 1032 & 17.4 \\
\hline $1940 \ldots \ldots \ldots$ & 34.3 & 10616 & 6142 & 1200 & 21.1 \\
\hline $1941 \ldots \ldots \ldots$ & . $\quad 36.2$ & 12133 & 8289 & 1805 & 23.5 \\
\hline $1947 \ldots \ldots \ldots$ & . 33.8 & 14436 & 10314 & 1700 & 21.0 \\
\hline $1948 \ldots \ldots \ldots$ & 36.4 & 15376 & 10707 & 1954 & 21.5 \\
\hline $1949 \ldots \ldots \ldots$ & . 34.4 & 14788 & 9907 & 1977 & 21.8 \\
\hline $1950 \ldots \ldots \ldots$ & 40.7 & 16752 & 12259 & 2678 & 24.3 \\
\hline $1951 \ldots \ldots \ldots$ & 38.0 & 17688 & 12873 & 2998 & 25.2 \\
\hline $1952 \ldots \ldots \ldots$ & . $\quad 39.7$ & 16913 & 12104 & 3166 & 26.4 \\
\hline $1953 \ldots \ldots \ldots$ & . $\quad 38.1$ & 17598 & 13762 & 3840 & 24.7 \\
\hline $1954 \ldots \ldots \ldots$ & 39.2 & 17780 & 13599 & 3991 & 25.6 \\
\hline $1955 \ldots \ldots \ldots$ & 40.3 & 19291 & 15428 & 5285 & 26.5 \\
\hline $1956 \ldots \ldots \ldots$ & 40.0 & 20726 & 15770 & 5428 & 25.8 \\
\hline $1957 \ldots \ldots \ldots$ & . 36.7 & 19793 & 15474 & 5644 & 23.4 \\
\hline $1958 \ldots$ & . 36.3 & 19482 & 15636 & 6477 & 24.4 \\
\hline $1959 \ldots \ldots \ldots$ & 40.0 & 21540 & 17185 & 7693 & 26.2 \\
\hline $1960 \ldots \ldots \ldots$ & $\begin{array}{l}35.7 \\
\end{array}$ & 21943 & 17196 & 7999 & 23.8 \\
\hline
\end{tabular}




\begin{tabular}{|c|c|c|c|c|c|}
\hline Year & $\begin{array}{c}\text { Building paper } \\
\text { and board con- } \\
\text { sumption }(Q 6), \\
\text { thoussnds } \\
\text { of tons }\end{array}$ & $\begin{array}{c}\text { Lumber price } \\
(P) \text { index } \\
1947-49=100 \\
\end{array}$ & $\begin{array}{c}\text { Paper price } \\
(P 2) \text { index } \\
1947-49=100 \\
\end{array}$ & $\begin{array}{c}\text { Paperboard price } \\
(P 3) \text { index } \\
1947-49=100 \\
\end{array}$ & $\begin{array}{c}\text { Softwood } \\
\text { plywood price } \\
(P 4) \text { index } \\
1947-49=100 \\
\end{array}$ \\
\hline 1929. & 786 & 31.2 & 62.7 & 51.2 & 44.9 \\
\hline 1930. & 568 & 28.5 & 62.6 & 43.4 & 41.5 \\
\hline$\ldots \ldots$ & 495 & 23.1 & 60.6 & 37.3 & 34.0 \\
\hline 1932 . & 355 & 19.4 & 56.6 & 36.1 & 28.0 \\
\hline 1933. & 351 & 23.5 & 54.0 & 44.1 & 31.3 \\
\hline $1934 \ldots \ldots \ldots$ & 384 & 28.1 & 56.4 & 50.2 & 35.9 \\
\hline $1935 \ldots \ldots$ & 503 & 27.2 & 56.6 & 45.0 & 33.1 \\
\hline $1936 \ldots \ldots$ & 634 & 28.9 & 57.0 & 45.4 & 33.6 \\
\hline $1937 \ldots \ldots \ldots$ & 700 & 33.1 & 60.6 & 52.3 & 33.5 \\
\hline $1938 \ldots \ldots \ldots$ & 673 & 29.0 & 61.8 & 46.0 & 32.9 \\
\hline $1939 \ldots \ldots$ & 755 & 31.0 & 60.2 & 46.7 & 33.7 \\
\hline $1940 \ldots \ldots$ & 840 & 34.2 & 63.1 & 52.4 & 35.1 \\
\hline $1941 \ldots \ldots \ldots$ & . 1532 & 40.7 & 66.3 & 58.8 & 39.1 \\
\hline $1947 \ldots \ldots \ldots$ & . 2333 & 94.5 & 93.4 & 98.0 & 89.3 \\
\hline $1948 \ldots \ldots \ldots$ & . 2579 & 107.3 & 102.8 & 102.2 & 113.5 \\
\hline $1949 \ldots \ldots$ & . 1979 & 98.2 & 103.8 & 99.8 & 97.2 \\
\hline $1950 \ldots \ldots$ & . 2647 & 114.5 & 106.5 & 105.5 & 112.0 \\
\hline $1951 \ldots \ldots \ldots$ & . 2652 & 123.6 & 119.1 & 128.4 & 117.3 \\
\hline $1952 \ldots \ldots \ldots$ & . 2604 & 120.5 & 124.0 & 125.1 & 107.2 \\
\hline $1953 \ldots \ldots \ldots$ & . 2743 & 119.3 & 125.6 & 123.8 & 107.1 \\
\hline $1954 \ldots \ldots \ldots$ & . 2914 & 117.3 & 126.6 & 125.1 & 103.0 \\
\hline $1955 \ldots \ldots$ & . 3260 & 124.4 & 129.8 & 127.8 & 106.1 \\
\hline $1956 \ldots \ldots$ & . 3116 & 127.2 & 137.3 & 135.2 & 97.4 \\
\hline $1957 .$. & . 2928 & 119.7 & 141.9 & 137.2 & 88.7 \\
\hline $1958 \ldots \ldots \ldots$ & . 3104 & 118.0 & 142.3 & 137.5 & 89.6 \\
\hline $1959 \ldots \ldots$ & . 3439 & 127.1 & 143.4 & 138.0 & 95.2 \\
\hline $1960 \ldots \ldots$ & . 3266 & 121.4 & 145.4 & 137.1 & 82.6 \\
\hline
\end{tabular}




\begin{tabular}{|c|c|c|c|c|}
\hline Year & $\begin{array}{c}\text { Softwood } \\
\text { lumber price } \\
\text { (P5) } \\
\text { dollars per thou- } \\
\text { sand board feet }\end{array}$ & $\begin{array}{c}\text { Building paper } \\
\text { and board price } \\
(P 6) \\
\text { index, } \\
1947-49=100\end{array}$ & $\begin{array}{c}\text { Sawlog } \\
\text { price } \\
(P 7) \\
\text { dollars per thou- } \\
\text { sand board feet }\end{array}$ & $\begin{array}{c}\text { Pulpwood } \\
\text { price } \\
(P 8) \\
\text { dollars } \\
\text { per cord }\end{array}$ \\
\hline 1929. & 25.8 & 86.5 & 16.00 & 13.09 \\
\hline 1930. & . 22.1 & 84.5 & 15.50 & 12.32 \\
\hline $1931 \ldots$ & . 16.3 & 79.3 & 11.00 & 10.94 \\
\hline 1932. & $\begin{array}{ll}\ldots & 13.7\end{array}$ & 78.1 & 9.50 & 9.19 \\
\hline 1933. & . $\quad 16.9$ & 76.9 & 9.50 & 7.37 \\
\hline 1934. & . 21.8 & 79.3 & 11.00 & 7.73 \\
\hline 1935. & . 19.8 & 77.7 & 11.50 & 7.64 \\
\hline $1936 \ldots$ & . 21.3 & 77.7 & 14.00 & 7.71 \\
\hline $1937 \ldots$ & 24.5 & 79.3 & 15.50 & 7.90 \\
\hline $1938 \ldots$ & . . 21.0 & 79.3 & 14.50 & 8.10 \\
\hline $1939 \ldots$ & . 22.4 & 79.3 & 14.50 & 7.82 \\
\hline $1940 \ldots$ & . . 25.3 & 79.3 & 15.50 & 7.99 \\
\hline 1941. & . $\quad 30.7$ & 79.3 & 17.00 & 8.33 \\
\hline $1947 \ldots$ & . . $\quad 68.1$ & 93.3 & 33.70 & 15.62 \\
\hline $1948 \ldots$ & . 77.1 & 102.7 & 39.30 & 16.61 \\
\hline 1949 . & . $\quad 68.8$ & 104.1 & 39.00 & 15.62 \\
\hline 1950. & 78.1 & 107.7 & 44.70 & 16.90 \\
\hline 1951. & . 88.3 & 113.6 & 47.90 & 19.60 \\
\hline $1952 \ldots$ & . . 86.4 & 115.7 & 50.60 & 19.74 \\
\hline 1953. & . 84.0 & 121.7 & 48.00 & 19.74 \\
\hline 1954. & 80.9 & 127.7 & 48.10 & 19.88 \\
\hline $1955 \ldots$ & 86.7 & 130.9 & 52.20 & 20.45 \\
\hline 1956. & 89.1 & 136.9 & 55.10 & 21.87 \\
\hline $1957 \ldots$ & 83.4 & 141.5 & 52.80 & 22.01 \\
\hline $1958 \ldots$ & 81.2 & 143.2 & 53.10 & 22.15 \\
\hline 1959. & 88.2 & 146.4 & 57.70 & 22.72 \\
\hline 1960. & 83.5 & 145.7 & 58.40 & 23.43 \\
\hline
\end{tabular}




\begin{tabular}{|c|c|c|c|c|}
\hline Year & $\begin{array}{c}\text { Peeler } \\
\text { log price } \\
(P 9), \\
\text { dollars per thou- } \\
\text { sand board feet }\end{array}$ & $\begin{array}{c}\text { Softwood } \\
\text { stumpage price } \\
(P 10), \\
\text { dollars per thou- } \\
\text { sand board feet }\end{array}$ & $\begin{array}{c}\text { Wallboard } \\
\text { price } \\
\text { (X1), } \\
\text { index, } \\
1947-49 \stackrel{100}{=} 100\end{array}$ & $\begin{array}{c}\text { Three-year } \\
\text { average } \\
\text { lumber price } \\
(X 2) \\
\text { index, } \\
1947-49=100\end{array}$ \\
\hline 1929. & 34.20 & 3.23 & 70.7 & 31.4 \\
\hline 1930. & 34.20 & 3.31 & 74.4 & 30.7 \\
\hline $1931 \ldots$ & . $\quad 23.90$ & 3.35 & 74.4 & 29.9 \\
\hline 1932. & . $\quad 21.70$ & 2.36 & 74.4 & 27.6 \\
\hline 1933. & . $\quad 21.70$ & 2.13 & 74.4 & 23.7 \\
\hline $1934 \ldots$ & . 25.40 & 2.34 & 74.4 & 22.0 \\
\hline 1935. & . 25.40 & 3.12 & 74.4 & 23.7 \\
\hline 1936. & . 25.00 & 3.36 & 74.4 & 26.3 \\
\hline $1937 \ldots$ & . $\quad 27.50$ & 3.32 & 66.0 & 28.1 \\
\hline 1938. & . 29.00 & 4.74 & 65.7 & 29.7 \\
\hline 1939. & . $\quad 27.50$ & 3.90 & 65.4 & 30.3 \\
\hline 1940. & 28.00 & 3.36 & 65.1 & 31.0 \\
\hline $1941 \ldots$ & . $\quad 32.00$ & 6.55 & 65.1 & 31.4 \\
\hline $1947 \ldots$ & . $\quad 56.40$ & 10.03 & 95.0 & 53.9 \\
\hline $1948 \ldots$ & . $\quad 79.70$ & 17.44 & 102.5 & 68.4 \\
\hline $1949 \ldots$ & . 74.90 & 15.60 & 102.5 & 87.0 \\
\hline 1950 . & . $\quad 89.40$ & 20.66 & 104.4 & 100.0 \\
\hline $1951 \ldots$ & . $\quad 96.50$ & 30.84 & 117.4 & 106.7 \\
\hline $1952 \ldots$ & . 96.00 & 30.43 & 117.4 & 112.1 \\
\hline 1953. & . 96.30 & 26.06 & 120.2 & 119.5 \\
\hline $1954 \ldots$ & . 94.80 & 23.71 & 121.1 & 121.1 \\
\hline 1955. & . 96.30 & 28.85 & 121.1 & 119.0 \\
\hline 1956. & . 99.10 & 34.05 & 124.9 & 120.3 \\
\hline $1957 \ldots$ & 98.70 & 27.03 & 124.9 & 123.0 \\
\hline $1958 \ldots$ & . $\quad 95.70$ & 23.38 & 129.5 & 123.8 \\
\hline $1959 \ldots$ & . 97.10 & 30.57 & 130.4 & 121.6 \\
\hline 1960. & .100 .10 & 28.15 & 130.5 & 121.6 \\
\hline
\end{tabular}




\begin{tabular}{|c|c|c|c|c|}
\hline Th & $\begin{array}{c}\text { Three-year average } \\
\text { softwood } \\
\text { plywood price } \\
(X 3) \\
\text { index, } \\
1947-49=100\end{array}$ & $\begin{array}{l}\text { Three-year average } \\
\text { building } \\
\text { board price } \\
\text { (X4) } \\
\text { index, } \\
1947-49=100\end{array}$ & $\begin{array}{c}\text { Three-year average } \\
\text { wallboard } \\
\text { price } \\
(X 5) \\
\text { index, } \\
1947-49=100\end{array}$ & $\begin{array}{c}\text { Five-year } \\
\text { average lum- } \\
\text { ber price } \\
\text { (X66) } \\
\text { index, } \\
\text { 1947-49 }=100 \\
\end{array}$ \\
\hline$\ldots \ldots \ldots$ & 49.8 & 100.2 & 76.7 & 32.1 \\
\hline $1930 \ldots \ldots \ldots \ldots \ldots$ & 46.8 & 94.2 & 73.9 & 31.8 \\
\hline $1931 \ldots \ldots \ldots \ldots \ldots$ & 44.2 & 89.5 & 73.2 & 30.8 \\
\hline $1932 \ldots \ldots \ldots \ldots \ldots$ & 40.1 & 83.4 & 73.2 & 28.8 \\
\hline $1933 \ldots \ldots \ldots \ldots \ldots$ & 34.5 & 80.6 & 74.4 & 26.5 \\
\hline $1934 \ldots \ldots \ldots \ldots \ldots \ldots$ & 31.1 & 78.1 & 74.4 & 25.1 \\
\hline $1935 \ldots \ldots \ldots \ldots \ldots$ & 31.7 & 78.1 & 74.4 & 24.5 \\
\hline $1936 \ldots \ldots \ldots \ldots \ldots$ & 33.4 & 78.0 & 74.4 & 24.3 \\
\hline $1937 \ldots \ldots \ldots \ldots \ldots \ldots$ & 34.2 & 78.2 & 74.4 & 25.4 \\
\hline $1938 \ldots \ldots \ldots \ldots \ldots$ & 33.4 & 78.2 & 71.6 & 28.2 \\
\hline $1939 \ldots \ldots \ldots \ldots \ldots \ldots$ & 33.3 & 78.8 & 68.7 & 29.3 \\
\hline $1940 \ldots \ldots \ldots \ldots \ldots \ldots$ & 33.4 & 79.3 & 65.7 & 29.8 \\
\hline $1941 \ldots \ldots \ldots \ldots \ldots \ldots$ & 33.9 & 79.3 & 65.4 & 31.2 \\
\hline $1947 \ldots \ldots \ldots \ldots \ldots \ldots$ & 47.2 & 80.5 & 71.4 & 50.6 \\
\hline $1948 \ldots \ldots \ldots \ldots \ldots \ldots$ & 62.4 & 85.1 & 81.3 & 60.6 \\
\hline $1949 \ldots \ldots \ldots \ldots \ldots$ & 85.7 & 92.9 & 92.5 & 72.7 \\
\hline $1950 \ldots \ldots \ldots \ldots \ldots$ & 100.0 & 100.0 & 100.0 & 82.2 \\
\hline $1951 \ldots \ldots \ldots \ldots$ & 107.6 & 104.8 & 103.1 & 94.8 \\
\hline $1952 \ldots \ldots \ldots \ldots \ldots \ldots$ & 108.8 & 108.5 & 108.1 & 107.6 \\
\hline $1953 \ldots \ldots \ldots \ldots \ldots$ & . $\quad 112.2$ & 112.3 & 113.1 & 112.8 \\
\hline $1954 \ldots \ldots \ldots \ldots \ldots \ldots$ & . $\quad 110.5$ & 117.0 & 118.3 & 115.2 \\
\hline $1955 \ldots \ldots \ldots \ldots \ldots \ldots$ & . $\quad 105.8$ & 121.7 & 119.6 & 119.0 \\
\hline $1956 \ldots \ldots \ldots \ldots \ldots \ldots$ & . 105.4 & 126.8 & 120.8 & 121.0 \\
\hline $1957 \ldots \ldots \ldots \ldots \ldots \ldots$ & 102.2 & 131.8 & 122.4 & 121.7 \\
\hline $1958 \ldots \ldots \ldots \ldots \ldots \ldots$ & 97.4 & 136.4 & 123.6 & 121.6 \\
\hline $1959 \ldots \ldots \ldots \ldots \ldots \ldots$ & 91.9 & 140.5 & 126.4 & 121.3 \\
\hline $1960 \ldots \ldots \ldots \ldots \ldots \ldots$ & 91.2 & 143.7 & 128.3 & 123.3 \\
\hline
\end{tabular}




\begin{tabular}{|c|c|c|c|c|}
\hline$F$ & $\begin{array}{c}\text { Five-year average } \\
\text { softwood } \\
\text { plywood price } \\
\text { (X7) } \\
\text { index, } \\
1947-49=100\end{array}$ & $\begin{array}{c}\text { Five-year average } \\
\text { building } \\
\text { board price } \\
\text { (X8) } \\
\text { index, } \\
1947-49 \stackrel{=}{=} 100\end{array}$ & $\begin{array}{c}\text { Five-year average } \\
\text { wallboard } \\
\text { price } \\
(X 9) \\
\text { index, } \\
1947-49 \stackrel{=}{=} 100\end{array}$ & $\begin{array}{c}\text { Five-year } \\
\text { average clay } \\
\text { products price } \\
(X 10) \\
\text { index } \\
1947-49=100\end{array}$ \\
\hline 1929. & 52.7 & 102.8 & 78.1 & 65.1 \\
\hline$\ldots \ldots \ldots \ldots$ & 50.0 & 99.5 & 76.6 & 63.7 \\
\hline $1931 \ldots \ldots \ldots \ldots \ldots$ & 47.1 & 94.3 & 75.1 & 62.0 \\
\hline$\ldots \ldots \ldots \ldots \ldots$ & 43.2 & 89.3 & 74.1 & 59.7 \\
\hline $1933 \ldots \ldots \ldots \ldots \ldots$ & 38.9 & 85.2 & 73.7 & 57.0 \\
\hline $1934 \ldots \ldots \ldots \ldots \ldots$ & 35.9 & 81.1 & 73.7 & 54.8 \\
\hline $1935 \ldots \ldots \ldots \ldots \ldots$ & 34.1 & 79.6 & 74.4 & 54.8 \\
\hline $1936 \ldots \ldots \ldots \ldots \ldots$ & 32.5 & 78.3 & 74.4 & 55.0 \\
\hline$\ldots \ldots \ldots \ldots \ldots$ & 32.4 & 77.9 & 74.4 & 55.8 \\
\hline $1938 \ldots \ldots \ldots \ldots \ldots$ & 33.5 & 78.2 & 72.7 & 58.0 \\
\hline $1939 \ldots \ldots \ldots \ldots \ldots$ & 33.8 & 78.7 & 71.0 & 59.7 \\
\hline $1940 \ldots \ldots \ldots \ldots \ldots$ & 33.4 & 78.7 & 69.2 & 59.9 \\
\hline $1941 \ldots \ldots \ldots \ldots \ldots$ & 33.8 & 79.0 & 67.3 & 60.4 \\
\hline 1947. & 44.6 & 80.0 & 69.0 & 72.5 \\
\hline $1948 \ldots \ldots \ldots \ldots \ldots$ & 54.7 & 82.8 & 74.9 & 77.2 \\
\hline $1949 \ldots \ldots \ldots \ldots \ldots$ & 68.9 & 87.5 & 82.3 & 84.2 \\
\hline $1950 \ldots \ldots \ldots \ldots \ldots$ & 79.6 & 92.4 & 89.8 & 91.8 \\
\hline $1951 \ldots \ldots \ldots \ldots \ldots$ & 93.2 & 98.1 & 96.9 & 99.3 \\
\hline$\ldots \ldots \ldots \ldots$ & 105.9 & 104.3 & 104.4 & 106.8 \\
\hline $1953 \ldots \ldots \ldots \ldots \ldots$ & 109.4 & 108.8 & 108.8 & 112.5 \\
\hline $1954 \ldots \ldots \ldots \ldots \ldots$ & 108.2 & 112.6 & 112.4 & 117.9 \\
\hline $1955 \ldots \ldots \ldots \ldots \ldots$ & 109.3 & 117.3 & 116.1 & 123.4 \\
\hline $1956 \ldots \ldots \ldots \ldots$ & 108.1 & 121.9 & 119.4 & 128.9 \\
\hline $1957 \ldots \ldots$ & 104.2 & 126.6 & 120.9 & 134.3 \\
\hline $1958 \ldots \ldots \ldots \ldots \ldots \ldots$ & 100.5 & 131.7 & 122.4 & 140.7 \\
\hline $1959 \ldots \ldots \ldots \ldots \ldots$ & 97.0 & 136.0 & 124.3 & 146.3 \\
\hline $1960 \ldots \ldots \ldots \ldots \ldots$ & 95.4 & 139.8 & 126.2 & 151.8 \\
\hline
\end{tabular}




\begin{tabular}{|c|c|c|c|c|}
\hline $\mathbf{F}$ & $\begin{array}{c}\text { Five-year average } \\
\text { structural } \\
\text { steel price } \\
\text { (X11) } \\
\text { index, } \\
1947-49=100\end{array}$ & $\begin{array}{c}\text { Ten-year average } \\
\text { lumber } \\
\text { price } \\
(X 12) \\
\text { index, } \\
1947-49=100\end{array}$ & $\begin{array}{c}\text { Ten-year average } \\
\text { clay products } \\
\text { price } \\
\text { (XI1) } \\
\text { index, } \\
1947-49=100\end{array}$ & $\begin{array}{c}\text { Ten-year } \\
\text { average } \\
\text { structural } \\
\text { steel price } \\
\text { (X14) } \\
\text { index, } \\
1947-49=100\end{array}$ \\
\hline$\ldots \ldots \ldots \ldots \ldots$ & 63.6 & 35.2 & 66.8 & 68.8 \\
\hline $1930 \ldots \ldots \ldots \ldots \ldots$ & 61.6 & 34.6 & 66.8 & 66.9 \\
\hline $1931 \ldots \ldots \ldots \ldots \ldots$ & 59.7 & 32.0 & 64.8 & 63.3 \\
\hline $1932 \ldots \ldots \ldots \ldots \ldots$ & 57.6 & 31.3 & 63.2 & 62.0 \\
\hline $1933 \ldots \ldots \ldots \ldots \ldots$ & 55.8 & 30.0 & 61.6 & 61.5 \\
\hline $1934 \ldots \ldots \ldots \ldots \ldots$ & 54.3 & 28.6 & 60.0 & 59.0 \\
\hline $1935 \ldots \ldots \ldots \ldots \ldots$ & 53.4 & 28.1 & 59.2 & 57.5 \\
\hline $1936 \ldots \ldots \ldots \ldots \ldots$ & 54.0 & 27.5 & 58.5 & 56.8 \\
\hline $1937 \ldots \ldots \ldots \ldots \ldots \ldots$ & 55.5 & 27.1 & 57.7 & 56.5 \\
\hline $1938 \ldots \ldots \ldots \ldots \ldots$ & 59.6 & 27.3 & 57.5 & 57.7 \\
\hline $1939 \ldots \ldots \ldots \ldots \ldots \ldots$ & 63.1 & 27.2 & 57.3 & 58.7 \\
\hline $1940 \ldots \ldots \ldots \ldots \ldots \ldots$ & 65.1 & 27.2 & 57.3 & 59.3 \\
\hline $1941 \ldots \ldots \ldots \ldots \ldots$ & 67.1 & 27.8 & 57.7 & 60.5 \\
\hline $1947 \ldots \ldots \ldots \ldots \ldots \ldots$ & 68.8 & 42.1 & 67.2 & 68.7 \\
\hline $1948 \ldots \ldots \ldots \ldots \ldots \ldots$ & 72.2 & 48.2 & 70.4 & 70.0 \\
\hline $1949 \ldots \ldots \ldots \ldots \ldots$ & 79.3 & 56.1 & 74.6 & 73.4 \\
\hline $1950 \ldots \ldots \ldots \ldots \ldots$ & 88.3 & 62.8 & 78.9 & 77.9 \\
\hline $1951 \ldots \ldots \ldots \ldots \ldots \ldots$ & 99.1 & 70.8 & 84.0 & 83.2 \\
\hline $1952 \ldots \ldots \ldots \ldots \ldots$ & . $\quad 109.9$ & 79.1 & 89.7 & 89.3 \\
\hline $1953 \ldots \ldots$ & . $\quad 119.2$ & 86.7 & 94.9 & 95.7 \\
\hline $1954 \ldots \ldots \ldots \ldots \ldots \ldots$ & . $\quad 126.2$ & 94.0 & 101.0 & 102.8 \\
\hline $1955 \ldots \ldots \ldots \ldots \ldots \ldots$ & . $\quad 132.5$ & 100.6 & 107.6 & 110.4 \\
\hline $1956 \ldots \ldots \ldots \ldots \ldots$ & . $\quad 138.6$ & 107.9 & 114.1 & 118.8 \\
\hline $1957 \ldots \ldots \ldots \ldots \ldots \ldots$ & 145.5 & 114.7 & 120.5 & 127.7 \\
\hline $1958 \ldots \ldots \ldots$ & 156.8 & 117.2 & 126.6 & 138.0 \\
\hline $1959 \ldots \ldots \ldots$ & 168.2 & 118.3 & 132.1 & 147.2 \\
\hline $1960 \ldots \ldots \ldots \ldots \ldots$ & 179.4 & 121.2 & 137.6 & 155.9 \\
\hline
\end{tabular}




\begin{tabular}{|c|c|c|c|c|}
\hline Year & $\begin{array}{c}\text { Wages in } \\
\text { construction } \\
(X 15), \\
\text { dollars per hour }\end{array}$ & $\begin{array}{c}\text { Wages in } \\
\text { construction } \\
\text { three-year average } \\
\text { (X16), } \\
\text { dollars per hour }\end{array}$ & $\begin{array}{c}\text { Wages in } \\
\text { construction } \\
\text { five-year average } \\
\text { (X17), } \\
\text { dollars per hour }\end{array}$ & $\begin{array}{c}\text { Value of } \\
\text { private } \\
\text { residential } \\
\text { construction } \\
(18), \\
\text { millions of } \\
\text { dollars }\end{array}$ \\
\hline $1929 \ldots \ldots \ldots \ldots$ & 1.360 & 1.310 & 1.270 & 3625 \\
\hline $1930 \ldots \ldots \ldots \ldots \ldots \ldots$ & . 1.380 & 1.340 & 1.300 & 2075 \\
\hline $1931 \ldots \ldots \ldots \ldots \ldots$ & 1.270 & 1.360 & 1.340 & 1565 \\
\hline $1932 \ldots \ldots \ldots \ldots \ldots$ & . $\quad 1.020$ & 1.337 & 1.340 & 630 \\
\hline $1933 \ldots \ldots \ldots \ldots \ldots$ & . 1.006 & 1.223 & 1.280 & 470 \\
\hline $1934 \ldots \ldots \ldots \ldots \ldots$ & . 1.097 & 1.099 & 1.207 & 625 \\
\hline $1935 \ldots \ldots \ldots \ldots \ldots$ & . 1.093 & 1.041 & 1.155 & 1010 \\
\hline $1936 \ldots \ldots \ldots \ldots \ldots$ & . 1.149 & 1.065 & 1.097 & 1565 \\
\hline $1937 \ldots \ldots \ldots \ldots \ldots$ & . 1.321 & 1.113 & 1.073 & 1875 \\
\hline $1938 \ldots \ldots \ldots \ldots \ldots$ & 1.413 & 1.188 & 1.133 & 1990 \\
\hline $1939 \ldots \ldots \ldots \ldots \ldots$ & 1.443 & 1.294 & 1.215 & 2680 \\
\hline 1940 . & . 1.473 & 1.392 & 1.284 & 2985 \\
\hline $1941 \ldots \ldots \ldots \ldots \ldots$ & . 1.495 & 1.443 & 1.360 & 3510 \\
\hline $1947 \ldots \ldots \ldots \ldots \ldots$ & . 2.019 & 1.697 & 1.654 & 7535 \\
\hline$\ldots \ldots \ldots \ldots \ldots$ & 2.248 & 1.825 & 1.745 & 10122 \\
\hline$\ldots \ldots \ldots \ldots \ldots$ & 2.411 & 2.021 & 1.871 & 9642 \\
\hline 1950. & . $\quad 2.518$ & 2.226 & 2.027 & 14100 \\
\hline $1951 \ldots \ldots \ldots \ldots \ldots$ & 2.669 & 2.392 & 2.198 & 12529 \\
\hline $1952 \ldots \ldots \ldots \ldots \ldots$ & . 2.842 & 2.533 & 2.373 & 12842 \\
\hline 1953. & 3.009 & 2.676 & 2.538 & 13777 \\
\hline $1954 \ldots \ldots \ldots \ldots \ldots$ & . 3.134 & 2.840 & 2.690 & 15379 \\
\hline $1955 \ldots \ldots \ldots \ldots \ldots$ & . $\quad 3.237$ & 2.995 & 2.834 & 18705 \\
\hline $1956 \ldots \ldots$ & 3.371 & 3.127 & 2.978 & 17677 \\
\hline $1957 \ldots \ldots \ldots \ldots \ldots \ldots$ & . $\quad 3.532$ & 3.247 & 3.119 & 17019 \\
\hline 1958. & 3.692 & 3.380 & 3.257 & 18047 \\
\hline$\ldots \ldots \ldots \ldots$ & . 3.861 & 3.532 & 3.393 & 24962 \\
\hline $1960 \ldots \ldots \ldots \ldots \ldots$ & . 4.031 & 3.695 & 3.539 & 22546 \\
\hline
\end{tabular}




\begin{tabular}{|c|c|c|c|c|}
\hline Year & $\begin{array}{c}\text { Value of private } \\
\text { non-residential } \\
\text { construction } \\
(X 19), \\
\text { millions of } \\
\text { dollars }\end{array}$ & $\begin{array}{c}\text { Value of } \\
\text { public } \\
\text { construction } \\
(X 20), \\
\text { millions of } \\
\text { dollars }\end{array}$ & $\begin{array}{c}\text { Value of } \\
\text { maintenance } \\
\text { and repair, } \\
(X 21), \\
\text { millions of } \\
\text { dollars }\end{array}$ & $\begin{array}{c}\text { Index of } \\
\text { manufacturing } \\
\text { production } \\
(X 22) \\
\text { index, } \\
1947-49=100\end{array}$ \\
\hline 1929 & 4682 & 2486 & 4201 & 58 \\
\hline $1930 \ldots \ldots \ldots \ldots \ldots \ldots$ & 3808 & 2858 & 3874 & 48 \\
\hline $1931 \ldots \ldots \ldots \ldots \ldots$ & 2203 & 2659 & 3232 & 39 \\
\hline $1932 \ldots \ldots \ldots \ldots \ldots \ldots$ & 1046 & 1862 & 2576 & 30 \\
\hline $1933 \ldots \ldots \ldots \ldots \ldots$ & 761 & 1648 & 2478 & 36 \\
\hline $1934 \ldots \ldots \ldots \ldots \ldots \ldots$ & 884 & 2211 & 2942 & 39 \\
\hline $1935 \ldots \ldots \ldots \ldots \ldots \ldots$ & 989 & 2233 & 3145 & 46 \\
\hline $1936 \ldots \ldots \ldots \ldots \ldots$ & 1416 & 3516 & 3795 & 55 \\
\hline $1937 \ldots \ldots \ldots \ldots \ldots \ldots$ & 2028 & 3096 & 3895 & 60 \\
\hline $1938 \ldots \ldots \ldots \ldots \ldots$ & 1570 & 3420 & 3884 & 46 \\
\hline $1939 \ldots \ldots \ldots \ldots \ldots$ & 1709 & 3809 & 3978 & 57 \\
\hline $1940 \ldots \ldots \ldots \ldots \ldots \ldots$ & 2069 & 3628 & 4119 & 66 \\
\hline $1941 \ldots \ldots \ldots \ldots \ldots \ldots$ & 2696 & 5751 & 4485 & 88 \\
\hline $1947 \ldots \ldots \ldots \ldots \ldots \ldots$ & 6946 & 3434 & 10374 & 100 \\
\hline $1948 \ldots \ldots \ldots \ldots \ldots \ldots$ & 8273 & 4827 & 11801 & 103 \\
\hline $1949 \ldots \ldots \ldots \ldots \ldots \ldots$ & 8117 & 6404 & 11966 & 97 \\
\hline $1950 \ldots \ldots \ldots \ldots \ldots$ & 8854 & 7001 & 12084 & 113 \\
\hline $1951 \ldots \ldots \ldots \ldots \ldots \ldots$ & 10791 & 9419 & 13386 & 121 \\
\hline $1952 \ldots \ldots \ldots \ldots \ldots$ & 11007 & 10901 & 14153 & 125 \\
\hline $1953 \ldots \ldots \ldots \ldots \ldots$ & 11947 & 11394 & 14379 & 136 \\
\hline $1954 \ldots \ldots \ldots \ldots \ldots \ldots$ & 12300 & 11922 & 14666 & 127 \\
\hline $1955 \ldots \ldots \ldots \ldots \ldots \ldots$ & 13915 & 11961 & 15843 & 146 \\
\hline $1956 \ldots \ldots \ldots \ldots \ldots \ldots$ & I 5390 & 12748 & 16978 & 150 \\
\hline $1957 \ldots \ldots \ldots \ldots \ldots \ldots$ & 16747 & 14079 & 17920 & 150 \\
\hline $1958 \ldots \ldots \ldots \ldots \ldots$ & 15446 & 15457 & 17846 & 138 \\
\hline $1959 \ldots \ldots \ldots \ldots \ldots \ldots$ & 15382 & 16211 & 19252 & 158 \\
\hline $1960 \ldots \ldots \ldots \ldots \ldots \ldots$ & 17057 & 15953 & 19556 & 162 \\
\hline
\end{tabular}




\begin{tabular}{|c|c|c|c|c|c|}
\hline Year & $\begin{array}{l}\text { Population } \\
(X 23), \\
\text { in millions }\end{array}$ & $\begin{array}{c}\text { Per capita } \\
\text { income } \\
(X 24), \\
\text { thousands } \\
\text { of dollars }\end{array}$ & $\begin{array}{l}\text { Value of total } \\
\text { construction } \\
\text { (X25), } \\
\text { millions } \\
\text { of dollars }\end{array}$ & $\begin{array}{l}\text { Freight } \\
\text { rates } \\
(X 26), \\
\text { cents per } \\
\text { ton mile }\end{array}$ & $\begin{array}{l}\text { Trend } \\
(X 27)\end{array}$ \\
\hline $1929 \ldots \ldots \ldots$ & 121.8 & 0.68 & 14994 & 1.088 & 1 \\
\hline $1930 \ldots \ldots \ldots$ & 123.2 & 0.60 & 12615 & 1.074 & 2 \\
\hline $1931 \ldots \ldots \ldots$ & 124.1 & 0.51 & 9659 & 1.062 & 3 \\
\hline $1932 \ldots \ldots \ldots$ & 124.9 & 0.39 & 6114 & 1.056 & 4 \\
\hline $1933 \ldots \ldots \ldots$ & 125.7 & 0.36 & 5357 & 1.009 & 5 \\
\hline $1934 \ldots \ldots \ldots$ & 126.5 & 0.41 & 6662 & 0.989 & 6 \\
\hline $1935 \ldots \ldots \ldots$ & 127.4 & 0.46 & 7377 & 0.998 & 7 \\
\hline $1936 \ldots \ldots \ldots$ & 128.2 & 0.52 & 10292 & 0.984 & 8 \\
\hline $1937 \ldots \ldots \ldots$ & 129.0 & 0.55 & 10894 & 0.945 & 9 \\
\hline $1938 \ldots \ldots \ldots$ & 130.0 & 0.50 & 10864 & 0.994 & 10 \\
\hline $1939 \ldots \ldots \ldots$ & 131.0 & 0.54 & 12176 & 0.983 & 11 \\
\hline $1940 \ldots \ldots \ldots$ & 132.1 & 0.58 & 12801 & 0.955 & 12 \\
\hline $1941 \ldots \ldots \ldots$ & 133.4 & 0.70 & 16442 & 0.944 & 13 \\
\hline $1947 \ldots \ldots \ldots$ & 144.1 & 1.18 & 28289 & 1.085 & 19 \\
\hline $1948 \ldots \ldots \ldots$ & 146.6 & 1.29 & 35023 & 1.262 & 20 \\
\hline $1949 \ldots \ldots \ldots$ & 149.2 & 1.27 & 36129 & 1.352 & 21 \\
\hline $1950 \ldots \ldots$ & 151.7 & 1.37 & 42039 & 1.341 & 22 \\
\hline $1951 \ldots \ldots \ldots$ & 154.4 & 1.47 & 46125 & 1.348 & 23 \\
\hline $1952 \ldots \ldots \ldots$ & 157.0 & 1.52 & 48903 & 1.443 & 24 \\
\hline $1953 \ldots \ldots \ldots$ & 159.6 & 1.58 & 51497 & 1.491 & 25 \\
\hline $1954 \ldots \ldots \ldots$ & 162.4 & 1.58 & 54267 & 1.433 & 26 \\
\hline $1955 \ldots \ldots \ldots$ & 165.3 & 1.66 & 60424 & 1.382 & 27 \\
\hline $1956 \ldots \ldots \ldots$ & 168.2 & 1.74 & 63012 & 1.396 & 28 \\
\hline $1957 \ldots \ldots \ldots$ & 171.2 & 1.80 & 65765 & 1.457 & 29 \\
\hline $1958 \ldots \ldots \ldots$ & 174.1 & 1.82 & 66796 & 1.477 & 30 \\
\hline $1959 \ldots \ldots$ & 177.3 & 1.90 & 75807 & 1.459 & 31 \\
\hline $1960 \ldots \ldots \ldots$ & 180.7 & 1.95 & 75112 & 1.417 & 32 \\
\hline
\end{tabular}




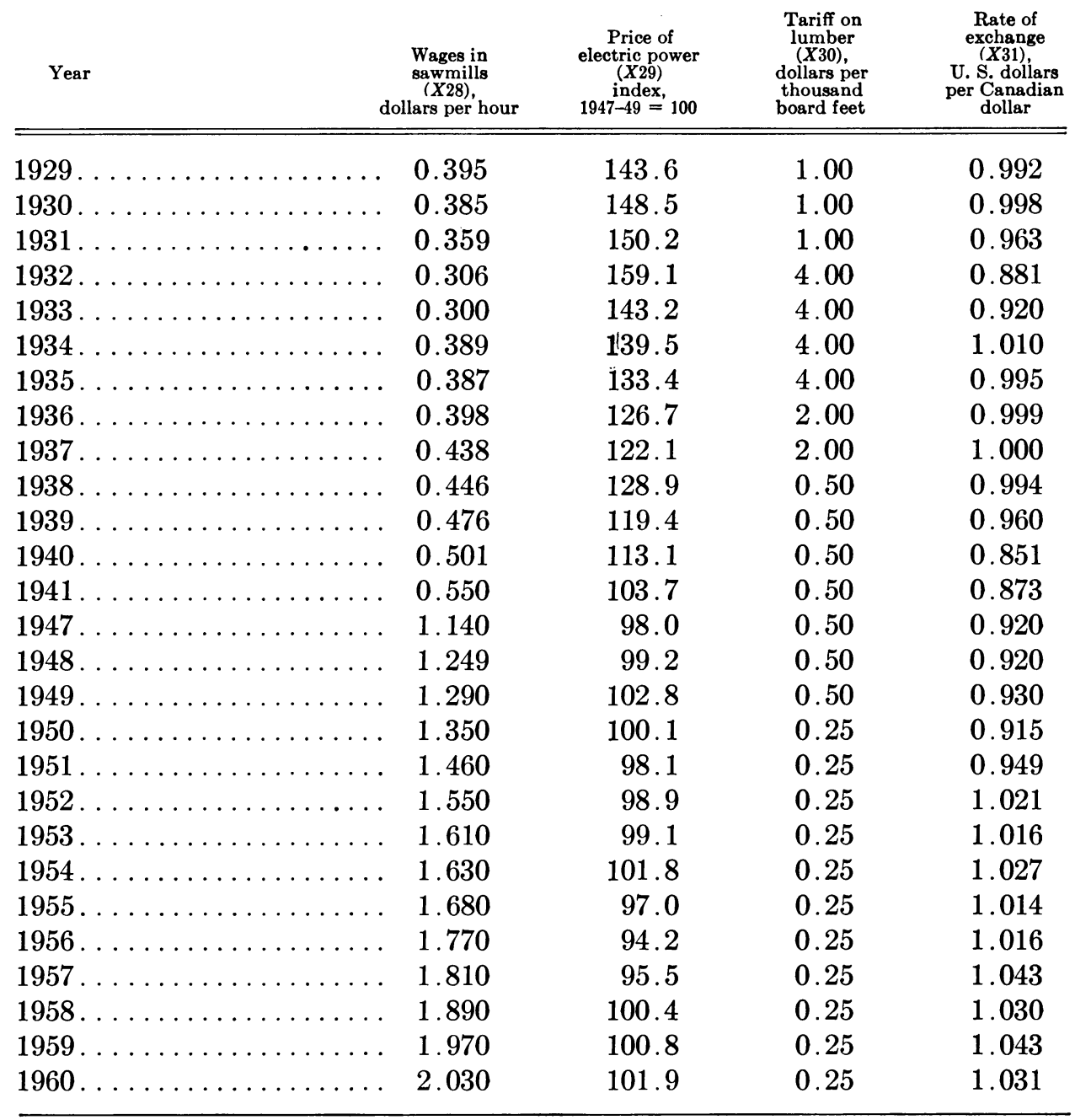




\begin{tabular}{|c|c|c|c|c|}
\hline Year & $\begin{array}{l}\text { Wages in } \\
\text { pulp and paper } \\
\text { (X32), } \\
\text { dollars } \\
\text { per hour } \\
\end{array}$ & 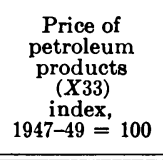 & 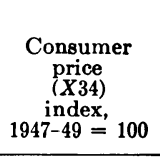 & 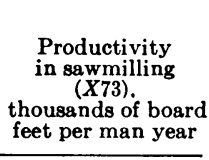 \\
\hline $1929 \ldots \ldots$ & 0.53 & 69.9 & 73.3 & 55.0 \\
\hline $1930 \ldots \ldots \ldots \ldots \ldots$ & . 0.53 & 60.4 & 71.4 & 50.8 \\
\hline $1931 \ldots \ldots \ldots \ldots \ldots$ & 0.50 & 38.7 & 65.0 & 44.7 \\
\hline $1932 \ldots \ldots \ldots \ldots \ldots$ & 0.46 & 44.5 & 58.4 & 38.9 \\
\hline $1933 \ldots \ldots \ldots \ldots$ & . 0.44 & 40.2 & 55.3 & 45.4 \\
\hline $1934 \ldots \ldots \ldots \ldots \ldots$ & . 0.52 & 49.5 & 57.2 & 39.5 \\
\hline $1935 \ldots \ldots \ldots \ldots$ & . 0.54 & 50.3 & 58.7 & 43.5 \\
\hline $1936 \ldots \ldots \ldots \ldots \ldots$ & . 0.54 & 56.2 & 59.3 & 46.0 \\
\hline $1937 \ldots \ldots \ldots \ldots \ldots$ & . 0.61 & 59.3 & 61.4 & 41.9 \\
\hline $1938 \ldots \ldots \ldots \ldots \ldots$ & . 0.63 & 54.9 & 60.3 & 46.5 \\
\hline $1939 \ldots \ldots \ldots \ldots \ldots$ & . 0.63 & 51.2 & 59.4 & 39.7 \\
\hline $1940 \ldots \ldots \ldots \ldots \ldots$ & . 0.66 & 49.0 & 59.9 & 40.8 \\
\hline $1941 \ldots \ldots \ldots \ldots \ldots$ & . 0.71 & 55.9 & 62.9 & 40.2 \\
\hline $1947 \ldots \ldots \ldots \ldots \ldots$ & . $\quad 1.22$ & 88.2 & 95.5 & 45.3 \\
\hline $1948 \ldots \ldots \ldots \ldots \ldots \ldots$ & . 1.36 & 111.7 & 102.8 & 49.0 \\
\hline $1949 \ldots \ldots \ldots \ldots \ldots$ & . 1.41 & 100.1 & 101.8 & 47.5 \\
\hline $1950 \ldots \ldots \ldots \ldots \ldots$ & . 1.48 & 103.7 & 102.8 & 51.1 \\
\hline $1951 \ldots \ldots \ldots \ldots \ldots$ & . 1.60 & 110.5 & 111.0 & 48.4 \\
\hline $1952 \ldots \ldots \ldots \ldots \ldots$ & . $\quad 1.69$ & 109.3 & 113.5 & 52.2 \\
\hline $1953 \ldots \ldots \ldots \ldots \ldots$ & . $\quad 1.79$ & 112.7 & 114.4 & 52.6 \\
\hline $1954 \ldots \ldots \ldots \ldots \ldots$ & . 1.84 & 110.8 & 114.8 & 57.1 \\
\hline $1955 \ldots \ldots \ldots \ldots \ldots$ & . 1.94 & 112.7 & 114.5 & 55.1 \\
\hline $1956 \ldots \ldots \ldots \ldots \ldots \ldots$ & . 2.06 & 118.2 & 116.2 & 57.3 \\
\hline $1957 \ldots \ldots \ldots \ldots \ldots \ldots$ & . 2.17 & 127.0 & 120.2 & 56.0 \\
\hline $1958 \ldots \ldots \ldots \ldots \ldots \ldots$ & . 2.25 & 117.7 & 123.5 & 60.0 \\
\hline $1959 \ldots \ldots \ldots \ldots \ldots \ldots$ & . 2.33 & 116.6 & 124.6 & 62.8 \\
\hline $1960 \ldots \ldots \ldots \ldots \ldots \ldots$ & . 2.43 & 117.5 & 126.5 & 60.8 \\
\hline
\end{tabular}




\begin{tabular}{|c|c|c|c|}
\hline Year & $\begin{array}{c}\text { Productivity in } \\
\text { pulp and paper } \\
\text { (X74), } \\
\text { thousds of tons } \\
\text { per man year }\end{array}$ & $\begin{array}{c}\text { Price of structural } \\
\text { clay products } \\
\text { (X87) } \\
\text { index, } \\
1947-49 \stackrel{=}{=} 100\end{array}$ & $\begin{array}{c}\text { Price of structural } \\
\text { steel shapes } \\
\text { in88) } \\
\text { index, } \\
1947-49=100\end{array}$ \\
\hline 1929. & 87.0 & 61.0 & 61.6 \\
\hline 1930. & 82.0 & 57.8 & 54.8 \\
\hline $1931 \ldots$ & 86.9 & 53.9 & 52.2 \\
\hline $1932 \ldots$ & 80.8 & 49.7 & 50.8 \\
\hline $1933 \ldots$ & 85.9 & 51.8 & 52.2 \\
\hline 1934. & 74.1 & 60.7 & 57.0 \\
\hline 1935. & 82.5 & 58.8 & 57.8 \\
\hline 1936. & 92.8 & 57.9 & 59.7 \\
\hline $1937 \ldots$ & 93.0 & 60.8 & 71.1 \\
\hline $1938 \ldots$ & 88.9 & 60.4 & 69.7 \\
\hline 1939. & 97.9 & 61.5 & 67.4 \\
\hline 1940. & 99.2 & 61.4 & 67.4 \\
\hline 1941. & . $\quad 110.3$ & 65.2 & 67.4 \\
\hline $1947 \ldots$ & $\begin{array}{ll}\ldots & 101.9\end{array}$ & 93.3 & 84.5 \\
\hline $1948 \ldots$ & . $\quad 102.8$ & 101.4 & 102.8 \\
\hline 1949 . & 100.1 & 105.3 & 112.6 \\
\hline 1950 . & . $\quad 113.9$ & 112.6 & 121.0 \\
\hline $1951 \ldots$ & . $\quad 116.8$ & 121.4 & 128.4 \\
\hline $1952 \ldots$ & . . $\quad 113.0$ & 122.0 & 131.0 \\
\hline 1953. & $\begin{array}{ll}\text {. . } \quad 120.9\end{array}$ & 128.1 & 138.2 \\
\hline 1954. & . . 121.1 & 133.1 & 143.8 \\
\hline $1955 \ldots$ & . $\quad 132.9$ & 140.1 & 151.8 \\
\hline 1956. & . 136.7 & 148.0 & 162.8 \\
\hline $1957 \ldots$ & . 133.3 & 154.0 & 187.5 \\
\hline 1958. & . . $\quad 140.1$ & 156.5 & 195.3 \\
\hline 1959. & 151.2 & 160.2 & 199.5 \\
\hline $1960 \ldots$ & . $\quad 153.8$ & 161.8 & 199.5 \\
\hline
\end{tabular}




\section{Forecasts of Exogenous Variables}

\begin{tabular}{|c|c|c|c|c|c|}
\hline fi & $\begin{array}{c}\text { Wages in } \\
\text { construction } \\
\text { five-year average } \\
\text { (X17), } \\
\text { dollars } \\
\text { per hour }\end{array}$ & $\begin{array}{c}\text { Index of } \\
\text { manufacturing } \\
\text { production } \\
\text { (X22) } \\
\text { index, } \\
1947-49=100\end{array}$ & $\begin{array}{l}\text { Population } \\
\quad(X 23), \\
\text { in millions }\end{array}$ & $\begin{array}{c}\text { Per capita } \\
\text { income } \\
(X 24), \\
\text { thousands } \\
\text { of dollars }\end{array}$ & $\begin{array}{l}\text { Value of total } \\
\text { construction } \\
(X 25) . \\
\text { millions } \\
\text { of dollars }\end{array}$ \\
\hline 1961. & 3.710 & 167.319 & 182.504 & 2.017 & 80236.93 \\
\hline 1962. & 3.860 & 172.237 & 185.297 & 2.075 & 83799.96 \\
\hline 1963. & 4.010 & 177.156 & 188.090 & 2.133 & 87362.99 \\
\hline 1964. & . 4.160 & 182.075 & 190.883 & 2.191 & 90926.02 \\
\hline 1965. & . 4.310 & 186.993 & 193.676 & 2.249 & 94489.05 \\
\hline 1966 . & . 4.460 & 191.912 & 196.469 & 2.307 & 98052.07 \\
\hline 1967. & . 4.610 & 196.831 & 199.262 & 2.365 & 101615.10 \\
\hline $1968 \ldots \ldots$ & . $\quad 4.759$ & 201.749 & 202.055 & 2.424 & 105178.13 \\
\hline $1969 \ldots \ldots$ & $\begin{array}{l}. \\
.\end{array}$ & 206.668 & 204.848 & 2.482 & 108741.16 \\
\hline 1970 . & . $\quad 5.059$ & 211.587 & 207.641 & 2.540 & 112304.19 \\
\hline 1971. & . $\quad 5.209$ & 216.505 & 210.434 & 2.598 & 115867.22 \\
\hline $1972 \ldots \ldots$ & . $\quad 5.359$ & 221.424 & 213.228 & 2.656 & 119430.24 \\
\hline $1973 \ldots \ldots$ & . $\quad 5.509$ & 226.343 & 216.020 & 2.714 & 122993.27 \\
\hline $1974 \ldots \ldots$ & . 5.659 & 231.262 & 218.813 & 2.772 & 126556.30 \\
\hline $1975 \ldots \ldots$ & 5.808 & 236.180 & 221.606 & 2.830 & 130119.33 \\
\hline Year & & $\begin{array}{l}\text { Freight } \\
\text { rates } \\
\text { (X26), } \\
\text { cents per } \\
\text { ton mile }\end{array}$ & $\begin{array}{l}\text { Wages in } \\
\text { sawmmills } \\
\text { (X28), } \\
\text { dollars } \\
\text { per hour }\end{array}$ & $\begin{array}{c}\text { Price of } \\
\text { electric power } \\
\text { (X29) } \\
\text { index, } \\
1947-49=100\end{array}$ & $\begin{array}{l}\text { Wages in } \\
\text { pulp and paper } \\
\text { (X32), } \\
\text { dollars } \\
\text { per hour }\end{array}$ \\
\hline 1961. & 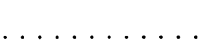 & 1.520 & 2.098 & 98.997 & 2.517 \\
\hline 1962. & & 1.539 & 2.164 & 98.979 & 2.609 \\
\hline 1963. & & 1.557 & 2.230 & 98.962 & 2.701 \\
\hline 1964. & & 1.576 & 2.296 & 98.944 & 2.793 \\
\hline 1965. & & 1.594 & 2.362 & 98.926 & 2.885 \\
\hline 1966. & & 1.613 & 2.428 & 98.909 & 2.977 \\
\hline $1967 \ldots$ & $\ldots$ & 1.631 & 2.495 & 98.891 & 3.069 \\
\hline 1968. & & 1.650 & 2.561 & 98.874 & 3.161 \\
\hline 1969. & & 1.668 & 2.627 & 98.856 & 3.253 \\
\hline $1970 \ldots$ & $\ldots \ldots \ldots$ & 1.687 & 2.693 & 98.839 & 3.345 \\
\hline 1971. & & 1.705 & 2.759 & 98.821 & 3.437 \\
\hline $1972 \ldots$ & $\ldots \ldots \ldots$ & 1.724 & 2.825 & 98.803 & 3.529 \\
\hline 1973. & & 1.742 & 2.891 & 98.786 & 3.621 \\
\hline $1974 \ldots$ & $\ldots \ldots \ldots$ & 1.761 & 2.957 & 98.768 & 3.714 \\
\hline $1975 \ldots \ldots$ & $\ldots \ldots \ldots \ldots$ & 1.779 & 3.023 & 98.751 & 3.806 \\
\hline
\end{tabular}




\begin{tabular}{|c|c|c|c|c|}
\hline Year & $\begin{array}{l}\text { Price of petroleum } \\
\text { products } \\
\text { (X33) } \\
\text { index, } \\
1947-49=100\end{array}$ & $\begin{array}{c}\text { Consumer } \\
\text { price index } \\
(X 34) \\
\text { index } \\
1947-49=100\end{array}$ & $\begin{array}{c}\text { Productivity } \\
\text { in sawmilling } \\
\text { (X73), } \\
\text { thounds board } \\
\text { feet per man year }\end{array}$ & $\begin{array}{c}\text { Productivity in } \\
\text { pulp and paper } \\
(X 74) \\
\text { thousands of tons } \\
\text { per man year }\end{array}$ \\
\hline 1961. & 124.431 & 129.314 & 63.137 & 154.876 \\
\hline 1962. & 126.196 & 131.488 & 64.363 & 158.969 \\
\hline 1963. & 127.961 & 133.663 & 65.589 & 163.062 \\
\hline 1964. & 129.726 & 135.837 & 66.815 & 167.154 \\
\hline 1965. & 131.491 & 138.011 & 68.041 & 171.247 \\
\hline 1966 . & 133.256 & 140.186 & 69.267 & 175.340 \\
\hline 1967. & 135.021 & 142.360 & 70.493 & 179.433 \\
\hline 1968. & 136.786 & 144.534 & 71.719 & 183.526 \\
\hline 1969. & 138.551 & 146.708 & 72.945 & 187.619 \\
\hline 1970 . & 140.316 & 148.883 & 74.171 & 191.712 \\
\hline 1971. & 142.081 & 151.057 & 75.397 & 195.805 \\
\hline 1972 . & 143.846 & 153.231 & 76.622 & 199.898 \\
\hline 1973. & 145.611 & 155.405 & 77.848 & 203.991 \\
\hline 1974. & 147.376 & 157.580 & 79.074 & 208.084 \\
\hline 1975. & 149.141 & 159.754 & 80.300 & 212.177 \\
\hline
\end{tabular}




\section{APPENDIX F \\ FORECASTING EQUATIONS*}

\begin{tabular}{|c|c|c|c|}
\hline \multirow{2}{*}{ Independent variables } & \multicolumn{3}{|c|}{ Lumber consumption $(Q 1)$} \\
\hline & $\mathrm{CRF}$ & SS & ERF \\
\hline $\mathrm{R}^{2}$. & 0.97456 & & 0.97390 \\
\hline Regression constant. & -32.42220 & 80.46246 & 129.98076 \\
\hline Wages in construction... & -5.43132 & 3.73052 & -13.40211 \\
\hline Index of manufacturing production. ....... & 0.21018 & 0.16917 & 0.16403 \\
\hline Population........................... & $\ldots \ldots \ldots$ & $\ldots \ldots \ldots$ & ........ \\
\hline Per capita income ....................... $(X 24)$ & .. & & \\
\hline Value of construction... & & .00032 & .00087 \\
\hline Freight rates. . & 5.21827 & -4.87912 & 8.02005 \\
\hline.$(X 27)$ & $\ldots .$. & -1.15058 & -.79551 \\
\hline Wages in sawmills...... & & -22.60670 & \\
\hline Price of electric power $\ldots \ldots \ldots \ldots \ldots \ldots \ldots$ & -.28337 & -.39279 & -.45425 \\
\hline Tariff on lumber............... & -1.12248 & -.80563 & -.28387 \\
\hline Rate of exchange.. & -21.12683 & -22.03814 & -45.56739 \\
\hline Wages in pulp and paper.... & & -1.01157 & \\
\hline Price of petroleum products. . & -0.00682 & 0.02439 & -0.14956 \\
\hline Consumer price index. . & 0.21138 & & 0.20272 \\
\hline Productivity in sawmilling $\ldots \ldots \ldots \ldots \ldots \ldots \ldots(X 73)$ & 0.54652 & 0.31991 & 0.53660 \\
\hline Productivity in pulp and paper.... & -0.14154 & -0.09534 & -0.36184 \\
\hline Ratio past prices plywood/lumber............. $(X 75)$ & 22.46671 & 2.90383 & \\
\hline Ratio past prices building board/lumber..... & & -1.69074 & \\
\hline Ratio past prices clay products/lumber...... & & & \\
\hline Ratio past prices steel/lumber. & 21.32572 & 1.85553 & \\
\hline Ratio past prices plywood/building board......... (X81) & -42.74111 & -6.89947 & \\
\hline Ratio past prices wallboard/building board.......(X82) & 78.00821 & 5.53252 & \\
\hline Ratio past prices wallboard/plywood...........(X85) & -31.15252 & 2.76072 & \\
\hline Dummy variable.... & -3.27979 & 1.38767 & -17.06200 \\
\hline Price of plywood. & $\ldots$ & .12795 & \\
\hline Price of peeler logs... & & .26960 & \\
\hline Price of sawlog stumpage....... & $\ldots \ldots \ldots$ & $\ldots \ldots \ldots$ & \\
\hline
\end{tabular}

${ }^{*} \mathrm{CRF}=$ complete reduced form; $\mathrm{SS}=$ solved structural; $\mathrm{ERF}=$ exogenous reduced form. 


\begin{tabular}{|c|c|c|c|}
\hline \multirow{2}{*}{ Independent variables } & \multicolumn{3}{|c|}{ Paper consumption $(Q 2)$} \\
\hline & $\mathrm{CRF}$ & SS & ERF \\
\hline $\mathrm{R}^{2}$ & 0.99867 & & 0.99809 \\
\hline Regression constant. & -7285.70130 & 4812.64120 & 11769.00000 \\
\hline Wages in construction................. (X17) & -782.74527 & -509.98473 & -2119.24710 \\
\hline Index of manufacturing production........(X22) & 65.28040 & -24.19169 & 19.63423 \\
\hline Population..................... & $\ldots \ldots \ldots$ & -5.58220 & ........ \\
\hline Per capita income...... & & -4469.50390 & \\
\hline Value of construction. & & -0.01112 & 0.19104 \\
\hline Freight rates. . . . . . . . . . . & -3498.23940 & 945.41911 & -2112.39930 \\
\hline Trend $\ldots \ldots \ldots \ldots \ldots \ldots \ldots \ldots \ldots \ldots \ldots(X 27)$ & ......... & -95.36105 & -58.63945 \\
\hline Wages in sawmills... & $\ldots \ldots \ldots$ & 1487.59720 & \\
\hline Price of electric power. . & -0.83060 & -80.40902 & -29.88749 \\
\hline Tariff on lumber. & -86.64726 & -6.95774 & 78.34377 \\
\hline Rate of exchange... & -1567.84290 & 311.39427 & -937.31223 \\
\hline Wages in pulp and paper............... & & 2619.25760 & \\
\hline Price of petroleum products. . . . . . . . . . . . . (X33) & -2.01072 & 41.47484 & 8.43462 \\
\hline Consumer price index . . . . . . . . . . . . . . & 112.17805 & 39.24173 & 18.34293 \\
\hline Productivity in sawmilling. & -21.50991 & 4.39549 & -46.10668 \\
\hline Productivity in pulp and paper. & 51.52992 & 136.56692 & 49.35785 \\
\hline Ratio past prices plywood/lumber........ (X75) & 1244.80770 & -89.76111 & \\
\hline Ratio past prices building board/lumber....(X76) & & 52.17063 & \\
\hline Ratio past prices clay products/lumber......(X78) & & & \\
\hline Ratio past prices steel/lumber........... (X79) & 1301.85140 & -57.25554 & \\
\hline Ratio past prices plywood/building board...(X81) & -20230.00000 & 617.46685 & +0 \\
\hline Ratio past prices wallboard/building board. (X82) & 34820.00000 & -964.03296 & \\
\hline Ratio past prices wallboard/plywood. & -9394.54140 & -114.08991 & \\
\hline Dummy variable......... & -1394.38950 & 460.07490 & 707.83214 \\
\hline Price of plywood........... & & 150.97265 & \\
\hline Price of peeler $\operatorname{logs} . . .$. & & -11.14150 & \\
\hline Price of sawlog stumpage...... & $\ldots \ldots \ldots$ & $\ldots \ldots \ldots \ldots$ & 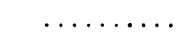 \\
\hline
\end{tabular}

${ }^{*} \mathrm{CRF}=$ complete reduced form; $\mathrm{SS}=$ solved structural; $\mathrm{ERF}=$ exogenous reduced form. 


\begin{tabular}{|c|c|c|c|}
\hline \multirow{2}{*}{ Independent variables } & \multicolumn{3}{|c|}{ Paperboard consumption $(Q 3)$} \\
\hline & $\mathrm{CRF}$ & SS & ERF \\
\hline $\mathrm{R}^{2}$. & 0.99871 & & 0.99823 \\
\hline 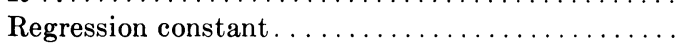 & -4086.95210 & -4843.46600 & -1558.68130 \\
\hline Wages in construction. . . . . . . . . . . . . (X17) & 233.32146 & 2089.81570 & 521.53529 \\
\hline Index of manufacturing production. .......(X22) & 35.90455 & 57.20597 & 33.57408 \\
\hline Population.............. . . . . . . . . (X23) & $\ldots \ldots \ldots \ldots$ & $\ldots$ & encon \\
\hline Per capita income $\ldots \ldots \ldots \ldots \ldots \ldots \ldots \ldots \ldots \ldots$ & . & . & \\
\hline Value of construction ............... $(X 25)$ & & 0.04555 & 0.03158 \\
\hline Freight rates $\ldots \ldots \ldots \ldots \ldots \ldots \ldots \ldots \ldots \ldots \ldots$ & -2285.33710 & -2380.22890 & -36.69974 \\
\hline Trend ............... & & 27.56173 & 4.36159 \\
\hline Wages in sawmills . . . . . . . . . . . . (X28) & & -6095.86720 & . \\
\hline Price of electric power $\ldots \ldots \ldots \ldots \ldots \ldots(X 29)$ & -10.41782 & 3.99662 & -13.28686 \\
\hline Tariff on lumber........ & 195.05569 & 28.51129 & 71.10151 \\
\hline Rate of exchange..................... (X31) & 4094.52570 & 779.92750 & 2230.82870 \\
\hline Wages in pulp and paper................ (X32) & $\ldots \ldots \ldots$ & 370.11273 & $\ldots \ldots \ldots$ \\
\hline Price of petroleum products . . . . . . . . . . . (X33) & 8.37058 & 2.38184 & 13.57916 \\
\hline Consumer price index . . . . . . . . . . . . (X34) & -8.27747 & $\ldots \ldots \ldots$ & -47.66604 \\
\hline Productivity in sawmilling $\ldots \ldots \ldots \ldots \ldots(X 73)$ & -5.60016 & -18.01178 & -18.56406 \\
\hline Productivity in pulp and paper.......... (X74) & 84.14971 & 34.88220 & 70.98984 \\
\hline Ratio past prices plywood/lumber........(X75) & -1240.14140 & 367.82132 & \\
\hline Ratio past prices building board/lumber....(X76) & $\ldots \ldots \ldots$ & -213.78379 & \\
\hline Ratio past prices clay products/lumber. . . . (X78) & $\ldots \ldots \ldots$ & $\ldots \ldots \ldots$ & \\
\hline Ratio past prices steel/lumber.............(X79) & 627.30494 & 234.62060 & \\
\hline Ratio past prices plywood/building board...(X81) & -7228.76060 & -2530.25350 & \\
\hline Ratio past prices wallboard/building board. (X82) & 14030.00000 & 3950.41170 & \\
\hline Ratio past prices wallboard/plywood ......(X85) & -4793.78770 & 467.51709 & \\
\hline Dummy variable $\ldots \ldots \ldots \ldots \ldots \ldots \ldots \ldots(X 86)$ & 1233.26970 & 4170.22000 & 2956.56420 \\
\hline Price of plywood....... & & -46.81279 & \\
\hline Price of peeler logs..... & & 45.65557 & \\
\hline Price of sawlog stumpage. & & & \\
\hline
\end{tabular}

${ }^{*} \mathrm{CRF}=$ complete reduced form; $\mathrm{SS}=$ solved structural $; \mathrm{ERF}=$ exogenous reduced form. 


\begin{tabular}{|c|c|c|c|}
\hline \multirow{2}{*}{ Independent variables } & \multicolumn{3}{|c|}{ Softwood plywood consumption (Q4) } \\
\hline & CRF & ss & ERF \\
\hline $\mathbf{R}^{2}$. & 0.99902 & & 0.99673 \\
\hline Regression constant. & -22392.00000 & -3653.19810 & -2214.62280 \\
\hline Wages in construction. & 1286.19300 & 1491.89790 & 65.40890 \\
\hline Index of manufacturing production. . & 26.94229 & 9.89221 & -4.91260 \\
\hline Population..................... & & & \\
\hline Per capita income................... $(X 24)$ & & & \\
\hline Value of construction $\ldots \ldots \ldots \ldots \ldots \ldots \ldots(X 25)$ & & 0.04133 & 0.09444 \\
\hline Freight rates........... & 1694.26420 & $\ldots .$. & -3568.54880 \\
\hline Trend. & $\ldots \ldots$ & & 100.51536 \\
\hline Wages in sawmills. & & 1581.84350 & \\
\hline Price of electric power. & 20.86852 & 1.44524 & 11.71390 \\
\hline Tariff on lumber...... & 59.61634 & & 165.84580 \\
\hline Rate of exchange............ & 2106.88280 & & -702.76815 \\
\hline Wages in pulp and paper.................. $(X 32)$ & & · & \\
\hline Price of petroleum products. . . . . . . . . . . (X33) & -15.28194 & & -11.08698 \\
\hline Consumer price index. & 29.10415 & & 28.44923 \\
\hline Productivity in sawmilling. & -1.48507 & 1.53467 & 13.59317 \\
\hline Productivity in pulp and paper... & 30.90084 & & 21.85830 \\
\hline Ratio past prices plywood/lumber. . . . . . (X75) & 823.21450 & 4.19037 & \\
\hline Ratio past prices building board/lumber.... (X76) & $\ldots \ldots \ldots$ & $\ldots \ldots \ldots$ & ..... \\
\hline Ratio past prices clay products/lumber. . . . (X78) & & & \\
\hline Ratio past prices steel/lumber. & 2808.54550 & & \\
\hline Ratio past prices plywood/building board...(X81) & -11645.00000 & -1219.39830 & \\
\hline Ratio past prices wallboard/building board. (X82) & 18463.00000 & & \\
\hline Ratio past prices wallboard/plywood.. & -5116.18000 & 765.23045 & \\
\hline Dummy variable $\ldots \ldots \ldots \ldots \ldots \ldots \ldots(X 86)$ & 273.01399 & -860.01554 & -1600.45290 \\
\hline Price of plywood.... & & & .......... \\
\hline Price of peeler logs.. & $\ldots \ldots \ldots$ & -12.66148 & \\
\hline Price of sawlog stumpage $\ldots \ldots \ldots \ldots \ldots \ldots(\hat{P} 10)$ & $\ldots \ldots \ldots$ & $\ldots \ldots \ldots$ & 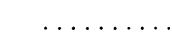 \\
\hline
\end{tabular}

* $\mathrm{CRF}=$ complete reduced form; $\mathrm{SS}=$ solved structural; $\mathrm{ERF}=$ exogenous reduced form. 


\begin{tabular}{|c|c|c|c|}
\hline \multirow{2}{*}{ Independent variables } & \multicolumn{3}{|c|}{ Softwood lumber consumption (Q5) } \\
\hline & CRF & SS & ERF \\
\hline $\mathbf{R}^{2}$. & 0.98247 & & 0.97339 \\
\hline Regression constant. & -16.91114 & 24.05174 & 50.36866 \\
\hline 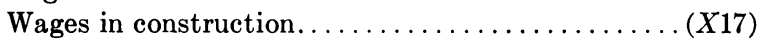 & -3.46580 & 3.51960 & -9.09575 \\
\hline Index of manufacturing production . . . . . . . . (X22) & 0.03680 & 0.26283 & 0.11955 \\
\hline Population $\ldots \ldots \ldots \ldots \ldots \ldots \ldots \ldots \ldots \ldots \ldots \ldots \ldots \ldots \ldots$ & . & . & \\
\hline Per capita income $\ldots \ldots \ldots \ldots \ldots \ldots \ldots \ldots \ldots \ldots \ldots \ldots \ldots$ & . & $\ldots \ldots$ & $\ldots \ldots \ldots$ \\
\hline 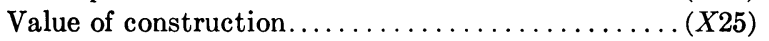 & & 0.00037 & 0.00029 \\
\hline Freight rates $\ldots \ldots \ldots \ldots \ldots \ldots \ldots \ldots \ldots \ldots \ldots \ldots \ldots \ldots$ & -3.36680 & -8.36753 & 9.72000 \\
\hline$\ldots \ldots \ldots \ldots(X 27)$ & & 0.11854 & -0.13021 \\
\hline Wages in sawmills..... . & $\ldots \ldots \ldots$ & -39.68589 & $\ldots \ldots \ldots$ \\
\hline Price of electric power . . . . . . . . . . . . . . . (X29) & -0.16393 & -0.06283 & -0.21694 \\
\hline Tariff on lumber. . . . . . . . . . . . . . . . . (X30) & -0.36883 & -0.58515 & -0.21831 \\
\hline Rate of exchange $\ldots \ldots \ldots \ldots \ldots \ldots \ldots \ldots \ldots \ldots \ldots \ldots \ldots$ & -14.63762 & -8.22896 & -24.19165 \\
\hline 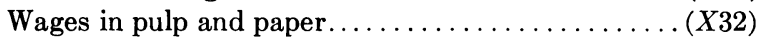 & $\ldots \ldots$ & -2.02861 & $\ldots \ldots$ \\
\hline Price of petroleum products. . . . . . . . . . . . (X33) & 0.01436 & -0.04370 & -0.10619 \\
\hline Consumer price index . . . . . . . . . . . . . . . (X34) & 0.21736 & $\ldots \ldots \ldots$ & .23073 \\
\hline Productivity in sawmilling $\ldots \ldots \ldots \ldots \ldots \ldots \ldots(X 73)$ & 0.28357 & 0.10874 & 25978 \\
\hline Productivity in pulp and paper. . . . . . . . . . (X74) & 0.04371 & -.19119 & -0.11112 \\
\hline Ratio past prices plywood/lumber........... (X75) & 7.03001 & 5.62504 & $\ldots \ldots$ \\
\hline Ratio past prices building board/lumber. . . . . . (X76) & $\ldots \ldots \ldots$ & -2.99268 & \\
\hline Ratio past prices clay products/lumber.......... (X78) & $\ldots \ldots \ldots$ & -3.73691 & \\
\hline Ratio past prices steel/lumber.............. (X79) & 10.81844 & 6.17670 & \\
\hline Ratio past prices plywood/building board.... & 9.89236 & -9.86954 & \\
\hline Ratio past prices wallboard/building board......(X82) & 9.35827 & 11.09492 & \\
\hline Ratio past prices wallboard/plywood........... (X85) & -5.18982 & 3.04709 & $\ldots \ldots \ldots$ \\
\hline Dummy variable $\ldots \ldots \ldots \ldots \ldots \ldots \ldots \ldots \ldots \ldots \ldots \ldots$ & -4.41181 & 6.65183 & -12.83948 \\
\hline Price of plywood... & & 0.25658 & \\
\hline Price of peeler logs... & & 0.29756 & \\
\hline Price of sawlog stumpage......... & & -0.06693 & \\
\hline
\end{tabular}




\begin{tabular}{|c|c|c|c|}
\hline \multirow{2}{*}{ Independent variables } & \multicolumn{3}{|c|}{ Building board and paper consumption (Q6) } \\
\hline & $\mathrm{CRF}$ & SS & ERF \\
\hline 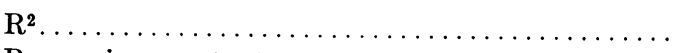 & 0.99313 & & 0.99011 \\
\hline Regression constant..... & 3549.99790 & -142.74710 & 0.23155 \\
\hline 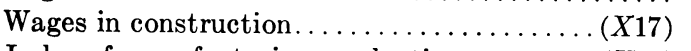 & -674.48802 & -132.37597 & -134.23667 \\
\hline Index of manufacturing production. . . . . . (X22) & 7.40117 & 7.77031 & 13.66945 \\
\hline Population.................... $(X 23)$ & $\ldots \ldots \ldots$ & & \\
\hline Per capita income $\ldots \ldots \ldots \ldots \ldots \ldots \ldots \ldots \ldots \ldots \ldots$ & & . & \\
\hline Value of construction..... & & 0.02299 & 0.00329 \\
\hline Freight rates. . . . . . . . . . . . . . . . $(X 26)$ & -1801.16620 & -292.78256 & -477.95737 \\
\hline Trend....................... & & 31.18870 & 1.15345 \\
\hline Wages in sawmills...... & & 32.18298 & \\
\hline 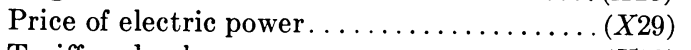 & 0.88356 & -0.15085 & 1.98877 \\
\hline Tariff on lumber.................... $(X 30)$ & 157.95882 & 14.8 & -6.77431 \\
\hline Rate of exchange $\ldots \ldots \ldots \ldots \ldots \ldots \ldots \ldots(X 31)$ & 1105.40830 & 264.97231 & -842.80722 \\
\hline Wages in pulp and paper............... $(X 32)$ & 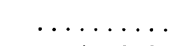 & -1126.45880 & 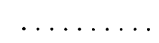 \\
\hline Price of petroleum products . . . . . . . . $(X 33)$ & 1.92324 & 1.60576 & 0.93760 \\
\hline Consumer price index ............... $(X 34)$ & 10.95087 & $\ldots \ldots \ldots$ & 0.30783 \\
\hline Productivity in sawmilling . . . . . . . . . $(X 73)$ & 20.22467 & -4.43303 & 9.04375 \\
\hline Productivity in pulp and paper. . . . . . . $(X 74)$ & 21.35773 & 7.12163 & 7.26498 \\
\hline Ratio past prices plywood/lumber........ (X75) & -1981.64340 & 196.20311 & \\
\hline Ratio past prices building board/lumber. . . (X76) & $\ldots \ldots \ldots$ & -169.74311 & \\
\hline Ratio past prices clay products/lumber. . . (X78) & & -130.74573 & \\
\hline Ratio past prices steel/lumber..........(X79) & -337.18190 & 216.10828 & \\
\hline Ratio past prices plywood/building board...(X81) & 478.54678 & -355.57415 & \\
\hline Ratio past prices wallboard/building board. (X82) & 128.28480 & 102.08996 & \\
\hline Ratio past prices wallboard/plywood.......(X85) & -816.45326 & -3.70751 & \\
\hline Dummy variable $\ldots \ldots \ldots \ldots \ldots \ldots \ldots \ldots(X 86)$ & -345.02908 & 761.38906 & 956.05006 \\
\hline Price of plywood... & 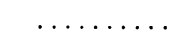 & 46.09616 & \\
\hline Price of peeler $\operatorname{logs} . \ldots \ldots \ldots$ & & -0.36206 & \\
\hline Price of sawlog stumpage................ $(\widehat{P} 10)$ & & 1.20975 & $\cdots \cdots \cdots$ \\
\hline
\end{tabular}

\footnotetext{
* $\mathrm{CRF}=$ complete reduced form; $\mathrm{SS}=$ solved structural; $\mathrm{ERF}=$ exogenous reduced form.
} 


\begin{tabular}{|c|c|c|c|}
\hline \multirow[b]{2}{*}{ Independent variables } & \multicolumn{3}{|c|}{ Lumber price index $(P 1)$} \\
\hline & $\mathrm{CRF}$ & SS & ERF \\
\hline $\mathrm{R}^{2}$. & 0.99803 & & 0.99515 \\
\hline Regression constant. & -130.13830 & -60.35262 & 61.33725 \\
\hline Wages in construction. ................ $(X 17)$ & -10.02376 & 16.63460 & -21.89579 \\
\hline Index of manufacturing production . . . . . . . (X22) & 0.16926 & 0.75426 & 0.21837 \\
\hline 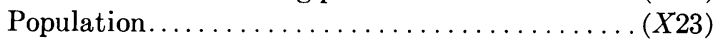 & - & $\ldots \ldots \ldots$ & \\
\hline Per capita income $\ldots \ldots \ldots \ldots \ldots \ldots \ldots \ldots \ldots \ldots \ldots \ldots$ & & & \\
\hline Value of construction................ & & 0.00143 & 0.00139 \\
\hline 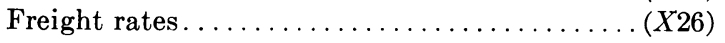 & -33.06586 & -21.75211 & 37.64471 \\
\hline 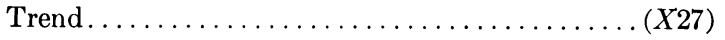 & & 1.66299 & -0.70110 \\
\hline 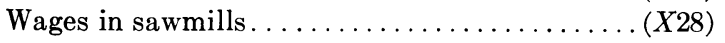 & & -164.02016 & \\
\hline 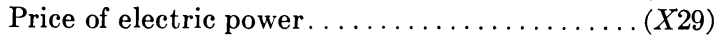 & -0.00192 & 0.37675 & -.26720 \\
\hline Tariff on lumber............ & 1.94781 & 1.00537 & 1.59159 \\
\hline Rate of exchange $\ldots \ldots \ldots \ldots \ldots \ldots \ldots \ldots \ldots \ldots \ldots \ldots$ & 15.25261 & 27.50207 & -5.13441 \\
\hline Wages in pulp and paper.............. (X32) & $\ldots \ldots \ldots$ & -4.50948 & $\ldots$ \\
\hline Price of petroleum products . . . . . . . . . . (X33) & 0.05851 & -0.08646 & -0.11838 \\
\hline Consumer price index . . . . . . . . . . . . (X34) & 0.74214 & $\ldots \ldots \ldots$ & 0.00195 \\
\hline Productivity in sawmilling $\ldots \ldots \ldots \ldots \ldots(X 73)$ & 0.00572 & -0.58572 & -0.33533 \\
\hline Productivity in pulp and paper. . . . . . . . (X74) & 0.33019 & -0.42501 & -0.06419 \\
\hline Ratio past prices plywood/lumber..........(X75) & 5.09688 & 12.94738 & $\ldots$ \\
\hline Ratio past prices building board/lumber. . . . (X76) & $\ldots \ldots \ldots$ & -7.53852 & . . \\
\hline Ratio past prices clay products/lumber. . . . . . (X78) & $\ldots \ldots \ldots$ & $\ldots \ldots$ & \\
\hline Ratio past prices steel/lumber............. (X79) & 26.64638 & 8.27327 & \\
\hline Ratio past prices plywood/building board......(X81) & -86.35503 & -30.76336 & \\
\hline Ratio past prices wallboard/building board....(X82) & 233.94828 & 24.66334 & \\
\hline Ratio past prices wallboard/plywood........(X85) & -74.44073 & 12.31095 & \\
\hline Dummy variable................... $(X 86)$ & 33.43303 & 94.66343 & 44.87104 \\
\hline Price of plywood. & & 0.57037 & \\
\hline Price of peeler logs....... & & 1.20223 & \\
\hline Price of sawlog stumpage $\ldots \ldots \ldots \ldots \ldots \ldots(\hat{P} 10)$ & & & \\
\hline
\end{tabular}

* $\mathrm{CRF}=$ complete reduced form; $\mathrm{SS}=$ solved structural; $\mathrm{ERF}=$ exogenous reduced form. 


\begin{tabular}{|c|c|c|c|}
\hline \multirow{2}{*}{ Independent variables } & \multicolumn{3}{|c|}{ Paper price index $(P 2)$} \\
\hline & $\mathrm{CRF}$ & Ss & ERF \\
\hline $\mathbf{R}^{2}$. & 0.99929 & & 0.99858 \\
\hline Regression constant. & 93.73515 & 56.76204 & 13.19252 \\
\hline Wages in construction. & 21.71212 & 31.49120 & 20.17060 \\
\hline Index of manufacturing production........ & -0.09379 & 1.49388 & -0.02712 \\
\hline Population.................. & $\ldots \ldots$ & 0.34471 & \\
\hline Per capita income. & & 275.99992 & \\
\hline Value of construction... & & 0.00069 & -0.00002 \\
\hline Freight rates......... & -11.43625 & -58.38172 & 14.99457 \\
\hline Trend....... & $\ldots \ldots \ldots$ & 2.25815 & 0.21901 \\
\hline Wages in sawmills....... & $\ldots \ldots$ & -91.85319 & \\
\hline Price of electric power. . & -0.17198 & 1.40839 & -0.14470 \\
\hline Tariff on lumber..... & -0.23707 & 0.42966 & -0.61706 \\
\hline Rate of exchange.. & -9.27861 & 4.08139 & 14.40781 \\
\hline Wages in pulp and paper. & & -48.24127 & \\
\hline Price of petroleum products... & 0.16166 & -0.72742 & 0.15681 \\
\hline Consumer price index. & 0.61242 & -2.42325 & 0.36677 \\
\hline Productivity in sawmilling........ & -0.14647 & -0.27142 & -0.30784 \\
\hline Productivity in pulp and paper $\ldots \ldots \ldots \ldots \ldots(X 74)$ & -0.08011 & -2.86012 & -0.04325 \\
\hline Ratio past prices plywood/lumber. & -16.07029 & 5.54300 & \\
\hline Ratio past prices building board/lumber... & .. & -3.22169 & \\
\hline Ratio past prices clay products/lumber....... & & & \\
\hline Ratio past prices steel/lumber............ & -15.41327 & 3.53569 & \\
\hline Ratio past prices plywood/building board.... & 38.08787 & -38.12882 & \\
\hline Ratio past prices wallboard/building board . . . . . (X82) & -34.73803 & 59.53137 & \\
\hline Ratio past prices wallboard/plywood. & 19.33625 & 7.04454 & \\
\hline Dummy variable... & -14.87904 & 22.82314 & 0.55865 \\
\hline Price of plywood.. & $\ldots$ & -1.27274 & \\
\hline Price of peeler logs.. & & 0.68794 & \\
\hline Price of sawlog stumpage.. & & & \\
\hline
\end{tabular}

* $\mathrm{CRF}=$ complete reduced form; $\mathrm{SS}=$ solved structural; $\mathrm{ERF}=$ exogenous reduced form. 


\begin{tabular}{|c|c|c|c|}
\hline \multirow{2}{*}{ Independent variables } & \multicolumn{3}{|c|}{ Paperboard price index $(P 3)$} \\
\hline & $\mathrm{CRF}$ & SS & ERF \\
\hline $\mathrm{R}^{2}$. & 0.99786 & & 0.99421 \\
\hline Regression constant. & -74.54774 & -6.78727 & 91.45501 \\
\hline Wages in construction $\ldots \ldots \ldots \ldots \ldots \ldots \ldots \ldots \ldots \ldots$ & 26.79900 & 44.66596 & 14.78731 \\
\hline Index of manufacturing production ........... $(X 22)$ & -0.43580 & 1.22269 & -0.13132 \\
\hline 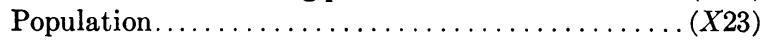 & $\ldots \ldots$ & 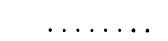 & \\
\hline Per capita income $\ldots \ldots \ldots \ldots \ldots \ldots \ldots \ldots \ldots \ldots \ldots \ldots \ldots \ldots$ & $\ldots \ldots \ldots$ & $\ldots \ldots \ldots$ & $\ldots \ldots \ldots$ \\
\hline Value of construction $\ldots \ldots \ldots \ldots \ldots \ldots \ldots \ldots \ldots \ldots \ldots$ & & 0.00097 & 0.00036 \\
\hline 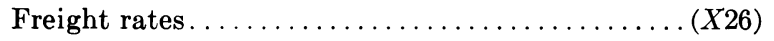 & -60.51235 & -50.87367 & 6.69651 \\
\hline 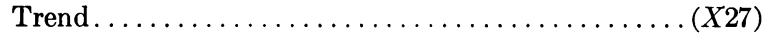 & . & 1.50800 & -0.92190 \\
\hline 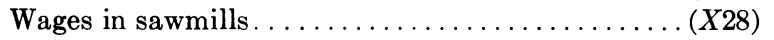 & & -130.28796 & $\ldots \ldots$ \\
\hline 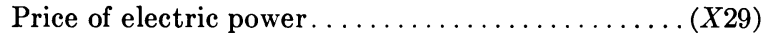 & -0.66297 & 0.33711 & -0.83188 \\
\hline Tariff on lumber........... & 1.98146 & 0.60940 & 2.93692 \\
\hline Rate of exchange.. & 17.95553 & 16.67005 & 15.89007 \\
\hline Wages in pulp and paper................. (X32) & & -15.43798 & \\
\hline Price of petroleum products. . . & 0.33833 & -0.17572 & 0.04989 \\
\hline 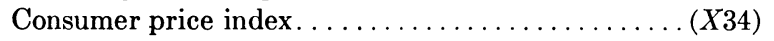 & 0.99841 & $\ldots \ldots$ & 0.86319 \\
\hline Productivity in sawmilling $\ldots \ldots \ldots \ldots \ldots \ldots(X 73)$ & -0.33113 & -0.38498 & -0.42904 \\
\hline 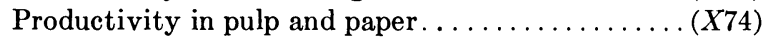 & 0.19421 & -1.45499 & -0.08172 \\
\hline Ratio past prices plywood/lumber........... (X75) & 33.91930 & 7.86176 & $\ldots$ \\
\hline Ratio past prices building board/lumber. . . . . . (X76) & $\ldots \ldots$ & -4.56938 & \\
\hline Ratio past prices clay products/lumber ........(X78) & $\ldots \ldots$ & $\ldots$ & . \\
\hline Ratio past prices steel/lumber............. (X79) & 30.46805 & 5.01475 & \\
\hline Ratio past prices plywood/building board.......(X81) & 18.31305 & -54.07989 & \\
\hline Ratio past prices wallboard/building board. . & 56.97328 & 84.43369 & \\
\hline Ratio past prices wallboard/plywood .........(X85) & -21.58782 & 9.99230 & \\
\hline Dummy variable......... & 19.91970 & 56.29481 & 0.98369 \\
\hline Price of plywood. . & $\ldots$. & 1.95263 & \\
\hline Price of peeler logs..... & & 0.97580 & \\
\hline Price of sawlog stumpage $\ldots \ldots \ldots \ldots \ldots \ldots \ldots(\hat{P} 10)$ & & & \\
\hline
\end{tabular}

* $\mathrm{CRF}=$ complete reduced form; $\mathrm{SS}=$ solved structural $; \mathrm{ERF}=$ exogenous reduced form. 


\begin{tabular}{|c|c|c|c|}
\hline \multirow{2}{*}{ Independent variables } & \multicolumn{3}{|c|}{ Softwond plywood price index $(P 4)$} \\
\hline & $\mathrm{CRF}$ & Ss & ERF \\
\hline & 0.99647 & & 0.98399 \\
\hline Regression constant. & -603.10679 & 23.61076 & 113.04464 \\
\hline Wages in construction. & 47.14320 & 40.72421 & -44.96374 \\
\hline Index of manufacturing production.. & 0.01260 & 0.27003 & 0.10888 \\
\hline Population.............. & & & \\
\hline Per capita income $\ldots \ldots \ldots \ldots \ldots \ldots \ldots \ldots(X 24)$ & & & \\
\hline Value of construction.... & 0.00054 & 0.00113 & 0.00185 \\
\hline Freight rates.......... & 14.07288 & $\ldots \ldots \ldots$ & 68.47016 \\
\hline$\ldots(X 27)$ & $\ldots \ldots \ldots$ & & -1.69136 \\
\hline Wages in sawmills... & & -254.84795 & \\
\hline Price of electric power. & -0.25895 & -0.23284 & -0.33178 \\
\hline Tariff on lumber. & 3.17790 & $\ldots \ldots \ldots$ & 1.77870 \\
\hline Rate of exchange................ & 91.38672 & . & -42.36755 \\
\hline Wages in pulp and paper........... & -142.54026 & & \\
\hline Price of petroleum products........ & 0.37608 & . & -0.18799 \\
\hline Consumer price index...... & 1.83479 & & 0.13892 \\
\hline Productivity in sawmilling. . . . . . . . & 0.36236 & -0.24725 & -0.22962 \\
\hline Productivity in pulp and paper............ (X74) & 0.53886 & . & -0.13258 \\
\hline Ratio past prices plywood/lumber.... & & 0.11438 & \\
\hline Ratio past prices building board/lumber......(X76) & 1.21917 & $\ldots \ldots \ldots$ & \\
\hline Ratio past prices clay products/lumber.......(X78) & 229.45989 & 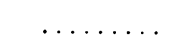 & \\
\hline Ratio past prices steel/lumber.. & -56.93055 & & \\
\hline Ratio past prices plywood/building board......(X81) & -310.25002 & -33.28581 & \\
\hline Ratio past prices wallboard/building board....(X82) & 610.59502 & & \\
\hline Ratio past prices wallboard/plywood. & -240.96713 & 20.88843 & \\
\hline Dummy variable $\ldots \ldots \ldots \ldots \ldots \ldots \ldots$ & 63.55295 & 138.55555 & 47.01359 \\
\hline Price of plywood.... & & & \\
\hline Price of peeler logs. . & & 2.03987 & \\
\hline Price of sawlog stumpage... & & & \\
\hline
\end{tabular}

* $\mathrm{CRF}=$ complete reduced form; $\mathrm{SS}=$ solved structural $; \mathrm{ERF}=$ exogenous reduced form. 


\begin{tabular}{|c|c|c|c|}
\hline \multirow{2}{*}{ Independent variables } & \multicolumn{3}{|c|}{ Softwood lumber price $(P 5)$} \\
\hline & CRF & SS & ERF \\
\hline & 0.99842 & & 0.99411 \\
\hline Regression constant & 165.12506 & -15.14456 & 60.27083 \\
\hline Wages in construction...... & 22.84705 & 7.44355 & -15.88929 \\
\hline Index of manufacturing production. . & -0.26186 & 0.55579 & 0.19204 \\
\hline Population..................... & -2.31730 & - & $\ldots \ldots \ldots$ \\
\hline Per capita income.. & & & \\
\hline Value of construction. & 0.00164 & 0.00079 & 0.00098 \\
\hline Freight rates................ & -28.98012 & -17.69429 & 18.72046 \\
\hline Trend............ & $\ldots \ldots \ldots$ & 0.50601 & -0.68231 \\
\hline Wages in saw mills. & & -79.39829 & \\
\hline Price of electric power & -0.33124 & 0.14871 & -0.25869 \\
\hline Tariff on lumber. & 2.88472 & 0.89597 & 1.39458 \\
\hline Rate of exchange.. & 5.25905 & 16.01357 & -6.27635 \\
\hline Wages in pulp and paper.... & & -4.28991 & \\
\hline Price of petroleum products. . & 0.14996 & -0.02631 & -0.08477 \\
\hline price index $\ldots \ldots \ldots \ldots \ldots \ldots \ldots$ & 0.40810 & & 0.23665 \\
\hline nilling. .......... & -0.06210 & -0.34683 & -0.28348 \\
\hline Productivity in pulp and paper...... & 0.16034 & -0.40431 & -0.14671 \\
\hline Ratio past prices plywood/lumber.......... & & 11.89402 & \\
\hline Ratio past prices building board/lumber....... (X76) & -4.67837 & -6.32795 & \\
\hline Ratio past prices clay products/lumber........... (X78) & 60.61817 & -7.90160 & \\
\hline Ratio past prices steel/lumber.............. & -14.03475 & 13.06048 & \\
\hline d/building bop & 52.26162 & -20.87034 & \\
\hline /building board. & 11.19659 & 23.46243 & \\
\hline s wallboard/ply & & 6.44318 & \\
\hline Dummy variable... & 42.31171 & 53.34199 & 24.13467 \\
\hline Price of plywood... & & 0.54260 & \\
\hline Price of peeler logs. . & & 0.62921 & \\
\hline Price of sawlog stumpage... & & 0.07311 & \\
\hline
\end{tabular}

${ }^{*} \mathrm{CRF}=$ complete reduced form; $\mathrm{SS}=$ solved structural $; \mathrm{ERF}=$ exogenous reduced form. 


\begin{tabular}{|c|c|c|c|}
\hline \multirow{2}{*}{ Independent variables } & \multicolumn{3}{|c|}{ Building paper and board price index $(P 6)$} \\
\hline & CRF & Ss & ERF \\
\hline $\mathbf{R}^{2}$. & 0.99949 & & 0.99903 \\
\hline Regression constant. & 221.15897 & 107.37546 & 81.05272 \\
\hline Wages in construction. & 26.19137 & -8.00007 & 25.36385 \\
\hline Index of manufacturing production. & -0.16121 & 0.46951 & -0.22429 \\
\hline Population..................... & $\ldots \ldots$ & & \\
\hline Per capita income.... & & & \\
\hline Value of construction... & 0.00080 & 0.00139 & 0.00065 \\
\hline Freight rates........... & -4.18131 & -17.69051 & 0.28681 \\
\hline Trend..... & -2.24665 & -0.50371 & -0.73644 \\
\hline Wages in sawmills. & 33.28050 & 1.94090 & \\
\hline Price of electric power. & -0.25473 & 0.39298 & -0.22896 \\
\hline Tariff on lumber. & -0.27484 & 0.89587 & -0.29426 \\
\hline Rate of exchange.. & -25.92885 & 16.01183 & 14.83930 \\
\hline Wages in pulp and paper.... & -28.74077 & 42.41807 & \\
\hline Price of petroleum products... & 0.18850 & -0.11663 & 0.29816 \\
\hline Consumer price index. & & & -0.30182 \\
\hline Productivity in sawmilling. & -0.04704 & -0.26788 & -0.00832 \\
\hline Productivity in pulp and paper..... & -0.20457 & -1.01540 & -0.03245 \\
\hline Ratio past prices plywood/lumber............ (X75) & -31.47842 & 11.85623 & \\
\hline Ratio past prices building board/lumber. & & -10.25725 & \\
\hline Ratio past prices clay products/lumber.........(X78) & -52.01826 & -7.90075 & \\
\hline Ratio past prices steel/lumber. & 13.12998 & 13.05906 & \\
\hline Ratio past prices plywood/building board.. & & -21.48558 & \\
\hline Ratio past prices wallboard/building board... & 32.78090 & 6.16590 & \\
\hline Ratio past prices wallboard/plywood. & 24.80415 & -0.22372 & \\
\hline Dummy variable................. & -23.62881 & -17.89771 & 2.82676 \\
\hline Price of plywood.. & $\ldots \ldots$ & -1.10008 & \\
\hline Price of peeler logs.... & & -0.02185 & \\
\hline Price of sawlog stumpage.. & & 0.07310 & \\
\hline
\end{tabular}

* $\mathrm{CRF}=$ complete reduced form; $\mathrm{SS}=$ solved structural; $\mathrm{ERF}=$ exogenous reduced form. 


\begin{tabular}{|c|c|c|c|c|}
\hline \multirow{2}{*}{ Independent variables } & \multicolumn{2}{|c|}{ Sawlog price (P7) } & \multicolumn{2}{|c|}{ Pulpwood price $(P 8)$} \\
\hline & CRF & ERF & $\mathrm{CRF}$ & ERF \\
\hline $\mathrm{R}^{2}$. & 0.99746 & 0.99643 & 0.99848 & 0.99757 \\
\hline Regression constant. & -107.13577 & 0.52976 & 0.22381 & -3.44509 \\
\hline Wages in construction. ............... $(X 17)$ & 0.80741 & -10.92849 & 3.06829 & 3.46637 \\
\hline Index of manufacturing production.... (X22) & 0.12448 & 0.09571 & -0.01292 & 0.01839 \\
\hline Population........................ (X23) & $\ldots \ldots \ldots$ & $\ldots \ldots \ldots$ & ........ & \\
\hline Per capita income ............... (X24) & $\ldots \ldots \ldots$ & $\ldots \ldots \ldots$ & ... & \\
\hline Value of construction............. $(X 25)$ & $\ldots \ldots$ & 0.00071 & & 0.37948 \\
\hline Freight rates.................. (X26) & -6.23373 & 9.05745 & -9.83745 & -2.77508 \\
\hline Trend $\ldots \ldots \ldots \ldots \ldots \ldots \ldots \ldots \ldots \ldots \ldots \ldots+(X 27)$ & $\ldots \ldots$ & 0.24335 & & -0.29679 \\
\hline Wages in sawmills.... & & & & \\
\hline Price of electric power. . . . . . . . $(X 29)$ & 0.13649 & 0.04706 & 0.04110 & 0.02358 \\
\hline Tariff on lumber........ & -0.35078 & 0.30017 & -0.41464 & -0.34858 \\
\hline Rate of exchange................ (X31) & -1.78462 & -1.86452 & -0.63823 & 0.98233 \\
\hline Wages in pulp and paper........... (X32) & & . & . & \\
\hline Price of petroleum products. . . . . . . . (X33) & 0.03660 & -0.04223 & 0.05476 & 0.02770 \\
\hline Consumer price index............... $(X 34)$ & 0.36998 & 0.10895 & 0.15218 & 0.15800 \\
\hline Productivity in sawmilling. . . . . . . $(X 73)$ & 0.04402 & -0.03388 & -0.03568 & -0.05677 \\
\hline Productivity in pulp and paper.......(X74) & 0.07199 & -0.05883 & 0.00860 & -0.00143 \\
\hline Ratio past prices plywood/lumber....(X75) & 5.64423 & & 3.16680 & ...... \\
\hline $\begin{array}{l}\text { Ratio past prices building } \\
\text { board/lumber........... }\end{array}$ & & & & \\
\hline $\begin{array}{l}\text { Ratio past prices clay } \\
\text { products/lumber.... }\end{array}$ & & & & \\
\hline Ratio past prices steel/lumber........(X79) & 13.52117 & & -1.10287 & \\
\hline $\begin{array}{l}\text { Ratio past prices plywood/building } \\
\quad \text { board.......................... (X81) }\end{array}$ & -37.57592 & & 10.93877 & \\
\hline $\begin{array}{l}\text { Ratio past prices wallboard/building } \\
\quad \text { board } \ldots \ldots \ldots \ldots \ldots \ldots \ldots \ldots \ldots(X 82)\end{array}$ & 103.99937 & & -17.34704 & \\
\hline Ratio past prices wallboard/plywood. (X85) & -25.12956 & $\ldots \ldots \ldots$ & 3.81619 & \\
\hline Dummy variable................... $(X 86)$ & 8.57569 & 5.11306 & 1.92920 & 2.11638 \\
\hline Price of plywood. & $\ldots \ldots$ & $\ldots \ldots$ & $\ldots \ldots \ldots$ & \\
\hline Price of peeler logs......... & $\cdots \cdots$ & & $\cdots \cdots$ & \\
\hline Price of sawlog stumpage... & & & & \\
\hline
\end{tabular}

${ }^{*} \mathrm{CRF}=$ complete reduced form; $\mathrm{ERF}=$ exogenous reduced form. 


\begin{tabular}{|c|c|c|c|c|}
\hline \multirow{2}{*}{ Independent variables } & \multicolumn{2}{|c|}{$\begin{array}{c}\text { Peeler } \\
\log \text { price }(P 9)\end{array}$} & \multicolumn{2}{|c|}{$\begin{array}{c}\text { Softwood } \\
\text { stumpage price }(P 10)\end{array}$} \\
\hline & CRF & ERF & $\mathrm{CRF}$ & ERF \\
\hline & \multicolumn{2}{|c|}{ Peeler } & \multicolumn{2}{|c|}{ Softwood } \\
\hline $\mathrm{R}^{2}$. & 0.99719 & 0.99103 & 0.97347 & 0.95334 \\
\hline Regression constant. . & -149.64351 & -25.69291 & -73.79658 & -8.02978 \\
\hline Wages in construction............. $(X 17)$ & -6.17401 & -14.99605 & -4.75431 & -13.29659 \\
\hline Index of manufacturing production....(X22) & 0.12343 & 0.21378 & 0.05260 & 0.16967 \\
\hline Population $\ldots \ldots \ldots \ldots \ldots \ldots \ldots \ldots,(X 23)$ & $\ldots \ldots$ & $\ldots \ldots \ldots$ & $\ldots \ldots \ldots$ & ........ \\
\hline Per capita income $\ldots \ldots \ldots \ldots \ldots \ldots(X 24)$ & . & & & \\
\hline Value of construction ............... $(X 25)$ & & 0.00069 & & 0.00083 \\
\hline Freight rates $\ldots \ldots \ldots \ldots \ldots \ldots$ & -2.17763 & 67.45060 & -22.97134 & 32.07165 \\
\hline Trend. & $\ldots \ldots$ & 0.22367 & $\ldots \ldots$ & -0.35844 \\
\hline Wages in sawmills.............. $(X 28)$ & & & $\ldots \ldots$ & $\ldots \ldots \ldots$ \\
\hline Price of electric power.......... & 0.13641 & 0.02721 & 0.15958 & 0.03048 \\
\hline Tariff on lumber................. (X30) & 0.95175 & 0.38558 & 1.13994 & 0.58940 \\
\hline Rate of exchange................ (X31) & -8.36027 & -13.40646 & 13.95428 & 8.86816 \\
\hline Wages in pulp and paper............. $(X 32)$ & & & & \\
\hline Price of petroleum products. . . . . . . . $(X 33)$ & 0.20792 & 0.15945 & 0.06624 & -0.09642 \\
\hline Consumer price index........... & 0.86315 & 0.08445 & 0.31343 & -0.14862 \\
\hline Productivity in sawmilling. ......... (X73) & 0.04794 & -0.20113 & -0.14047 & -0.42023 \\
\hline Productivity in pulp and paper.......(X74) & 0.10145 & -0.13866 & 0.27126 & -0.00769 \\
\hline Ratio past prices plywood/lumber.... (X75) & -1.51802 & & -6.16130 & \\
\hline $\begin{array}{l}\text { Ratio past prices building } \\
\text { board/lumber........... }\end{array}$ & & & & \\
\hline $\begin{array}{l}\text { Ratio past prices clay } \\
\text { products/lumber..... }\end{array}$ & & & & \\
\hline Ratio past prices steel/lumber.......(X79) & 23.23089 & $\ldots \ldots \ldots$ & 6.62354 & \\
\hline $\begin{array}{l}\text { Ratio past prices plywood/building } \\
\text { board } \ldots \ldots \ldots \ldots \ldots \ldots \ldots \ldots \ldots(X 81) \ldots \ldots \ldots\end{array}$ & -97.47483 & & -5.55362 & \\
\hline Ratio past prices wallboard/building & & & & \\
\hline$\ldots \ldots \ldots \ldots \ldots(X 82)$ & 258.40679 & & 77.17148 & \\
\hline Ratio past prices wallboard/plywood. (X85) & -75.38673 & $\ldots \ldots$ & -23.32085 & \\
\hline Dummy variable................. $(X 86)$ & -12.44000 & 2.52464 & -8.07926 & 3.65334 \\
\hline Price of plywood. & $\ldots+$ & $\ldots$. & $\ldots \ldots$ & \\
\hline Price of peeler logs... & & & & \\
\hline Price of sawlog stumpage.. & & & & \\
\hline
\end{tabular}

${ }^{*} \mathrm{CRF}=$ complete reduced form; $\mathrm{ERF}=$ exogenous reduced form. 


\section{APPENDIX G \\ TRENDS IN VARIABLES}

Figures $\mathrm{A}$ to $\mathrm{P}$ show for each variable predicted, each observation for the period 1929 to 1960, and unadjusted predicted values for the years 1965, 1970 and 1975

Predicted values obtained from complete reduced form equations are indicated by the numeral 1 , those obtained from the solved structural equations by 2 , and those from the exogenous reduced form equations by 3 .

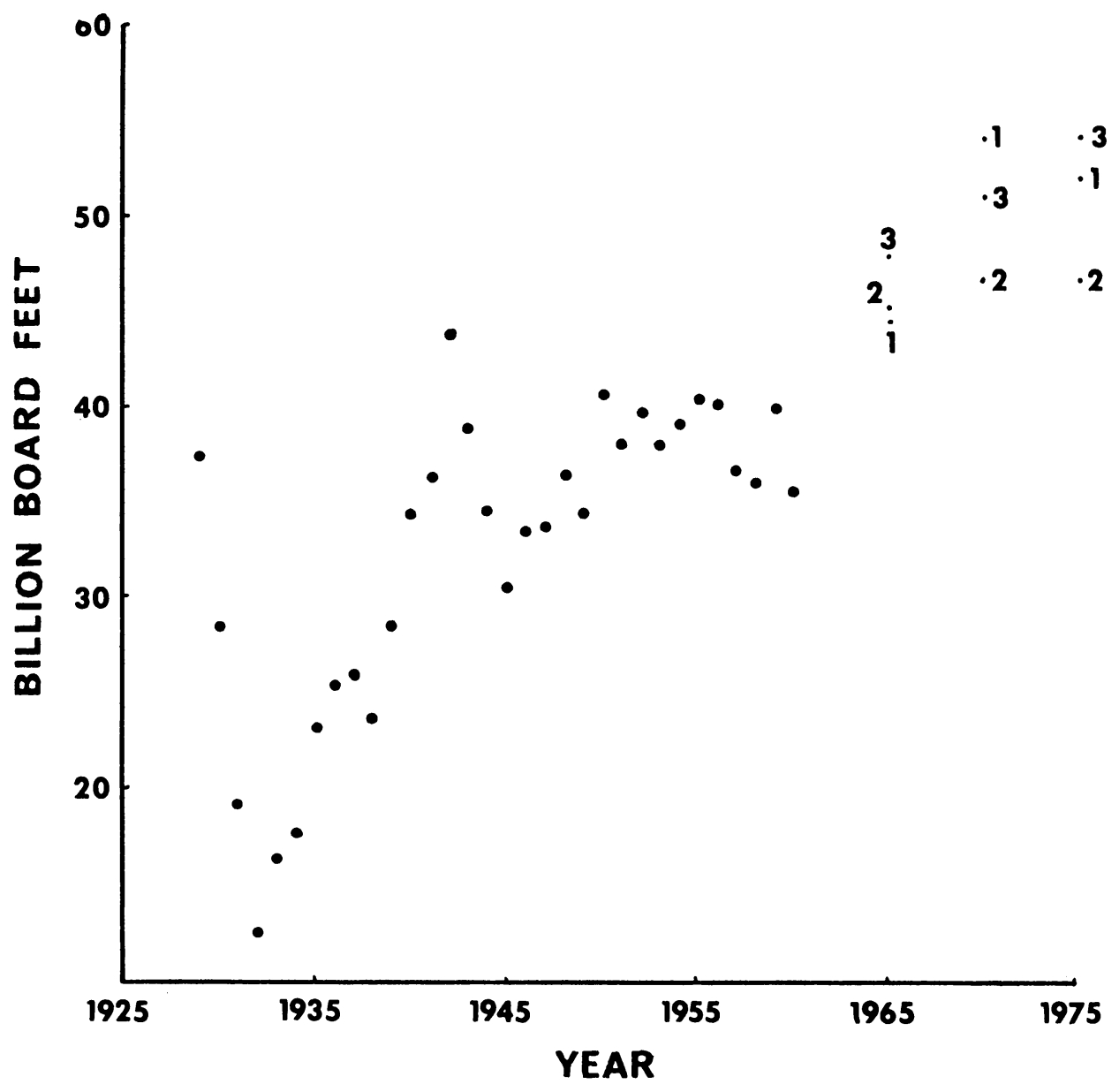

FIG.A. LUMBER CONSUMPTION (Q1) 


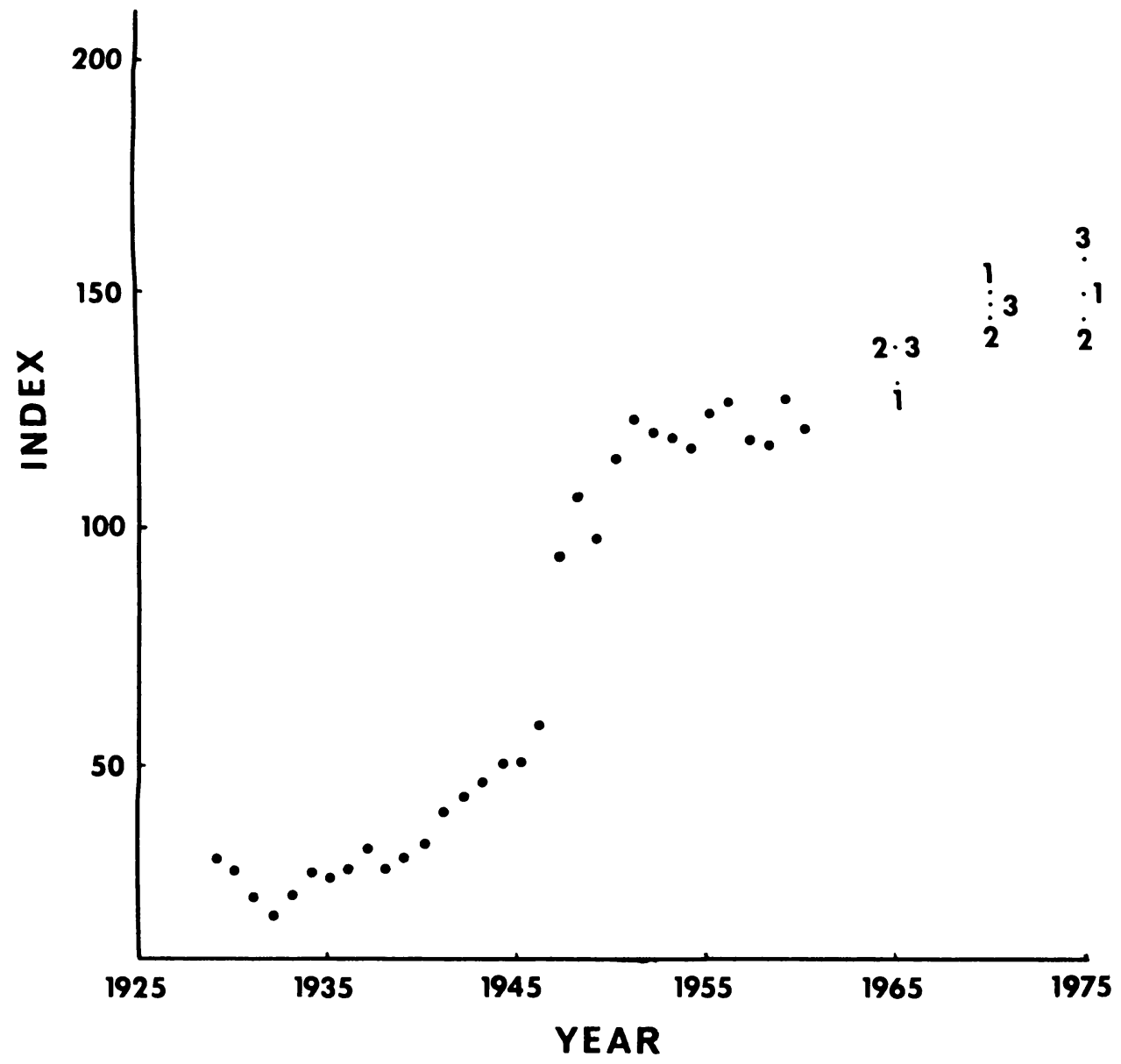

FIG.B. LUMBER PRICE INDEX (P1) 


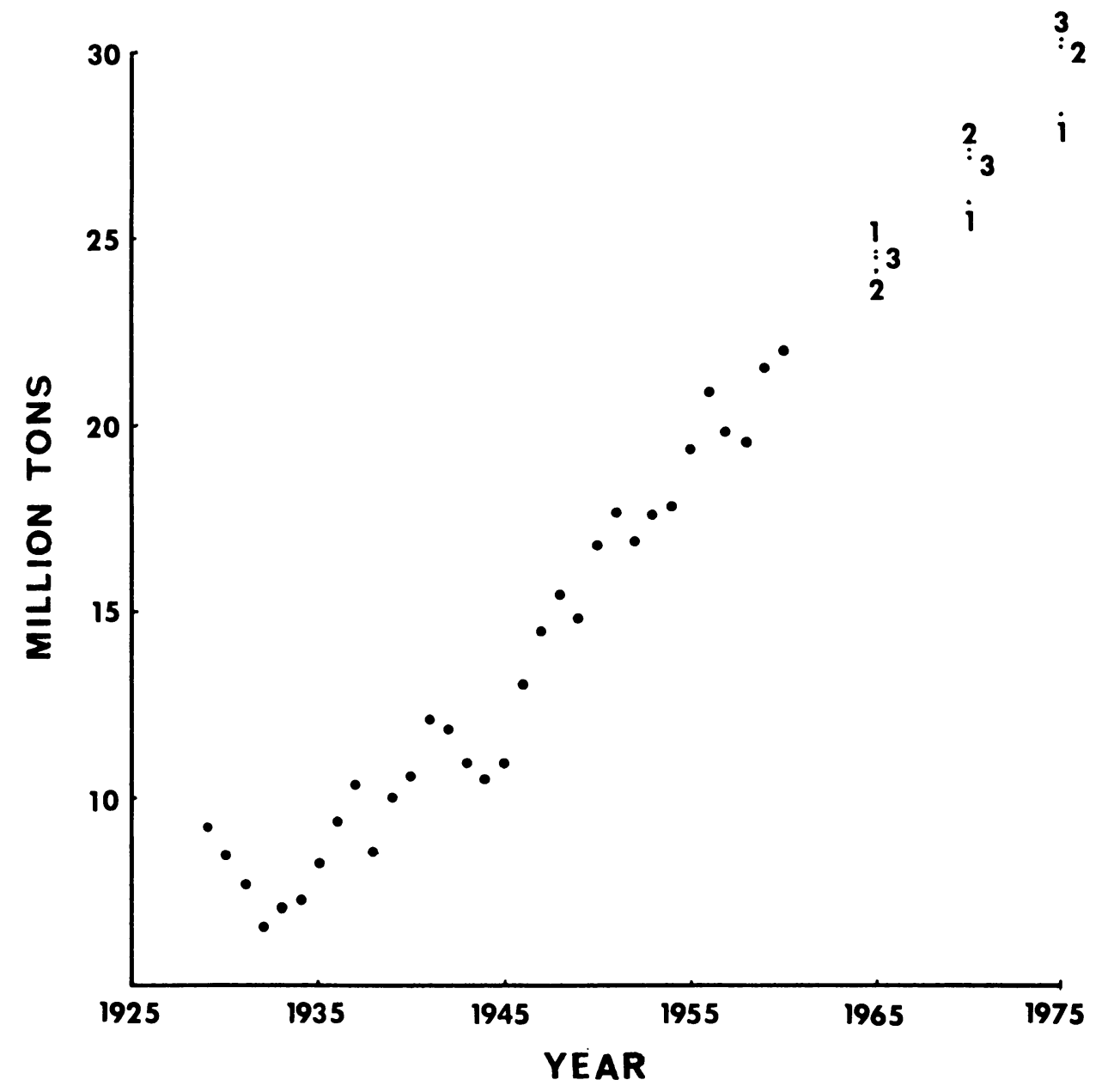

FIG.C. PAPER CONSUMPTION (Q2) 


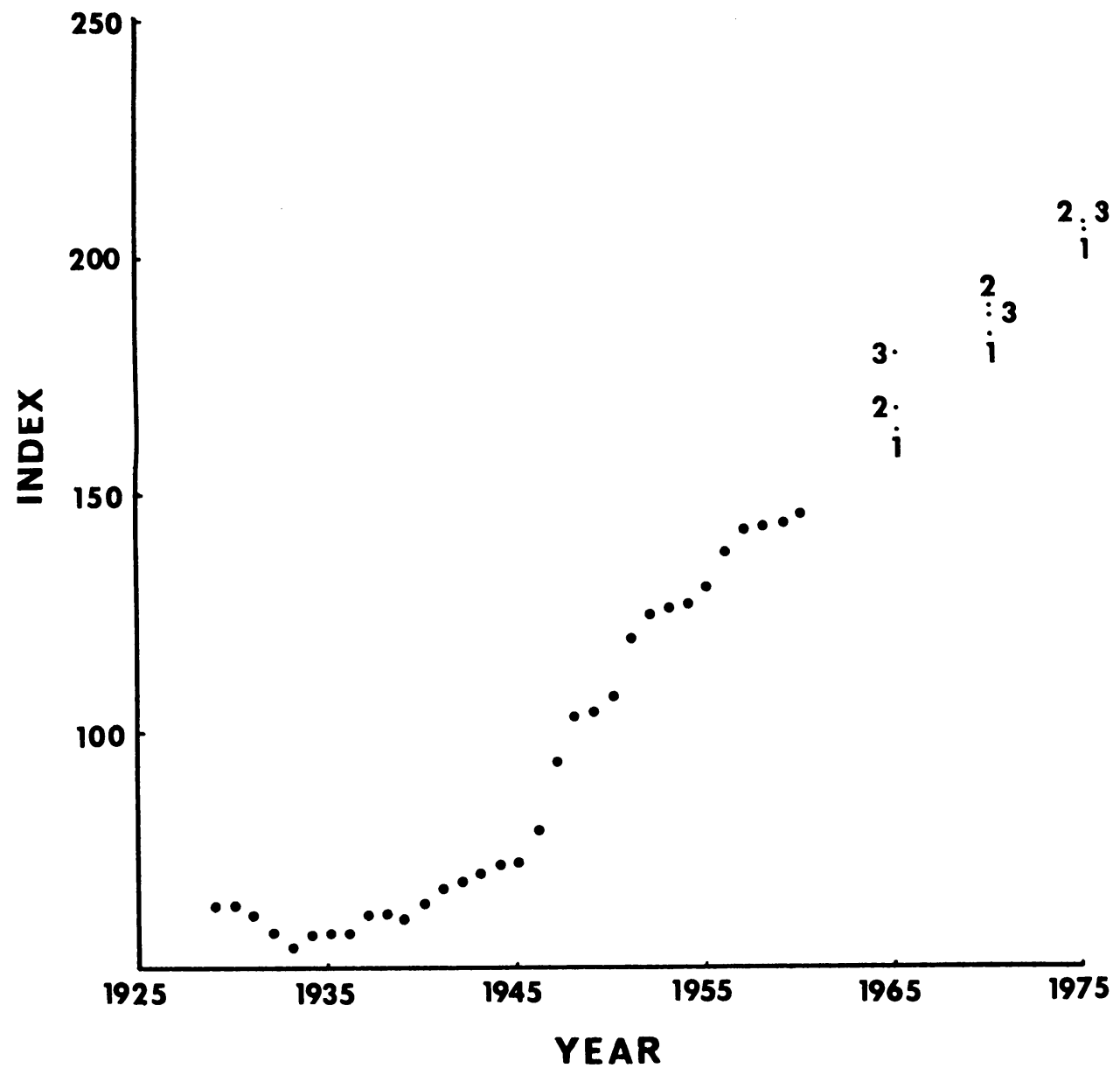

FIG.D. PAPER PRICE INDEX (P2) 


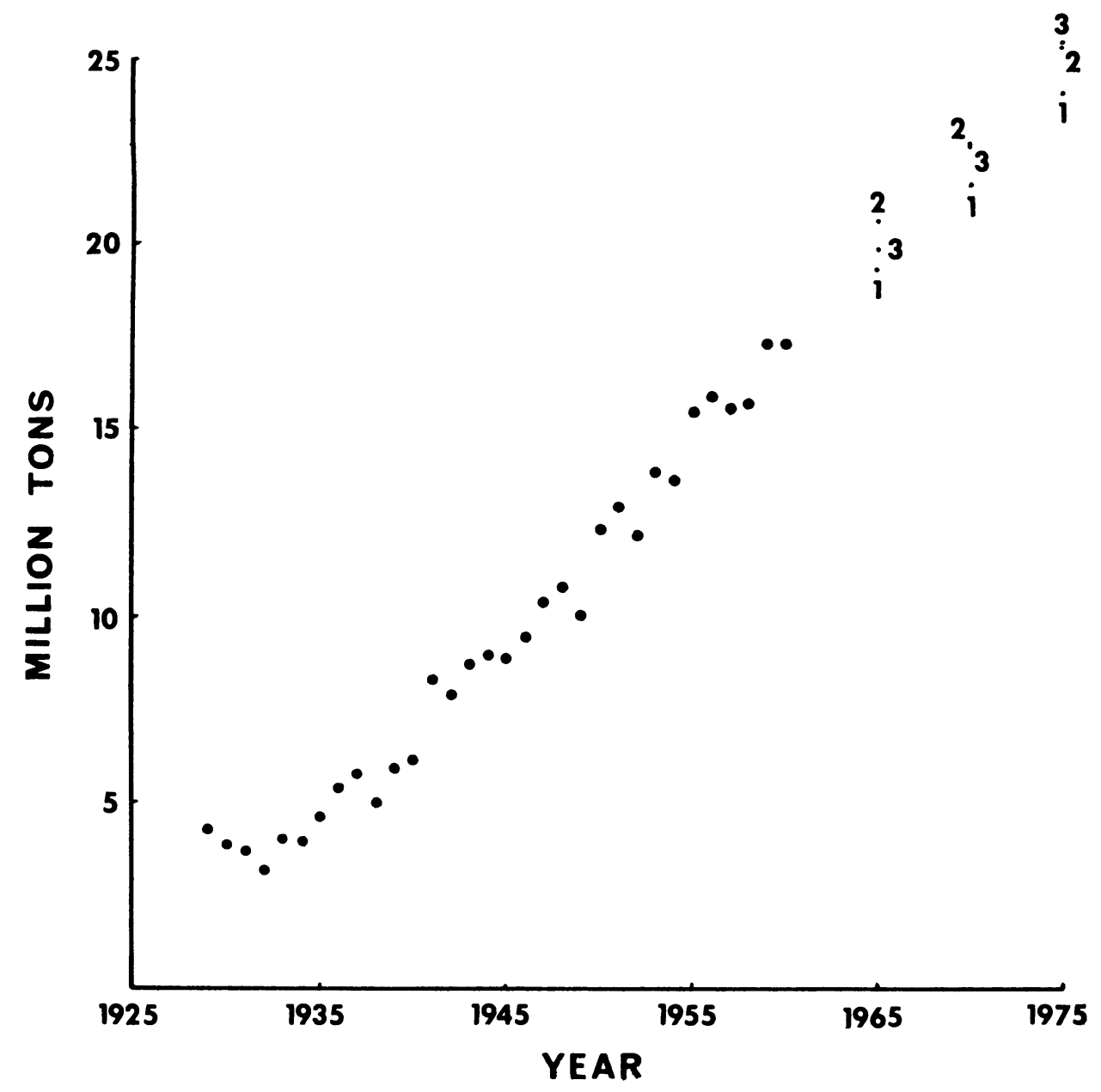

FIG. E. PAPERBOARD CONSUMPTION (Q3) 


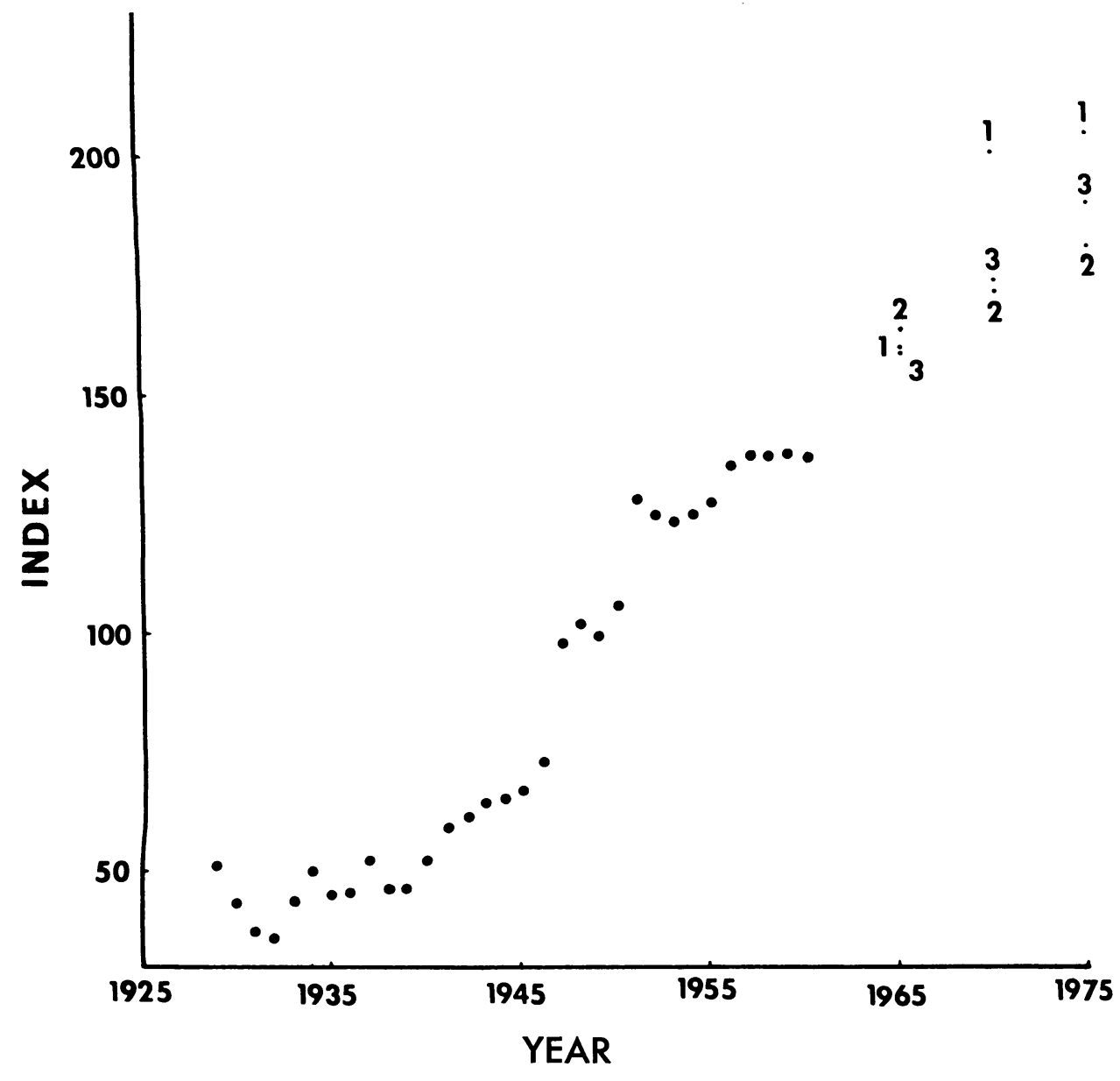

FIG. F. PAPERBOARD PRICE INDEX (P3) 


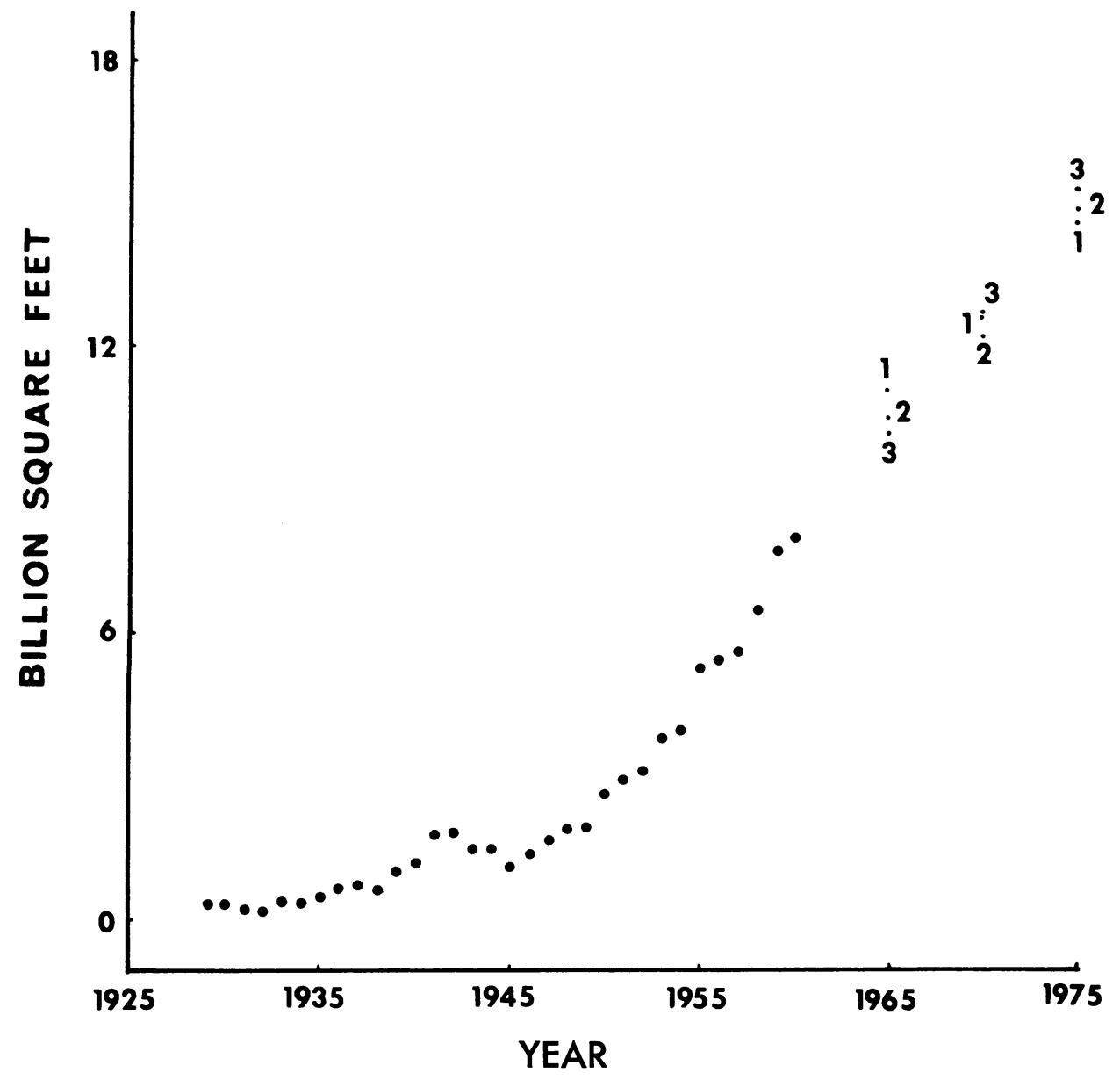

FIG. G. SOFTWOOD PLYWOOD CONSUMPTION (Q4) 


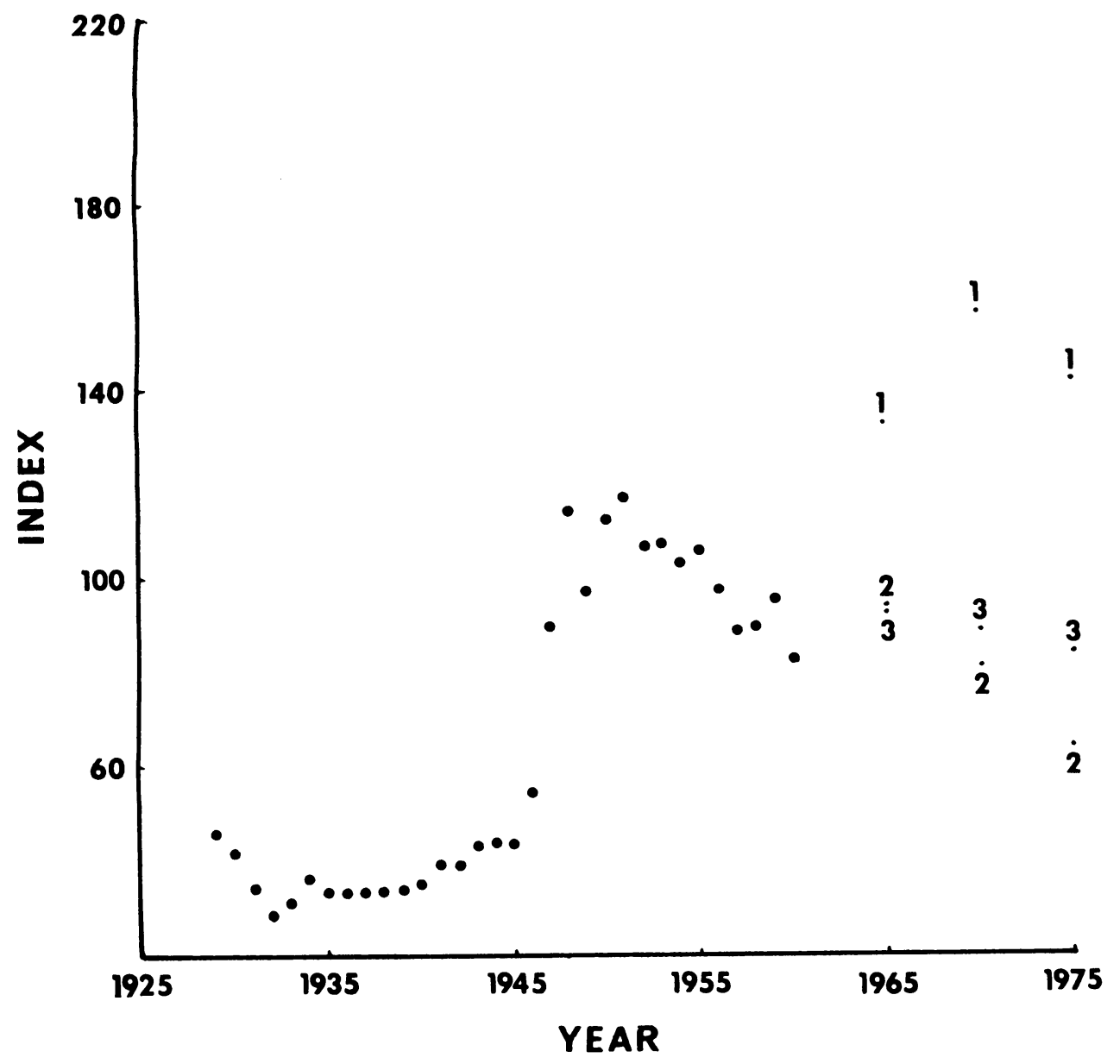

FIG.H. SOFTWOOD PLYWOOD PRICE INDEX (P4) 


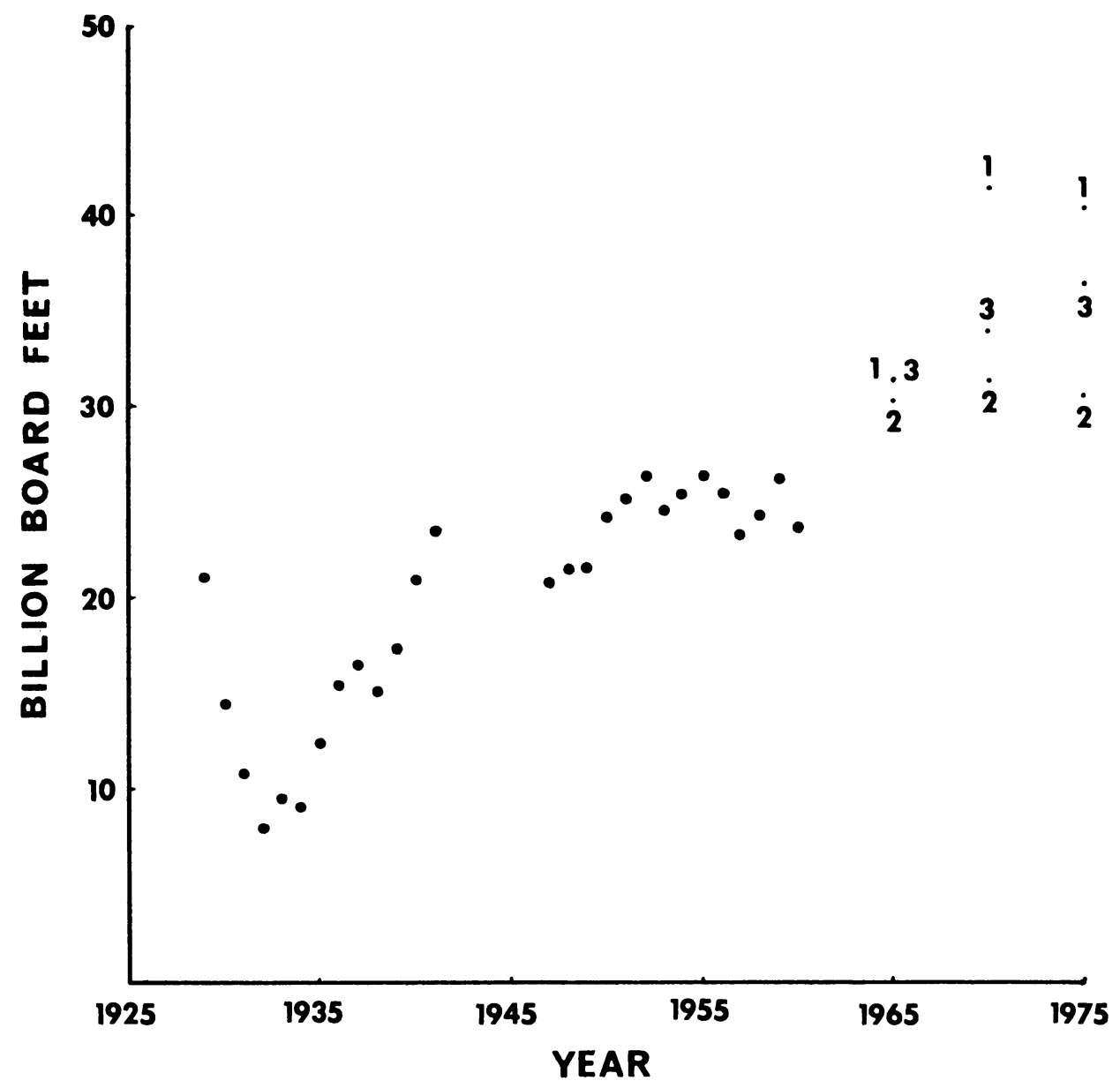

FIG. I. SOFTWOOD LUMBER CONSUMPTION (Q5) 


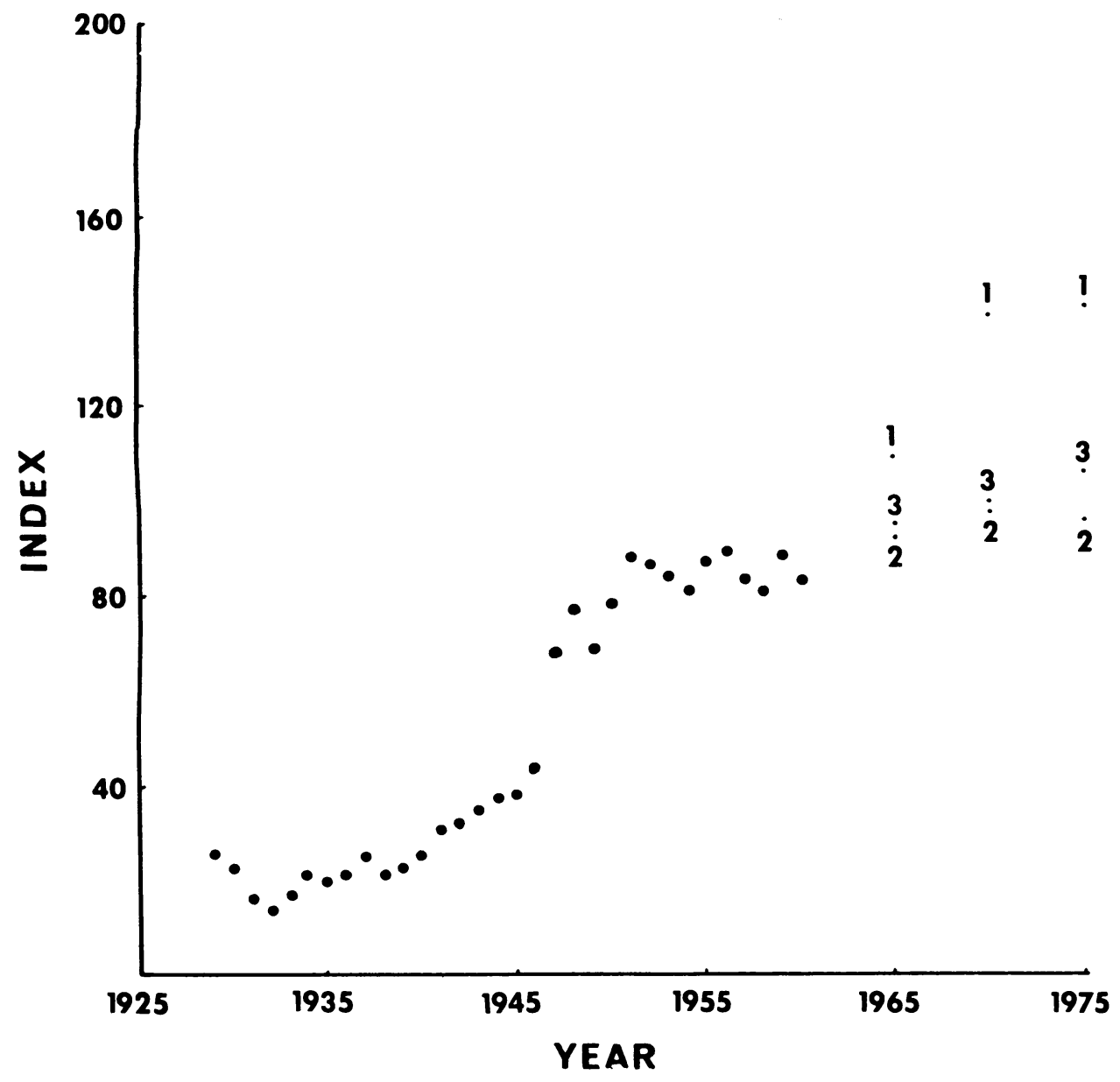

FIG. J. SOFTWOOD LUMBER PRICE INDEX (P5) 


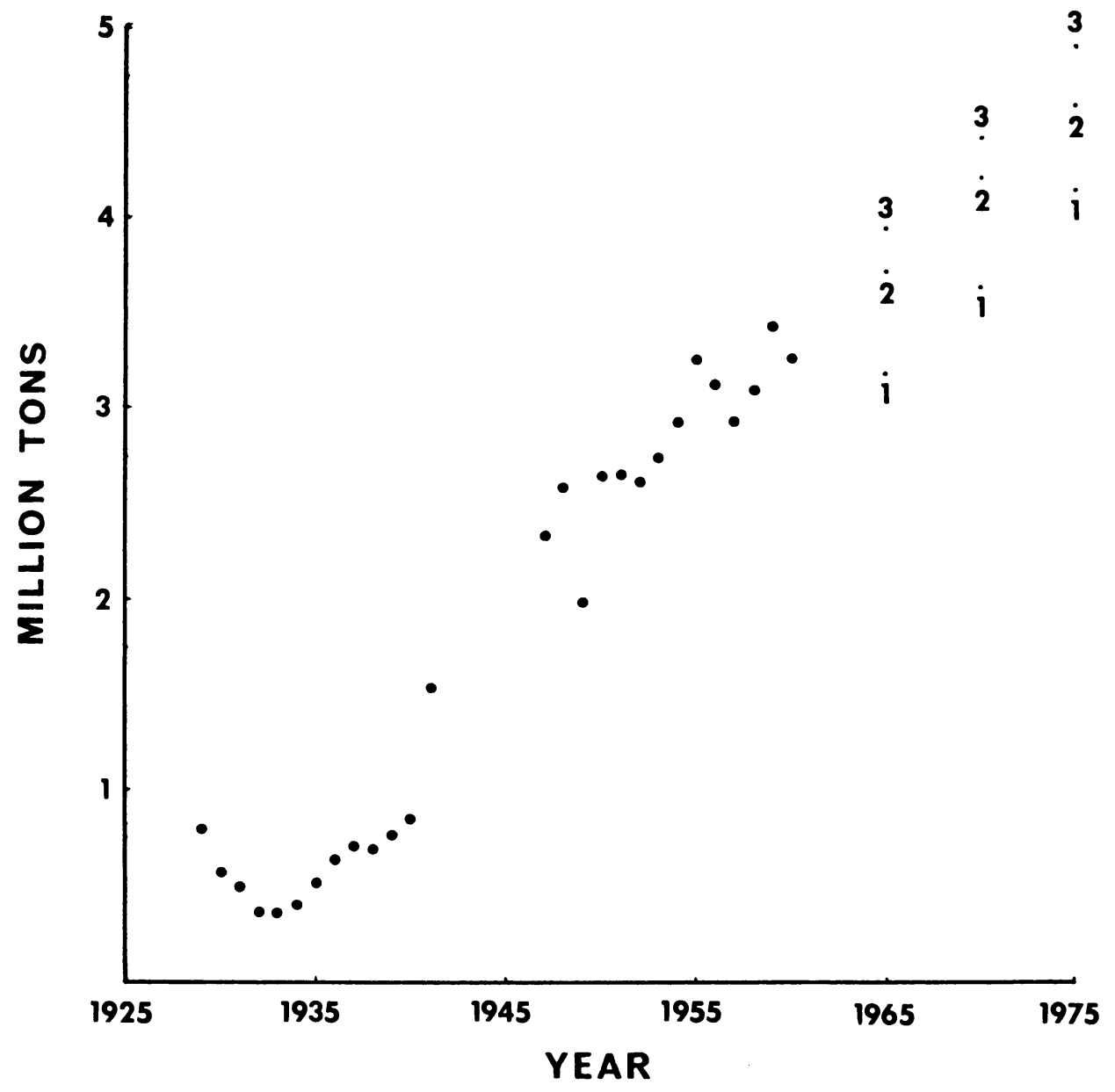

FIG.K. BUILDING PAPER AND BOARD CONSUMPTION (Q6) 


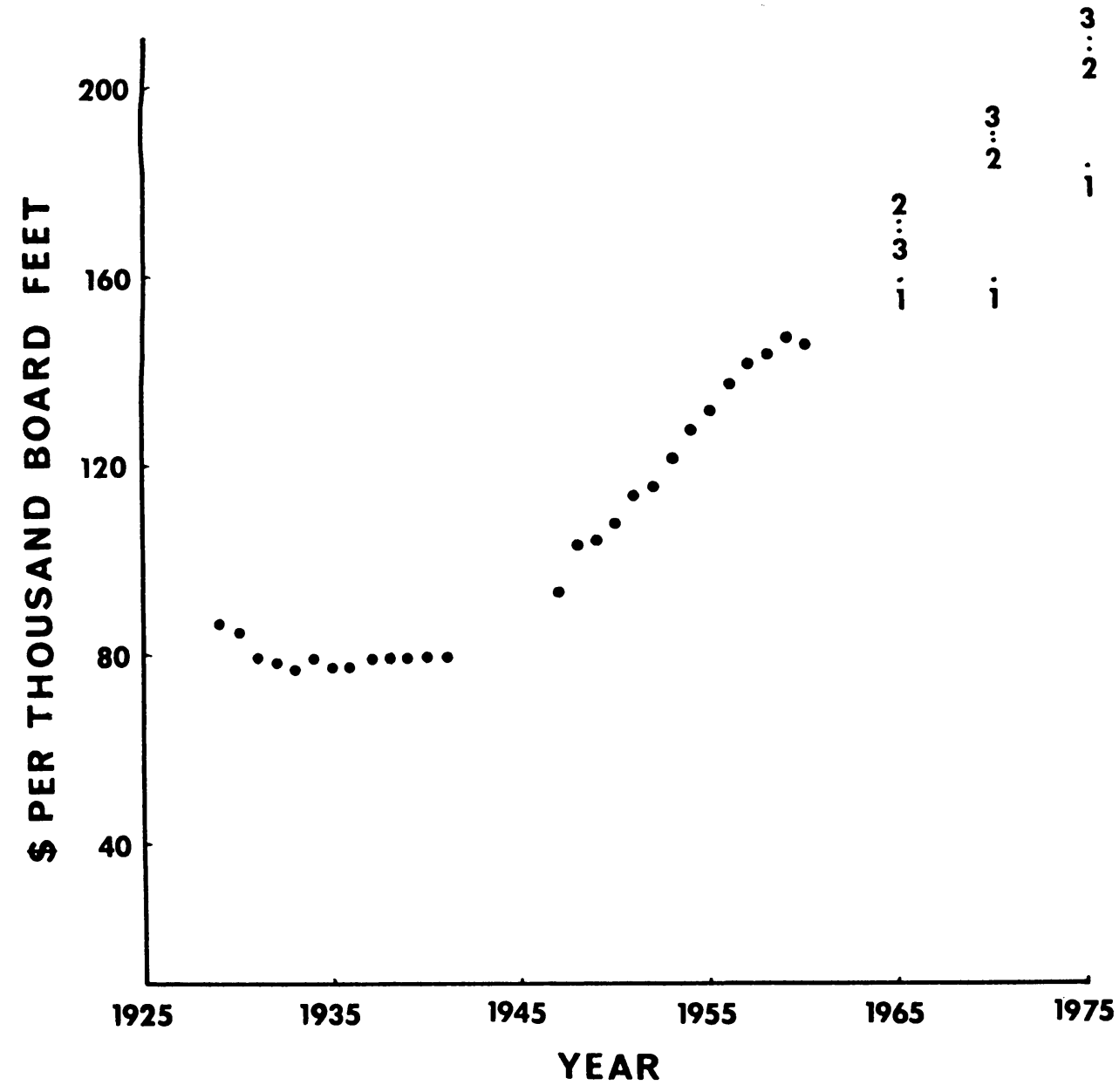

FIG. L. BUILDING PAPER AND BOARD PRICE INDEX (P6) 


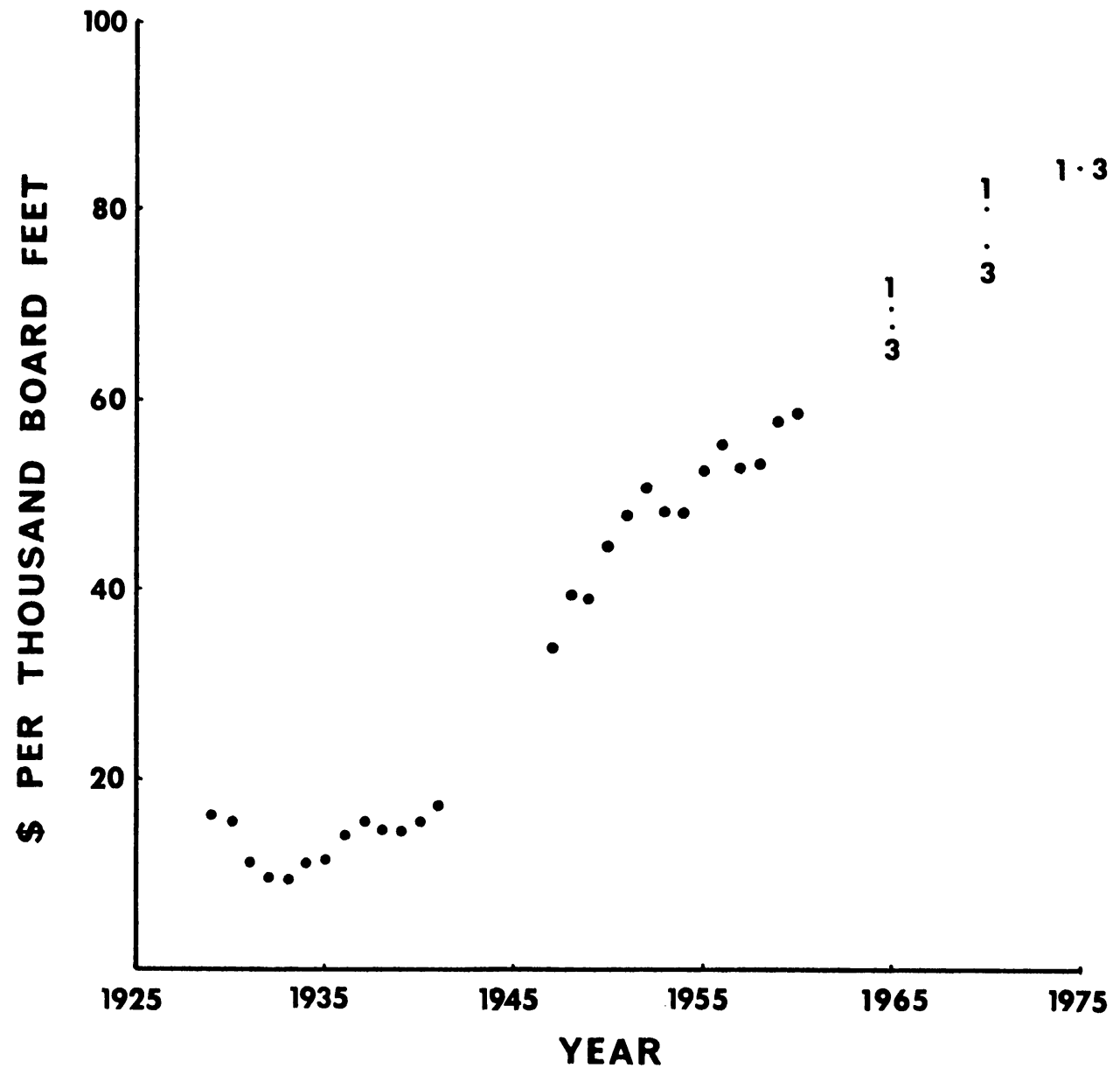

FIG. M. SAWLOG PRICE (P7) 


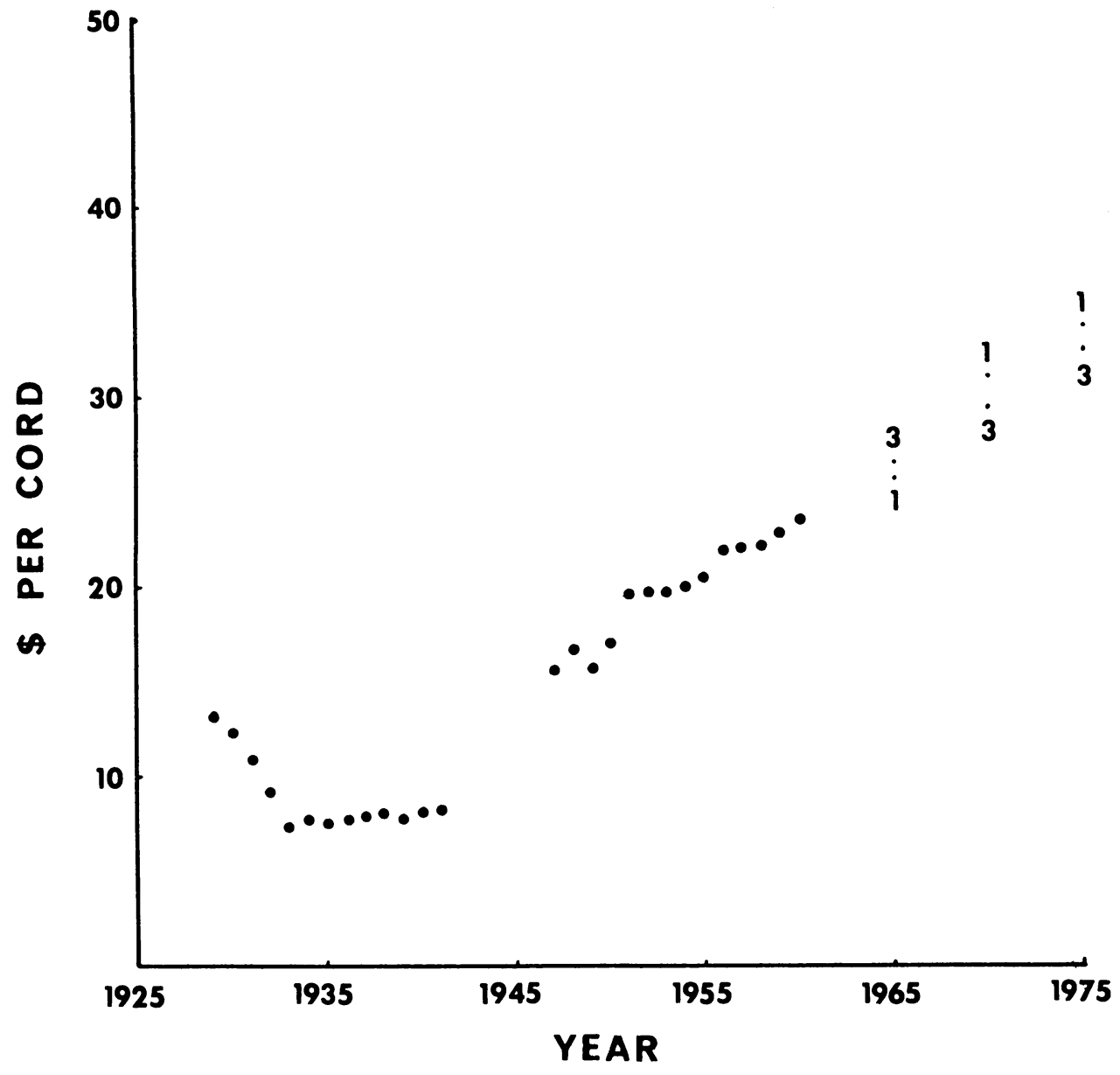

FIG. N. PULPWOOD PRICE (P8) 


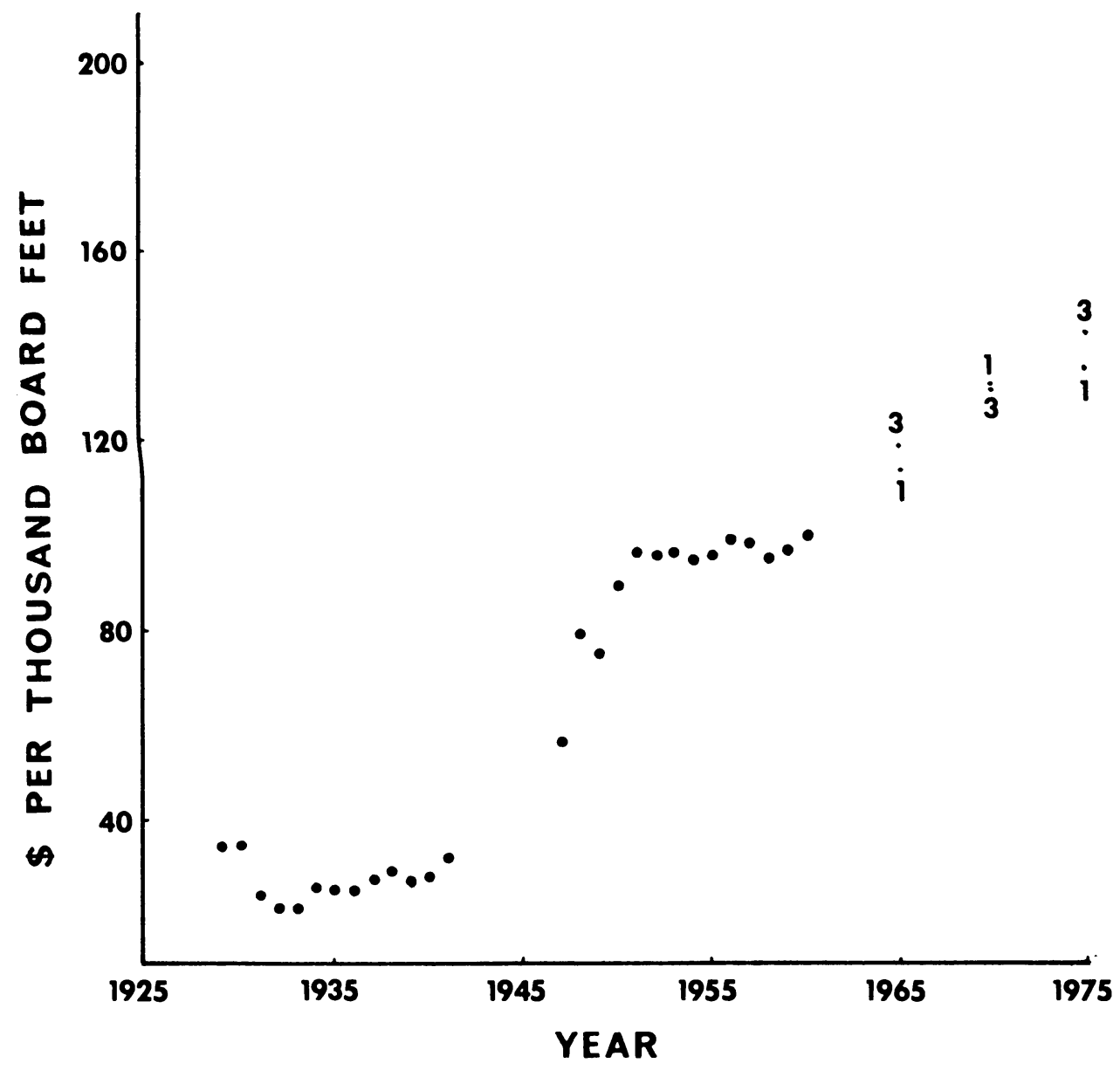

FIG. O. PEELER LOG PRICE (P9) 


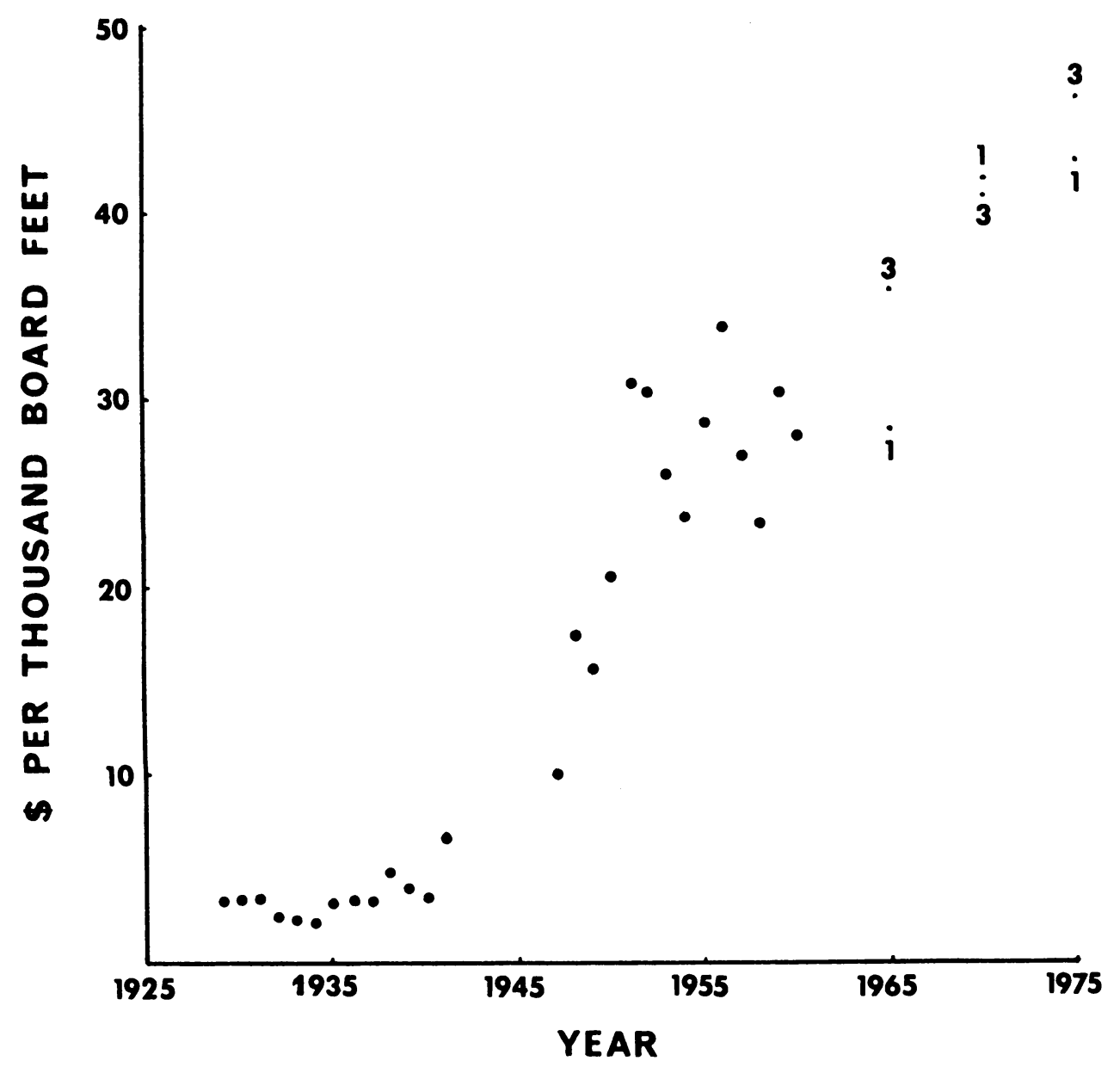

FIG. P. SOFTWOOD STUMPAGE PRICE (P 10) 


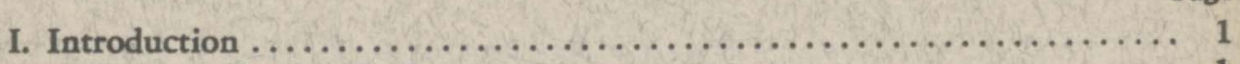

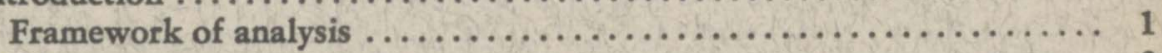

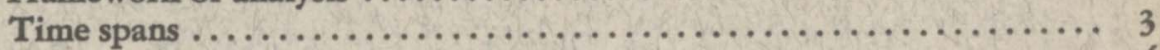

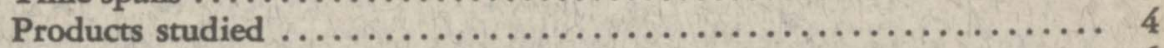

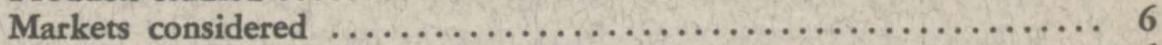

Related studies $\ldots \ldots \ldots \ldots \ldots \ldots \ldots \ldots \ldots \ldots \ldots \ldots \ldots \ldots \ldots, 6 \ldots \ldots \ldots \ldots$

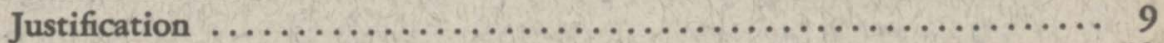

II. Structure $\ldots \ldots \ldots \ldots \ldots \ldots \ldots \ldots \ldots \ldots \ldots \ldots \ldots \ldots \ldots \ldots \ldots \ldots \ldots \ldots \ldots \ldots, 13$

Relationships considered $\ldots \ldots \ldots \ldots \ldots \ldots \ldots \ldots \ldots \ldots \ldots \ldots \ldots \ldots$

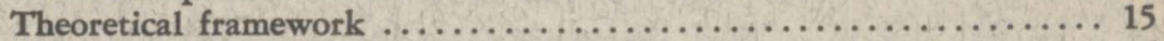

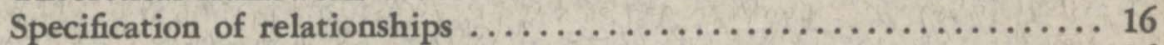

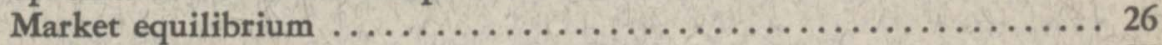

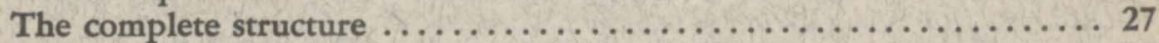

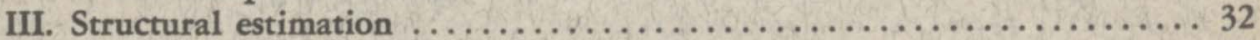

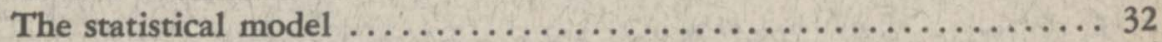

Computational procedure $\ldots \ldots \ldots \ldots \ldots \ldots \ldots \ldots \ldots \ldots \ldots \ldots \ldots$

Estimates of structural coefficients . . . . . . . . . . . . . . . . . 35

Estimates of demand and supply elasticities $\ldots \ldots \ldots \ldots \ldots \ldots \ldots \ldots .40$

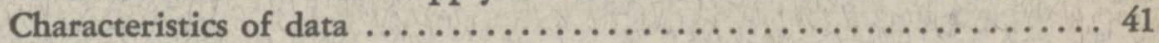

Discussion of estimated relationships $\ldots \ldots \ldots \ldots \ldots \ldots \ldots \ldots \ldots, 42$

Remarks .................................... 47

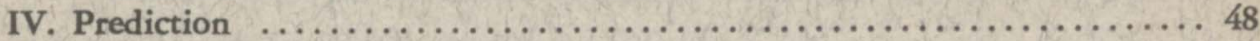

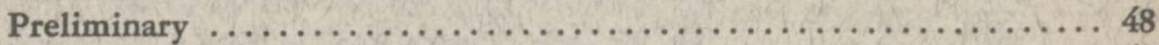

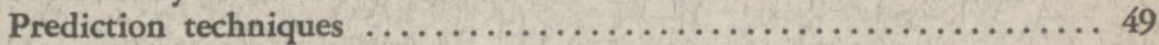

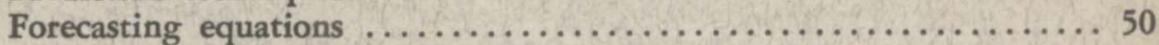

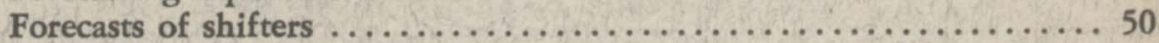

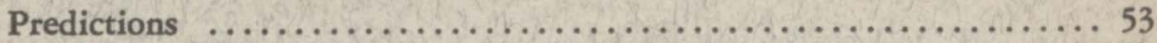

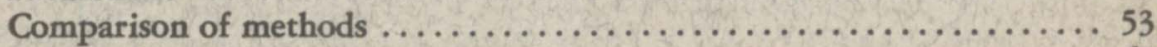

Adjustment of forecasts $\ldots \ldots \ldots \ldots \ldots \ldots \ldots \ldots \ldots \ldots \ldots \ldots \ldots \ldots \ldots \ldots \ldots$

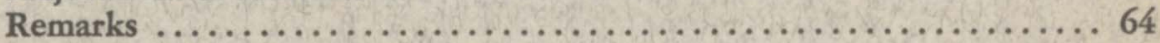

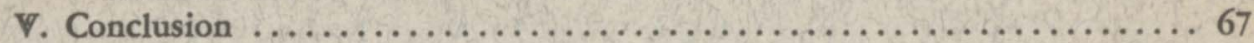

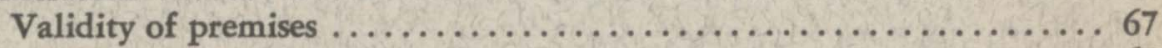

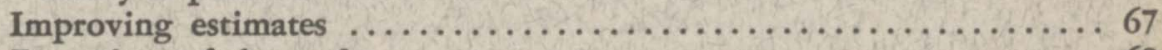

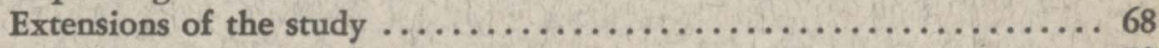

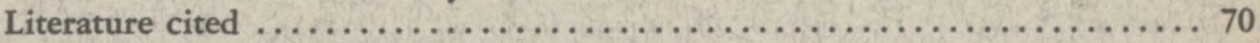

Appendix A. Sectors of demand and supply for wood products $\ldots \ldots \ldots \ldots \ldots 73$

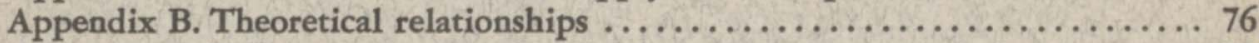

Appendix C. Test regressions on length of moving average period . . . . . . 79

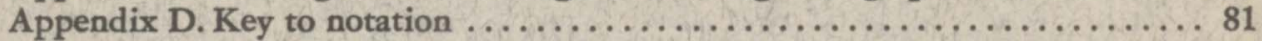

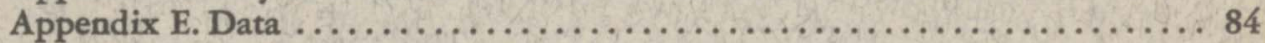

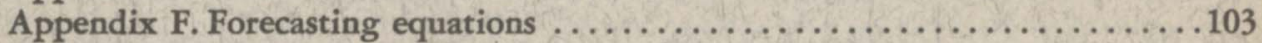

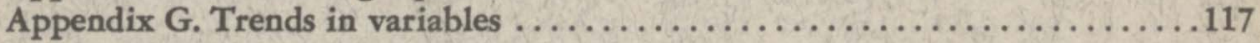


The journal HILGARDIA is published at irregular intervals, in volumes of about 650 to 700 pages. The number of issues per volume varies.

Single copies of any issue may be obtained free, as long as the supply lasts; please request by volume and issue number from:

\author{
Agricultural Publications \\ University Hall \\ University of California \\ Berkeley, California $\mathbf{9 4 7 2 0}$
}

The limit to nonresidents of California is 10 separate titles. The limit to California residents is 20 separate titles.

The journal will be sent regularly to libraries, schools, or institutions in one of the following ways:

1. In exchange for similar published material on research.

2. As a gift to qualified repository libraries only.

3. On a subseription basis- $\$ 7.50$ a year paid in advance. All subseriptions will be started with the first number issued during a calendar year. Subscribers starting during any given year will be sent back numbers to the first of that year and will be billed for the ensuing year the following January. Make checks or money orders payable to The Regents of The University of California; send payment with order to Agricultural Publications at above address. 